Supporting Information

\title{
How Reliable is the Ideal Adsorbed Solution Theory for Estimation of Mixture Separation Selectivities in Microporous Crystalline Adsorbents?
}

Rajamani Krishna* and Jasper M. van Baten

Van 't Hoff Institute for Molecular Sciences

University of Amsterdam

Science Park 904

1098 XH Amsterdam, The Netherlands email: r.krishna@contact.uva.n1 


\section{Table of Contents}

1 Preamble .................................................................................................................................... 6

2 Structural details of microporous crystalline materials ................................................ 7

2.1 List of Tables for Structural details of microporous crystalline materials............................. 8

3 Configurational-Bias Monte Carlo Simulation Methodology ..................................... 10

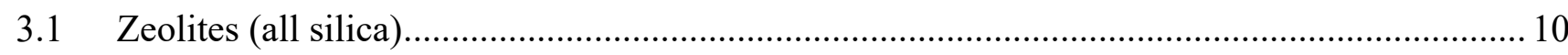

3.2 Force fields and CBMC simulation methodology for water/alcohol mixtures ....................... 10

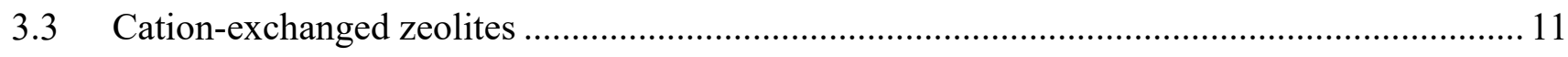

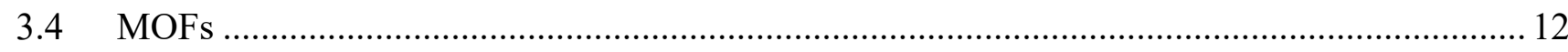

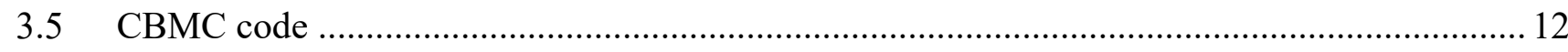

3.6 List of Tables for Configurational-Bias Monte Carlo Simulation Methodology..................... 13

3.7 List of Figures for Configurational-Bias Monte Carlo Simulation Methodology .................... 14

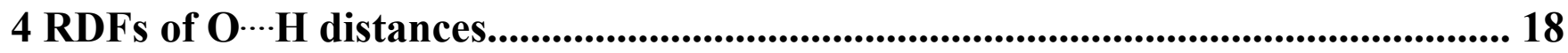

4.1 List of Figures for RDFs of $\mathrm{O} \cdots \mathrm{H}$ distances …........................................................ 19

5 IAST calculations of mixture adsorption equilibrium ............................................. 23

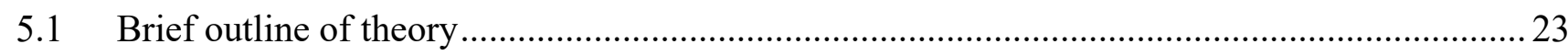

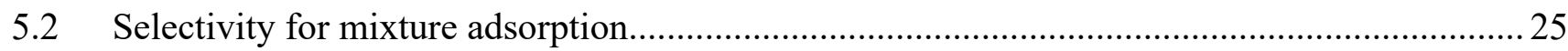

5.3 Fractional occupancy related to the surface potential ...............................................26

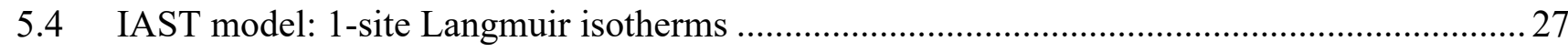

6 The Real Adsorbed Solution Theory (RAST) ............................................................ 31

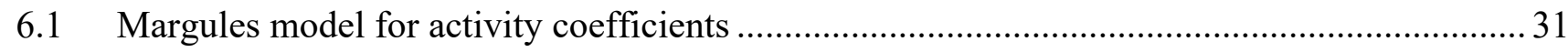

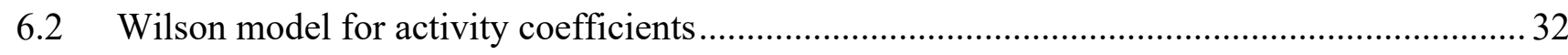

7 CBMC data for mixture adsorption and RAST analysis...................................... 34

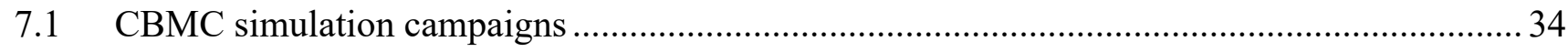

7.2 Determination of activity coefficients from CBMC mixture adsorption data ....................... 34 
7.3 Determination of Margules and Wilson fit parameters from mixture adsorption data .35

8 Mixture adsorption in all-silica MFI zeolite.................................................................. 36

8.1 Adsorption of mixtures of light gaseous molecules in MFI zeolite ....................................... 36

8.2 Preferential location of guest molecules at intersections of MFI zeolite.............................. 38

8.3 Adsorption of $\mathrm{C}_{2} \mathrm{H}_{4} /$ benzene and $\mathrm{C}_{3} \mathrm{H}_{6}$ /benzene mixtures in MFI zeolite............................ 38

8.4 Adsorption of mixtures of linear and branched alkanes in MFI zeolite................................ 40

8.5 List of Tables for Mixture adsorption in all-silica MFI zeolite ......................................... 43

8.6 List of Figures for Mixture adsorption in all-silica MFI zeolite ......................................... 45

$9 \mathrm{CO}_{2} / \mathrm{CH}_{4} / \mathrm{N}_{2}$ mixture adsorption in ISV ................................................................62

9.1 List of Tables for $\mathrm{CO} 2 / \mathrm{CH} 4 / \mathrm{N} 2$ mixture adsorption in ISV ..............................................63

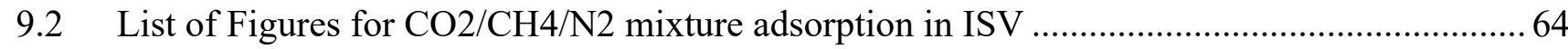

10 Binary mixture adsorption in all-silica CHA zeolite ............................................... 67

$10.1 \quad \mathrm{CO}_{2} / \mathrm{CH}_{4}$ mixture adsorption in all-silica $\mathrm{CHA}$ zeolite ..............................................67

10.2 Water/ethanol mixture adsorption in all-silica CHA zeolite .......................................... 68

10.3 List of Tables for Binary mixture adsorption in all-silica CHA zeolite............................ 71

10.4 List of Figures for Binary mixture adsorption in all-silica CHA zeolite...........................73

11 Binary mixture adsorption in all-silica DDR zeolite ................................................ 83

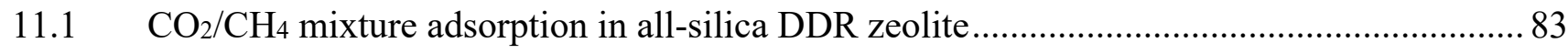

11.2 Water/ethanol mixture adsorption in all-silica DDR zeolite ...................................... 84

11.3 List of Tables for Binary mixture adsorption in all-silica DDR zeolite........................... 87

11.4 List of Figures for Binary mixture adsorption in all-silica DDR zeolite...........................89

12 Binary mixture adsorption in all-silica MOR zeolite ............................................ 98

$12.1 \quad \mathrm{CO}_{2} / \mathrm{CH}_{4}$ mixture adsorption in all-silica MOR zeolite ............................................ 98

12.2 $\quad \mathrm{CO}_{2} / \mathrm{C}_{3} \mathrm{H}_{8}$ mixture adsorption in all-silica MOR zeolite.......................................... 99

12.3 List of Tables for Binary mixture adsorption in all-silica MOR zeolite .......................... 101

12.4 List of Figures for Binary mixture adsorption in all-silica MOR zeolite......................... 102 
13.1 List of Tables for $\mathrm{CO} 2 / \mathrm{CH} 4$ adsorption in AFX and JBW zeolites ....................................112

13.2 List of Figures for $\mathrm{CO} 2 / \mathrm{CH} 4$ adsorption in AFX and JBW zeolites..................................... 114

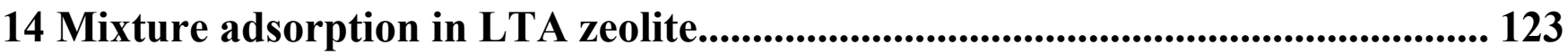

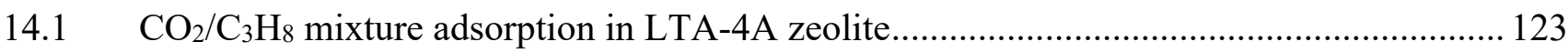

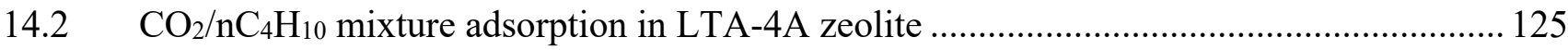

14.3 $\quad \mathrm{CO}_{2} / \mathrm{CH}_{4} / \mathrm{N}_{2}$ mixture adsorption in all-silica LTA zeolite ............................................. 125

14.4 List of Tables for Mixture adsorption in LTA zeolite......................................................... 127

14.5 List of Figures for Mixture adsorption in LTA zeolite …………………………................ 129

15 Mixture adsorption in FAU (all-silica) and $\mathrm{NaX}$ zeolites.................................... 142

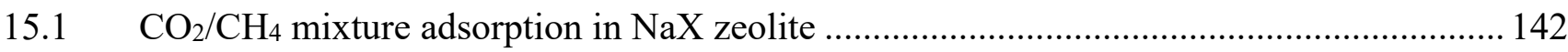

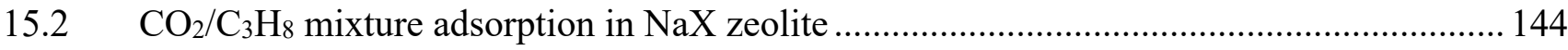

15.3 List of Tables for Mixture adsorption in FAU (all-silica) and NaX zeolites ........................ 147

15.4 List of Figures for Mixture adsorption in FAU (all-silica) and NaX zeolites....................... 149

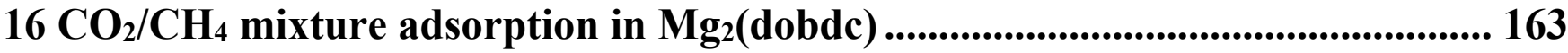

16.1 List of Tables for CO2/CH4 mixture adsorption in Mg2(dobdc) …....................................... 164

16.2 List of Figures for $\mathrm{CO} 2 / \mathrm{CH} 4$ mixture adsorption in $\mathrm{Mg} 2$ (dobdc) ........................................ 165

17 Adsorption of hexane isomers in $\mathrm{Mg}_{2}(\mathrm{dobdc})$ and $\mathrm{Co}(\mathrm{BDP})$............................... 170

17.1 List of Tables for Adsorption of hexane isomers in Mg2(dobdc) and Co(BDP)................. 172

17.2 List of Figures for Adsorption of hexane isomers in Mg2(dobdc) and $\mathrm{Co}(\mathrm{BDP}) \ldots \ldots \ldots \ldots \ldots . . . .174$

$18 \mathrm{C}_{2} \mathrm{H}_{2} / \mathrm{C}_{2} \mathrm{H}_{4}$ mixture adsorption in ZUL-100 and ZUL-200 ............................... 180

18.1 List of Tables for C2H2/C2H4 mixture adsorption in ZUL-100 and ZUL-200 .................. 182

18.2 List of Figures for C2H2/C2H4 mixture adsorption in ZUL-100 and ZUL-200 .................. 186

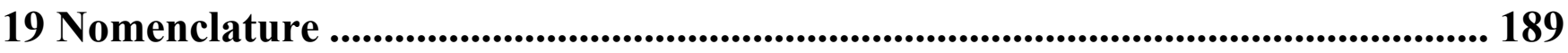

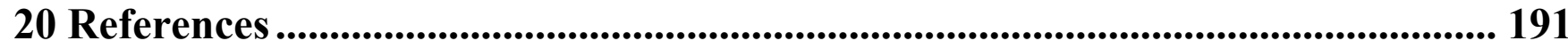




\section{Preamble}

The Supporting Information accompanying our article How Reliable is the Ideal Adsorbed Solution Theory for Estimation of Mixture Separation Selectivities in Microporous Crystalline Adsorbents? Provides (a) structural details of zeolites, and MOFs, (b) details of the CBMC simulation methodology, (b) details of the IAST, and Real Adsorbed Solution Theory (RAST) calculations for mixture adsorption equilibrium, (c) unary isotherm fits for all the guest/host combinations, (d) Margules and Wilson parameter fits for thermodynamic non-idealities, (e) Plots of CBMC simulation data and comparisons with IAST/RAST estimates for all guest/host combinations.

For ease of reading, the Supporting Information is written as a stand-alone document; as a consequence, there is some overlap of material with the main manuscript. 


\section{Structural details of microporous crystalline materials}

The investigated host materials fall into five broad classes.

1. One-dimensional (1D) channels ( $\mathrm{Mg}_{2}($ dobdc), JBW, $\mathrm{Co}(\mathrm{BDP}))$.

2. One-dimensional channels with side pockets (MOR)

3. Intersecting channels (MFI, ISV)

4. Cages separated by narrow windows (CHA, DDR, ZIF-8, AFX, LTA-4A)

5. Cavities with large windows (FAU (all-silica), $\mathrm{NaY}$ (144 Si, $48 \mathrm{Al}, 48 \mathrm{Na}^{+}, \mathrm{Si} / \mathrm{Al}=3$ ), $\mathrm{NaX}(106$ $\left.\left.\mathrm{Si}, 86 \mathrm{Al}, 86 \mathrm{Na}^{+}, \mathrm{Si} / \mathrm{Al}=1.23\right)\right)$

The crystallographic data are available on the zeolite atlas website of the International Zeolite Association (IZA). ${ }^{1,2}$ Further details on the structure, landscape, pore dimensions of a very wide variety of micro-porous materials are available in the published literature. ${ }^{3-10}$ Table S1, and Table S2 provide some salient structural information on various zeolites and MOFs of interest. 


\subsection{List of Tables for Structural details of microporous crystalline materials}

Table S1. Salient structural information.

\begin{tabular}{|c|c|c|c|c|}
\hline Structure & Topology & $\begin{array}{l}\text { Fractional } \\
\text { pore } \\
\text { volume, } \phi\end{array}$ & $\begin{array}{l}\text { Pore } \\
\text { volume/ } \\
\mathrm{cm}^{3} / \mathrm{g}\end{array}$ & $\begin{array}{l}\text { Framework } \\
\text { density/ } \\
\mathrm{kg} / \mathrm{m}^{3}\end{array}$ \\
\hline $\mathrm{Mg}_{2}(\mathrm{dobdc})$ & 1D hexagonal-shaped channels of $11 \AA$ & 0.708 & 0.782 & 905 \\
\hline IRMOF-1 & $\begin{array}{l}\text { Two alternating, inter-connected, cavities of } 10.9 \AA \text { and } \\
14.3 \AA \text { with window size of } 8 \AA .\end{array}$ & 0.812 & 1.369 & 593 \\
\hline $\mathrm{Co}(\mathrm{BDP})$ & $10 \AA$ square-shaped 1D channels & 0.669 & 0.927 & 721.55 \\
\hline JBW & 1D channels & 0.161 & 0.086 & 1873.80 \\
\hline CHA & $316 \AA^{3}$ cages separated by $3.77 \AA \times 4.23 \AA$ size windows & 0.382 & 0.264 & 1444 \\
\hline MOR & $\begin{array}{l}\text { 12-ring }(7.0 \AA \times 6.5 \AA) 1 \mathrm{D} \text { channels, connected to 8-ring } \\
(5.7 \AA \times 2.6 \AA) \text { pockets }\end{array}$ & 0.285 & 0.166 & 1714.69 \\
\hline DDR & $277.8 \AA^{3}$ cages separated by $3.65 \AA \times 4.37 \AA$ size windows & 0.245 & 0.139 & 1760 \\
\hline LTA-4A & $\begin{array}{l}\text { cages of } 743 \AA^{3} \text { volume, separated by } 4.11 \AA \times 4.47 \AA 8 \text { - } \\
\text { ring windows }\end{array}$ & 0.375 & 0.245 & 1529.6 \\
\hline AFX & $\begin{array}{l}490 \AA^{3} \text { size cages connected to pockets of } 98 \AA^{3} \text { in size. Cages are } \\
\text { separated by } 3.4 \AA \times 3.9 \AA \text { size windows. }\end{array}$ & 0.359 & 0.246 & 1463.71 \\
\hline ZIF-8 & $1168 \AA^{3}$ cages separated by $3.26 \AA$ size windows & 0.476 & 0.515 & 924 \\
\hline MFI & $\begin{array}{l}\text { 10-ring intersecting channels of } 5.4 \AA-5.5 \AA \text { and } 5.4 \AA- \\
5.6 \AA \text { size }\end{array}$ & 0.297 & 0.165 & 1796 \\
\hline ISV & $\begin{array}{l}\text { Intersecting channels of two sizes: 12-ring of } 6.1 \AA-6.5 \AA \\
\text { and 12-ring of } 5.9 \AA-6.6 \AA\end{array}$ & 0.426 & 0.278 & 1533 \\
\hline FAU (all silica) & $786 \AA^{3}$ cages separated by $7.4 \AA$ size windows & 0.439 & 0.328 & 1338 \\
\hline $\mathrm{NaY}$ & $786 \AA^{3}$ cages separated by $7.4 \AA$ size windows & 0.41 & 0.303 & 1347 \\
\hline $\mathrm{NaX}$ & $786 \AA^{3}$ cages separated by $7.4 \AA$ size windows & 0.40 & 0.280 & 1421 \\
\hline
\end{tabular}


Table S2. Pore volumes, surface areas, and characteristic (Delaunay) dimensions

\begin{tabular}{|c|c|c|c|}
\hline Structure & Pore volume $/ \mathrm{cm}^{3} \mathrm{~g}^{-1}$ & Surface area $/ \mathrm{m}^{2} \mathrm{~g}^{-1}$ & Delaunay diameter $/ \AA$ \\
\hline MFI & 0.165 & 487.2 & 5.16 \\
\hline ISV & 0.278 & 911.4 & 5.96 \\
\hline FAU (all silica) & 0.328 & 1086 & 7.4 \\
\hline $\mathrm{NaY}$ & 0.303 & 950 & 7.4 \\
\hline $\mathrm{NaX}$ & 0.280 & 950 & 7.4 \\
\hline $\mathrm{CHA}$ & 0.264 & 757.5 & 3.98 \\
\hline DDR & 0.139 & 350 & 4.02 \\
\hline AFX & 0.246 & 674.5 & 3.8 \\
\hline ZIF-8 & 0.515 & 1164.7 & 3.26 \\
\hline LTA-4A & 0.245 & 896 & 4 \\
\hline $\mathrm{Mg}_{2}($ dobdc $)$ & 0.782 & 1640.0 & 10.7 \\
\hline $\mathrm{Co}(\mathrm{BDP})$ & 0.927 & 2148.8 & 10 \\
\hline JBW & 0.086 & 25 & 3.66 \\
\hline MOR & 0.166 & 417 & 6.44 \\
\hline
\end{tabular}




\section{Configurational-Bias Monte Carlo Simulation Methodology}

The simulation methodologies and the force field information used are the same as detailed in the Supplementary Materials accompanying our earlier publications. ${ }^{3,5,9,11-14}$ A short summary is provided hereunder.

\subsection{Zeolites (all silica)}

$\mathrm{CH}_{4}$ molecules are described with a united atom model, in which each molecule is treated as a single interaction center. ${ }^{15}$ The interaction between adsorbed molecules is described with Lennard-Jones terms; see Figure S1. The Lennard-Jones parameters for $\mathrm{CH}_{4}$-zeolite interactions are taken from Dubbeldam et al. ${ }^{16}$. The force field for $\mathrm{H}_{2}$ corresponds to that given by Kumar et al. ${ }^{17}$ In implementing this force field, quantum effects for $\mathrm{H}_{2}$ have been ignored because the work of Kumar et al. ${ }^{17}$ has shown that quantum effects are of negligible importance for temperatures above $200 \mathrm{~K}$; all our simulations were performed at $300 \mathrm{~K}$. The Lennard-Jones parameters for $\mathrm{CO}_{2}$-zeolite and $\mathrm{N}_{2}$-zeolite are essentially those of Makrodimitris et al. ${ }^{18}$; see also García-Pérez et al. ${ }^{19}$ and García-Sanchez et al. ${ }^{20}$ For simulations with linear alkanes with two or more $\mathrm{C}$ atoms, the beads in the chain are connected by harmonic bonding potentials. A harmonic cosine bending potential models the bond bending between three neighboring beads, a Ryckaert-Bellemans potential controls the torsion angle. The beads in a chain separated by more than three bonds interact with each other through a Lennard-Jones potential; see schematic in Figure S1. The force fields of Dubbeldam et al. ${ }^{16}$ was used for the variety of potentials. The Lennard-Jones potentials are shifted and cut at $12 \AA$.

The zeolite frameworks were considered to be rigid in all the simulation results reported in the article.

\subsection{Force fields and CBMC simulation methodology for water/alcohol mixtures}

For simulations of adsorption of guest molecules water, methanol, and ethanol, the force field implementation follows earlier publications. ${ }^{21-24}$ Water is modeled using the Tip5pEw potential. ${ }^{25}$ The 
alcohols are described with the TraPPE force field. ${ }^{26}$ Intramolecular potentials are included to describe the flexibility of alcohols, while the water molecules are kept rigid. The bond lengths are fixed for all molecules. Bond bending potentials are considered for methanol and ethanol, and a torsion potential is used for ethanol. ${ }^{26}$ The force field parameters are summarized in Table S3.

All simulations are performed in the grand canonical ensemble; the chemical potentials of each component in the bulk fluid phase equal that of the corresponding guest adsorbate within the microporous framework. In our simulations, the partial fugacities in the bulk fluid mixture as specified; this fixes the values of the chemical potentials.

Following Kiselev and co-workers, ${ }^{27}$ the zeolite is modeled as a rigid crystal. The interactions of the guest (pseudo) atoms with the host zeolite atoms aredominated by the dispersive interactions with the oxygen atoms, these interactions are described with a Lennard-Jones potential; see Table S4.

The Lorentz-Berthelot mixing rules were applied for calculating the Lennard-Jones parameters describing guest-host interactions

$$
\begin{aligned}
& \sigma_{\text {guest-host }}=\frac{\left(\sigma_{\text {guest }}+\sigma_{\text {host }}\right)}{2} \\
& \frac{\varepsilon_{\text {guest-host }}}{k_{B}}=\sqrt{\frac{\varepsilon_{\text {guest }}}{k_{B}} \times \frac{\varepsilon_{\text {host }}}{k_{B}}}
\end{aligned}
$$

The Lennard-Jones potentials are shifted and cut at $12 \AA$. Periodic boundary conditions were employed. The Configurational-Bias Monte Carlo (CBMC) simulation technique used is identical to that used by Kuhn et al., ${ }^{24}$ and is described in detail by Frenkel and Smit. ${ }^{28}$

\subsection{Cation-exchanged zeolites}

The following two cation-exchanged structures were investigated

$\mathrm{NaX}\left(106 \mathrm{Si}, 86 \mathrm{Al}, 86 \mathrm{Na}^{+}, \mathrm{Si} / \mathrm{Al}=1.23\right)$

$\mathrm{NaY}\left(144 \mathrm{Si}, 48 \mathrm{Al}, 48 \mathrm{Na}^{+}, \mathrm{Si} / \mathrm{Al}=3\right.$ ) 
The presence of cations reduces the accessible pore volume. The location of the cations are pictured in Figure S2, and Figure S3.

The force field information for the simulations with cations are taken from García-Sanchez et al. ${ }^{20}$ In the MC simulations, the cations were allowed to move within the framework and both Lennard-Jones and Coulombic interactions are taken into consideration.

In the CBMC simulations both Lennard-Jones and Coulombic interactions are taken into consideration; see schematic sketch in Figure S4.

\subsection{MOFs}

The metal organic framework structures were considered to be rigid in the simulations. For the atoms in the host metal organic framework, the generic $\mathrm{UFF}^{29}$ and $\mathrm{DREIDING}^{30}$ force fields were used. The Lorentz-Berthelot mixing rules were applied for calculating $\sigma$ and $\varepsilon / k_{\mathrm{B}}$ for guest-host interactions.

The structural information on MgMOF-74 $\left(=\operatorname{Mg}_{2}(\right.$ dobdc $)=\operatorname{Mg} \backslash($ dobdc $)$ with dobdc $=\left(\operatorname{dobdc}^{4-}=1,4-\right.$ dioxido-2,5-benzenedicarboxylate)) was obtained from a variety of references. ${ }^{31-36}$ The simulations for MgMOF-74 were carried out with the force field information provided by Yazaydin et al. ${ }^{36}$

The structural information for $\mathrm{Co}(\mathrm{BDP})$ with $\left(\mathrm{BDP}^{2-}=1,4-\right.$ benzenedipyrazolate) is from Choi et al. ${ }^{37}$ and Salles et al. ${ }^{38}$.

\subsection{CBMC code}

All simulations reported in this work were carried out using an in-house BIGMAC code, originally developed by T.J.H. Vlugt. This code was modified to handle rigid molecular structures and charges. The calculation of the accessible pore volume using the Widom insertion of He probe atoms is implemented within the BIGMAC code.

All CBMC simulations reported in this work were conducted at a temperature $T=300 \mathrm{~K}$. 


\subsection{List of Tables for Configurational-Bias Monte Carlo Simulation Methodology}

Table S3. Lennard-Jones parameters for guest pseudo-atoms. as provided in Table 1 of Kuhn et al. ${ }^{24}$ The water model has two off-center charges that are labeled M in the Table. The name "alcohol" refers to both methanol and ethanol molecules.

\begin{tabular}{|l|l|l|l|l|}
\hline Molecule & (pseudo-) atom & $\sigma / \AA$ & $\varepsilon / k \mathrm{~B} / \mathrm{K}$ & charge \\
\hline water & $\mathrm{O}$ & 3.097 & 89.516 & 0 \\
\hline water & $\mathrm{H}$ & 0 & 0 & 0.241 \\
\hline water & $\mathrm{M}$ & 0 & 0 & -0.241 \\
\hline methanol & $\mathrm{CH} 3$ & 3.75 & 98 & 0.265 \\
\hline ethanol & $\mathrm{CH} 3$ & 3.75 & 98 & 0 \\
\hline ethanol & $\mathrm{CH} 2$ & 3.95 & 46 & 0.265 \\
\hline alcohol & $\mathrm{O}$ & 3.02 & 93 & -0.7 \\
\hline alcohol & $\mathrm{H}$ & 0 & 0 & 0.435 \\
\hline
\end{tabular}

Table S4. Lennard-Jones parameters for host atoms in all-silica zeolites.

\begin{tabular}{|l|l|l|l|}
\hline (pseudo-) atom & $\sigma / \AA$ & $\varepsilon / k_{\mathrm{B}} / \mathrm{K}$ & charge \\
\hline $\mathrm{Si}$ & & & 2.05 \\
\hline $\mathrm{O}$ & 3 & 93.53 & -1.025 \\
\hline
\end{tabular}




\subsection{List of Figures for Configurational-Bias Monte Carlo Simulation Methodology}

\section{Potential for molecules}

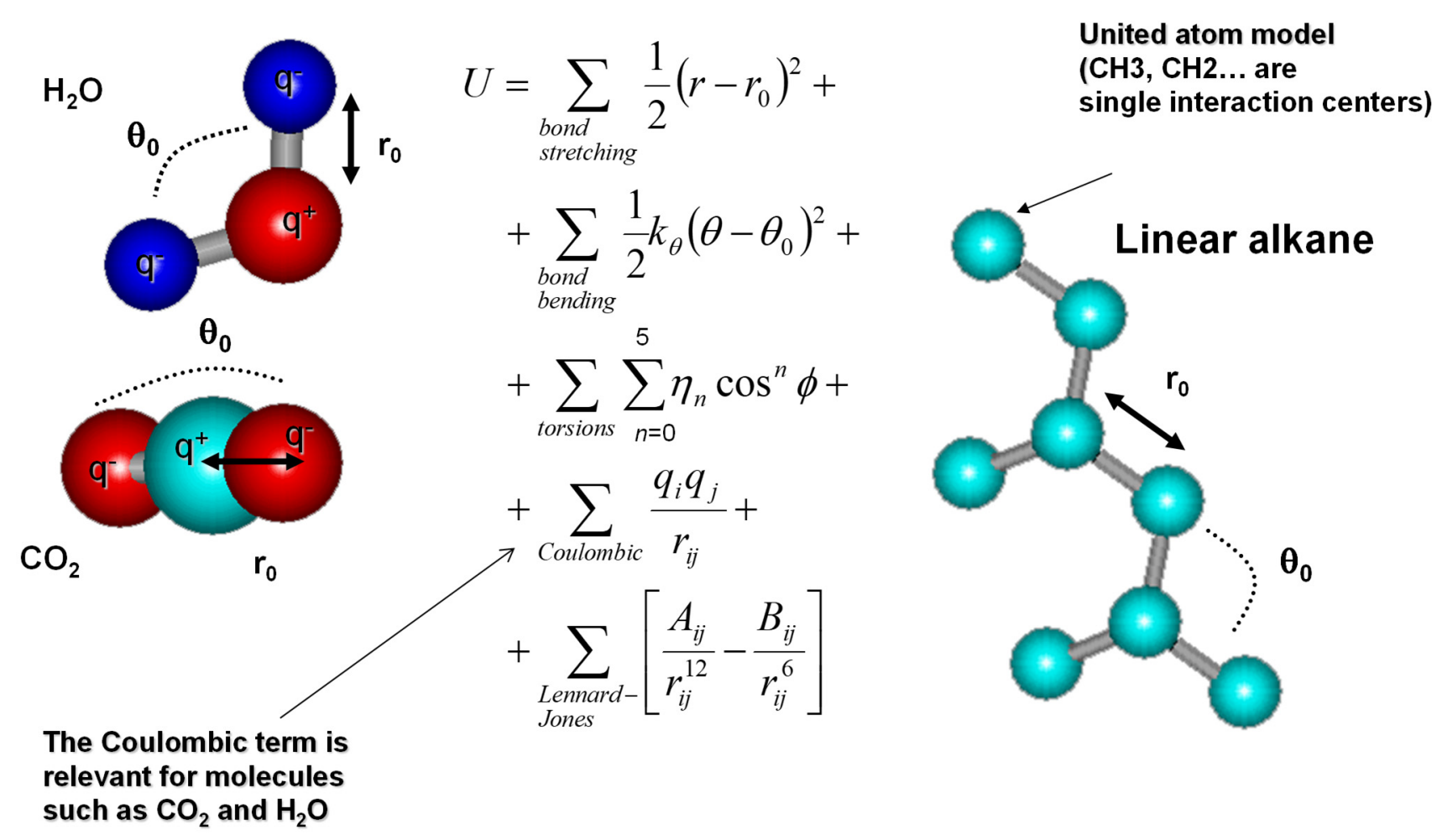

Figure S1. Potential for molecules. 


\section{$\mathrm{NaX}(106 \mathrm{Si}, 86 \mathrm{Al}, 86 \mathrm{Na}+, \mathrm{Si} / \mathrm{Al}=1.23)$}

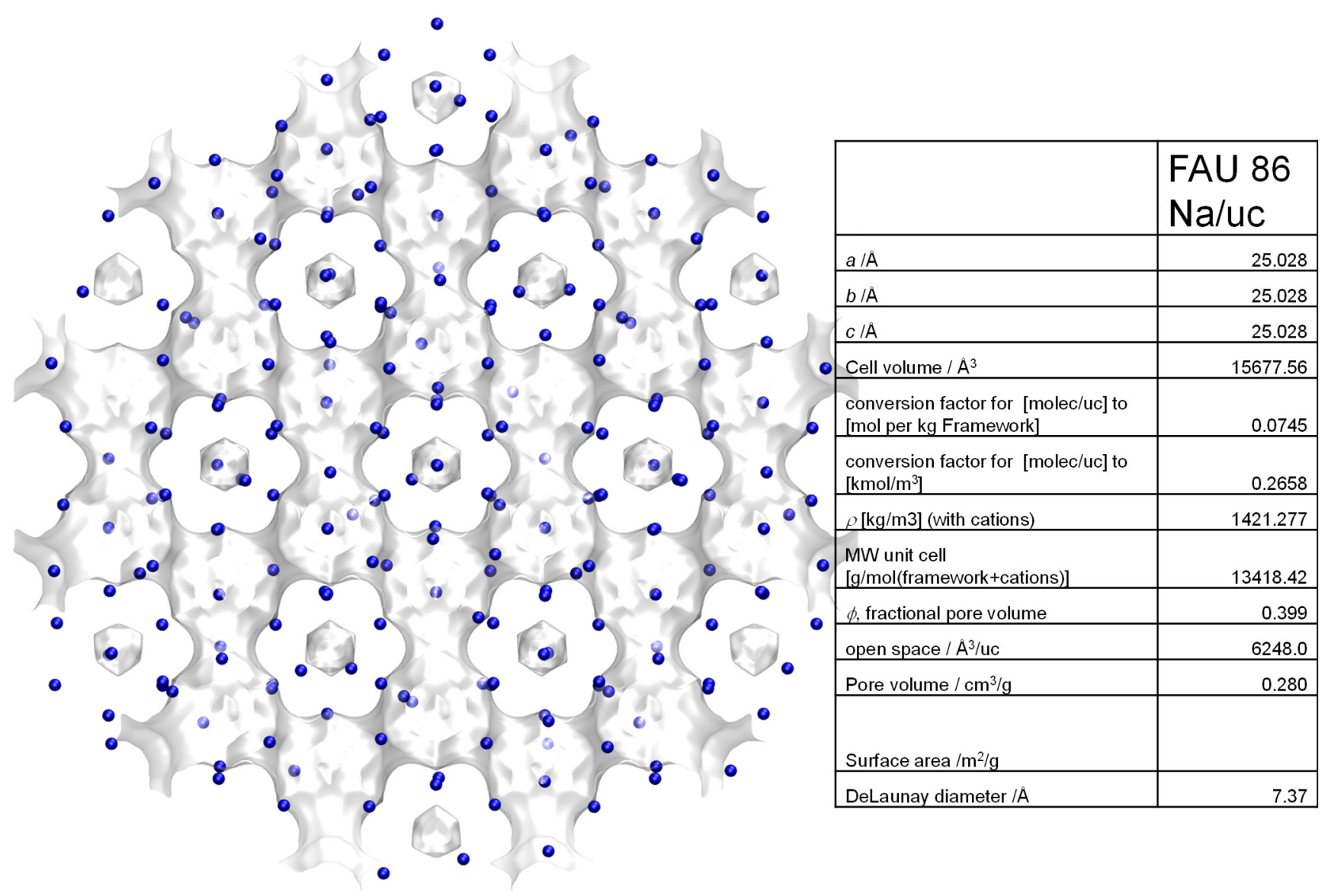

Figure $\mathrm{S} 2$. Location of cations for $\mathrm{NaX}$ zeolite (106 Si, $86 \mathrm{Al}, 86 \mathrm{Na}^{+}, \mathrm{Si} / \mathrm{Al}=1.23$ ) 


\section{$\mathrm{NaY}(144 \mathrm{Si}, 48 \mathrm{Al}, 48 \mathrm{Na}+, \mathrm{Si} / \mathrm{Al}=3$ )}

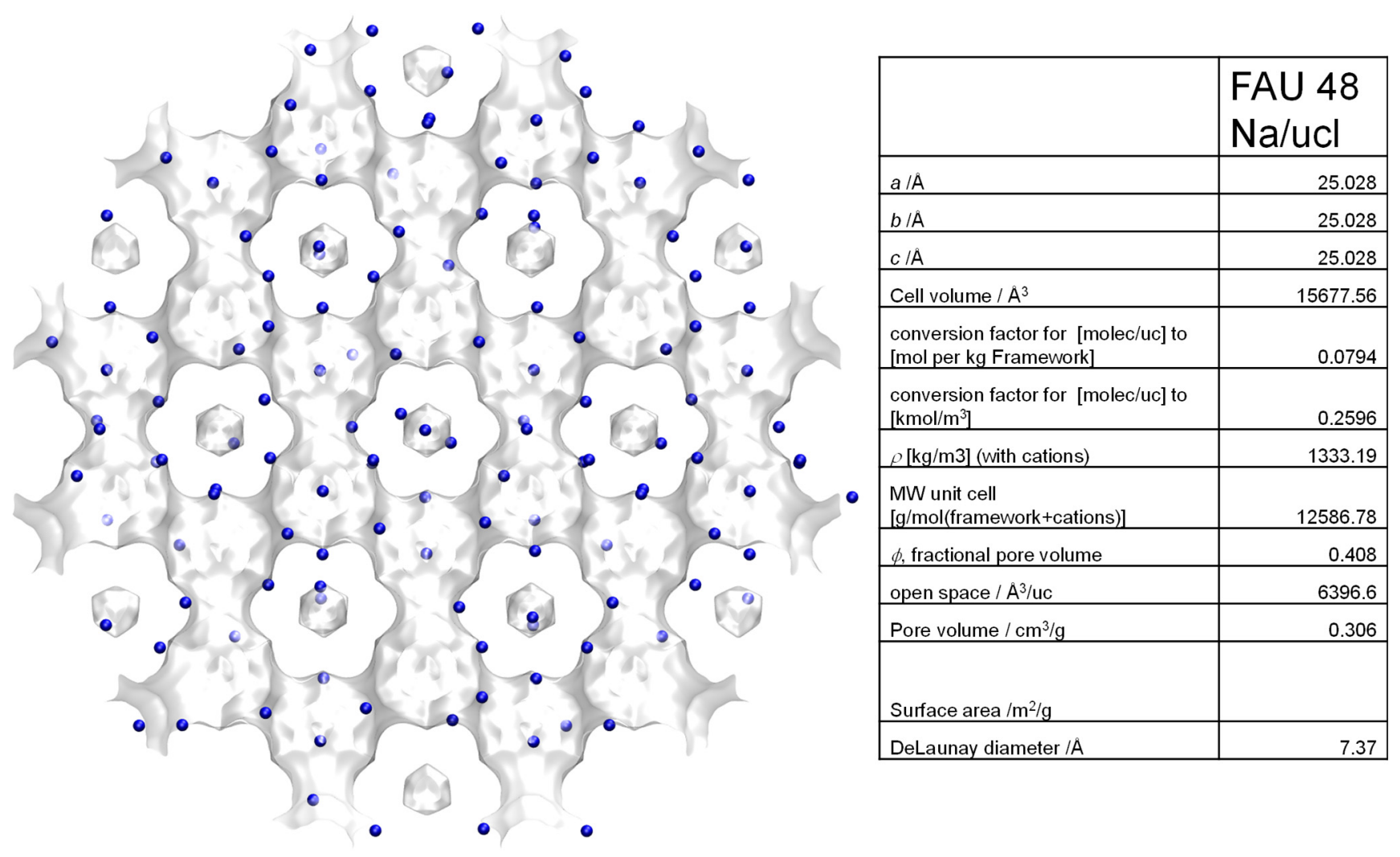

Figure S3. Location of cations for $\mathrm{NaY}$ zeolite (144 Si, $48 \mathrm{Al}, 48 \mathrm{Na}^{+}, \mathrm{Si} / \mathrm{Al}=3$ ) 


\section{Guest-host interactions}

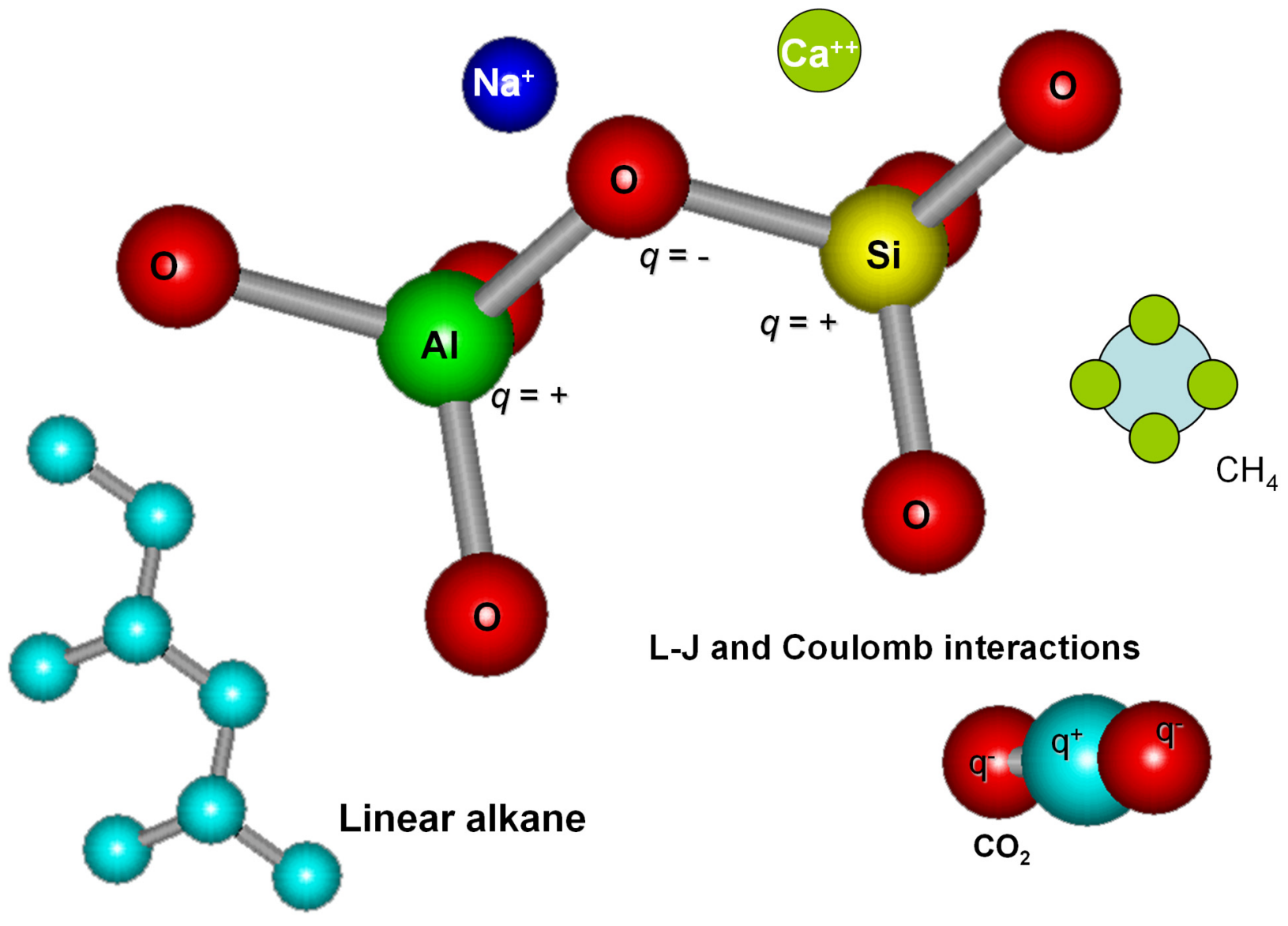

Figure S4. Guest-host interactions. 


\section{RDFs of $\mathrm{O} \cdot \cdots \cdot \mathrm{H}$ distances}

In order to demonstrate the occurrence of hydrogen bonding in water/methanol, and water/ethanol mixtures CBMC simulation data on the spatial locations of the guest molecules were sampled to determine the $\mathrm{O} \cdots \mathrm{H}$ distances of various pairs of molecules. distances. By sampling a total of $10^{6}$ simulation steps, the radial distribution functions (RDF) of $\mathrm{O} \cdots \mathrm{H}$ distances were determined for water-water, water-alcohol, and alcohol-alcohol pairs. Figure S5 shows the RDF of O...H distances for molecular pairs of water(1)/ethanol(2) mixture adsorption in CHA zeolite at $300 \mathrm{~K}$. The partial fugacities of components 1 and 2 are $f_{1}=2.5 \mathrm{kPa}, f_{2}=7.5 \mathrm{kPa}$. We note the first peaks in the RDFs occur at a distance less than $2 \AA$, that is characteristic of hydrogen bonding. ${ }^{21,39}$ The heights of the first peaks are a direct reflection of the degree of hydrogen bonding between the molecular pairs. We may conclude, therefore that for water/methanol mixtures the degree of H-bonding between water-methanol pairs is significantly larger, by about an order of magnitude, than for water-water, and methanol-methanol pairs.

A visual appreciation of hydrogen bonding is gleaned from the snapshots in Figure S6 for water/ethanol mixture adsorption in CHA.

Figure S7 shows the corresponding results for $\mathrm{RDF}$ of $\mathrm{O} \cdots \mathrm{H}$ distances for molecular pairs of water(1)/ethanol(2) mixture adsorption in DDR zeolite at $300 \mathrm{~K}$. The H-bonding between water/ethanol pairs is much stronger than for water/water and ethanol/ethanol pairs; these conclusions are in line with those for CHA zeolite. A visual appreciation of hydrogen bonding is gleaned from the snapshots in Figure S8 for water/ethanol mixture adsorption in DDR. 


\subsection{List of Figures for RDFs of $\mathrm{O} \cdots \cdot \mathrm{H}$ distances}

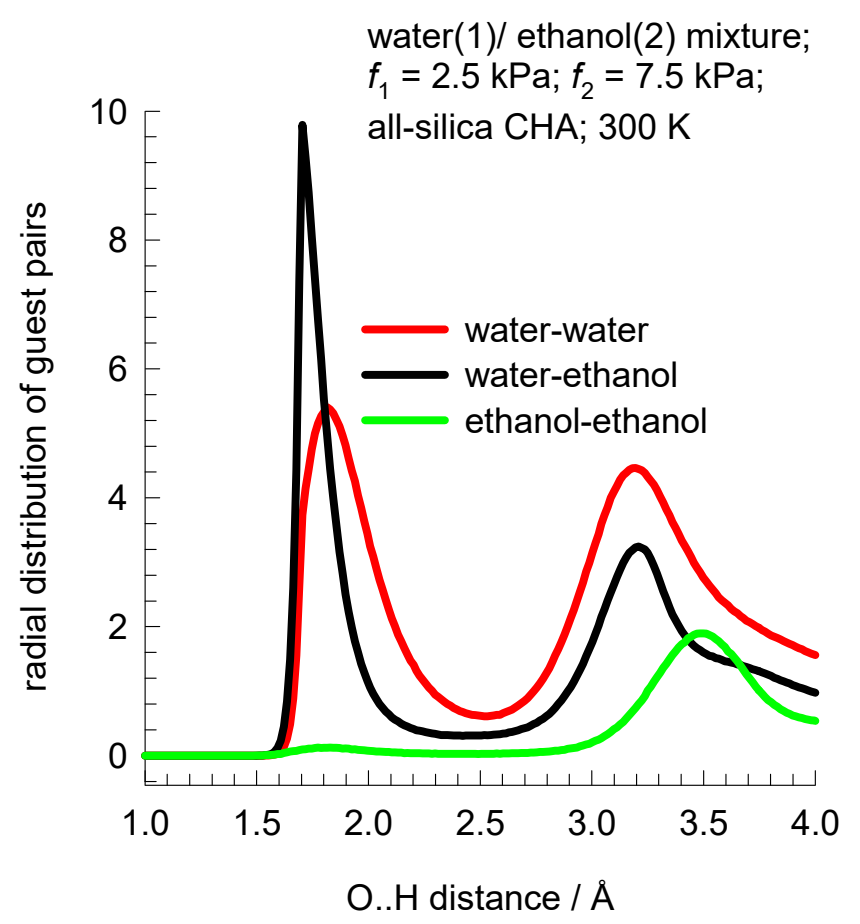

Figure S5. RDF of $\mathrm{O} \cdots \cdot \mathrm{H}$ distances for molecular pairs of water(1)/ethanol(2) mixture adsorption in $\mathrm{CHA}$ zeolite at $300 \mathrm{~K}$. The partial fugacities of components 1 and 2 are $f_{1}=2.5 \mathrm{kPa}, f_{2}=7.5 \mathrm{kPa}$. The magnitudes of the first peaks is a direct reflection of the degree of hydrogen bonding between the molecular pairs. 


\section{water/ethanol}

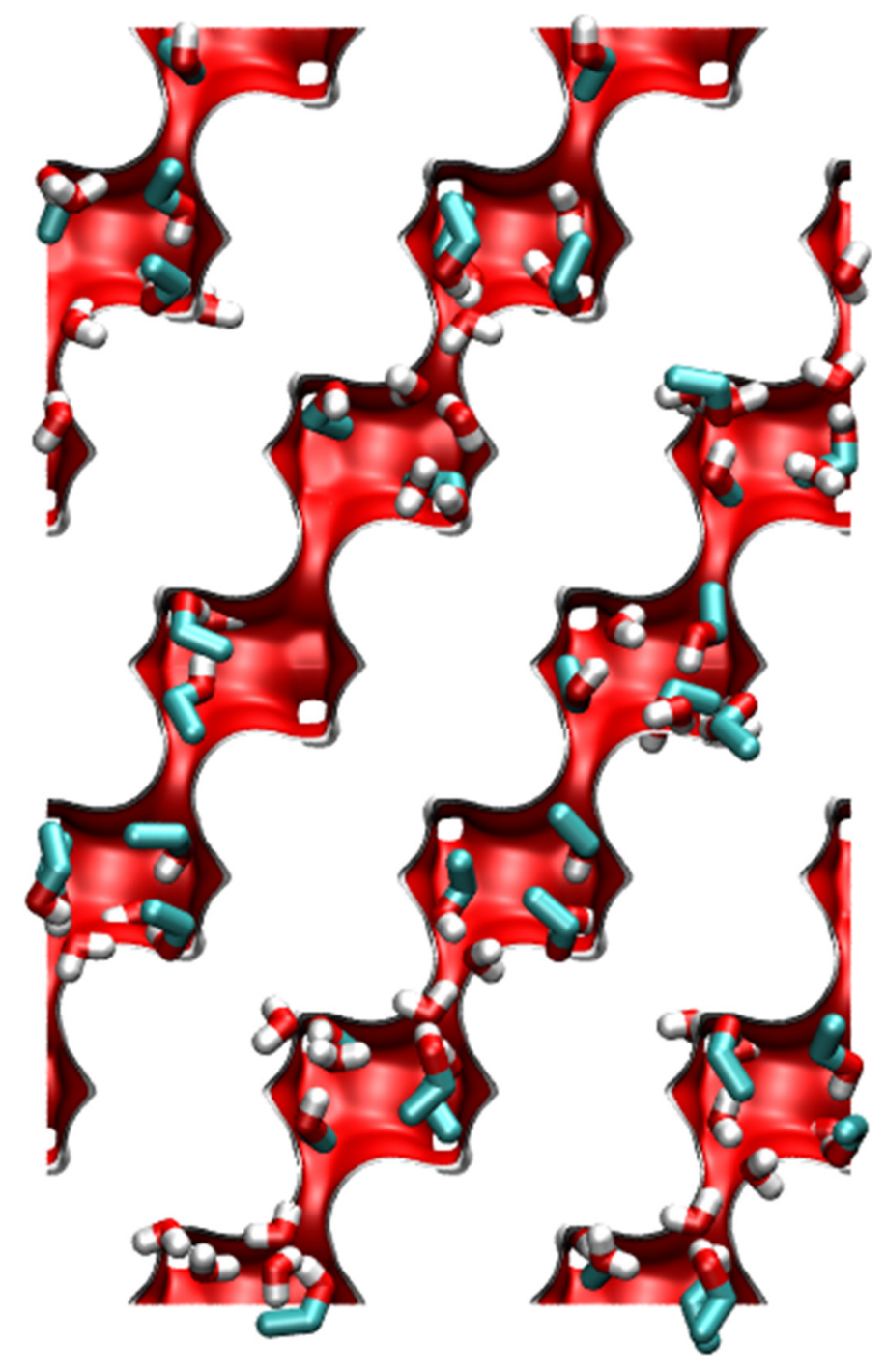

Figure S6. Snapshots showing location and conformations of guest molecules for adsorption of water(1)/ethanol(2) mixture adsorption in CHA zeolite at $300 \mathrm{~K}$. The partial fugacities of components 1 and 2 are $f_{1}=2.5 \mathrm{kPa}, f_{2}=7.5 \mathrm{kPa}$. 


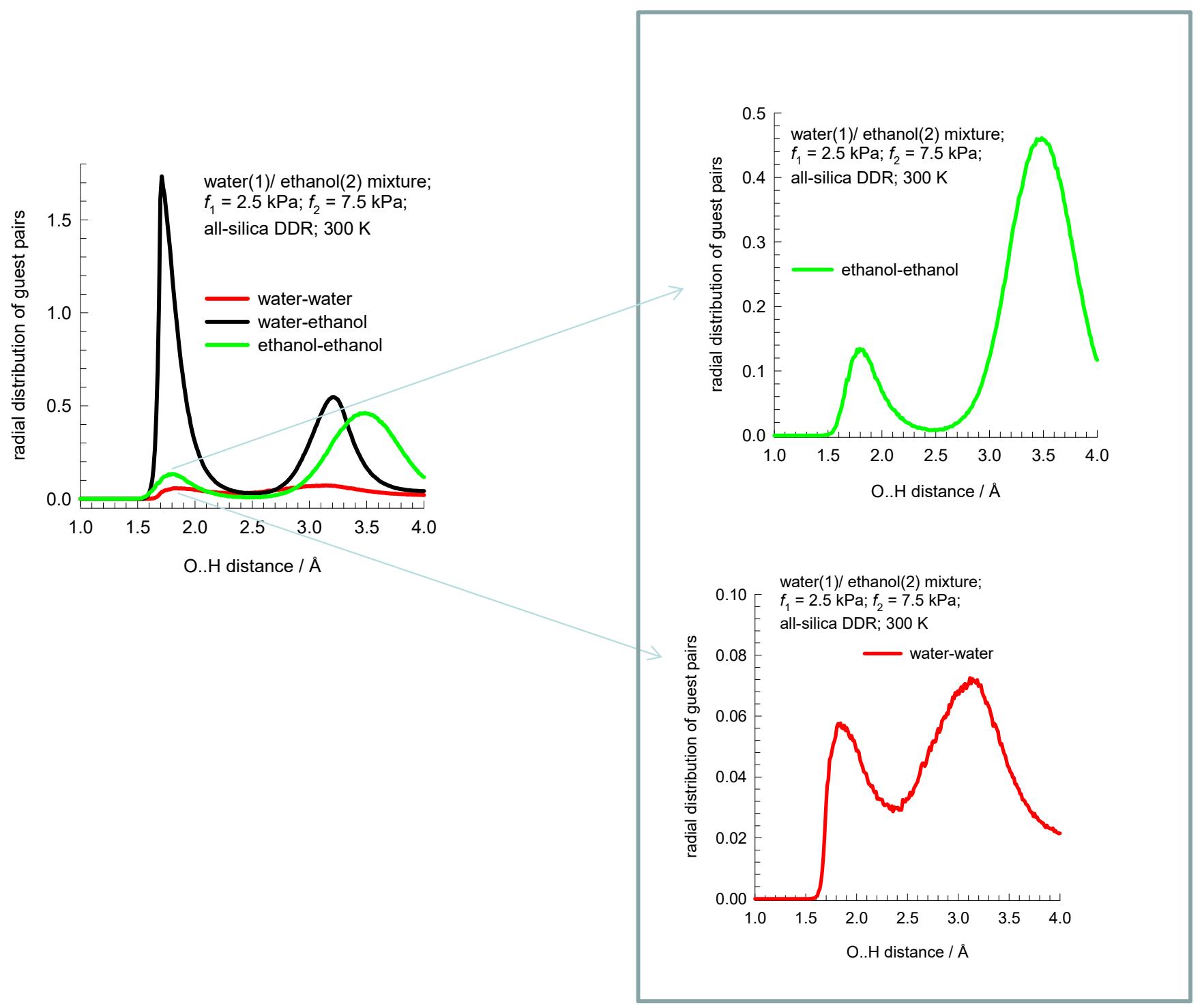

Figure S7. RDF of $\mathrm{O} \cdots \cdot \mathrm{H}$ distances for molecular pairs of water(1)/ethanol(2) mixture adsorption in DDR zeolite at $300 \mathrm{~K}$. The partial fugacities of components 1 and 2 are $f_{1}=2.5 \mathrm{kPa}, f_{2}=7.5 \mathrm{kPa}$. The inset plots the RDF for water-water pairs with different scale on the $y$-axis. 


\section{water/ethanol}

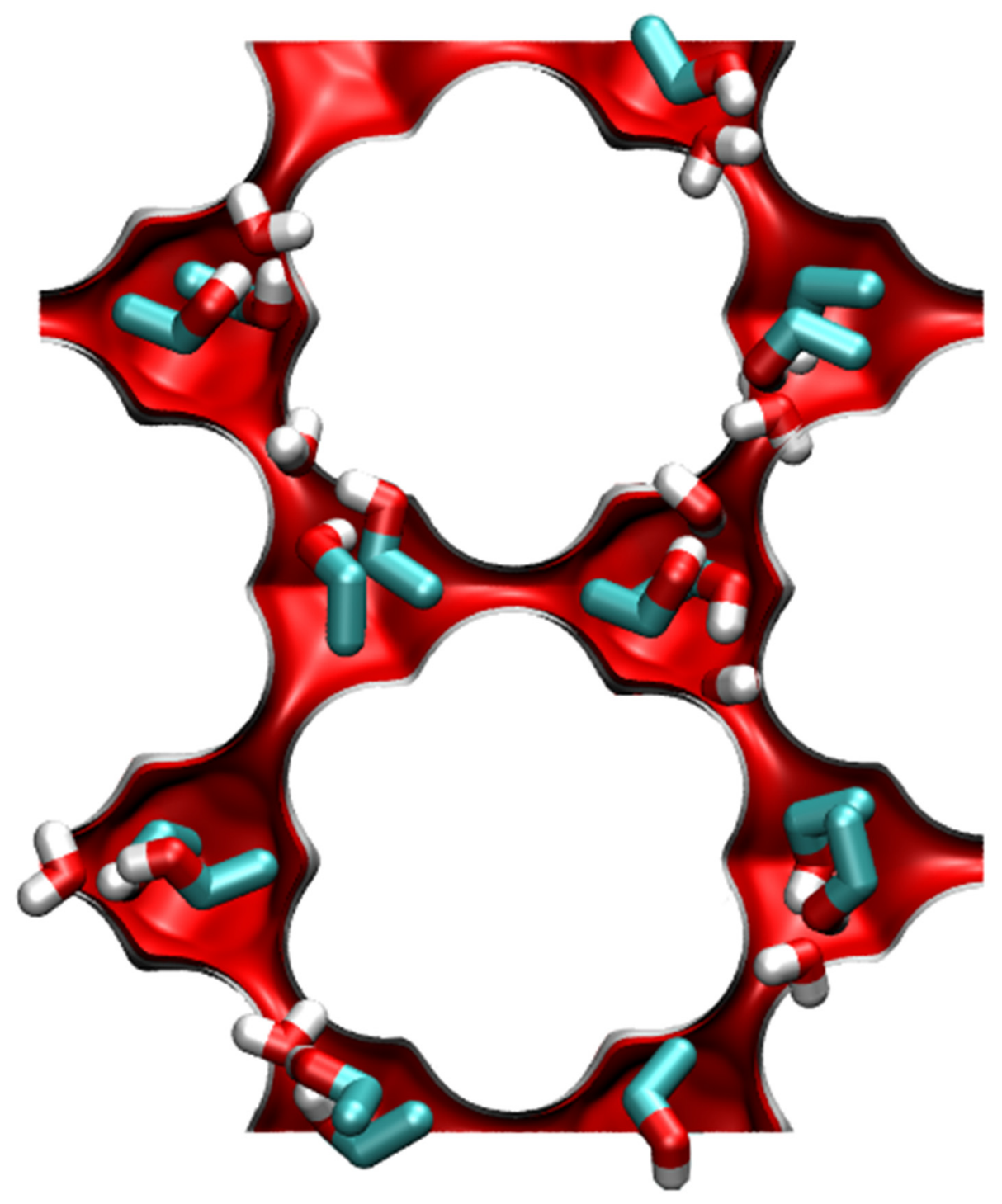

Figure S8. Snapshots showing location and conformations of guest molecules for adsorption of water(1)/ethanol(2) mixture adsorption in DDR zeolite at $300 \mathrm{~K}$. The partial fugacities of components 1 and 2 are $f_{1}=2.5 \mathrm{kPa}, f_{2}=7.5 \mathrm{kPa}$. 


\section{IAST calculations of mixture adsorption equilibrium}

\subsection{Brief outline of theory}

Within microporous crystalline materials such as zeolites and metal-organic frameworks (MOFs), the guest molecules exist in the adsorbed phase. The Gibbs adsorption equation ${ }^{40}$ in differential form is

$$
A d \pi=\sum_{i=1}^{n} q_{i} d \mu_{i}
$$

The quantity $A$ is the surface area per $\mathrm{kg}$ of framework, with units of $\mathrm{m}^{2}$ per $\mathrm{kg}$ of the framework of the crystalline material; $q_{\mathrm{i}}$ is the molar loading of component $i$ in the adsorbed phase with units moles per $\mathrm{kg}$ of framework; $\mu_{\mathrm{i}}$ is the molar chemical potential of component $i$. The spreading pressure $\pi$ has the same units as surface tension, i.e. $\mathrm{N} \mathrm{m}^{-1}$.

The chemical potential of any component in the adsorbed phase, $\mu_{\mathrm{i}}$, equals that in the bulk fluid phase. If the partial fugacities in the bulk fluid phase are $f_{\mathrm{i}}$, we have

$$
d \mu_{i}=R T d \ln f_{i}
$$

where $R$ is the gas constant $\left(=8.314 \mathrm{~J} \mathrm{~mol}^{-1} \mathrm{~K}^{-1}\right)$.

Briefly, the basic equation of Ideal Adsorbed Solution Theory (IAST) theory of Myers and Prausnitz ${ }^{41}$ is the analogue of Raoult's law for vapor-liquid equilibrium, i.e.

$$
f_{i}=P_{i}^{0} x_{i} ; \quad i=1,2, \ldots n
$$

where $x_{\mathrm{i}}$ is the mole fraction in the adsorbed phase

$$
x_{i}=\frac{q_{i}}{q_{1}+q_{2}+\ldots q_{n}}
$$

and $P_{i}^{0}$ is the pressure for sorption of every component $i$, which yields the same spreading pressure, $\pi$ for each of the pure components, as that for the mixture: 


$$
\frac{\pi A}{R T}=\int_{0}^{P_{1}^{0}} \frac{q_{1}^{0}(f)}{f} d f=\int_{0}^{P_{2}^{0}} \frac{q_{2}^{0}(f)}{f} d f=\int_{0}^{P_{3}^{0}} \frac{q_{3}^{0}(f)}{f} d f=\ldots
$$

where $q_{i}^{0}(f)$ is the pure component adsorption isotherm. The units of $\frac{\pi A}{R T} \equiv \Phi$, also called the surface potential, ${ }^{42,43}$ are $\mathrm{mol} \mathrm{kg}^{-1}$; the surface potential has also been called the adsorption potential in several recent publications. ${ }^{44-47}$

The unary isotherm may be described by say the 1-site Langmuir isotherm

$$
q^{0}(f)=q_{\text {sat }} \frac{b f}{1+b f} ; \quad \theta=\frac{b f}{1+b f}
$$

where we define the fractional occupancy of the adsorbate molecules, $\theta=q^{0}(f) / q_{\text {sat }}$. The superscript 0 is used to emphasize that $q^{0}(f)$ relates the pure component loading to the bulk fluid fugacity. More generally, the unary isotherms may need to be described by, say, the dual-site Langmuir-Freundlich model

$$
q^{0}(f)=q_{A, s a t} \frac{b_{A} f^{v_{A}}}{1+b_{A} f^{v_{A}}}+q_{B, s a t} \frac{b_{B} f^{v_{B}}}{1+b_{B} f^{v_{B}}}
$$

Each of the integrals in Eq (S6) can be evaluated analytically:

$$
\begin{aligned}
& \Phi=\int_{f=0}^{P_{i}^{0}} \frac{q^{0}(f)}{f} d f=\frac{q_{A, s a t}}{v_{A}} \ln \left(1+b_{A}\left(P_{i}^{0}\right)^{v_{A}}\right)+\frac{q_{B, s a t}}{v_{B}} \ln \left(1+b_{B}\left(P_{i}^{0}\right)^{v_{B}}\right) \\
& \Phi=\int_{f=0}^{P_{i}^{0}} \frac{q^{0}(f)}{f} d f=\frac{q_{A, s a t}}{v_{A}} \ln \left(1+b_{A}\left(\frac{f_{i}}{x_{i}}\right)^{v_{A}}\right)+\frac{q_{B, s a t}}{v_{B}} \ln \left(1+b_{B}\left(\frac{f_{i}}{x_{i}}\right)^{v_{B}}\right)
\end{aligned}
$$

The right members of eq (S9) is a function of $P_{i}^{0}$. For multicomponent mixture adsorption, each of the equalities on the right side of eq (S6) must be satisfied. These constraints may be solved using a suitable equation solver, to yield the set of values of $P_{1}^{0}, P_{2}^{0}, P_{3}^{0}, \ldots P_{n}^{0}$, all of which satisfy eq (S6). The corresponding values of the integrals using these as upper limits of integration must yield the same value of the surface potential $\frac{\pi A}{R T} \equiv \Phi$ for each component; this ensures that the obtained solution is the correct one.

The adsorbed phase mole fractions $x_{\mathrm{i}}$ are then determined from eq (S4) 


$$
x_{i}=\frac{f_{i}}{P_{i}^{0}} ; \quad i=1,2, \ldots n
$$

The applicability of eq (S10) mandates that all of the adsorption sites within the microporous material are equally accessible to each of the guest molecules, implying a homogeneous distribution of guest adsorbates within the pore landscape, with no preferential locations of any guest species. The circumstances in which this mandate is not fulfilled are highlighted in recent works. ${ }^{45-48}$

A further key assumption of the IAST is that the adsorption enthalpies and surface areas of the adsorbed molecules do not change upon mixing. If the total mixture loading is $q_{t}$, the area covered by the adsorbed mixture is $\frac{A}{q_{t}}$ with units of $\mathrm{m}^{2}$ (mole mixture) $)^{-1}$. Therefore, the assumption of no surface area change due to mixture adsorption translates as $\frac{A}{q_{t}}=\frac{A x_{1}}{q_{1}^{0}\left(P_{1}^{0}\right)}+\frac{A x_{2}}{q_{2}^{0}\left(P_{2}^{0}\right)}+\cdots \frac{A x_{n}}{q_{n}^{0}\left(P_{n}^{0}\right)}$; the total mixture loading is $q_{t}=q_{1}+q_{2} \ldots+q_{n}$ is calculated from

$$
\frac{1}{q_{t}}=\frac{x_{1}}{q_{1}^{0}\left(P_{1}^{0}\right)}+\frac{x_{2}}{q_{2}^{0}\left(P_{2}^{0}\right)}+\ldots .+\frac{x_{n}}{q_{n}^{0}\left(P_{n}^{0}\right)}
$$

in which $q_{1}^{0}\left(P_{1}^{0}\right), q_{2}^{0}\left(P_{2}^{0}\right), \ldots q_{n}^{0}\left(P_{n}^{0}\right)$ are determined from the unary isotherm fits, using the sorption pressures for each component $P_{1}^{0}, P_{2}^{0}, P_{3}^{0}, \ldots P_{n}^{0}$ that are available from the solutions to eqs (S6), and (S9). The occurrence of molecular clustering and hydrogen bonding should be expected to applicability of eq (S11) because the surface area occupied by a molecular cluster is different from that of each of the un-clustered guest molecules in the adsorbed phase.

The entire set of eqs (S4) to (S11) need to be solved numerically to obtain the loadings, $q_{\mathrm{i}}$ of the individual components in the mixture.

\subsection{Selectivity for mixture adsorption}

For $n$-component mixture adsorption, the selectivity of guest constituent $i$ with respect to another guest constituent $j$, in that mixture, $S_{a d s, i j}$, is defined by 


$$
S_{a d s, i j}=\frac{q_{i} / q_{j}}{f_{i} / f_{j}}=\frac{x_{i} / f_{i}}{x_{j} / f_{j}}
$$

where $q_{i}, q_{j}$ are the molar loadings of the constituents $i$ and $j$, in the adsorbed phase in equilibrium with a bulk fluid phase mixture with partial fugacities $f_{i}, f_{j}$, and mole fractions $y_{i}=f_{i} / f_{t} ; \quad f_{t}=\left(\sum_{k=1}^{n} f_{k}\right)$. In view of eqs (S10), and (S11), we may re-write eq (S12) as the ratio of the sorption pressures

$$
S_{a d s, i j}=\frac{P_{j}^{0}}{P_{i}^{0}}
$$

Applying the restriction specified by eq (S6), it follows that $S_{a d s, i j}$ is uniquely determined by the surface potential $\Phi$. It is important to note that eq (S13) is valid irrespective of the total number of components in the mixture. Put another way, the presence of component 3 in the ternary mixture has no influence of the adsorption selectivity $S_{a d s, 12}=\frac{P_{2}^{0}}{P_{1}^{0}}$ for the 1-2 pair, except insofar as the presence of component 3 alters the value of the surface potential $\Phi$ for the 1-2-3 mixture. Therefore, for an ideal adsorbed phase mixture, the presence of additional guest constituents, say species $3,4,5$, etc. do not influence the selectivity of the 1-2 pair. We use CBMC simulations to seek verification of this important feature of the IAST.

\subsection{Fractional occupancy related to the surface potential}

For the general case, from knowledge of the surface potential, $\frac{\pi A}{R T}$, the fractional occupancy for mixture adsorption is then calculated using

$$
\theta \equiv \frac{q_{t}}{q_{\text {sat }, \text { mix }}}=1-\exp \left(-\Phi / q_{\text {sat }, \text { mix }}\right)
$$

For a binary mixture, the saturation capacity $q_{\text {sat,mix }}$ is calculated from the saturation capacities of the constituent guests 


$$
q_{\text {sat }, \text { mix }}=\frac{1}{\frac{x_{1}}{q_{1, \text { sat }}}+\frac{x_{2}}{q_{2, \text { sat }}}} ; \quad q_{1, \text { sat }}=q_{1, A, \text { sat }}+q_{1, B, \text { sat }} ; \quad q_{2, \text { sat }}=q_{2, A, \text { sat }}+q_{2, B, \text { sat }}
$$

where

$$
x_{1}=\frac{q_{1}}{q_{1}+q_{2}} ; \quad x_{2}=\frac{q_{2}}{q_{1}+q_{2}}
$$

are the mole fractions in the adsorbed mixture. For equimolar mixtures, $x_{1}=x_{2}=0.5$, eq (S16) simplifies

to yield $q_{\text {sat } m i x}=\frac{2}{\frac{1}{q_{1, s a t}}+\frac{1}{q_{2, \text { sat }}}}$.

The fundamental justification of Eq (S15) is provided by applying eq (S11) to pore saturation conditions.

Equation (S14) is the appropriate generalization of eq (S29), derived in the following section for the mixed-gas Langmuir model. It is also to be noted that eq (15) of our earlier publication ${ }^{49}$ has a typographical error in the calculation of $q_{\text {sat,mix }}$; the correct form is given by eq (S15).

\subsection{IAST model: 1-site Langmuir isotherms}

The IAST procedure will be applied for binary mixture adsorption in which the unary isotherms are described by the 1-site Langmuir model in which the saturation capacities of components 1 and 2 are identical to each other, i.e. $q_{1, s a t}=q_{2, s a t}=q_{\text {sat }}$ :

$$
q^{0}(f)=q_{s a t} \frac{b f}{1+b f} ; \quad \theta=\frac{b f}{1+b f}
$$

where we define the fractional occupancy of the adsorbate molecules, $\theta=q^{0}(f) / q_{\text {sat }}$. The superscript 0 is used to emphasize that $q^{0}(f)$ relates the pure component loading to the bulk fluid fugacity.

For unary adsorption, the surface potential for a 1-site Langmuir isotherm can be calculated analytically

$\Phi=q_{\text {sat }} \ln \left(1+b P^{0}\right)$

The objective is to determine the molar loadings, $q_{1}$, and $q_{2}$, in the adsorbed phase. 
Performing the integration of eq (S6) results in an expression relating the sorption pressures $P_{i}^{0}$ of the two species

$$
\begin{aligned}
& \Phi=q_{\text {sat }} \ln \left(1+b_{1} P_{1}^{0}\right)=q_{\text {sat }} \ln \left(1+b_{2} P_{2}^{0}\right) \\
& b_{1} P_{1}^{0}=b_{2} P_{2}^{0}=\exp \left(\frac{\Phi}{q_{\text {sat }}}\right)-1
\end{aligned}
$$

In view of eq (S13), we may derive the following expression for $S_{a d s, 12}$

$$
S_{a d s, 12}=\frac{P_{2}^{0}}{P_{1}^{0}}=\frac{b_{1}}{b_{2}}
$$

The adsorbed phase mole fractions of component 1 , and component 2 are given by eq (S10)

$$
x_{1}=\frac{f_{1}}{P_{1}^{0}} ; \quad x_{2}=1-x_{1}=\frac{f_{2}}{P_{2}^{0}}
$$

Combining eqs (S19), and (S21):

$$
\begin{aligned}
& \exp \left(\frac{\pi A}{q_{s a t} R T}\right)-1=b_{1} \frac{f_{1}}{x_{1}}=b_{2} \frac{f_{2}}{1-x_{1}} \\
& \frac{\pi A}{q_{\text {sat }} R T}=\ln \left(1+b_{1} \frac{f_{1}}{x_{1}}\right)=\ln \left(1+b_{2} \frac{f_{2}}{x_{2}}\right)
\end{aligned}
$$

The adsorbed phase mole fractions can be determined

$$
\frac{x_{1}}{x_{2}}=\frac{q_{1}}{q_{2}}=\frac{b_{1} f_{1}}{b_{2} f_{2}} ; \quad x_{1}=\frac{q_{1}}{q_{t}}=\frac{b_{1} f_{1}}{b_{1} f_{1}+b_{2} f_{2}} ; \quad x_{2}=\frac{q_{2}}{q_{t}}=\frac{b_{2} f_{2}}{b_{1} f_{1}+b_{2} f_{2}}
$$

Once $x_{1}$, and $x_{2}=1-x_{1}$ are determined, the sorption pressures can be calculated:

$$
P_{1}^{0}=\frac{f_{1}}{x_{1}} ; \quad P_{2}^{0}=\frac{f_{2}}{x_{2}}=\frac{f_{2}}{1-x_{1}}
$$

From eqs (S19), (S23), and (S24) we get

$$
\begin{aligned}
& b_{i} P_{1}^{0}=\frac{b_{1} f_{1}}{x_{1}}=b_{2} P_{2}^{0}=\frac{b_{2} f_{2}}{x_{2}}=b_{1} f_{1}+b_{2} f_{2} \\
& 1+b_{i} P_{1}^{0}=1+b_{2} P_{2}^{0}=1+b_{1} f_{1}+b_{2} f_{2}
\end{aligned}
$$

Combining eqs (S22), and (S25) we get the following expression for the surface potential for the mixture 
$\Phi=q_{\text {sat }} \ln \left(1+b_{1} f_{1}+b_{2} f_{2}\right)$

The total amount adsorbed, $q_{t}=q_{1}+q_{2}$ can be calculated from Eq (S11)

$$
q_{t}=q_{1}+q_{2}=q_{\text {sat }} \frac{b_{1} P_{1}^{0}}{1+b_{1} P_{1}^{0}}=q_{\text {sat }} \frac{b_{2} P_{2}^{0}}{1+b_{2} P_{2}^{0}}=q_{\text {sat }} \frac{b_{1} f_{1}+b_{2} f_{2}}{1+b_{1} f_{1}+b_{2} f_{2}}
$$

Combining eqs (S23), and (S27) we obtain the following explicit expressions for the component loadings, and fractional occupancies

$$
\theta_{1}=\frac{q_{1}}{q_{\text {sat }}}=\frac{b_{1} f_{1}}{1+b_{1} f_{1}+b_{2} f_{2}} ; \quad \theta_{2}=\frac{q_{2}}{q_{\text {sat }}}=\frac{b_{2} f_{2}}{1+b_{1} f_{1}+b_{2} f_{2}}
$$

Equation (S28) is commonly referred to as the mixed-gas Langmuir model.

From eqs (S19), (S27), and (S28) we derive the following expression for the total occupancy of the mixture

$$
\theta=\theta_{1}+\theta_{2}=\frac{q_{t}}{q_{\text {sat }}}=1-\exp \left(-\frac{\Phi}{q_{\text {sat }}}\right)=\frac{b_{1} f_{1}+b_{2} f_{2}}{1+b_{1} f_{1}+b_{2} f_{2}}
$$

For unary adsorption of component $i$, say, $f_{i}=P_{i}^{0}$, the occupancy of component 1 is

$$
\theta_{i}=1-\exp \left(-\frac{\Phi}{q_{\text {sat }}}\right)=\frac{b_{i} f_{i}}{1+b_{i} f_{i}} ; \quad \text { unary adsorption of species } \mathrm{i}
$$

From eqs (S29), and (S30) we may also conclude the occupancy may be considered to be the appropriate proxy for the spreading pressure. The conclusion that we draw from the foregoing analysis is that the equalities of spreading pressures for unary adsorption of component 1 , unary adsorption of component 2 , and binary 1-2 mixture adsorption also implies the corresponding equalities of the corresponding occupancies for unary adsorption of component 1 , unary adsorption of component 2 , and binary 1-2 mixture adsorption. 


\section{IAST calculations of mixture adsorption equilibrium}




\section{The Real Adsorbed Solution Theory (RAST)}

To account for non-ideality effects in mixture adsorption, we introduce activity coefficients $\gamma_{i}$ into Eq

$$
f_{i}=P_{i}^{0} x_{i} \gamma_{i}
$$

Following the approaches of Myers, Talu, and Sieperstein ${ }^{42,50,51}$ we model the excess Gibbs free energy for binary mixture adsorption as follows

$$
\frac{G^{\text {excess }}}{R T}=x_{1} \ln \left(\gamma_{1}\right)+x_{2} \ln \left(\gamma_{2}\right)
$$

For calculation of the total mixture loading $q_{t}=q_{1}+q_{2}$ we need to replace eq (S11) by

$$
\frac{1}{q_{t}}=\frac{x_{1}}{q_{1}^{0}\left(P_{1}^{0}\right)}+\frac{x_{2}}{q_{2}^{0}\left(P_{2}^{0}\right)}+\left(\frac{1}{q_{t}}\right)^{\text {excess }}
$$

The excess reciprocal loading for the mixture can be related to the partial derivative of the Gibbs free energy with respect to the surface potential at constant composition

$$
\left(\frac{1}{q_{t}}\right)^{\text {excess }}=\left.\frac{\partial\left(\frac{G^{\text {excess }}}{R T}\right)}{\partial \Phi}\right|_{T, x}
$$

\subsection{Margules model for activity coefficients}

The Margules model for activity coefficients is

$$
\begin{aligned}
& \ln \left(\gamma_{1}\right)=x_{2}^{2}\left(A_{12}+2\left(A_{21}-A_{12}\right) x_{1}\right)(1-\exp (-C \Phi)) \\
& \ln \left(\gamma_{2}\right)=x_{1}^{2}\left(A_{21}+2\left(A_{12}-A_{21}\right) x_{2}\right)(1-\exp (-C \Phi))
\end{aligned}
$$

In eq (S35) $C$ is a constant with the units $\mathrm{kg} \mathrm{mol}^{-1}$. The introduction of $(1-\exp (-C \Phi))$ imparts the correct limiting behaviors $\gamma_{i} \rightarrow 1 ; \Phi \rightarrow 0$ for the activity coefficients in the Henry regime, 
The Real Adsorbed Solution Theory (RAST)

$f_{t} \rightarrow 0 ; \Phi \rightarrow 0$. As pore saturation conditions are approached, this correction factor tends to unity $(1-\exp (-C \Phi)) \rightarrow 1$. The choice of $A_{12}=A_{21}=0$ in eq (S35), yields unity values for the activity coefficients.

For calculation of the total mixture loading $q_{t}=q_{1}+q_{2}$ we need to replace eq (S11) by

$$
\frac{1}{q_{t}}=\frac{x_{1}}{q_{1}^{0}\left(P_{1}^{0}\right)}+\frac{x_{2}}{q_{2}^{0}\left(P_{2}^{0}\right)}+x_{1} x_{2}\left[A_{12} x_{2}+A_{21} x_{1}\right] C \exp (-C \Phi)
$$

\subsection{Wilson model for activity coefficients}

The Wilson model for activity coefficients are given for binary mixtures by

$$
\begin{aligned}
& \ln \left(\gamma_{1}\right)=\left(1-\ln \left(x_{1} \Lambda_{11}+x_{2} \Lambda_{12}\right)-\frac{x_{1} \Lambda_{11}}{x_{1} \Lambda_{11}+x_{2} \Lambda_{12}}-\frac{x_{2} \Lambda_{21}}{x_{2}+x_{1} \Lambda_{21}}\right)(1-\exp (-C \Phi)) \\
& \ln \left(\gamma_{2}\right)=\left(1-\ln \left(x_{1} \Lambda_{21}+x_{2} \Lambda_{22}\right)-\frac{x_{1} \Lambda_{12}}{x_{1} \Lambda_{11}+x_{2} \Lambda_{12}}-\frac{x_{2} \Lambda_{22}}{x_{1} \Lambda_{21}+x_{2} \Lambda_{22}}\right)(1-\exp (-C \Phi))
\end{aligned}
$$

In Eq (S37), $\Lambda_{11} \equiv 1 ; \quad \Lambda_{22} \equiv 1$, and $C$ is a constant with the units $\mathrm{kg} \mathrm{mol}^{-1}$. The choice of $\Lambda_{12}=\Lambda_{21}=1$ in Eq (S37), yields unity values for the activity coefficients.

The excess reciprocal loading for the mixture can be related to the partial derivative of the Gibbs free energy with respect to the surface potential at constant composition

$$
\left(\frac{1}{q_{t}}\right)^{\text {excess }}=\left.\frac{\partial\left(\frac{G^{\text {excess }}}{R T}\right)}{\partial \Phi}\right|_{T, x}=\left[-x_{1} \ln \left(x_{1}+x_{2} \Lambda_{12}\right)-x_{2} \ln \left(x_{2}+x_{1} \Lambda_{21}\right)\right] C \exp (-C \Phi)
$$

For calculation of the total mixture loading we need to replace Eq (S11) by

$$
\frac{1}{q_{t}}=\frac{x_{1}}{q_{1}^{0}\left(P_{1}^{0}\right)}+\frac{x_{2}}{q_{2}^{0}\left(P_{2}^{0}\right)}+\left[-x_{1} \ln \left(x_{1}+x_{2} \Lambda_{12}\right)-x_{2} \ln \left(x_{2}+x_{1} \Lambda_{21}\right)\right] C \exp (-C \Phi)
$$

The parameters $\Lambda_{12}, \Lambda_{21}$, and $C$ can be fitted to match the experimental data on mixture adsorption. The implementation of the activity coefficients is termed as the Real Adsorbed Solution Theory (RAST). 
With the introduction of activity coefficients, the expression for the adsorption selectivity for binary mixtures is

$$
S_{a d s}=\frac{q_{1} / q_{2}}{y_{1} / y_{2}}=\frac{q_{1} / y_{1}}{q_{2} / y_{2}}=\frac{x_{1} / f_{1}}{x_{2} / f_{2}}=\frac{P_{2}^{0} \gamma_{2}}{P_{1}^{0} \gamma_{1}}
$$




\section{CBMC data for mixture adsorption and RAST analysis}

\subsection{CBMC simulation campaigns}

A comprehensive campaign of CBMC simulations for adsorption of a variety of binary mixtures in several host materials were carried out. Two types of mixture adsorption campaigns were conducted.

Campaign A. The bulk fluid phase composition held constant at a value say $y_{1}=y_{2}=0.5, y_{1}=0.1$, $y_{1}=0.15$, or $y_{1}=0.9$ and the bulk fluid phase fugacity $f_{t}=f_{1}+f_{2}$ was varied over a wide range from the Henry regime of adsorption, $f_{t} \rightarrow 0 ; \Phi \rightarrow 0$, to pore saturation conditions, typically $\Phi>30$.

Campaign B. The bulk fluid phase fugacity $f_{t}=f_{1}+f_{2}$ was held at a constant value, and the bulk fluid phase mixture composition $y_{1}$ was varied $0<y_{1}<1$.

Each CBMC simulation data point, for specified partial fugacities in the bulk fluid phase, $f_{1}, f_{2}$, yields the component loadings, $q_{1, C B M C} ; q_{2, C B M C}$, and the total mixture loading $q_{t, C B M C}=q_{1, C B M C}+q_{2, C B M C}$.

For each guest/host combination, CBMC simulations of the unary isotherms of the constituent guest molecules were also carried out.

\subsection{Determination of activity coefficients from CBMC mixture adsorption data}

For each CBMC mixture simulation campaign (Campaign A, or Campaign B), the mole fractions of the adsorbed phase, $\quad x_{1}=\frac{q_{1, C B M C}}{q_{t, C B M C}} ; x_{2}=\frac{q_{2, C B M C}}{q_{t, C B M C}} ; q_{t, C B M C}=q_{1, C B M C}+q_{2, C B M C}$ are determined. The sorption pressures $P_{1}^{0}, P_{2}^{0}$, each of which satisfying eq (S6), can be determined from using the unary isotherm fits for each of the components in the binary mixture.

The activity coefficients of the two components $\gamma_{1, C B M C} ; \gamma_{2, C B M C}$ are determined from eq (S31): 


$$
\gamma_{1, C B M C}=\frac{f_{1}}{P_{1}^{0} x_{1, C B M C}} ; \gamma_{2, C B M C}=\frac{f_{2}}{P_{2}^{0} x_{2, C B M C}}
$$

The activity coefficients of the two components $\gamma_{1, C B M C} ; \gamma_{2, C B M C}$, determined using eq (S41) are subject to a degree of scatter that is inherent in the CBMC mixture simulation data.

\subsection{Determination of Margules and Wilson fit parameters from mixture adsorption data}

For each mixture/host combination, the set of three Margules parameters $A_{12}, A_{21}, C$ that yield the minimum value for the objective function calculated as the sum of the mean-squared deviations between the CBMC simulated activity coefficients, and those predicted using RAST

$$
\text { Objective Function }=\left(\frac{\gamma_{1, C B M C}-\gamma_{1, R A S T}}{\gamma_{1, C B M C}}\right)^{2}+\left(\frac{\gamma_{2, C B M C}-\gamma_{2, R A S T}}{\gamma_{2, C B M C}}\right)^{2}
$$

An alternative objective function used for some data sets is to seek the minimum value for the objective function calculated as the sum of the mean-squared deviations between the CBMC simulated component loadings and those predicted using RAST

Objective Function $=\left(q_{1, C B M C}-q_{1, R A S T}\right)^{2}+\left(q_{2, C B M C}-q_{2, R A S T}\right)^{2}$

The $A_{12}, A_{21}, C$ were determined using the Excel solver function. For determination of the Margules parameters $A_{12}, A_{21}, C$, the $\mathrm{CBMC}$ data for both Campaigns $\mathrm{A}$, and $\mathrm{B}$ were employed.

A similar procedure is applied to determine the set of Wilson parameters. 


\section{Mixture adsorption in all-silica MFI zeolite}

MFI zeolite (also called silicalite-1) has a topology consisting of a set of intersecting straight channels, and zig-zag (or sinusoidal) channels of $5.4 \AA \times 5.5 \AA$ and $5.4 \AA \times 5.6 \AA$ size. The pore landscapes and structural details are provided in Figure S9, and Figure S10. The crystal framework density $\rho=1796 \mathrm{~kg}$ $\mathrm{m}^{-3}$. The pore volume $V_{\mathrm{p}}=0.165 \mathrm{~cm}^{3} / \mathrm{g}$.

\subsection{Adsorption of mixtures of light gaseous molecules in MFI zeolite}

The applicability of Raoult's law analog, eq (S4), mandates that all of the adsorption sites within the microporous material are equally accessible to each of the guest molecules, implying a homogeneous distribution of guest adsorbates within the pore landscape, with no preferential locations of any guest species. $^{46,48}$ This requirement of homogeneous distribution of guest molecules within MFI zeolite is fulfilled for light gaseous molecules such as $\mathrm{H}_{2}, \mathrm{~N}_{2}, \mathrm{CO}_{2}, \mathrm{CH}_{4}, \mathrm{C}_{2} \mathrm{H}_{4}, \mathrm{C}_{2} \mathrm{H}_{6}, \mathrm{C}_{3} \mathrm{H}_{6}, \mathrm{C}_{3} \mathrm{H}_{8}$, and n- $\mathrm{C}_{4} \mathrm{H}_{10}$. Figure $\mathrm{S} 11$ a shows computational snapshots for the adsorption of $\mathrm{CO}_{2}$, and $\mathrm{CH}_{4}$ within the intersecting channel topology of MFI zeolite. It is noticeable that neither guest species shows any preferential location and there is no visual indication of segregated adsorption. The only charged species is $\mathrm{CO}_{2}$; the coulombic interactions with the negatively charged oxygen atoms in the zeolite framework are not strong enough to cause segregation between $\mathrm{CO}_{2}$, and $\mathrm{CH}_{4}$. We should therefore expect the mixture adsorption characteristics to be adequately well described by the IAST. Figure S11b shows CBMC simulations for the unary isotherms of light gaseous molecules in MFI zeolite at $300 \mathrm{~K}$. The light gaseous guests can locate anywhere along the straight channels and zig-zag channels, and there are no perceptible isotherm inflections. The loadings, plotted on the $y$-axis are expressed in units of molecules per unit cell, $\Theta$. To obtain the loading $q$, with units of mol kg-1, the conversion factor is 1 molecule $\mathrm{uc}^{-1}=0.173366 \mathrm{~mol} \mathrm{~kg}^{-1}$ . These unary isotherms were each fitted with the dual-site Langmuir-Freundlich model, eq (S8); the parameter values are defined in Table S5. The IAST calculations for the adsorption selectivity, $S_{a d s}$, for five different binary mixtures $\mathrm{CO}_{2} / \mathrm{CH}_{4}, \mathrm{CO}_{2} / \mathrm{H}_{2}, \mathrm{CO}_{2} / \mathrm{N}_{2}, \mathrm{CH}_{4} / \mathrm{N}_{2}, \mathrm{C}_{3} \mathrm{H}_{8} / \mathrm{CH}_{4}$, are compared with the 


\section{Mixture adsorption in all-silica MFI zeolite}

corresponding $S_{a d s}$ values determined from CBMC simulations in Figure S12a,b. In Figure S12a the $S_{a d s}$ values are plotted as function of the surface potential, $\Phi$. In Figure S12b the $S_{a d s}$ values are plotted as function of the pore occupancy, $\theta$, determined from eq (S14). For all five mixtures the IAST estimations are in good agreement with the CBMC simulations. For $\mathrm{CO}_{2} / \mathrm{CH}_{4}$ and $\mathrm{CO}_{2} / \mathrm{N}_{2}$ mixtures, the $S_{a d s}$ increases as pore saturation conditions are approached, i.e. $\Phi>10 \mathrm{~mol} \mathrm{~kg}^{-1} ; \quad \theta>0.5$ because of entropy effects that favor the guest $\mathrm{CO}_{2}$ with the higher saturation capacity (cf. Figure $\mathrm{S} 11 \mathrm{~b}$ ); the explanation of entropy effects are provided in the published literature..$^{52,53}$

For $\mathrm{CO}_{2} / \mathrm{H}_{2}$ and $\mathrm{C}_{3} \mathrm{H}_{8} / \mathrm{CH}_{4}$ mixtures, the $S_{a d s}$ decreases as pore saturation conditions are approached, i.e. $\Phi>10 \mathrm{~mol} \mathrm{~kg}^{-1} ; \quad \theta>0.5$ because entropy effects favor the smaller guests $\mathrm{H}_{2}$ and $\mathrm{CH}_{4}$, respectively. The use of the mixed-gas Langmuir model, eq (S28), with equal saturation capacities is unable to cater for entropy effects as evidenced for the aforementioned four $\mathrm{CO}_{2} / \mathrm{CH}_{4}, \mathrm{CO}_{2} / \mathrm{N}_{2}, \mathrm{CO}_{2} / \mathrm{H}_{2}$ and $\mathrm{C}_{3} \mathrm{H}_{8} / \mathrm{CH}_{4}$ mixtures.

For $\mathrm{CH}_{4} / \mathrm{N}_{2}$ mixtures, the $S_{a d s}$ is practically independent of occupancy because the saturation capacities of $\mathrm{CH}_{4}$, and $\mathrm{N}_{2}$ are nearly the same, as evidenced in Figure $\mathrm{S} 11 \mathrm{~b}$.

A further important point to note is that for the adsorption selectivity as defined in eq (S13) for component 1 with respect to component 2, also holds for the same guest components in the presence of other guest species, 3, 4, 5, ..etc. Equation (S6) implies that if the comparisons are made at the same surface potential $\Phi$, the value of $S_{a d s}$ for component 1 with respect to component 2 , remains the same irrespective of the presence of additional guest components in the same host.

Figure $\mathrm{S} 13$ presents a comparison of $\mathrm{CO}_{2} / \mathrm{CH}_{4}, \mathrm{CO}_{2} / \mathrm{N}_{2}$, and $\mathrm{CH}_{4} / \mathrm{N}_{2}$ adsorption selectivities determined from binary mixtures, with the corresponding values determined from CBMC simulations two different ternary mixtures: $5 / 15 / 80 \mathrm{CO}_{2} / \mathrm{CH}_{4} / \mathrm{N}_{2}$, and $20 / 30 / 50 \mathrm{CO}_{2} / \mathrm{CH}_{4} / \mathrm{N}_{2}$ in MFI zeolite at $300 \mathrm{~K}$. Each of the three selectivities shows a unique dependence on $\Phi$, as prescribed by eq (S13). Put another way, the presence of component 3 in the ternary mixture has no influence of the adsorption selectivity for the 1-2 pair other than via the surface potential. 


\subsection{Preferential location of guest molecules at intersections of MFI zeolite}

Due to configurational considerations, branched alkanes prefer to locate at the channel intersections because of the extra "leg room" that is available here. An extra "push" is required to locate these molecules within the channel interiors. This extra push results in an inflection in the pure component isotherms at a loading of 4 molecules per unit cell because per unit cell of MFI, there are four channel intersection sites. $^{54-57}$ See CBMC simulation data for iso-butane (iC4), 2-methylpentane (2MP), and 2,2 dimethylbutane (22DMB) in Figure S14a. Figure S14b shows computational snapshots for the location of iC4 within the channel topology of MFI zeolite. Cyclic hydrocarbons, such as cyclohexane, Benzene $(\mathrm{Bz})$, and ethylbenzene (EthBz) also prefer to locate at the intersections; the unary isotherm for benzene also exhibits a strong inflection at a loading, $\Theta=4$ molecules per unit cell; see snapshots for location of benzene in Figure S14c.

Due to the preferential location of branched and cyclic hydrocarbons at the channel intersections, the adsorption of mixtures containing these types of hydrocarbons along with linear alkanes, exhibit entropy effects that favor the linear alkanes and alkenes. We illustrate these effects by considering the adsorption of five different binary mixtures: $\mathrm{C}_{2} \mathrm{H}_{4}(1) /$ benzene(2), $\mathrm{C}_{3} \mathrm{H}_{6}(1) /$ benzene(2), $\mathrm{C}_{3} \mathrm{H}_{8} /$ iso-butane(iC4), nC4/iC4, n-hexane(nC6)/2-methylpentane(2MP).

\subsection{Adsorption of $\mathrm{C}_{2} \mathrm{H}_{4} /$ benzene and $\mathrm{C}_{3} \mathrm{H}_{6} /$ benzene mixtures in MFI zeolite}

Figure S15a,b show computational snapshots of the location of guest molecules for (a) $\mathrm{C}_{2} \mathrm{H}_{4}(1) /$ benzene(2) and (b) $\mathrm{C}_{3} \mathrm{H}_{6}(1) /$ benzene(2) mixture adsorption in MFI zeolite at $300 \mathrm{~K}$. The benzene molecules are located at the intersections whereas the alkenes can locate anywhere along the straight and zig-zag channels. It is also evident from the snapshots that some of the alkene guest molecules are located remotely from the benzene; consequently, the competition faced by the alkenes is less severe than that anticipated by IAST that mandates a homogeneous distribution of adsorbates. We should therefore expect the IAST to overestimate the nature of competitive adsorption. To confirm this expectations, CBMC simulations of adsorption of $\mathrm{C}_{2} \mathrm{H}_{4}(1) /$ benzene(2) and $\mathrm{C}_{3} \mathrm{H}_{6}(1) /$ benzene(2) mixture with equal partial 
fugacitites $f_{1}=f_{2} ; \quad y_{1}=f_{1} /\left(f_{1}+f_{2}\right)=0.5$ were performed. These results are presented in Figure S16, and Figure S17; in these figures CBMC data are represented by symbols. The dashed lines are IAST estimations.

First, let us consider $\mathrm{C}_{2} \mathrm{H}_{4}(1)$ /benzene(2) mixture adsorption in MFI. Figure S16a shows the unary isotherms of $\mathrm{C}_{2} \mathrm{H}_{4}$ and benzene in MFI zeolite at $300 \mathrm{~K}$. Benzene is more strongly adsorbed than ethene at fluid phase fugacities $f_{\mathrm{i}}<10^{4} \mathrm{~Pa}$. The continuous solid lines are unary isotherm dual-LangmuirFreundlich fits with the parameters provided in Table S5. Figure S16b compares the component loadings in $\mathrm{C}_{2} \mathrm{H}_{4}(1)$ /benzene(2) mixtures with CBMC simulations of unary isotherms, where the comparison is made on the basis of partial fugacities in the bulk fluid phase. Figure S16c presents CBMC data for benzene (2)/ $\mathrm{C}_{2} \mathrm{H}_{4}(1)$ adsorption selectivity (indicated by symbols) compared with IAST (dashed lines) and RAST (continuous solid lines) estimates. In the RAST calculations, the Margules parameters (specified in Table S6) are fitted to match the component loadings for mixture adsorption. The IAST overestimates the adsorption selectivity because of the implicit assumption of homogeneous distribution of adsorbates. The IAST calculation assumes that $\mathrm{C}_{2} \mathrm{H}_{4}$ molecules compete with all of the benzene molecules, making no allowance for segregation and preferential adsorption of benzene at the intersections. Due to segregation effects the competition faced by $\mathrm{C}_{2} \mathrm{H}_{4}$ molecules within the channels is smaller than that in the entire pore space. In other words, the IAST anticipates a stiffer competition between benzene and $\mathrm{C}_{2} \mathrm{H}_{4}$ as it assumes a uniform distribution of composition; consequently, the separation selectivity is overestimated. Due to preferential location of benzene at the intersections, some ethene molecules are farther removed from benzene and suffer diminished competition.

In Figure S16d, the CBMC data for component loadings in mixture compared with IAST and RAST estimates. The IAST severely underestimates the alkene component loadings in the mixture.

In Figure S16e,f the activity coefficients determined from CBMC simulated data are compared with RAST model calculations. It is noteworthy that the activity coefficient of ethene falls significantly below unity with increasing bulk fluid phase fugacities, $f_{t}=f_{1}+f_{2}$. 
Precisely analogous results are obtained from the analysis of $\mathrm{CBMC}$ data for $\mathrm{C}_{3} \mathrm{H}_{6}(1) / \mathrm{Benzene}(2)$ mixture adsorption in MFI; the corresponding data are presented in Figure S17.

Figure S18a compare the CBMC data for adsorption selectivity $S_{a d s}$ of $\mathrm{C}_{2} \mathrm{H}_{4}(1) / \mathrm{Benzene}(2)$ $\mathrm{C}_{3} \mathrm{H}_{6}(1) /$ Benzene(2) mixtures, plotted as a function of the surface potential, $\Phi$. For both mixtures, the IAST overestimates $S_{a d s}$ value in favor of benzene.

\subsection{Adsorption of mixtures of linear and branched alkanes in MFI zeolite}

Figure S19, and Figure S20 show the computational snapshots for adsorption of $\mathrm{C}_{3} \mathrm{H}_{8} / \mathrm{iC} 4, \mathrm{nC} 4 / \mathrm{iC} 4$, and nC6/2MP mixtures MFI zeolite at $300 \mathrm{~K}$. Due to configurational considerations, the branched alkanes demand more "leg-room" and, consequently, are predominantly located at the channel intersections. The linear alkanes are able to locate at either the straight channels or zig-zag channels. Due to the segregated nature of adsorption, the competition between the linear and branched alkanes is less severe than anticipated by the IAST.

To confirm this expectation, the $\mathrm{CBMC}$ data for $\mathrm{C}_{3} \mathrm{H}_{8} / \mathrm{iC} 4, \mathrm{nC} 4 / \mathrm{iC} 4$, and $\mathrm{nC} 6 / 2 \mathrm{MP}$ mixture adsorption are presented in Figure S21, Figure S22, Figure S23, Figure S24, and Figure S25.

First, let us consider equimolar $\mathrm{C}_{3} \mathrm{H}_{8}(1) / \mathrm{iC} 4(2)$ mixture adsorption in MFI with equal partial fugacitites $f_{1}=f_{2} ; \quad y_{1}=f_{1} /\left(f_{1}+f_{2}\right)=0.5$. Figure S21a shows the unary isotherms of $\mathrm{C}_{3} \mathrm{H}_{8}(1)$, and iC4(2) in MFI zeolite at $300 \mathrm{~K}$. The branched alkane is more strongly adsorbed than $\mathrm{C}_{3} \mathrm{H}_{8}$ at fluid phase fugacities $f_{\mathrm{i}}<$ $10^{3} \mathrm{~Pa}$. Due to configurational considerations, iC4 molecules prefer to locate at the channel intersections because of the extra "leg room" that is available here. An extra "push" is required to locate iC4 within the channel interiors. This extra push results in an inflection in the $\mathrm{iC} 4$ at a loading of 4 molecules per unit cell. ${ }^{54-57}$ However, for $f_{\mathrm{t}}>10^{3} \mathrm{~Pa}$, the loadings of $\mathrm{C}_{3} \mathrm{H}_{8}$ exceed that of $\mathrm{iC} 4$ because the alkane can locate anywhere within the channels, whilst the adsorption of $\mathrm{iC} 4$ is restricted to the intersection sites. The continuous solid lines are unary isotherm dual-Langmuir-Freundlich fits with the parameters provided in Table S5. 
Figure S21b compares the component loadings in $\mathrm{C}_{3} \mathrm{H}_{8}(1) / \mathrm{iC} 4(2)$ mixtures with $\mathrm{CBMC}$ simulations of unary isotherms, where the comparison is made on the basis of partial fugacities in the bulk fluid phase. Figure S21c presents $\mathrm{CBMC}$ data for $\mathrm{C}_{3} \mathrm{H}_{8}(1) / \mathrm{iC} 4(2)$ adsorption selectivity (indicated by symbols) compared with IAST (dashed lines) and RAST (continuous solid lines) estimates. In the RAST calculations, the Margules parameters (specified in Table S6) are fitted to match the component loadings for mixture adsorption. The increase in the $\mathrm{C}_{3} \mathrm{H}_{8}(1) / \mathrm{iC} 4(2)$ adsorption selectivity with increased pore occupancy is the direct consequence of entropy effects that favor the guest with the higher saturation capacity, i.e. $\mathrm{C}_{3} \mathrm{H}_{8}$. The IAST overestimates the adsorption selectivity at pore saturation conditions because of the implicit assumption of homogeneous distribution of adsorbates. The IAST calculation assumes that $\mathrm{C}_{3} \mathrm{H}_{8}$ molecules compete with all of the $\mathrm{iC} 4$ molecules, making no allowance for segregation and preferential adsorption of $\mathrm{iC} 4 \mathrm{e}$ at the intersections. Due to segregation effects the competition faced by $\mathrm{C}_{3} \mathrm{H}_{8}$ molecules within the channels is smaller than that in the entire pore space. In other words, the IAST anticipates a stiffer competition between $\mathrm{iC}_{4}$ and $\mathrm{C}_{3} \mathrm{H}_{8}$ as it assumes a uniform distribution of composition; consequently, the separation selectivity is overestimated. A different way of viewing this is to state that entropy effects are moderated due to the occurrence of segregated adsorption.

In Figure S21d, the CBMC data for component loadings in mixture compared with IAST and RAST estimates. It is noteworthy that propane loading nearly coincides with that of $\mathrm{iC} 4$ at $f_{\mathrm{t}} \approx 5 \times 10^{3} \mathrm{~Pa}$. It is noteworthy that propane loading nearly coincides with that of iC4 at $f_{\mathrm{t}} \approx 5 \times 10^{3} \mathrm{~Pa}$. Entropy effects cause the loadings of propane to exceed that of iso-butane for $f_{\mathrm{t}}>5 \times 10^{3} \mathrm{~Pa}$. For $f_{\mathrm{t}}>5 \times 10^{3} \mathrm{~Pa}$, the IAST severely overestimates the $\mathrm{C}_{3} \mathrm{H}_{8}$ loadings in the mixture, whilst underestimating the iC4 loading.

In Figure S21e,f the activity coefficients determined from CBMC simulated data are compared with RAST model calculations. It is noteworthy that the activity coefficient of iC4 falls significantly below unity as pore saturation conditions are approached.

Analogous results are obtained from the analysis of $\mathrm{CBMC}$ data for $\mathrm{nC} 4(1) / \mathrm{iC} 4(2)$ mixture adsorption in MFI; the corresponding data are presented in Figure S22. 
Figure S23 presents CBMC simulation data for Campaign $\mathrm{B}\left(f_{t}=f_{1}+f_{2}=100 \mathrm{~Pa}\right.$; vary $\left.y_{1}\right)$ for $\mathrm{nC4}(1) / \mathrm{iC} 4(2)$ mixture adsorption in MFI zeolite at $300 \mathrm{~K}$ in which the bulk fluid phase composition $\mathrm{y}_{1}$ is varied from 0 to 1 . At the chosen total fugacity $f_{t}=f_{1}+f_{2}=100 \mathrm{~Pa}$, the IAST estimates are of adequate accuracy and the activity coefficients are close to unity.

Figure S18b compare the CBMC data for adsorption selectivity $S_{a d s}$ of $\mathrm{C}_{3} \mathrm{H}_{8}(1) / \mathrm{iC} 4(2) \mathrm{nC} 4(1) / \mathrm{iC} 4(2)$ mixtures, plotted as a function of the surface potential, $\Phi$. For both mixtures, the IAST overestimates $S_{a d s}$ value in favor of the linear alkane.

Figure S24 presents the CBMC data for nC6/2MP adsorption corresponding, respectively, to Campaign A $\left(f_{1}=f_{2} ; \quad y_{1}=f_{1} /\left(f_{1}+f_{2}\right)=0.5\right)$. Due to configurational considerations, the branched isomer 2MP is practically excluded due to mixture adsorption at saturation conditions in Campaign A. The experimental data of Titze et al. ${ }^{58}$ using Infra-Red Microscopy (IRM) are in good agreement with CBMC simulations; these provide experimental verification of the entropy effects that favor nC6.

Figure S25 present the CBMC data for nC6/2MP adsorption corresponding to Campaign $\mathrm{B}$ $\left(f_{t}=f_{1}+f_{2}=1 \mathrm{~Pa} ; \quad\right.$ vary $\left.y_{1}\right)$. At the chosen total fugacity $f_{t}=f_{1}+f_{2}=1 \mathrm{~Pa}$, the IAST estimates are of adequate accuracy and the activity coefficients are close to unity.

Figure S18a compare the CBMC data for adsorption selectivity $S_{a d s}$ of $\mathrm{C}_{2} \mathrm{H}_{4}(1) / \mathrm{Benzene}(2)$ $\mathrm{C}_{3} \mathrm{H}_{6}(1) /$ Benzene(2) mixtures, plotted as a function of the surface potential, $\Phi$. For both mixtures, the IAST overestimates $S_{a d s}$ value in favor of benzene. 


\subsection{List of Tables for Mixture adsorption in all-silica MFI zeolite}

Table S5. Dual-site Langmuir-Freundlich parameters for guest molecules in MFI at $300 \mathrm{~K}$. To convert from molecules $\mathrm{uc}^{-1}$ to $\mathrm{mol} \mathrm{\textrm {kg } ^ { - 1 }}$, multiply by 0.173367 .

\begin{tabular}{|c|c|c|c|c|c|c|}
\hline & \multicolumn{3}{|l|}{ Site A } & \multicolumn{3}{|l|}{ Site B } \\
\hline & $\begin{array}{l}\Theta_{\mathrm{A}, \mathrm{sat}} \\
\text { molecules uc }{ }^{-1}\end{array}$ & $\begin{array}{l}b_{\mathrm{A}} \\
\mathrm{Pa}^{-v A}\end{array}$ & $\begin{array}{l}v_{\mathrm{A}} \\
\text { dimensionless }\end{array}$ & $\begin{array}{l}\Theta_{\mathrm{B}, \mathrm{sat}} \\
\text { molecules uc }{ }^{-1}\end{array}$ & $\begin{array}{l}b_{\mathrm{B}} \\
\mathrm{Pa}^{-v B}\end{array}$ & $\begin{array}{l}v_{\mathrm{B}} \\
\text { dimensionless }\end{array}$ \\
\hline $\mathrm{H}_{2}$ & 30 & $3.57 \mathrm{E}-08$ & 1 & 42 & $1.39 \mathrm{E}-09$ & 1 \\
\hline $\mathrm{N}_{2}$ & 16 & $6.37 \mathrm{E}-07$ & 1 & 16 & $3.82 \mathrm{E}-07$ & 0.7 \\
\hline $\mathrm{CO}_{2}$ & 19 & $6.12 \mathrm{E}-06$ & 1 & 11 & $1.73 \mathrm{E}-08$ & 1 \\
\hline $\mathrm{CH}_{4}$ & 7 & $5.00 \mathrm{E}-09$ & 1 & 16 & $3.10 \mathrm{E}-06$ & 1 \\
\hline $\mathrm{C}_{2} \mathrm{H}_{6}$ & 3.3 & $4.08 \mathrm{E}-07$ & 1 & 13 & $7.74 \mathrm{E}-05$ & 1 \\
\hline $\mathrm{C}_{2} \mathrm{H}_{4}$ & 6.9 & $1.988 \mathrm{E}-04$ & 0.65 & 10.1 & $6.959 \mathrm{E}-06$ & 1.2 \\
\hline $\mathrm{C}_{3} \mathrm{H}_{8}$ & 1.4 & $3.35 \mathrm{E}-04$ & 0.67 & 10.7 & $6.34 \mathrm{E}-04$ & 1.06 \\
\hline $\mathrm{C}_{3} \mathrm{H}_{6}$ & 0.6 & $2.912 \mathrm{E}-06$ & 1 & 11.4 & $6.534 \mathrm{E}-04$ & 1 \\
\hline $\mathrm{nC}_{4} \mathrm{H}_{10}$ & 1.5 & $2.24 \mathrm{E}-03$ & 0.57 & 8.7 & $9.75 \mathrm{E}-03$ & 1.12 \\
\hline iso- $\mathrm{C}_{4} \mathrm{H}_{10}$ & 4 & $2.29 \mathrm{E}-02$ & 1 & 6 & $2.87 \mathrm{E}-05$ & 1 \\
\hline $\mathrm{nC}_{6} \mathrm{H}_{14}$ & 6.6 & $7.08 \mathrm{E}-01$ & 0.83 & 1.4 & $1.66 \mathrm{E}+01$ & 1.5 \\
\hline $2 \mathrm{MP}$ & 4 & 4.513 & 1.05 & 4 & 7.92E-05 & 1.13 \\
\hline Benzene & 4 & $1.359 \mathrm{E}-01$ & 1.06 & 8 & $2.339 \mathrm{E}-03$ & 0.52 \\
\hline
\end{tabular}


Table S6. Margules non-ideality parameters for binary mixtures in all-silica MFI zeolite at $300 \mathrm{~K}$.

\begin{tabular}{|l|l|l|l|}
\hline & $C / \mathrm{kg} \mathrm{mol}^{-1}$ & $A_{12}$ & $A 21$ \\
\hline $\mathrm{C}_{2} \mathrm{H}_{4} /$ Benzene & 0.433 & -3.107 & -8.369 \\
\hline $\mathrm{C}_{3} \mathrm{H}_{6} /$ Benzene & 0.271 & -2.001 & -9.149 \\
\hline $\mathrm{C}_{3} \mathrm{H}_{8} /$ iso- $_{4} \mathrm{H}_{10}$ & 0.322 & -2.814 & -3.859 \\
\hline $\mathrm{n}-\mathrm{C}_{4} \mathrm{H}_{10} /$ iso-C $4 \mathrm{H}_{10}$ & 0.190 & 0.578 & -3.175 \\
\hline $\mathrm{n}-\mathrm{C}_{6} \mathrm{H}_{12} / 2 \mathrm{MP}$ & 0.386 & 1.340 & 1.580 \\
\hline & & & \\
\hline
\end{tabular}




\subsection{List of Figures for Mixture adsorption in all-silica MFI zeolite}

\section{MFI pore landscape}

\begin{tabular}{|c|c|}
\hline & MFI \\
\hline$a / \AA$ & 20.022 \\
\hline$b / A$ & 19.899 \\
\hline$C / A$ & 13.383 \\
\hline Cell volume / $\AA^{3}$ & 5332.025 \\
\hline conversion factor for [molec/uc] to [mol per $\mathrm{kg}$ Framework] & 0.1734 \\
\hline conversion factor for $[\mathrm{molec} / \mathrm{uc}]$ to $\left[\mathrm{kmol}^{3} / \mathrm{m}^{3}\right]$ & 1.0477 \\
\hline$\rho[\mathrm{kg} / \mathrm{m} 3]$ & 1796.386 \\
\hline MW unit cell [g/mol(framework)] & 5768.141 \\
\hline$\phi$, fractional pore volume & 0.297 \\
\hline open space / $\AA^{3} / \mathrm{uc}$ & 1584.9 \\
\hline Pore volume $/ \mathrm{cm}^{3} / \mathrm{g}$ & 0.165 \\
\hline Surface area $/ \mathrm{m}^{2} / \mathrm{g}$ & 487.0 \\
\hline DeLaunay diameter /Å & 5.16 \\
\hline
\end{tabular}

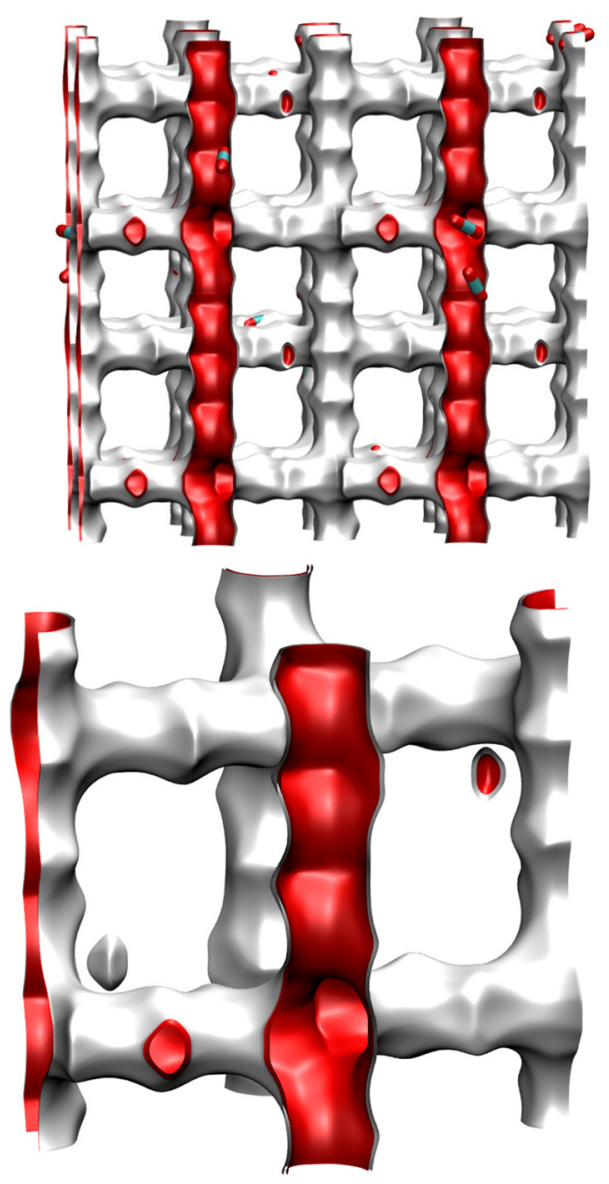

Figure S9. Pore landscape and structural data for MFI zeolite. 


\section{MFI channel dimensions}

10 ring channel of MFI viewed along [100]

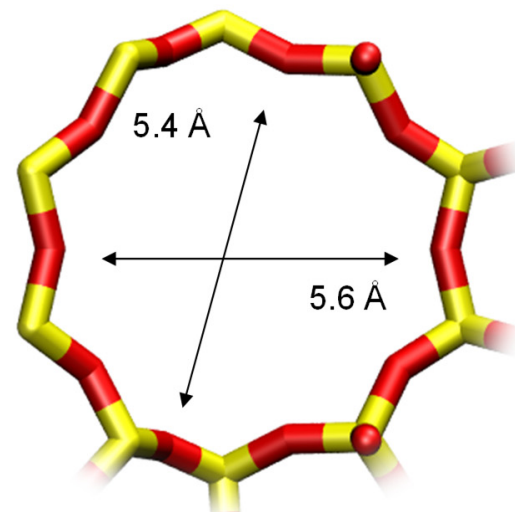

10 ring channel of MFI viewed along [010]
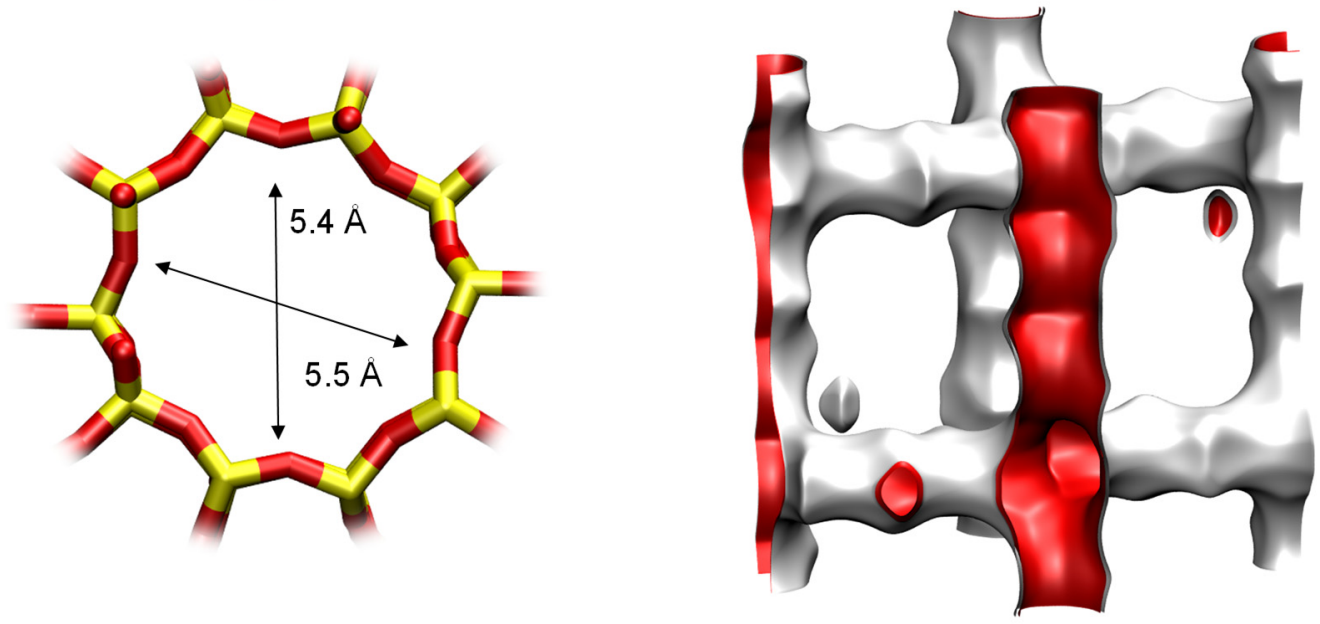

Figure S10. Pore landscape and structural data for MFI zeolite. 


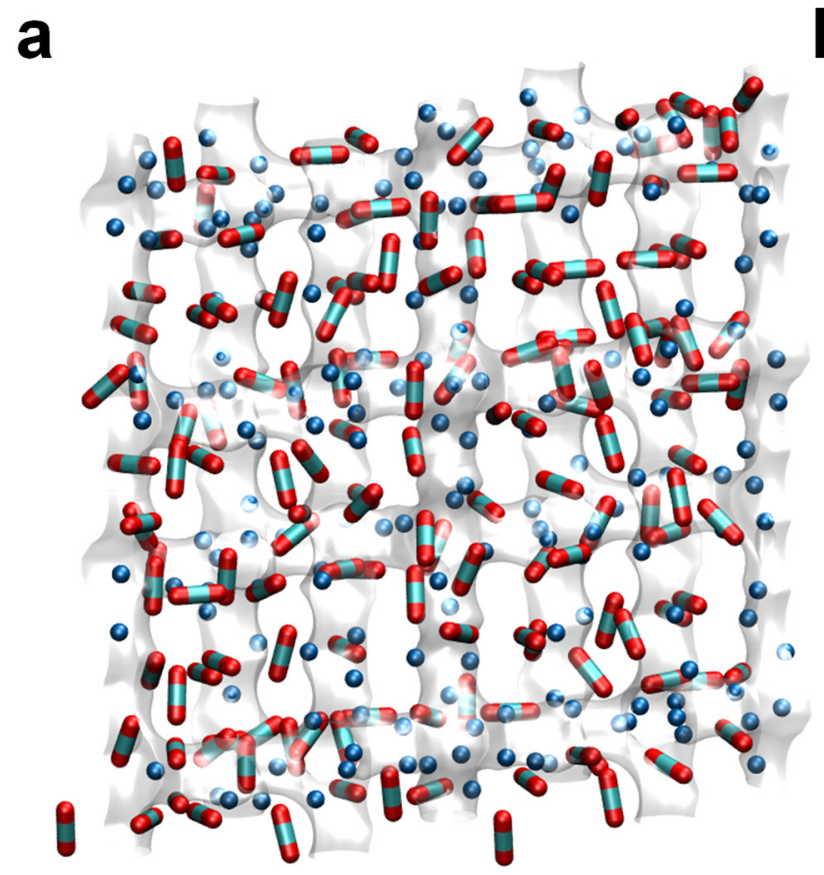

b

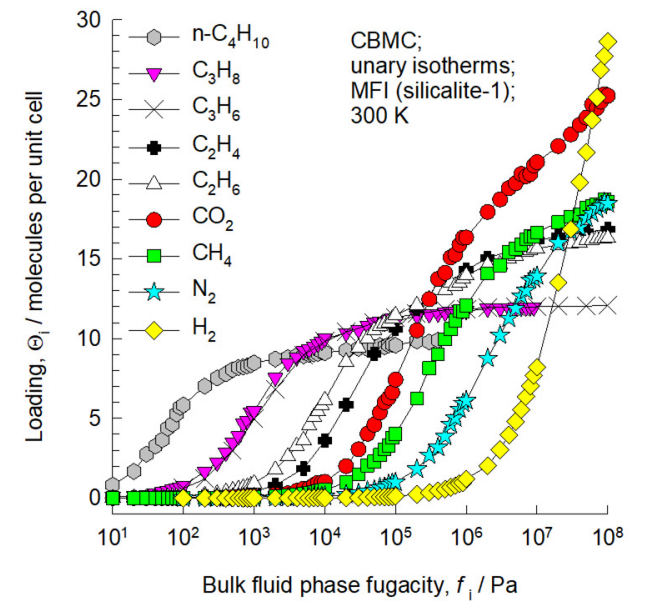

Figure S11. (a) Computational snapshots showing the distribution of. $\mathrm{CO}_{2}$ and $\mathrm{CH}_{4}$ for binary mixture adsorption. (b) CBMC simulations of unary isotherms for light gaseous molecules $\mathrm{H}_{2}, \mathrm{~N}_{2}, \mathrm{CO}_{2}, \mathrm{CH}_{4}$, $\mathrm{C}_{2} \mathrm{H}_{4}, \mathrm{C}_{2} \mathrm{H}_{6}, \mathrm{C}_{3} \mathrm{H}_{6}, \mathrm{C}_{3} \mathrm{H}_{8}$, and $\mathrm{n}-\mathrm{C}_{4} \mathrm{H}_{10}$ in MFI zeolite at $300 \mathrm{~K}$. 


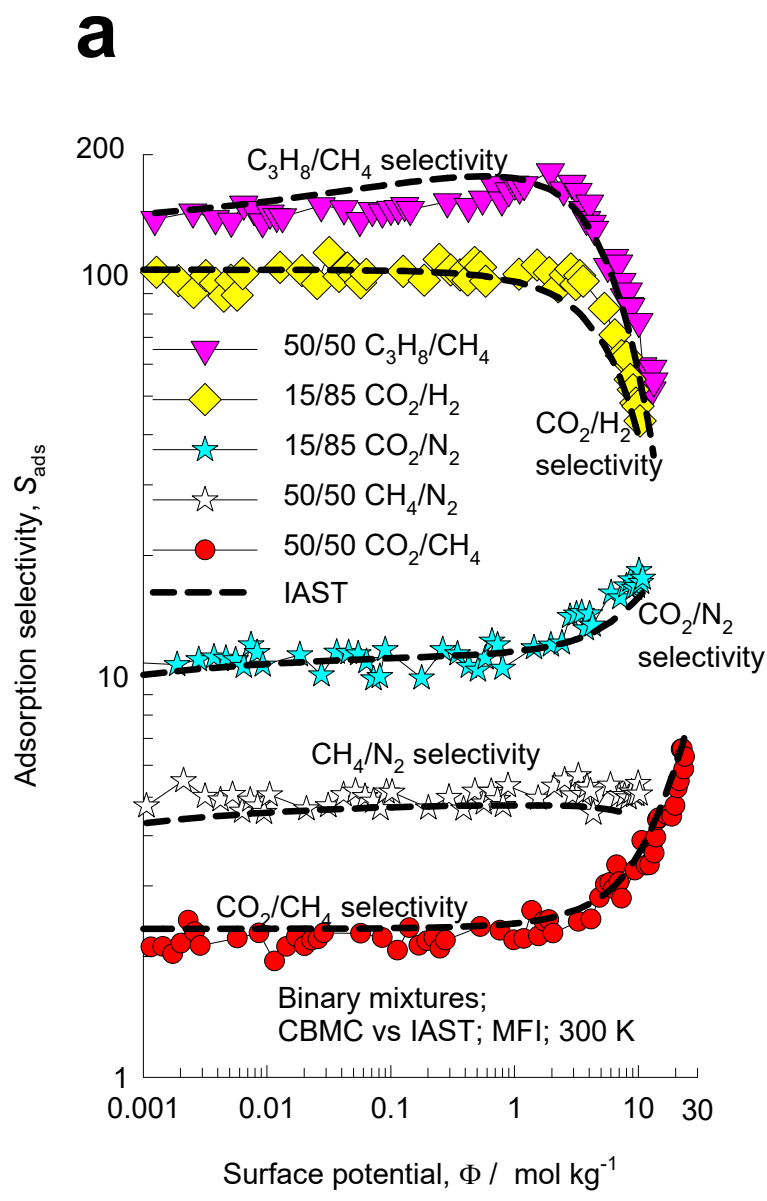

b

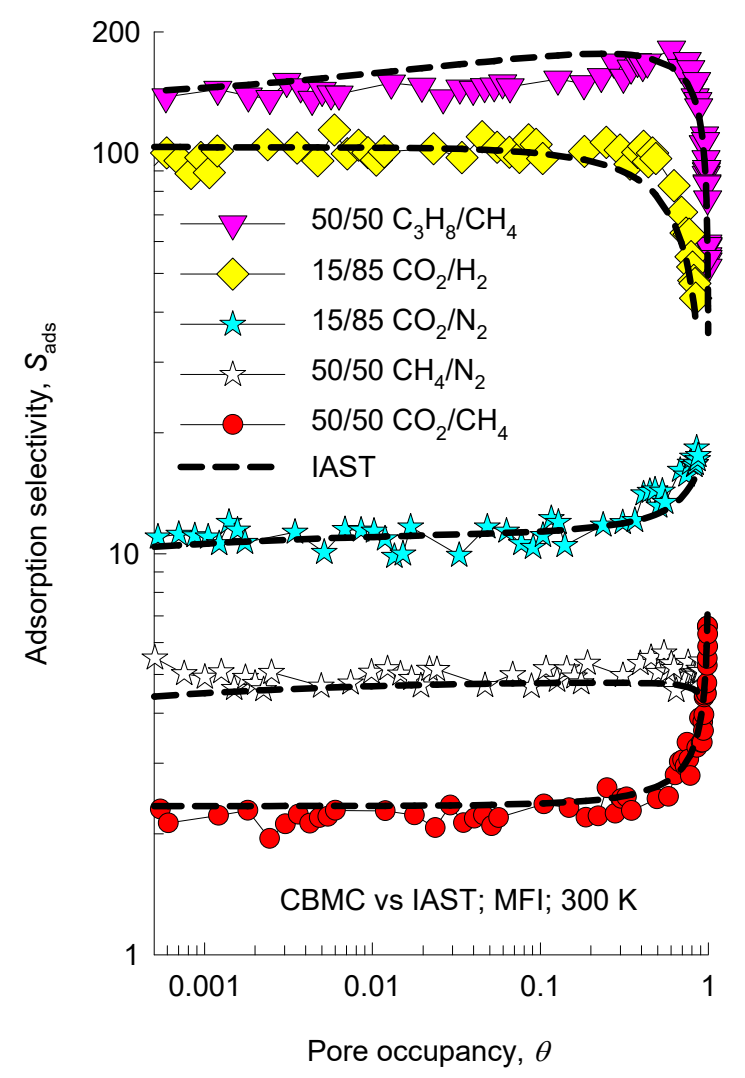

Figure S12. $(\mathrm{a}, \mathrm{b}) \mathrm{CBMC}$ simulations (indicated by symbols) of the adsorption selectivity, $S_{a d s}$, for five different binary $\mathrm{CO}_{2} / \mathrm{CH}_{4}, \mathrm{CO}_{2} / \mathrm{H}_{2}, \mathrm{CO}_{2} / \mathrm{N}_{2}, \mathrm{CH}_{4} / \mathrm{N}_{2}, \mathrm{C}_{3} \mathrm{H}_{8} / \mathrm{CH}_{4}$ mixtures compared with the IAST calculations (indicated by dashed lines) for corresponding $S_{a d s}$ values using the Dual-site LangmuirFreundlich fits of unary isotherms. In (a) the $S_{a d s}$ values are plotted as function of the surface potential, $\Phi$. In (b) the $S_{a d s}$ values are plotted as function of the pore occupancy, $\theta$, determined from eq (S14). 


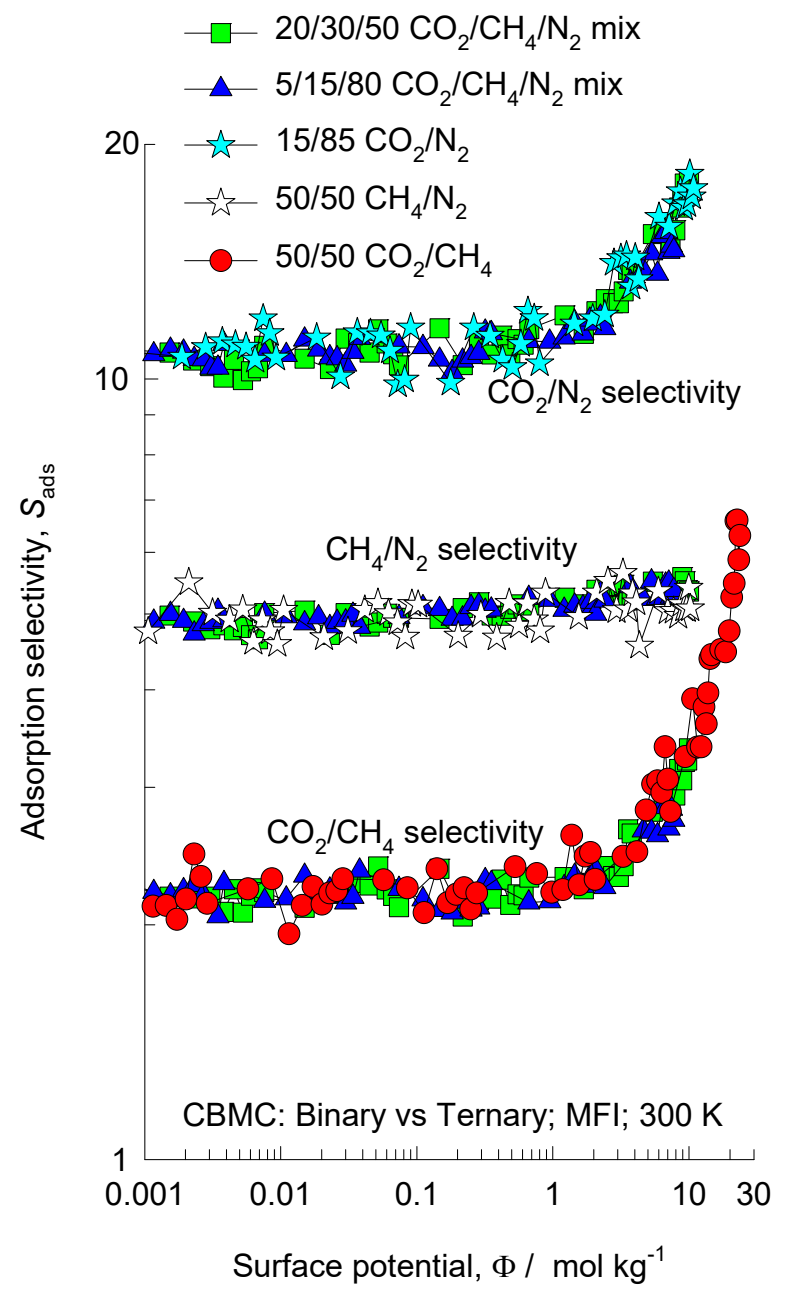

Figure S13. Comparison of $\mathrm{CO}_{2} / \mathrm{CH}_{4}, \mathrm{CO}_{2} / \mathrm{N}_{2}$, and $\mathrm{CH}_{4} / \mathrm{N}_{2}$ adsorption selectivities determined from binary mixtures, with the corresponding values in two different ternary mixtures: $5 / 15 / 80 \mathrm{CO}_{2} / \mathrm{CH}_{4} / \mathrm{N}_{2}$, and $20 / 30 / 50 \mathrm{CO}_{2} / \mathrm{CH}_{4} / \mathrm{N}_{2}$. The $x$-axis represents the surface potential, $\Phi$. 
a

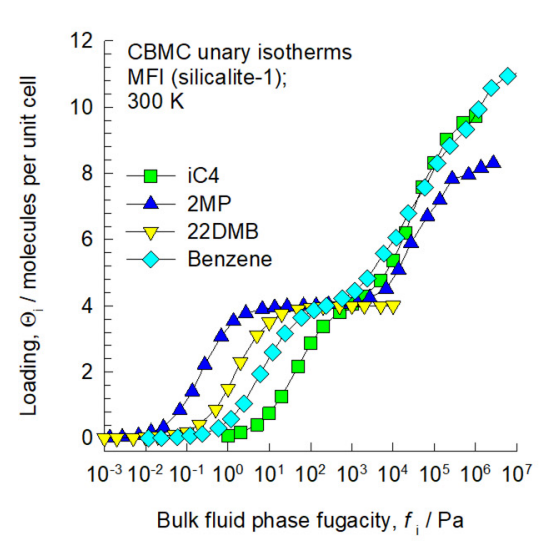

b

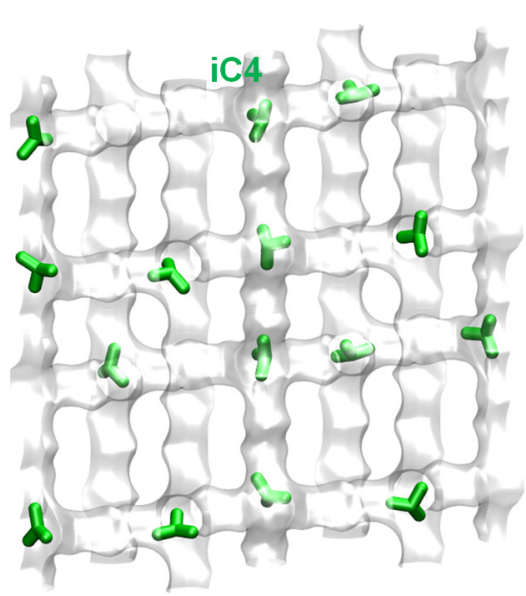

C

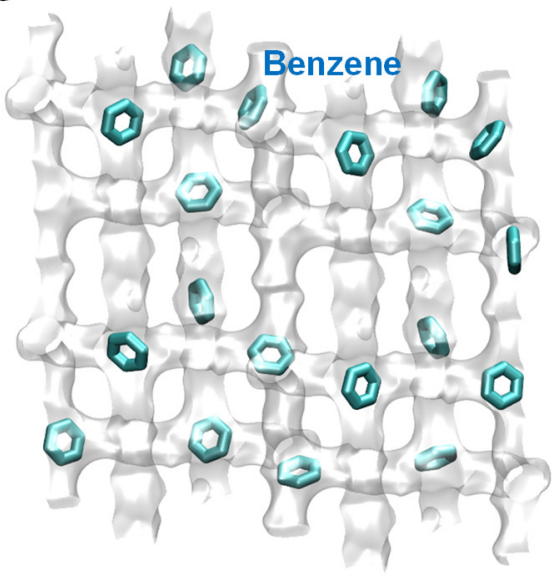

Figure S14. (a) CBMC simulations of unary isotherms for branched alkanes and benzene in MFI zeolite at $300 \mathrm{~K}$. (b, c) Computational snapshots showing the preferential location of (b) iC4 and (c) benzene at the channel intersections of MFI zeolite. 
a

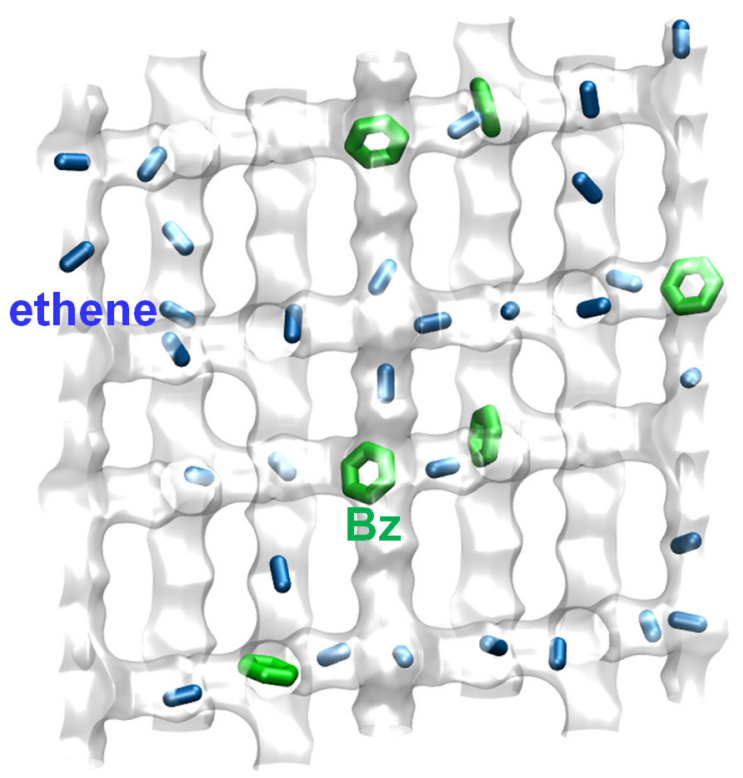

b

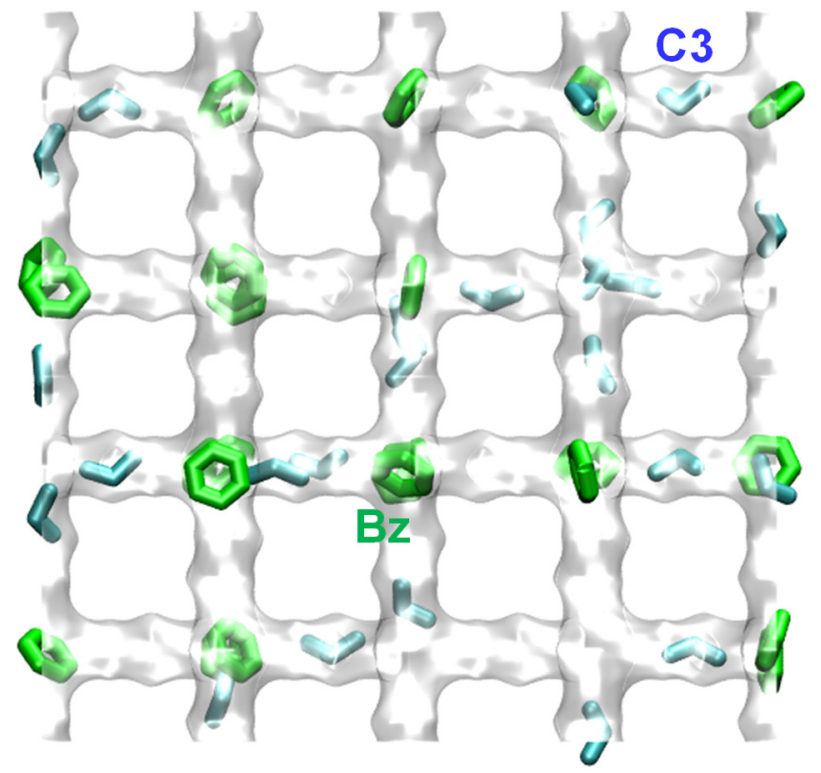

Figure S15. (a, b) Computational snapshots showing the location of guest molecules for (a) $\mathrm{C}_{2} \mathrm{H}_{4}(1) /$ Benzene(2) and (b) $\mathrm{C}_{3} \mathrm{H}_{6}(1) /$ Benzene(2) mixture adsorption in MFI zeolite at $300 \mathrm{~K}$. 

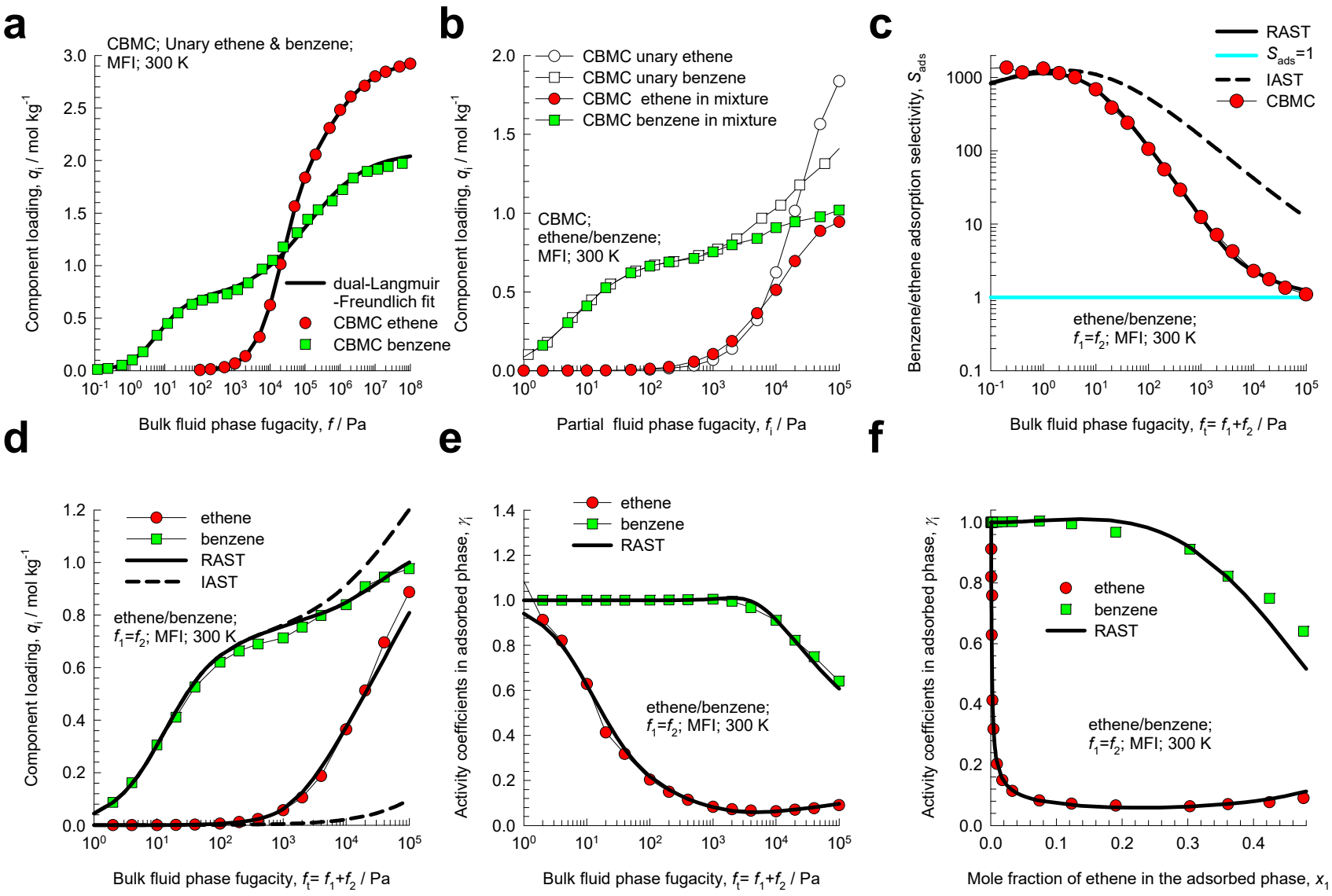

Figure S16. CBMC simulation data and analysis for Campaign A $\left(y_{1}=0.5\right)$ for $\mathrm{C}_{2} \mathrm{H}_{4}(1) / \mathrm{Benzene}(2)$ mixture adsorption in MFI zeolite at $300 \mathrm{~K}$. (a) Unary isotherms and fits. (b) Component loadings in mixture compared with CBMC simulations of unary isotherms. (c) $\mathrm{CBMC}$ data for Benzene(2)/ $\mathrm{C}_{2} \mathrm{H}_{4}(1)$ adsorption selectivity compared with IAST and RAST estimates. (d) CBMC data for component loadings in mixture compared with RAST estimates. (e, f) Activity coefficients from CBMC compared with RAST model calculations. The unary isotherm data fits and Margules parameters are provided in Table S5, and Table S6. 

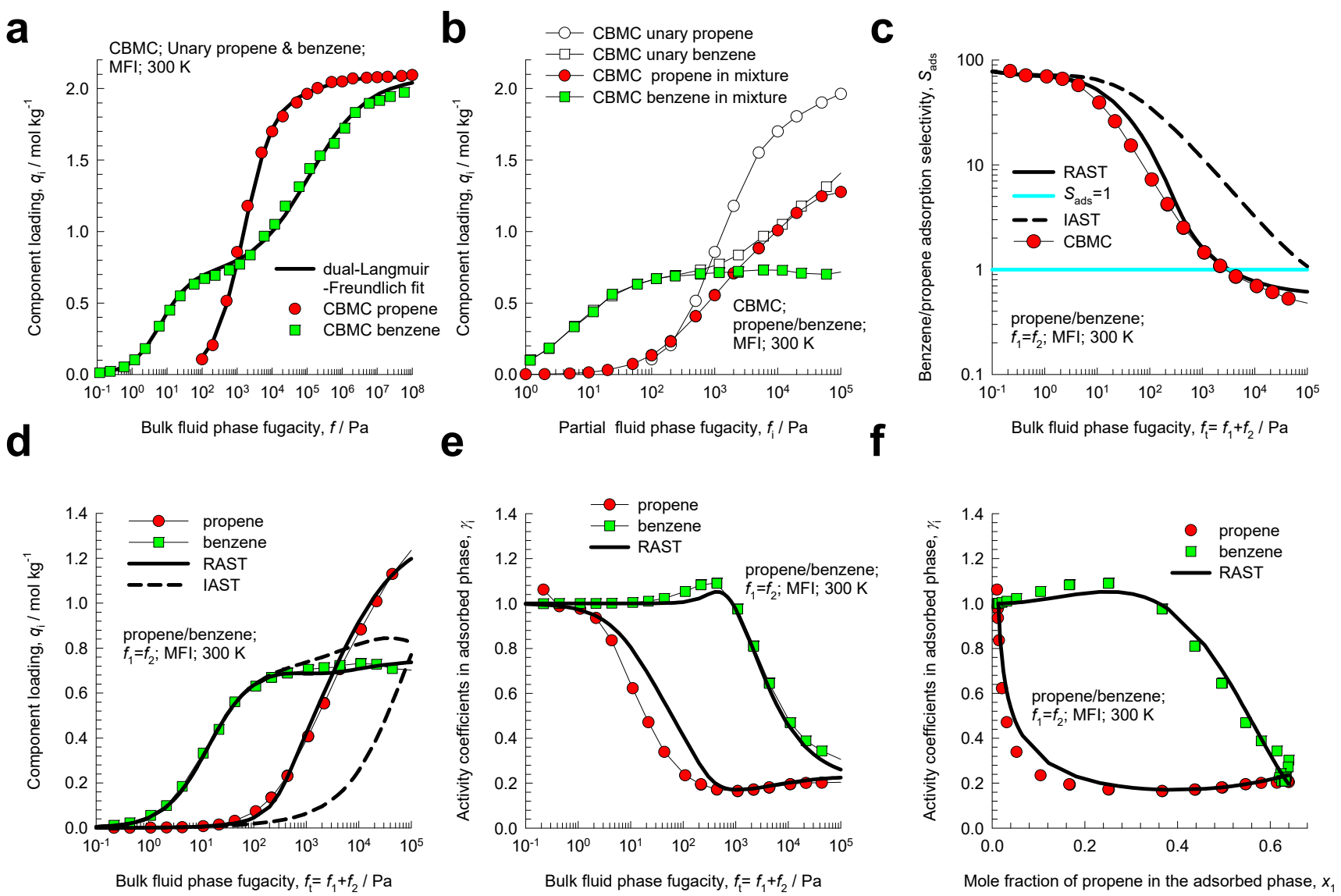

Figure S17. CBMC simulation data and analysis for Campaign A $\left(y_{1}=0.5\right)$ for $\mathrm{C}_{3} \mathrm{H}_{6}(1) / \mathrm{Benzene}(2)$ mixture adsorption in MFI zeolite at $300 \mathrm{~K}$. (a) Unary isotherms and fits. (b) Component loadings in mixture compared with CBMC simulations of unary isotherms. (c) $\mathrm{CBMC}$ data for Benzene(2)/ $\mathrm{C}_{3} \mathrm{H}_{6}(1)$ adsorption selectivity compared with IAST and RAST estimates. (d) CBMC data for component loadings in mixture compared with RAST estimates. (e, f) Activity coefficients from CBMC compared with RAST model calculations. The unary isotherm data fits and Margules parameters are provided in Table S5, and Table S6. 
a

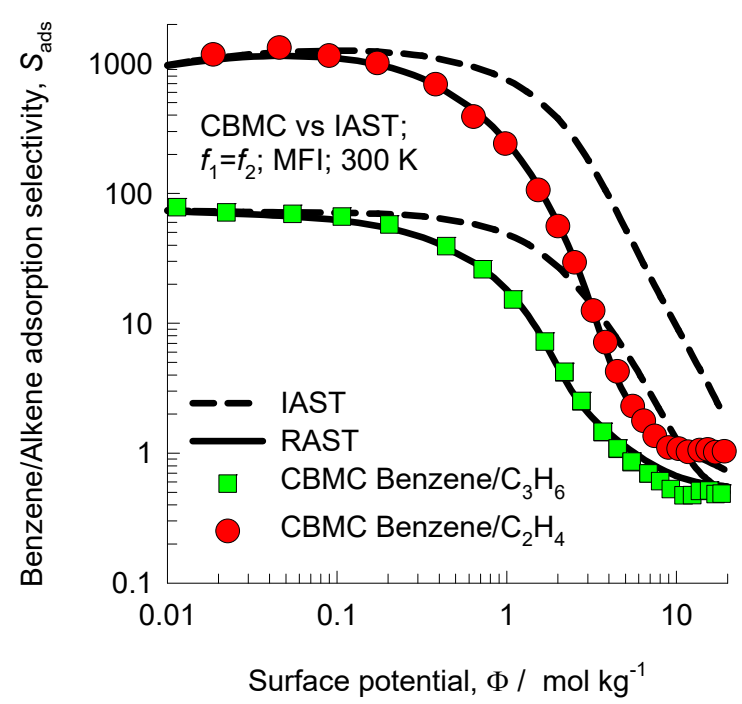

b

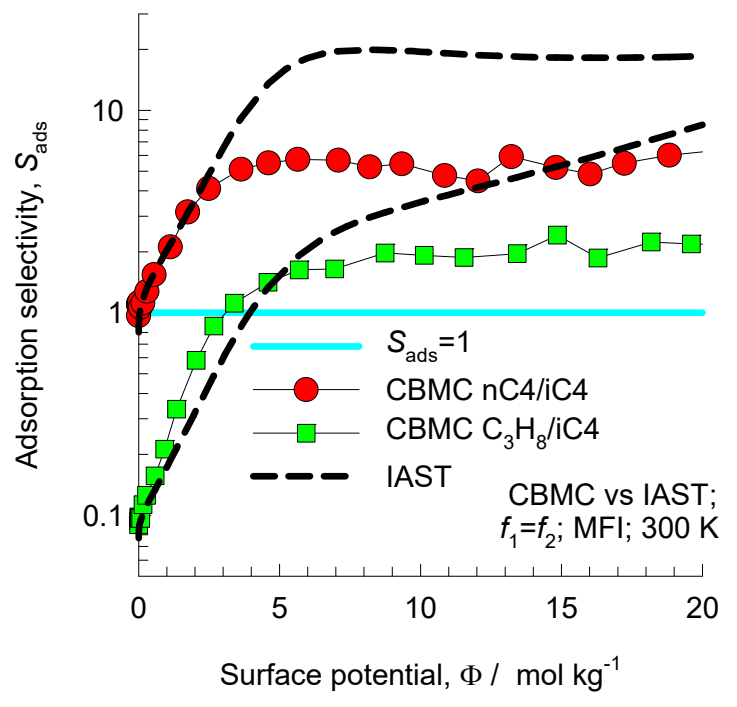

Figure S18. Adsorption selectivity $S_{a d s}$ for (a) benzene $/ \mathrm{C}_{2} \mathrm{H}_{4}$, and benzene $/ \mathrm{C}_{3} \mathrm{H}_{6}$ mixtures and (b) $\mathrm{C}_{3} \mathrm{H}_{8} / \mathrm{iC} 4$, and $\mathrm{nC} 4 / \mathrm{iC} 4$ mixtures plotted as function of the surface potential $\Phi$. The CBMC simulated values (indicated by symbols) are compared with RAST (continuous solid lines), and IAST (dashed lines) estimates. 

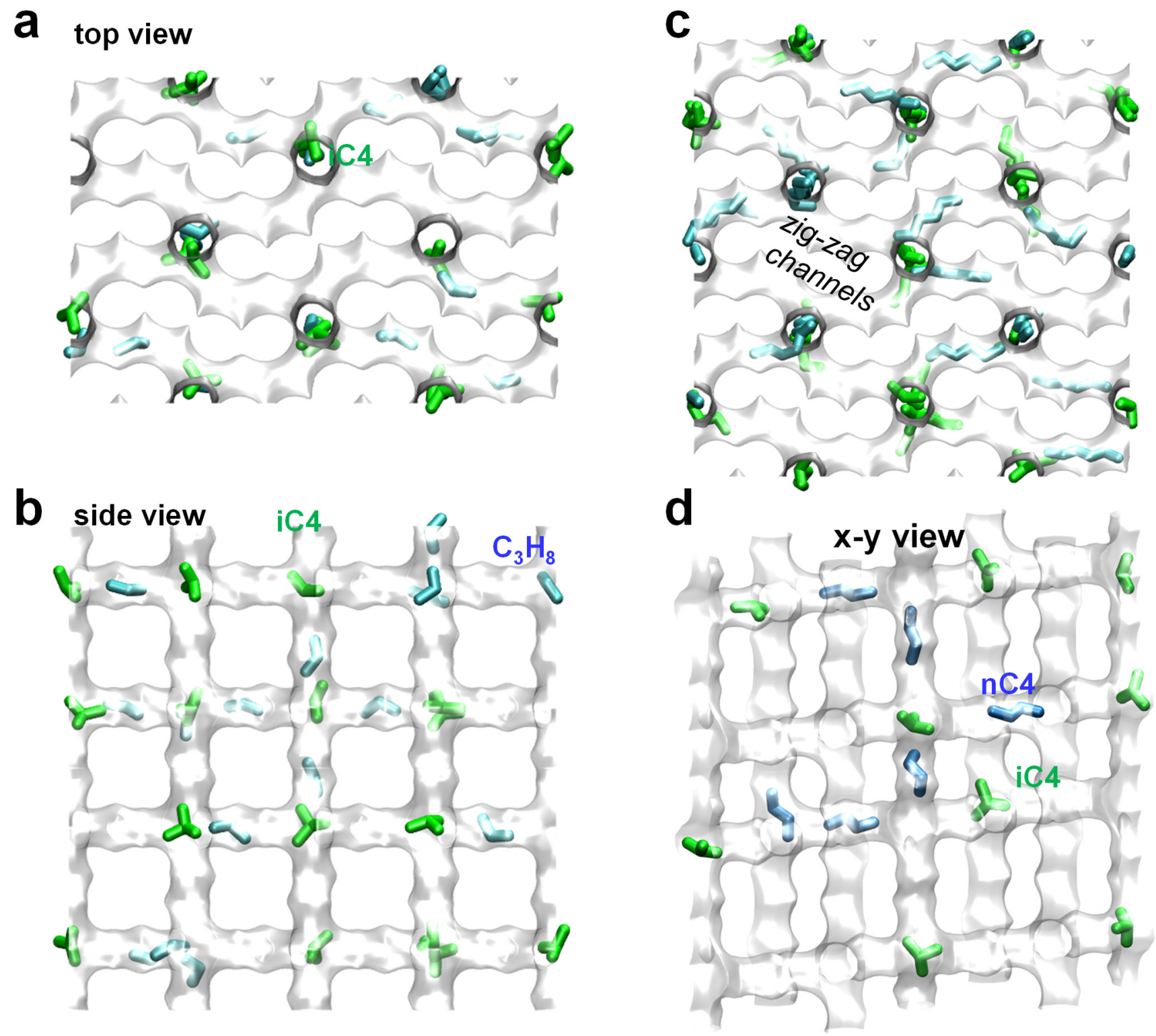

Figure S19. Computational snapshots showing the location of guest molecules for $(\mathrm{a}, \mathrm{b}) \mathrm{C}_{3} \mathrm{H}_{8}(1) / \mathrm{iC} 4(2)$ and (c, d) $\mathrm{nC} 4(1) / \mathrm{iC} 4(2)$ mixture adsorption in MFI zeolite at $300 \mathrm{~K}$. 


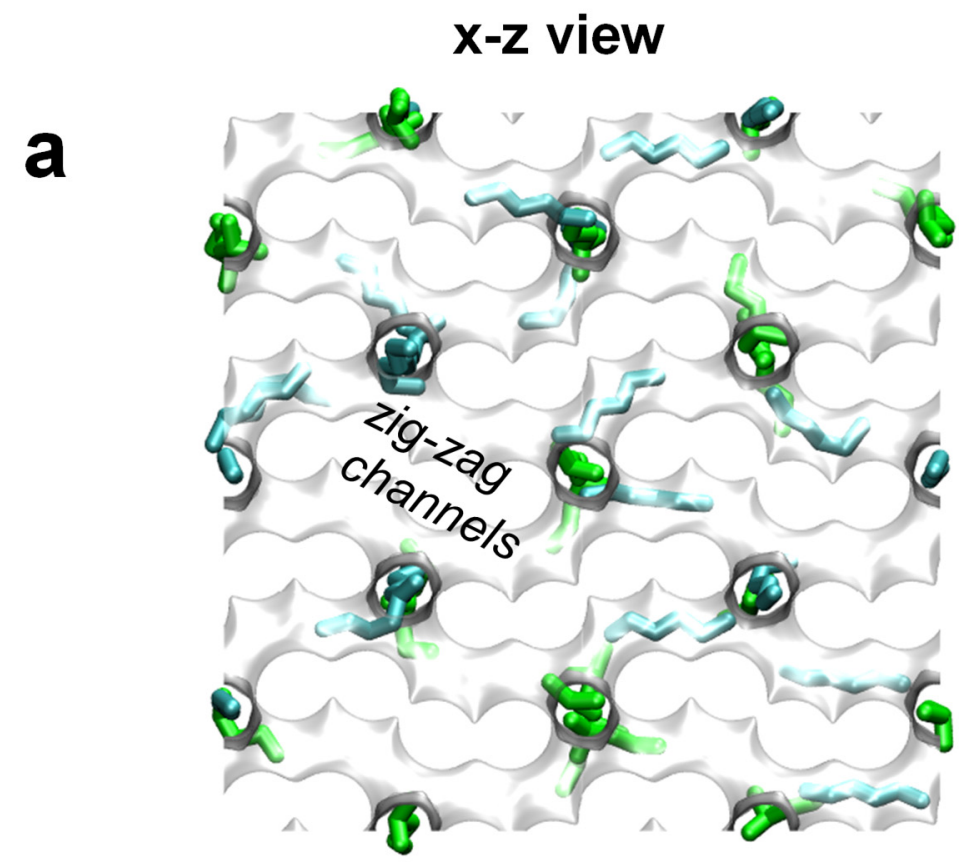

b

$x-y-$ view

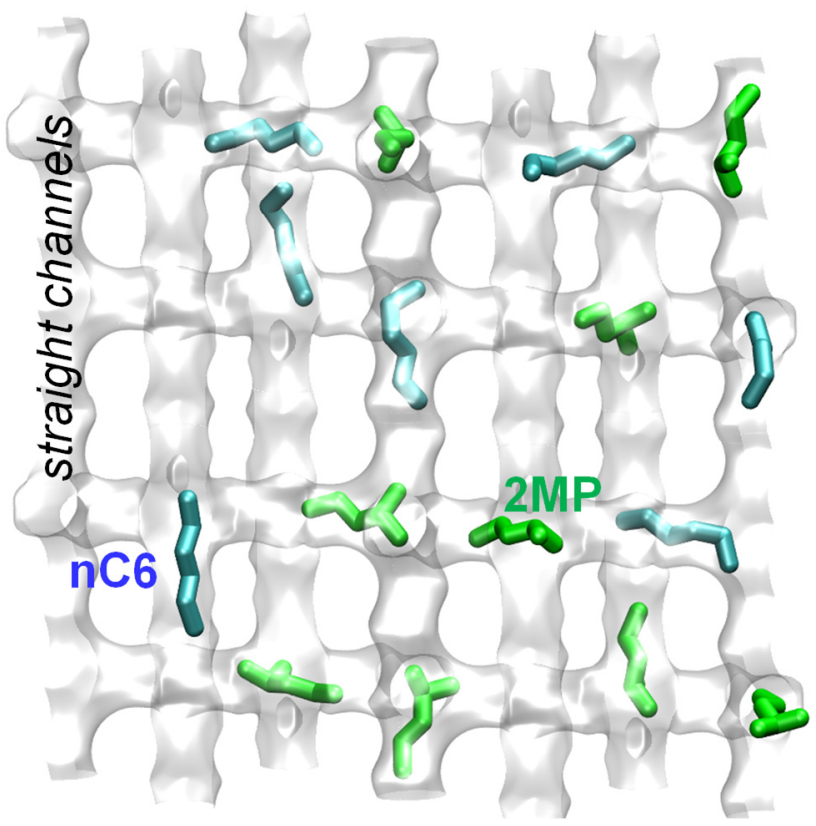

Figure S20. (a, b) Computational snapshots showing the location of guest molecules for nC6(1)/2MP(2) mixture adsorption in MFI zeolite at $300 \mathrm{~K}$. 

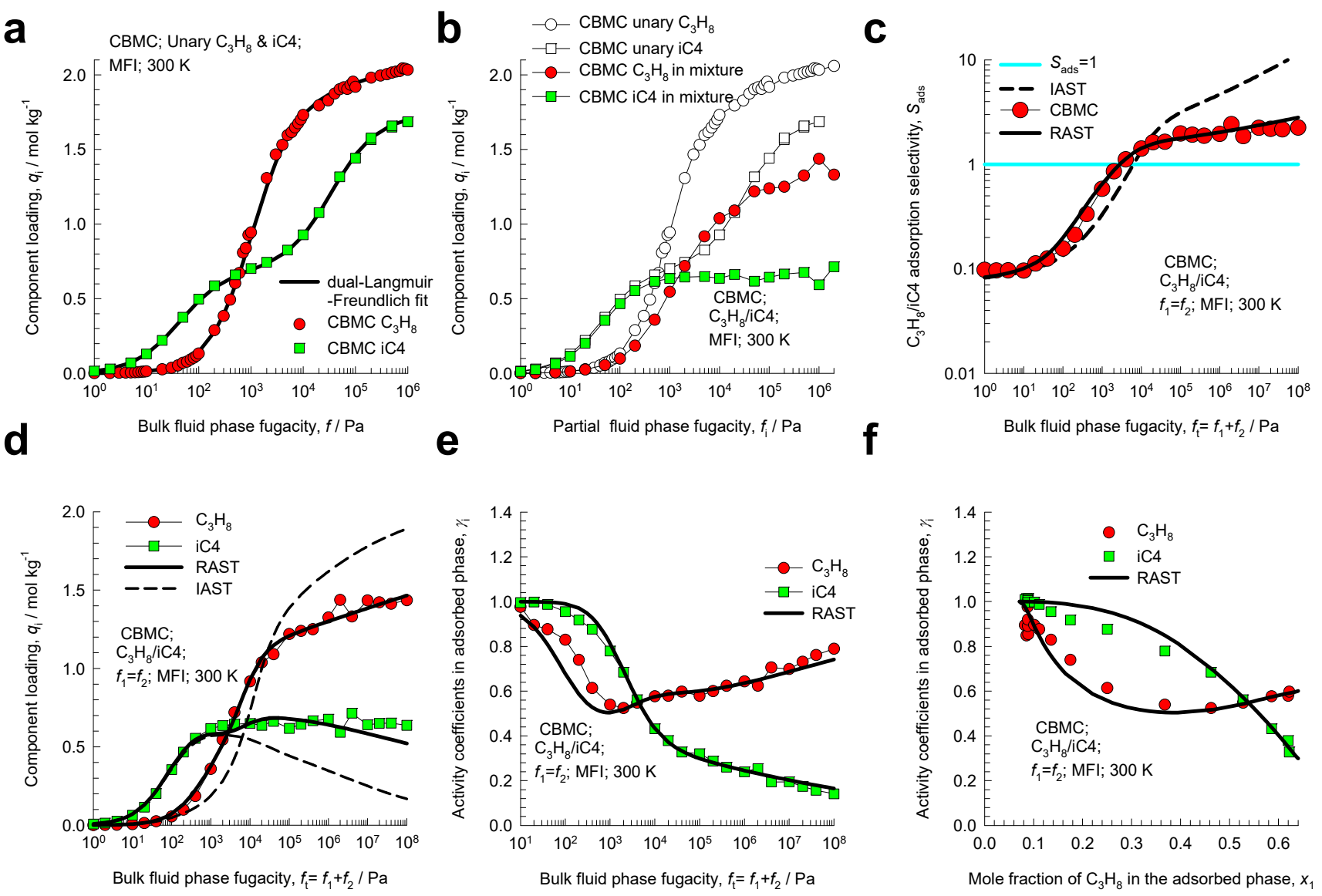

Figure S21. CBMC simulation data and analysis for Campaign $\mathrm{A}\left(y_{1}=0.5\right)$ for $\mathrm{C}_{3} \mathrm{H}_{8}(1) / \mathrm{iC} 4(2)$ mixture adsorption in MFI zeolite at $300 \mathrm{~K}$. (a) Unary isotherms and fits. (b) Component loadings in mixture compared with $\mathrm{CBMC}$ simulations of unary isotherms. (c) $\mathrm{CBMC}$ data for $\mathrm{C}_{3} \mathrm{H}_{8}(1) / \mathrm{iC} 4(2)$ adsorption selectivity compared with IAST and RAST estimates. (d) CBMC data for component loadings in mixture compared with RAST estimates. (e, f) Activity coefficients from CBMC compared with RAST model calculations. The unary isotherm data fits and Margules parameters are provided in Table S5, and Table S6. 

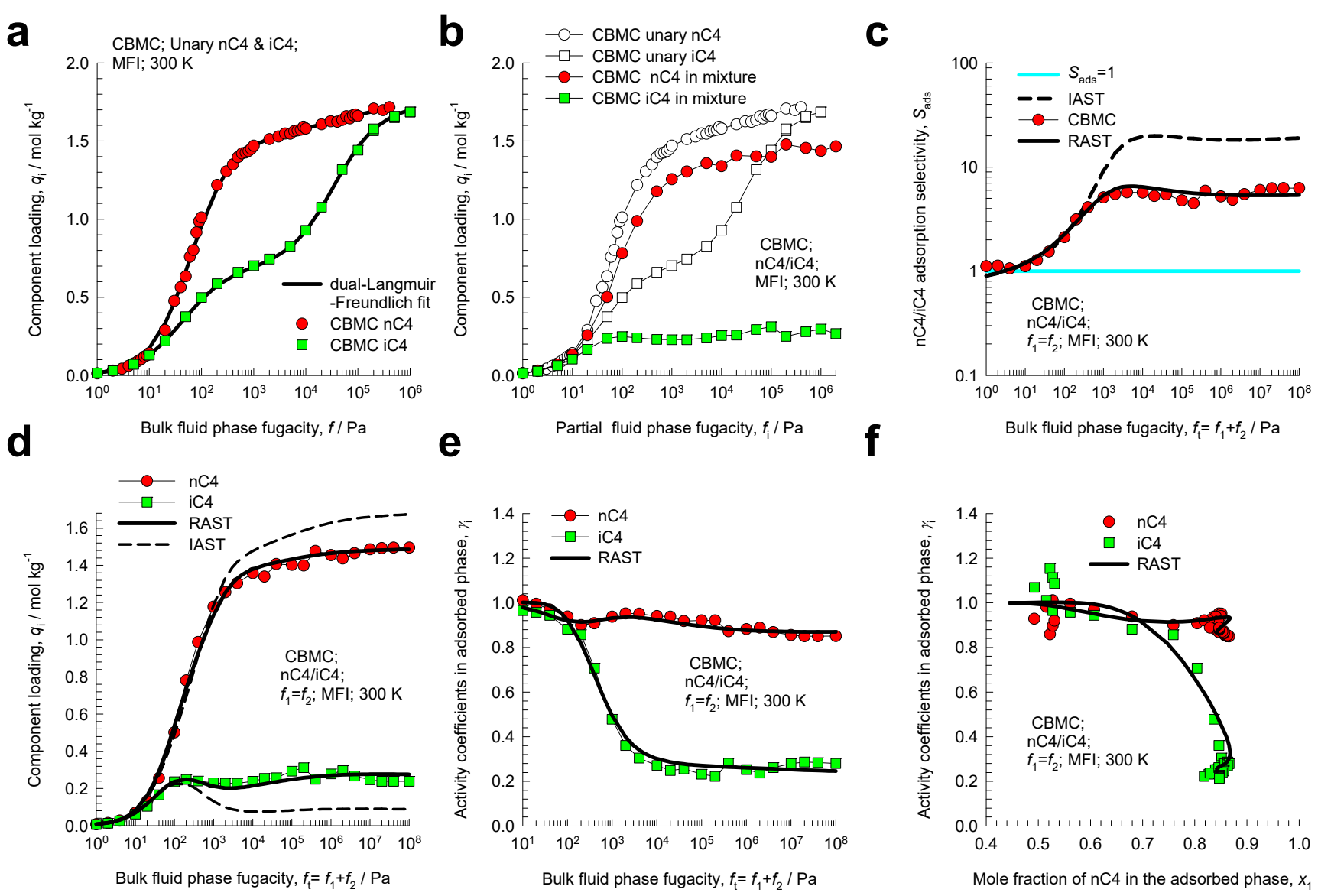

Figure S22. CBMC simulation data and analysis for Campaign A $\left(y_{1}=0.5\right)$ for $\mathrm{nC} 4(1) / \mathrm{iC} 4(2)$ mixture adsorption in MFI zeolite at $300 \mathrm{~K}$. (a) Unary isotherms and fits. (b) Component loadings in mixture compared with $\mathrm{CBMC}$ simulations of unary isotherms. (c) $\mathrm{CBMC}$ data for $\mathrm{nC} 4(1) / \mathrm{iC} 4(2)$ adsorption selectivity compared with IAST and RAST estimates. (d) CBMC data for component loadings in mixture compared with RAST estimates. (e, f) Activity coefficients from CBMC compared with RAST model calculations. The unary isotherm data fits and Margules parameters are provided in Table S5, and Table S6. 

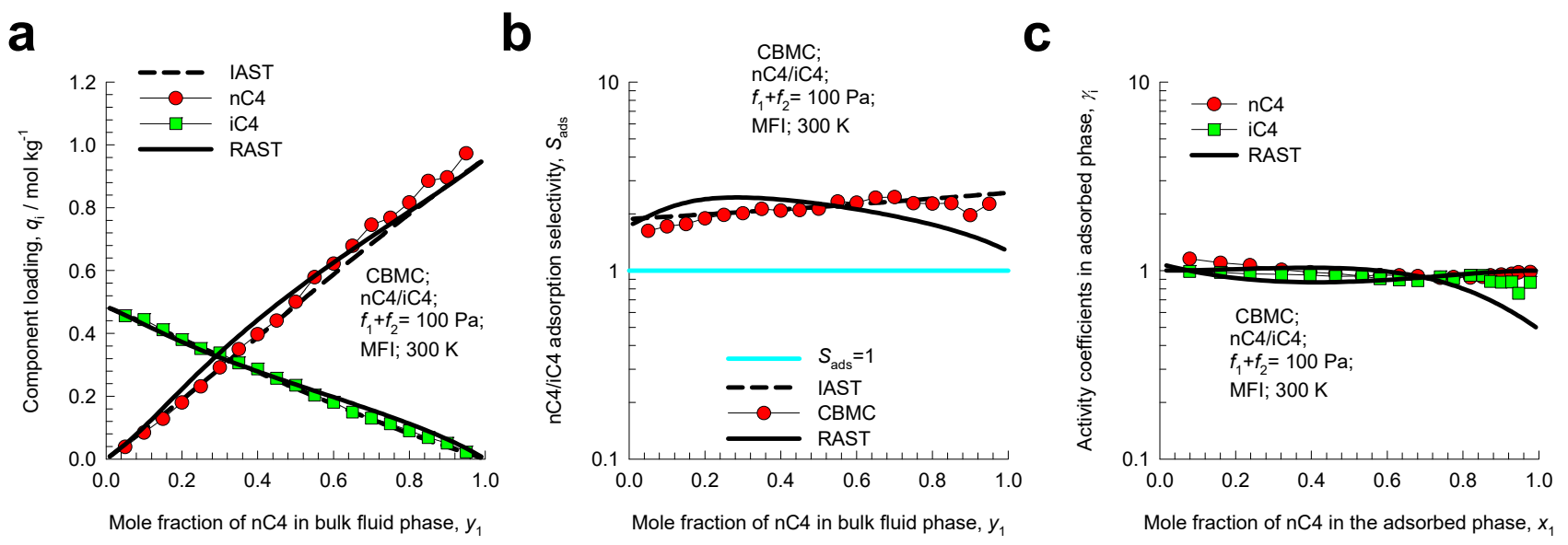

Figure S23. CBMC simulation data and analysis for Campaign $\mathrm{B}\left(f_{\mathrm{t}}=100 \mathrm{~Pa}\right)$ for $\mathrm{nC4}(1) / \mathrm{iC} 4(2)$ mixture adsorption in MFI zeolite at $300 \mathrm{~K}$. CBMC data for (a) component loadings and (b) nC4(1)/iC4(2) adsorption selectivity compared with IAST and RAST estimates. (c) Activity coefficients from CBMC compared with RAST model calculations. The unary isotherm data fits and Margules parameters are provided in Table S5, and Table S6. 

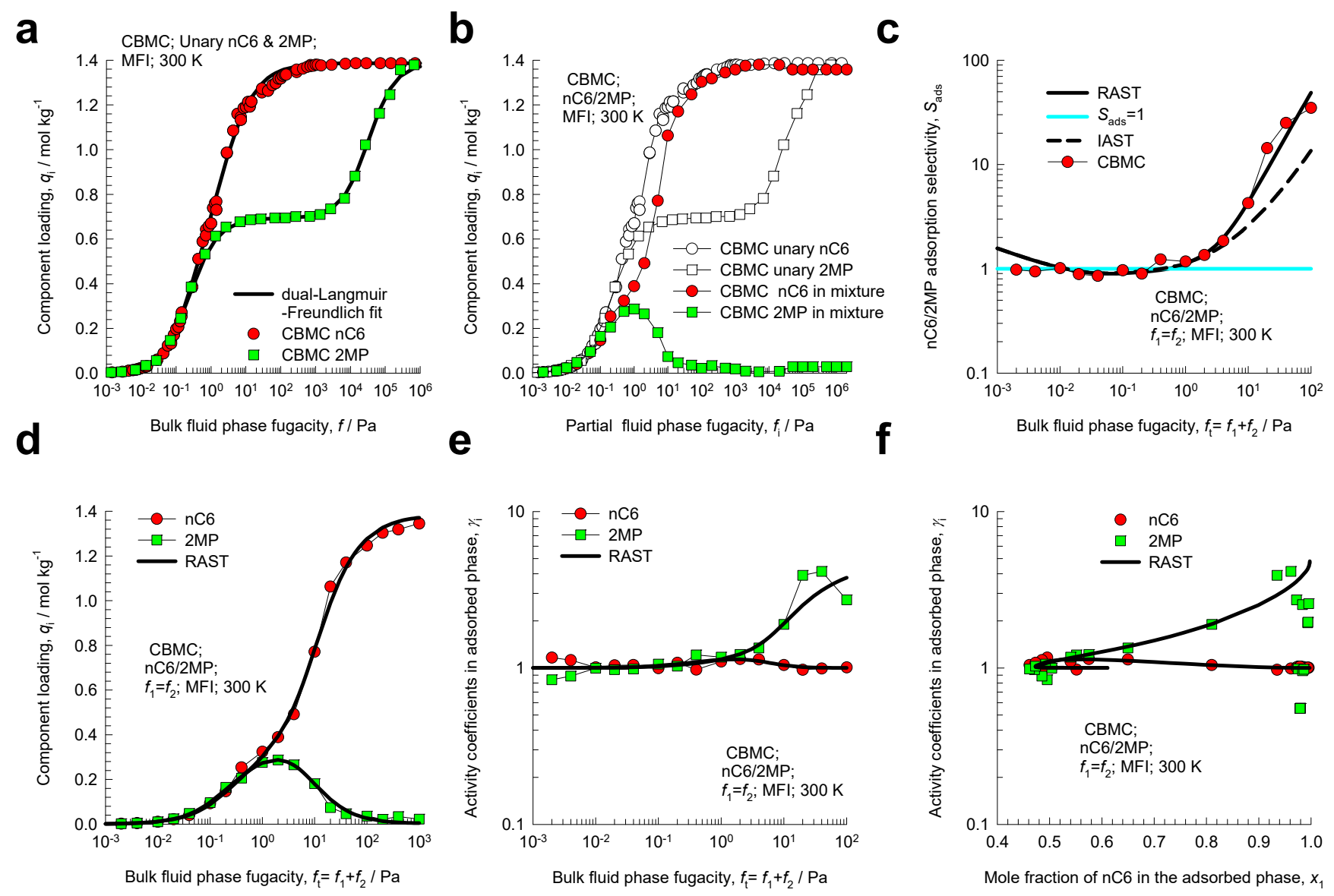

Figure S24. CBMC simulation data and analysis for Campaign A $\left(y_{1}=0.5\right)$ for $\mathrm{nC} 6(1) / 2 \mathrm{MP}(2)$ mixture adsorption in MFI zeolite at $300 \mathrm{~K}$. (a) Unary isotherms and fits. (b) Component loadings in mixture compared with CBMC simulations of unary isotherms. (c) CBMC data for $\mathrm{nC} 6(1) / 2 \mathrm{MP}(2)$ adsorption selectivity compared with IAST and RAST estimates. (d) CBMC data for component loadings in mixture compared with RAST estimates. (e, f) Activity coefficients from CBMC compared with RAST model calculations. The unary isotherm data fits and Margules parameters are provided in Table S5, and Table S6. 
a

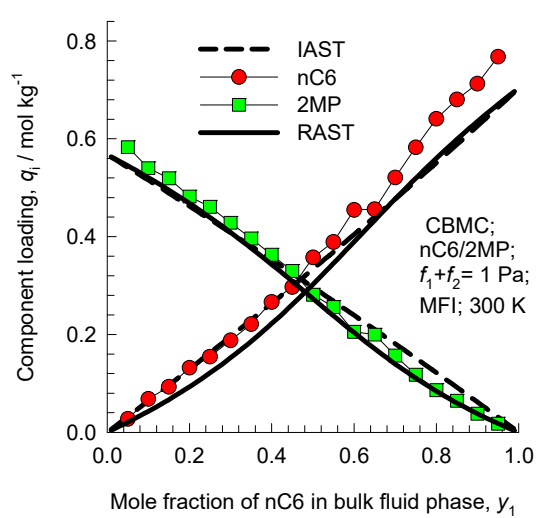

b

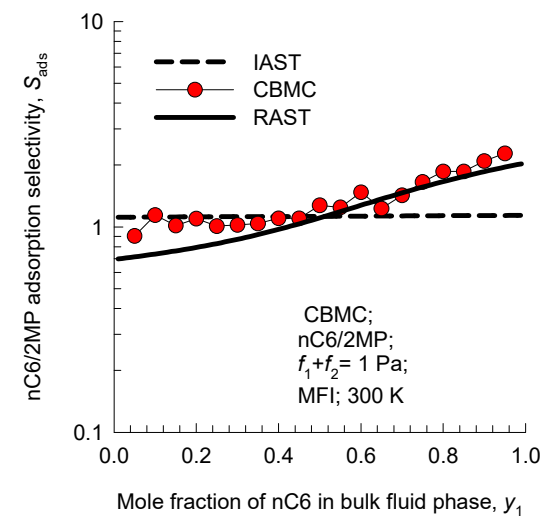

C

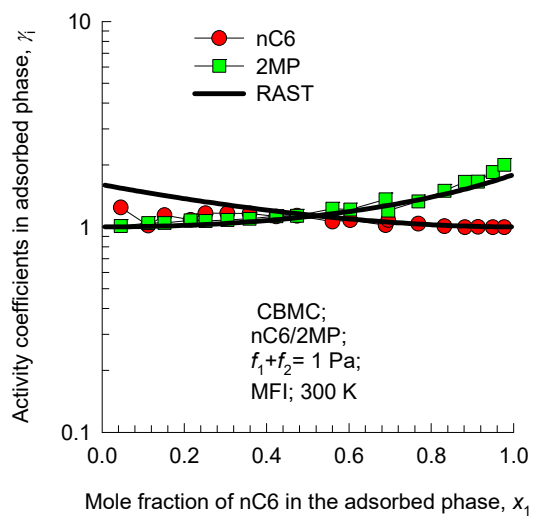

Figure S25. CBMC simulation data and analysis for Campaign B $\left(f_{\mathrm{t}}=100 \mathrm{~Pa}\right)$ for $\mathrm{nC} 6(1) / 2 \mathrm{MP}(2)$ mixture adsorption in MFI zeolite at $300 \mathrm{~K}$. CBMC data for (a) component loadings and (b) nC6(1)/2MP(2) adsorption selectivity compared with IAST and RAST estimates. (c) Activity coefficients from CBMC compared with RAST model calculations. The unary isotherm data fits and Margules parameters are provided in Table S5, and Table S6. 


\section{$9 \mathrm{CO}_{2} / \mathrm{CH}_{4} / \mathrm{N}_{2}$ mixture adsorption in ISV}

The pore landscapes and structural details of all-silica ISV zeolite are presented in Figure S26Figure S27. This zeolite has intersecting channels of two sizes: 12-ring of $6.1 \AA-6.5 \AA$ and 12 -ring of $5.9 \AA-6.6$ $\AA$.

Figure S28 compares the CBMC simulations data (indicated by symbols) of the $\mathrm{CO}_{2} / \mathrm{CH}_{4}$ adsorption selectivity, $S_{a d s}$, determined from two different CBMC campaigns: (i) $50 / 50 \mathrm{CO}_{2} / \mathrm{CH}_{4}$, (ii) equimolar $\left(f_{1}=f_{2}=f_{3}\right) 1 / 1 / 1 \mathrm{CO}_{2} / \mathrm{CH}_{4} / \mathrm{N}_{2}$ mixtures in ISV zeolite at $300 \mathrm{~K}$. In both cases the $S_{a d s}$ is plotted as function of the surface potential $\Phi$, determined from IAST for binary or ternary mixture adsorption. The CBMC data all show a unique dependence on $\Phi$, as prescribed by eq (S13). Put another way, the presence of component 3 in the ternary mixture has no influence of the adsorption selectivity for the 1-2 pair. The dashed lines are the IAST calculations (indicated by dashed lines); these show reasonably good agreement with the CBMC data. 


\subsection{List of Tables for $\mathrm{CO} 2 / \mathrm{CH} 4 / \mathrm{N} 2$ mixture adsorption in ISV}

Table S7. Dual-site Langmuir parameters for guest molecules in ISV (all-silica) at $300 \mathrm{~K}$.

\begin{tabular}{|l|l|l|l|l|l|l|}
\hline \multirow{2}{*}{} & \multicolumn{2}{|l|}{ Site A } & \multicolumn{2}{l|}{ Site B } \\
\cline { 2 - 8 } & $\begin{array}{l}q_{\mathrm{A}, \text { sat }} \\
\mathrm{mol} \mathrm{kg}\end{array}$ & $\begin{array}{l}b_{\mathrm{A}} \\
\mathrm{Pa}^{-v_{A}}\end{array}$ & $\begin{array}{l}q_{\mathrm{A}, \mathrm{sat}} \\
\mathrm{mol} \mathrm{kg}^{-1}\end{array}$ & $\begin{array}{l}b_{\mathrm{A}} \\
\mathrm{Pa}^{-v_{A}}\end{array}$ & $\begin{array}{l}q_{\mathrm{A}, \mathrm{sat}} \\
\mathrm{mol} \mathrm{kg}^{-1}\end{array}$ & $\begin{array}{l}b_{\mathrm{A}} \\
\mathrm{Pa}^{-v_{A}}\end{array}$ \\
\hline $\mathrm{CO}_{2}$ & 6.6 & $1.004 \mathrm{E}-06$ & 1 & 2.2 & $1.544 \mathrm{E}-09$ & 1 \\
\hline $\mathrm{CH} 4$ & 3.6 & $1.224 \mathrm{E}-06$ & 1 & 1.3 & $2.296 \mathrm{E}-08$ & 1 \\
\hline $\mathrm{N} 2$ & 3.5 & $2.019 \mathrm{E}-07$ & 1 & 2.5 & $1.469 \mathrm{E}-08$ & 1 \\
\hline
\end{tabular}




\subsection{List of Figures for $\mathrm{CO} 2 / \mathrm{CH} 4 / \mathrm{N} 2$ mixture adsorption in ISV}

ISV pore landscape

Intersecting 12-ring channels structure

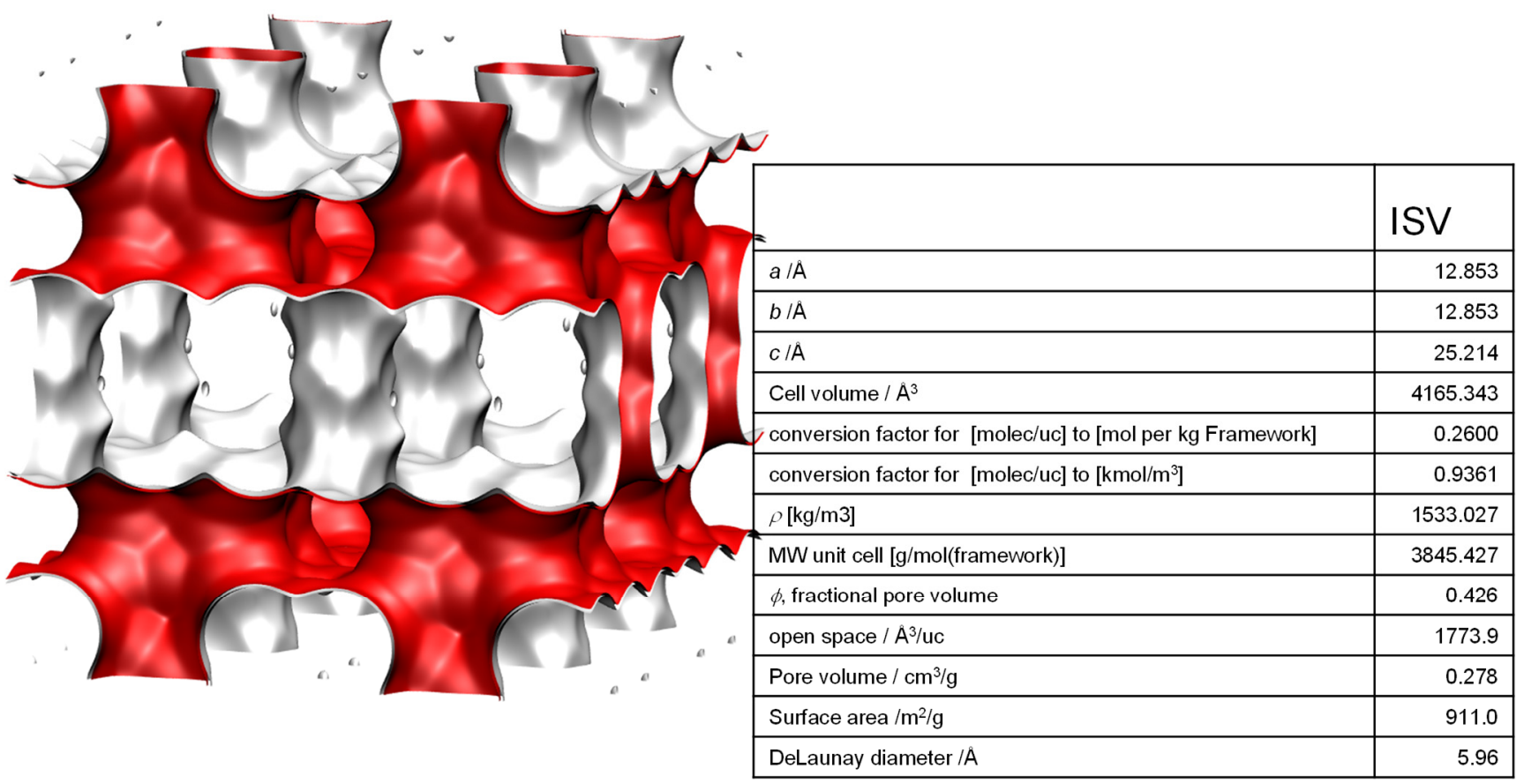

Structural information from: C. Baerlocher, L.B. McCusker, Database of Zeolite Structures, International Zeolite Association, http://www.iza-structure.org/databases/

Figure S26. Pore landscape and structural details of ISV zeolite. 


\section{ISV pore dimensions}

Intersecting 12-ring channels structure

This plot of surface area versus pore

dimension is determined using

combination of the DeLaunay

triangulation method for pore dimension

determination, and the procedure of

Duren for determination of the surface

area

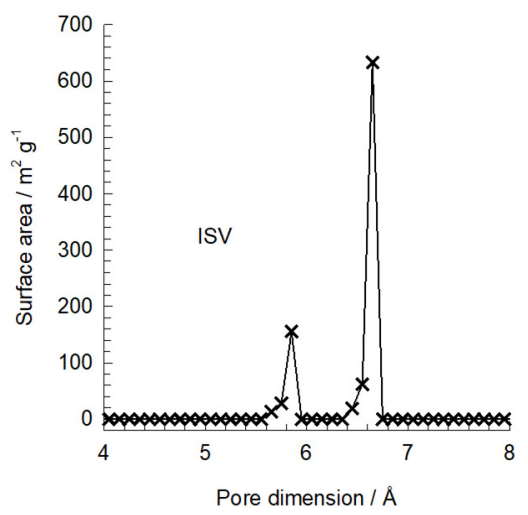

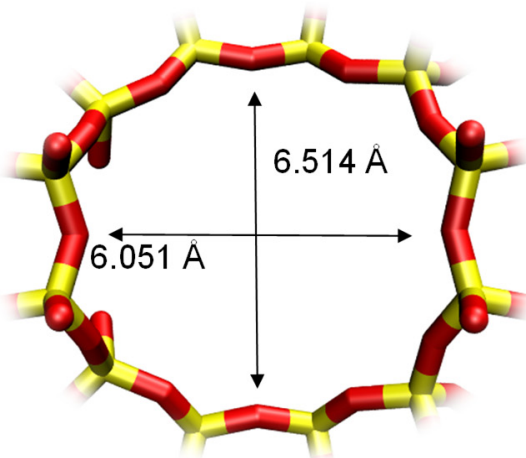

ISV $\left[\begin{array}{lll}1 & 0 & 0\end{array}\right]$

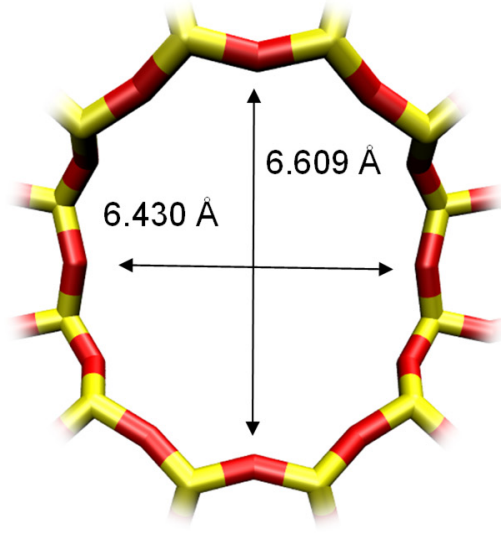

ISV [ll 001$]$

Figure S27. Channel dimensions of ISV zeolite. 


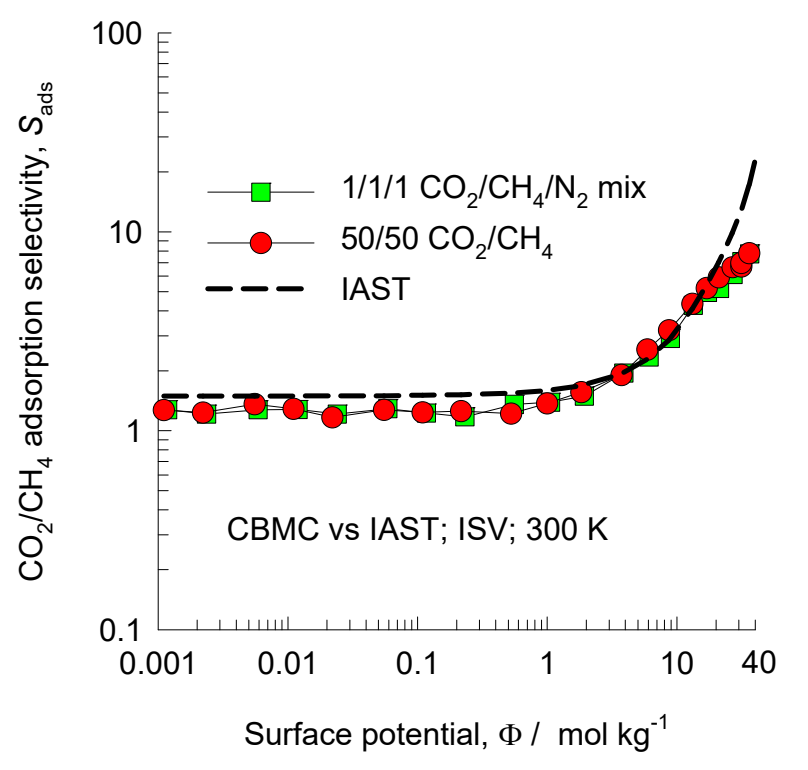

Figure S28. CBMC simulations (indicated by symbols) of the $\mathrm{CO}_{2} / \mathrm{CH}_{4}$ adsorption selectivity, $S_{a d s}$, determined from two different CBMC campaigns: (i) $50 / 50 \mathrm{CO}_{2} / \mathrm{CH}_{4}$, (ii) equimolar $\left(f_{1}=f_{2}=f_{3}\right) 1 / 1 / 1$ $\mathrm{CO}_{2} / \mathrm{CH}_{4} / \mathrm{N}_{2}$ mixtures in ISV zeolite at $300 \mathrm{~K}$. The dashed lines are the IAST calculations (indicated by dashed lines), these calculations coincide for the two different CBMC campaigns. The unary isotherm fit parameters are provided in Table S7. 


\section{Binary mixture adsorption in all-silica CHA zeolite}

CHA zeolite consists of cages of volume $316 \AA^{3}$, separated by $3.8 \AA \times 4.2 \AA 8$-ring windows; the pore landscape and structural details are provided in Figure S29, and Figure S30. SAPO-34 has the same structural topology of CHA zeolite.

\section{$10.1 \mathrm{CO}_{2} / \mathrm{CH}_{4}$ mixture adsorption in all-silica $\mathrm{CHA}$ zeolite}

A key assumption of the IAST is that the composition of the adsorbed phase is homogeneously and uniformly distributed within zeolite or metal-organic frameworks. Preferential location of molecules at certain locations within the crystalline, causes segregated adsorption and deviations from the assumption of homogeneous distribution. For separation of $\mathrm{CO}_{2}$ from gaseous mixtures with $\mathrm{CH}_{4}$, cage-type zeolites such as CHA, DDR, LTA, and ERI are of practical interest; these materials consist of cages separated by narrow windows, in the $3.3-4.5 \AA$ range. For adsorption of $\mathrm{CO}_{2} / \mathrm{CH}_{4}$ mixtures, $\mathrm{CBMC}$ simulations ${ }^{59}$ show that the window regions of cage-type zeolites has a significantly higher proportion of $\mathrm{CO}_{2}$ than within the cages; see computational snapshots in Figure S31 for CHA zeolite.

To demonstrate non-ideality effects in mixture adsorption, three different sets of CBMC campaigns wre conducted.

Figure S32 presents the CBMC data and analysis for Campaign A the ratio of partial fugacities

$f_{1} / f_{2}=1 ; \quad y_{1}=0.5$ and the bulk mixture fugacity, $f_{t}=f_{1}+f_{2}$ is varied.

Figure S33 presents the CBMC data and analysis for Campaign A the ratio of partial fugacities $f_{1} / f_{2}=15 / 85 ; \quad y_{1}=0.15$ and the bulk mixture fugacity, $f_{t}=f_{1}+f_{2}$ is varied.

Figure S34 presents the CBMC data and analysis for Campaign B in which total fugacity is held constant at the value $f_{\mathrm{t}}=1 \mathrm{MPa}$ and the bulk fluid phase mixture composition $y_{1}=f_{1} / f_{t}$ is varied. 
For all three sets of CBMC data, the IAST calculations overestimate the values of $S_{a d s}$ because the competitive adsorption is less severe due to the segregated nature of adsorption; the competition faced by $\mathrm{CH}_{4}$ is less severe than anticipated because of the preferential location of $\mathrm{CO}_{2}$ in the window regions. The departures from idealities are quantitatively captured by the RAST with fitted Wilson parameters.

In Figure S35, the CBMC simulated values of the adsorption selectivity $S_{a d s}$ determined from all three campaigns are plotted as function of the surface potential $\Phi$. At values of $\Phi>10 \mathrm{~mol} \mathrm{~kg}^{-1}$, corresponding to a pore occupancy $\theta>0.7$, the IAST significantly overestimates $S_{a d s}$.

\subsection{Water/ethanol mixture adsorption in all-silica CHA zeolite}

Two types of water/ethanol mixture adsorption campaigns were conducted.

Campaign A. The bulk fluid phase composition held constant at $y_{1}=y_{2}=0.5$, and the bulk fluid phase fugacity $f_{t}=f_{1}+f_{2}$ was varied over a wide range from the Henry regime of adsorption, $f_{t} \rightarrow 0 ; \Phi \rightarrow 0$ , to pore saturation conditions, typically $\Phi>50$.

Campaign B. The bulk fluid phase fugacity was held at a constant value $f_{t}=f_{1}+f_{2}=10 \mathrm{kPa}$, and the bulk fluid phase mixture composition $y_{1}$ was varied $0<y_{1}<1$.

The CBMC data and analysis for Campaign A are presented in Figure S36; the following major characteristics emerge. From Figure $\mathrm{S} 36 \mathrm{~b}$ we note that for a range of partial fugacities, $f_{1}$ in the bulk fluid phase, the component loading for water in the mixture (filled symbols) exceeds that of the pure component. The ethanol/water adsorption selectivity, $S_{a d s}$, determined from CBMC mixture simulations (symbols) has a tendency to undergo selectivity reversal in favor of water at high values of the bulk fluid phase fugacity $f_{t}=f_{1}+f_{2}$, as saturation conditions are approached; see Figure S36c. The selectivity 


\section{Binary mixture adsorption in all-silica CHA zeolite}

reversal in favor of the smaller guest molecule, water, is the consequence of entropy effects that favor the guest species with the higher packing efficiency, as explained in earlier works. ${ }^{45,52,53,60-62}$ The selectivity reversal phenomena is also anticipated by the IAST model (shown by the dashed line). An important characteristic is that the IAST over-predicts the alcohol/water selectivity at values of $f_{t}=f_{1}+f_{2}$ lower than that at which selectivity reversal occurs. For values of $f_{t}=f_{1}+f_{2}$ higher than that at selectivity reversal, the IAST estimates lie below the values determined from CBMC. The conclusion to be drawn is that IAST exaggerates entropy effects. Put another way, hydrogen bonding effects tend to moderate the influence of entropy effects because of molecular clustering attendant with mixture adsorption. As is to be expected the RAST model captures the right trends in the dependence of $S_{a d s}$ on $f_{t}=f_{1}+f_{2}$.

In Figure S36d, we note that the RAST estimates of the component loadings are in reasonably good agreement with CBMC simulated component loadings $q_{1, C B M C} ; q_{2, C B M C}$ (filled symbols). This is to be expected because the model parameters are chosen to fit the CBMC simulated component loadings. The success of the RAST model is therefore to be regarded as testimony to the applicability of the Margules model to describe the activity coefficients for mixture adsorption.

The activity coefficients in the adsorbed phase are plotted in Figure S36e,f. Both activity coefficients tend to unity in the Henry regime, as $\gamma_{i} \rightarrow 1 ; f_{t} \rightarrow 0$. The activity coefficient of water, $\gamma_{1}$, displays a minimum when plotted against the total bulk fluid phase fugacity $f_{t}=f_{1}+f_{2}$. The activity coefficient of alcohol tends to decrease to low values as $f_{t}=f_{1}+f_{2}$ increases. The activity coefficient of water, $\gamma_{1}$, tends to unity as the adsorbed phase mole fraction $x_{1} \rightarrow 1$; it displays a minimum. The activity coefficient of alcohol, $\gamma_{2}$, tends to unity as the adsorbed phase mole fraction $x_{2}=\left(1-x_{1}\right) \rightarrow 1$, decreasing in magnitude as $x_{1} \rightarrow 1$.

The CBMC data and analysis for Campaign B are presented in Figure S37. In Figure S37a, the RAST calculations using the fitted Margules parameters (continuous solid line) of the component loadings are, 
in agreement with CBMC simulated component loadings $q_{1, C B M C} ; q_{2, C B M C}$ (filled symbols) for binary mixture plotted as function of the mole fraction of component 1 in the bulk fluid phase, $y_{1}$. In Figure $\mathrm{S} 37 \mathrm{~b}$, the adsorption selectivity, $S_{a d s}$, determined from CBMC mixture simulations (symbols) are compared with calculations using the IAST (dashed line) and RAST (continuous solid line). The $x$-axis represents the mole fraction of component 1 in the bulk fluid phase, $y_{1}$. The ethanol/water adsorption selectivity experiences a selectivity reversal. The occurrence of selectivity reversal is caused by hydrogen bonding. This selectivity reversal is not anticipated by the IAST.

In Figure S38, the CBMC simulated values of the adsorption selectivity $S_{a d s}$ determined from both campaigns A and B are plotted as function of the surface potential $\Phi$. The CBMC simulated selectivity $S_{a d s}$ do not uniquely depend on $\Phi$, as prescribed by IAST. At values of $\Phi>25 \mathrm{~mol} \mathrm{~kg}^{-1}$, the IAST significantly underestimates the ethanol/water selectivity due to moderation of entropy effects. 


\subsection{List of Tables for Binary mixture adsorption in all-silica CHA zeolite}

Table S8. Dual-site Langmuir-Freundlich parameters for guest molecules in CHA (all-silica) at $300 \mathrm{~K}$.

\begin{tabular}{|l|l|l|l|l|l|l|}
\hline \multirow{2}{*}{} & \multicolumn{2}{|l|}{ Site A } & \multicolumn{2}{l|}{ Site B } \\
\cline { 2 - 7 } & $\begin{array}{l}q_{\mathrm{A}, \mathrm{sat}} \\
\mathrm{mol} \mathrm{kg}{ }^{-1}\end{array}$ & $\begin{array}{l}b_{\mathrm{A}} \\
\mathrm{Pa}^{-v A}\end{array}$ & $\begin{array}{l}v_{\mathrm{A}} \\
\text { dimensionless }\end{array}$ & $\begin{array}{l}q_{\mathrm{B}, \mathrm{sat}} \\
\mathrm{mol} \mathrm{\textrm {kg } ^ { - 1 }}\end{array}$ & $\begin{array}{l}b_{\mathrm{B}} \\
\mathrm{Pa}^{-v B}\end{array}$ & dimensionless \\
\hline $\mathrm{CO}_{2}$ & 6.8 & $2.4464 \mathrm{E}-06$ & 1.06 & 2.8 & $5.181 \mathrm{E}-06$ & 0.7 \\
\hline $\mathrm{CH}_{4}$ & 2.7 & $1.3131 \mathrm{E}-06$ & 1.02 & 5.5 & $2.703 \mathrm{E}-07$ & 0.84 \\
\hline
\end{tabular}

Fitted Margules non-ideality parameters for binary $\mathrm{CO}_{2} / \mathrm{CH}_{4}$ mixture adsorption in $\mathrm{CHA}$ at $300 \mathrm{~K}$.

\begin{tabular}{|l|l|l|l|}
\hline & $C / \mathrm{kg} \mathrm{mol}^{-1}$ & $A 12$ & $A 21$ \\
\hline $\mathrm{CO}_{2} / \mathrm{CH}_{4}$ & 0.169 & -0.496 & -0.226 \\
\hline
\end{tabular}


Table S9. Dual-site Langmuir-Freundlich parameters for water and unary 1-alcohols in CHA at $300 \mathrm{~K}$. The fit parameters are based on the CBMC simulations of pure component isotherms presented in earlier work. $^{47,61}$

\begin{tabular}{|c|c|c|c|c|c|c|}
\hline & \multicolumn{3}{|l|}{ Site A } & \multicolumn{3}{|l|}{ Site B } \\
\hline & $\begin{array}{l}q_{\mathrm{A}, \mathrm{sat}} \\
\mathrm{mol} \mathrm{kg-1}\end{array}$ & $\begin{array}{l}b_{\mathrm{A}} \\
\mathrm{Pa}^{-v A}\end{array}$ & $\begin{array}{l}v_{\mathrm{A}} \\
\text { dimensionless }\end{array}$ & $\begin{array}{l}q_{\mathrm{A}, \mathrm{sat}} \\
\text { mol kg-1 }\end{array}$ & $\begin{array}{l}b_{\mathrm{A}} \\
\mathrm{Pa}^{-v A}\end{array}$ & $\nu_{\mathrm{B}}$ \\
\hline water & 16.8 & $3.031 \mathrm{E}-54$ & 15.6 & 4.6 & $2.218 \mathrm{E}-05$ & 1 \\
\hline methanol & 3.7 & $4.281 \mathrm{E}-11$ & 3.37 & 3.7 & $4.545 \mathrm{E}-04$ & 1 \\
\hline ethanol & 2.5 & $8.578 \mathrm{E}-06$ & 1.07 & 2.9 & $3.505 \mathrm{E}-03$ & 1.1 \\
\hline
\end{tabular}

Fitted Margules non-ideality parameters for binary mixture adsorption in CHA at $300 \mathrm{~K}$. The fits are based on combining CBMC Campaigns A and B.

\begin{tabular}{|l|l|l|l|}
\hline & $C / \mathrm{kg} \mathrm{mol}^{-1}$ & $A 12$ & $A 21$ \\
\hline water/ethanol & 0.114 & -7.334 & -3.665 \\
\hline
\end{tabular}




\subsection{List of Figures for Binary mixture adsorption in all-silica CHA zeolite}

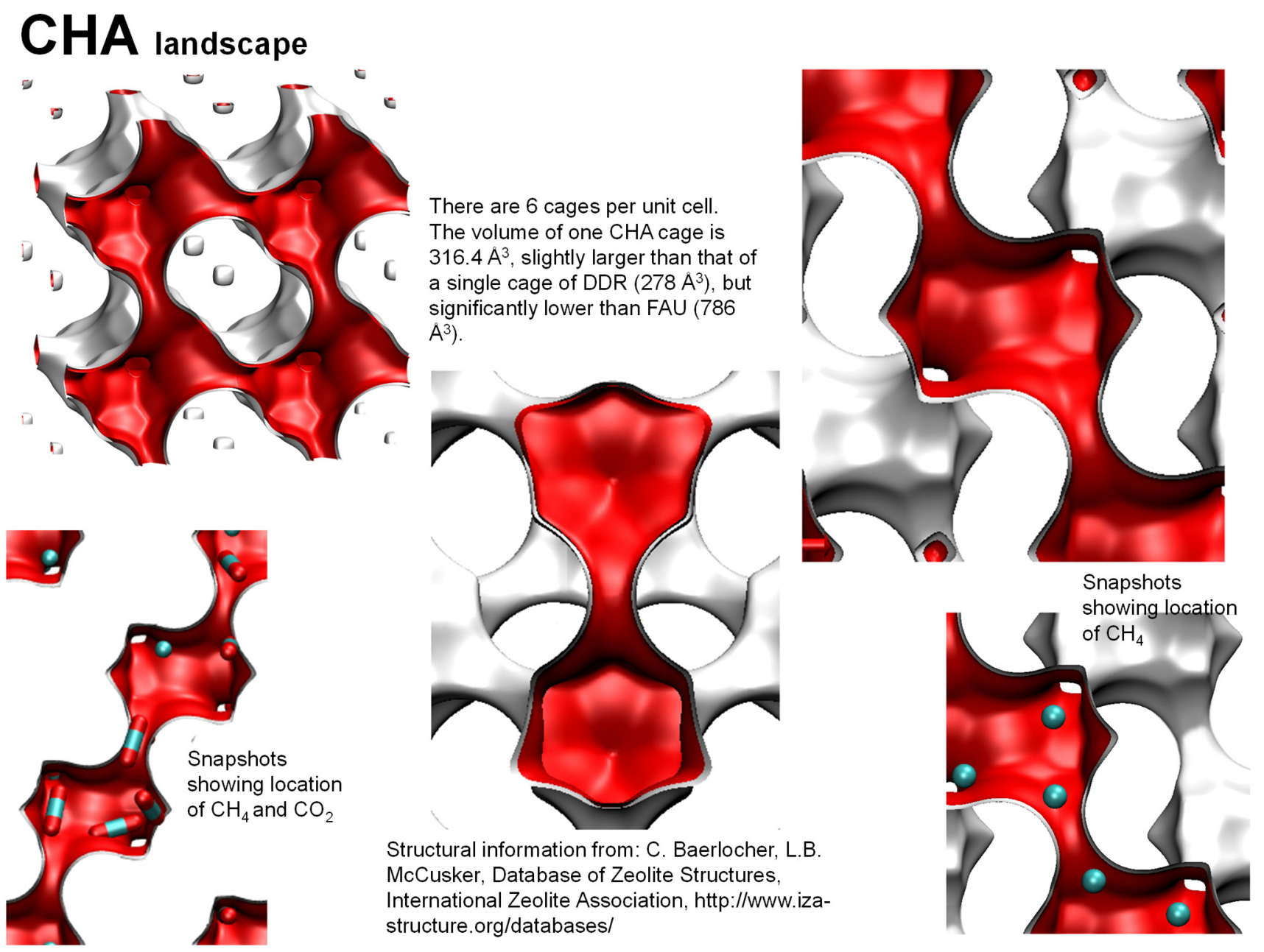

Figure S29. Pore landscape of all-silica CHA zeolite. 


\section{CHA window and pore dimensions}

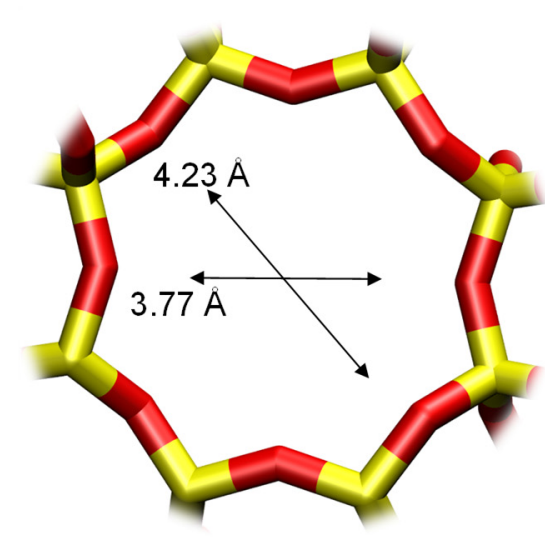

CHA

The window dimensions calculated using the van der Waals diameter of framework atoms $=2.7 \mathrm{~A}$ are indicated above by the arrows.

\begin{tabular}{|c|c|}
\hline & $\mathrm{CHA}$ \\
\hline$a / \AA$ & 15.075 \\
\hline$b / \AA$ & 23.907 \\
\hline$c / A$ & 13.803 \\
\hline Cell volume / $\AA^{3}$ & 4974.574 \\
\hline conversion factor for [molec/uc] to [mol per kg Framework] & 0.2312 \\
\hline conversion factor for $[\mathrm{molec} / \mathrm{uc}]$ to $\left[\mathrm{kmol} / \mathrm{m}^{3}\right]$ & 0.8747 \\
\hline$\rho[\mathrm{kg} / \mathrm{m} 3]$ & 1444.1 \\
\hline MW unit cell [g/mol(framework)] & 4326.106 \\
\hline$\phi$, fractional pore volume & 0.382 \\
\hline open space / $\AA^{3} / \mathrm{uc}$ & 1898.4 \\
\hline Pore volume $/ \mathrm{cm}^{3} / \mathrm{g}$ & 0.264 \\
\hline Surface area $/ \mathrm{m}^{2} / \mathrm{g}$ & 758.0 \\
\hline DeLaunay diameter $/ \AA$ & 3.77 \\
\hline
\end{tabular}

Figure S30. Structural details for CHA zeolite. 


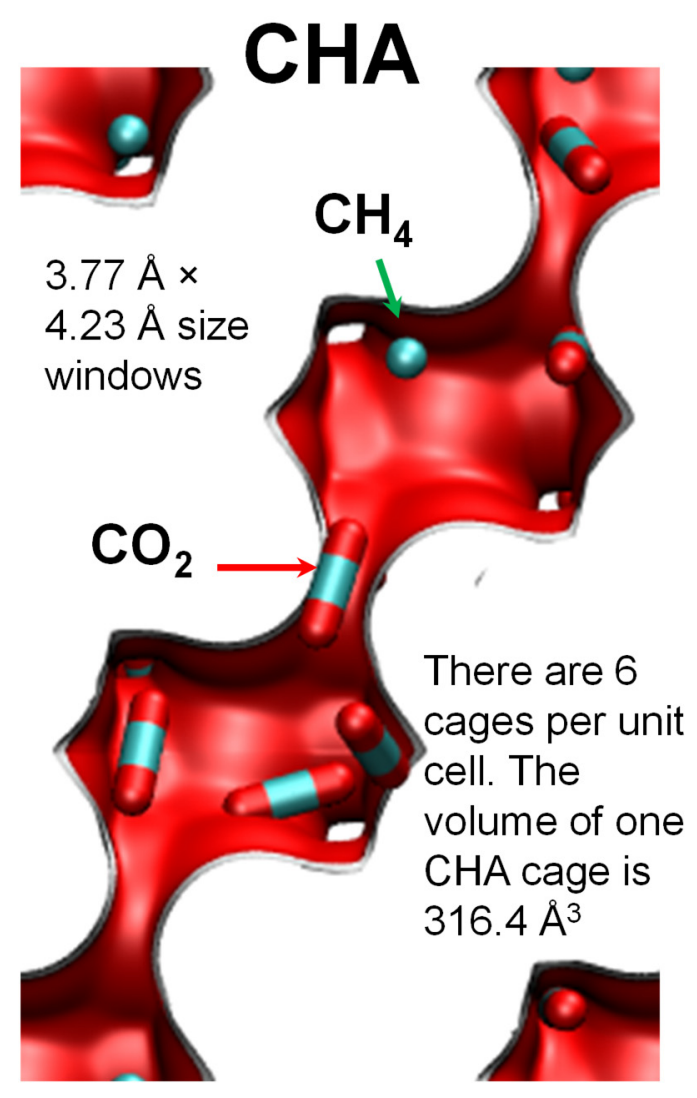

Figure S31. Computational snapshots for $\mathrm{CO}_{2}(1) / \mathrm{CH}_{4}(2)$ mixture adsorption in CHA zeolite at $300 \mathrm{~K}$. 

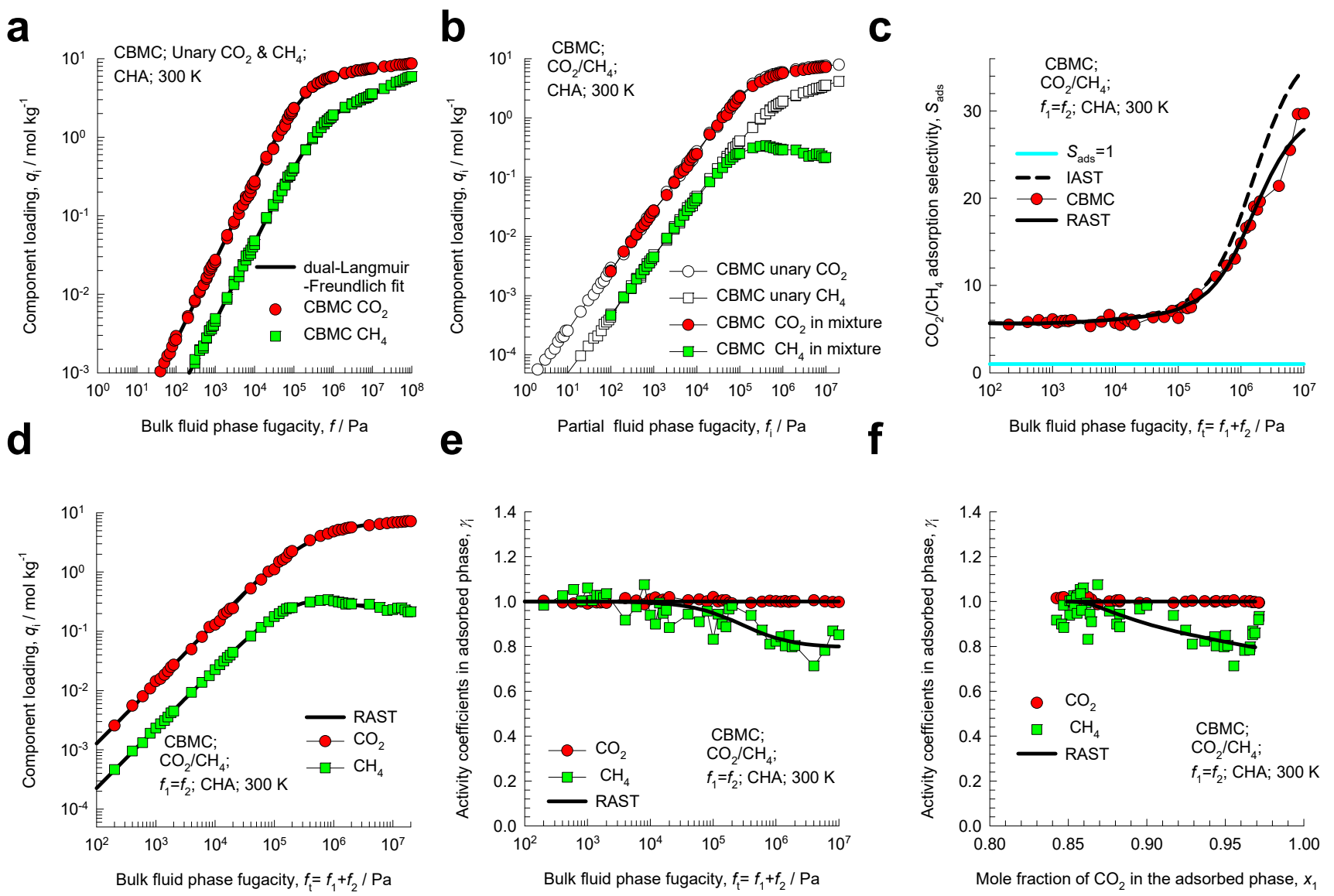

Figure S32. CBMC simulation data and analysis for Campaign A $\left(y_{1}=0.5\right)$ for $\mathrm{CO}_{2}(1) / \mathrm{CH}_{4}(2)$ mixture adsorption in CHA zeolite at $300 \mathrm{~K}$. (a) Unary isotherms and fits. (b) Component loadings in mixture compared with $\mathrm{CBMC}$ simulations of unary isotherms. (c) $\mathrm{CBMC}$ data for $\mathrm{CO}_{2}(1) / \mathrm{CH}_{4}(2)$ adsorption selectivity compared with IAST and RAST estimates. (d) CBMC data for component loadings in mixture compared with RAST estimates. (e, f) Activity coefficients from CBMC compared with RAST model calculations. The unary isotherm data fits and Margules parameters are provided in Table S8. 
a
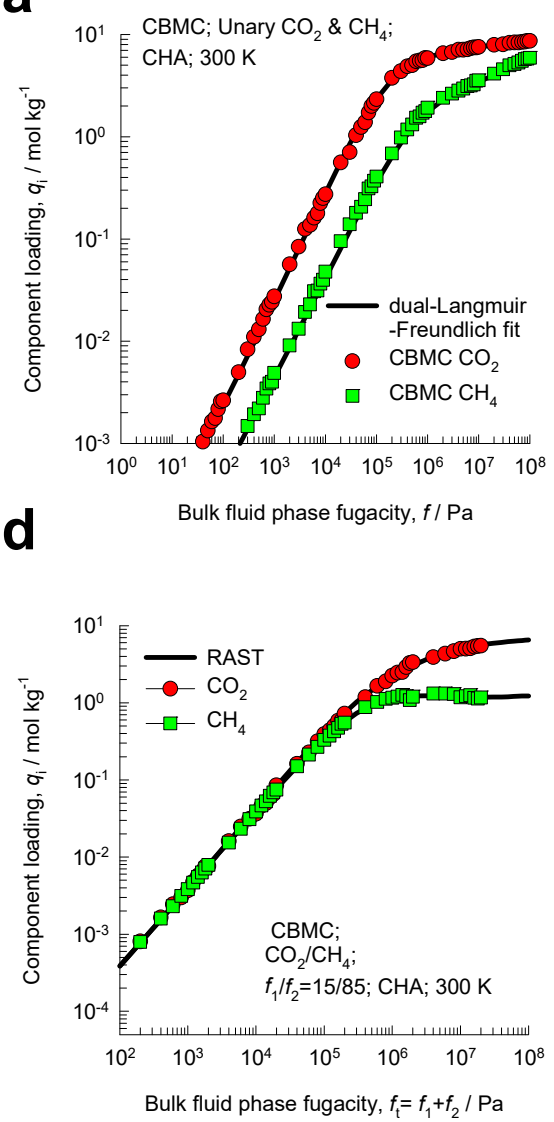

b
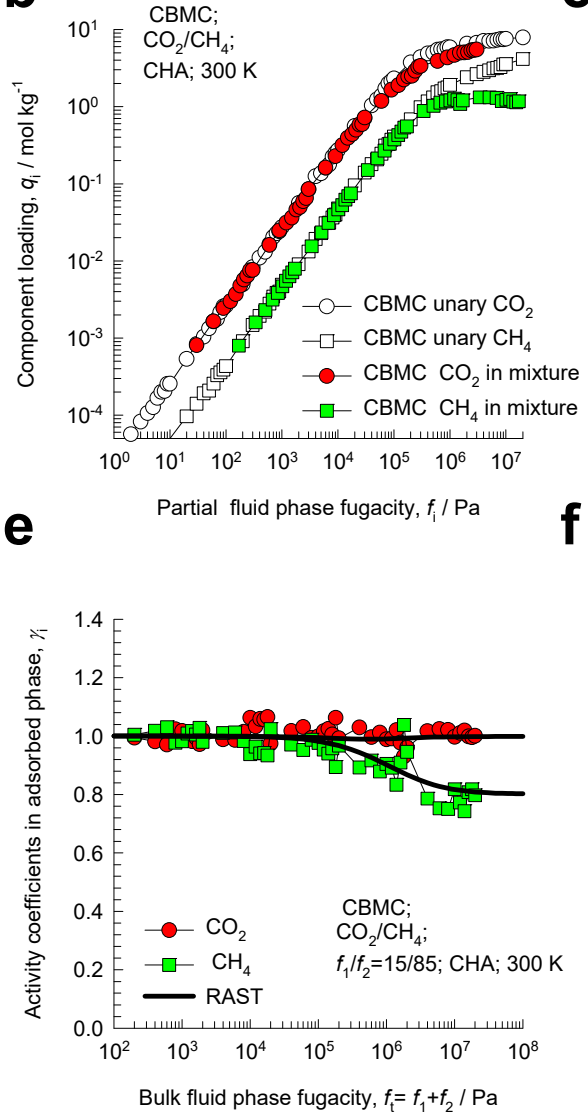

C

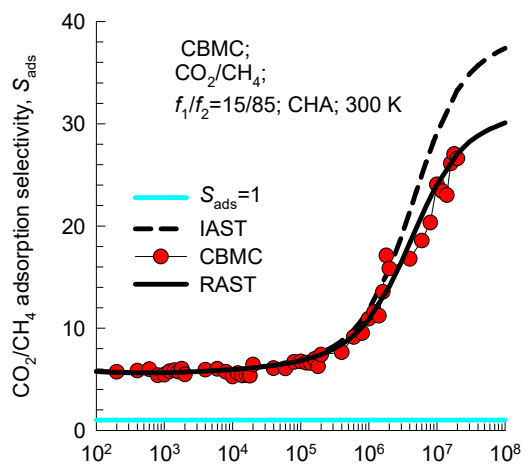

Bulk fluid phase fugacity, $f_{\mathrm{t}}=f_{1}+f_{2} / \mathrm{Pa}$

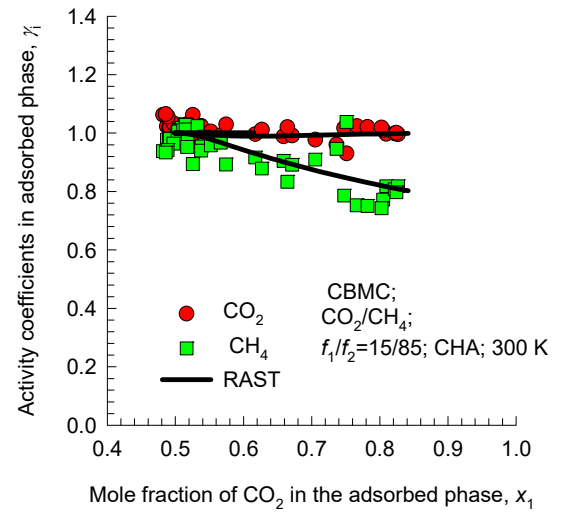

Figure S33. CBMC simulation data and analysis for Campaign $\mathrm{A}\left(y_{1}=0.15\right)$ for $\mathrm{CO}_{2}(1) / \mathrm{CH}_{4}(2)$ mixture adsorption in CHA zeolite at $300 \mathrm{~K}$. (a) Unary isotherms and fits. (b) Component loadings in mixture compared with CBMC simulations of unary isotherms. (c) $\mathrm{CBMC}$ data for $\mathrm{CO}_{2}(1) / \mathrm{CH}_{4}(2)$ adsorption selectivity compared with IAST and RAST estimates. (d) CBMC data for component loadings in mixture compared with RAST estimates. (e, f) Activity coefficients from CBMC compared with RAST model calculations. The unary isotherm data fits and Margules parameters are provided in Table S8. 

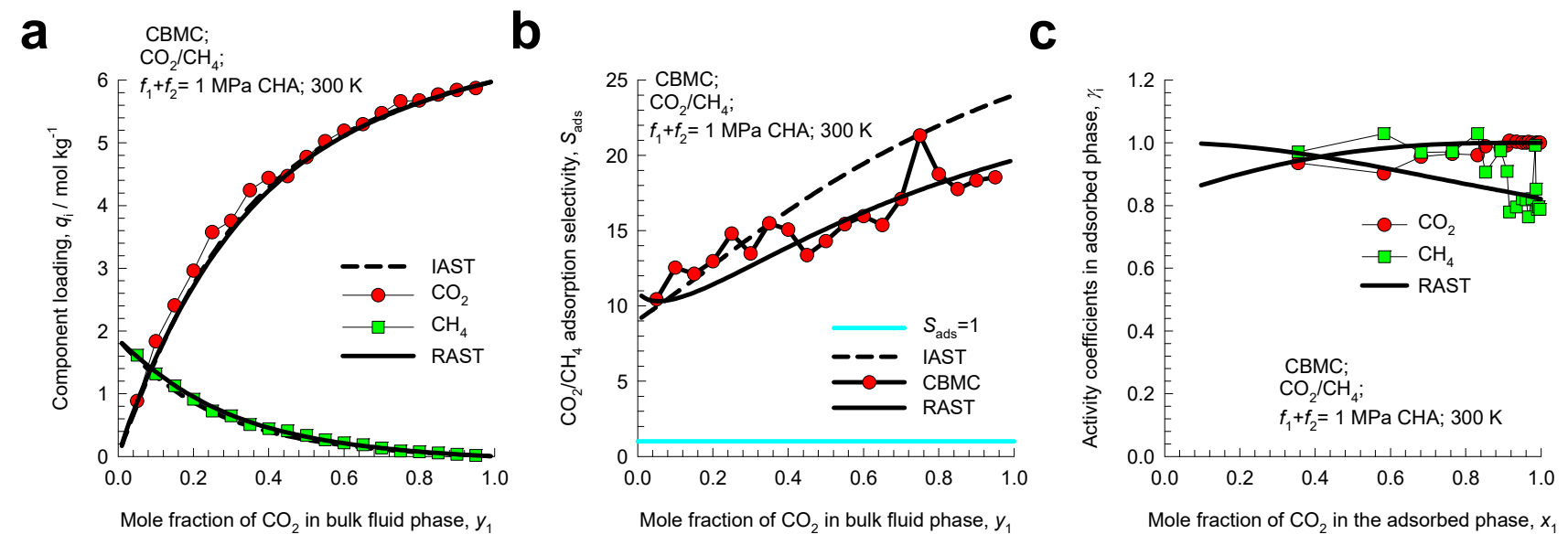

Figure S34. CBMC simulation data and analysis for Campaign $\mathrm{B}\left(f_{\mathrm{t}}=1 \mathrm{MPa}\right)$ for $\mathrm{CO}_{2}(1) / \mathrm{CH}_{4}(2)$ mixture adsorption in CHA zeolite at $300 \mathrm{~K}$. CBMC data for (a) component loadings and (b) $\mathrm{CO}_{2}(1) / \mathrm{CH}_{4}(2)$ adsorption selectivity compared with IAST and RAST estimates. (c) Activity coefficients from CBMC compared with RAST model calculations. The unary isotherm data fits and Margules parameters are provided in Table S8. 


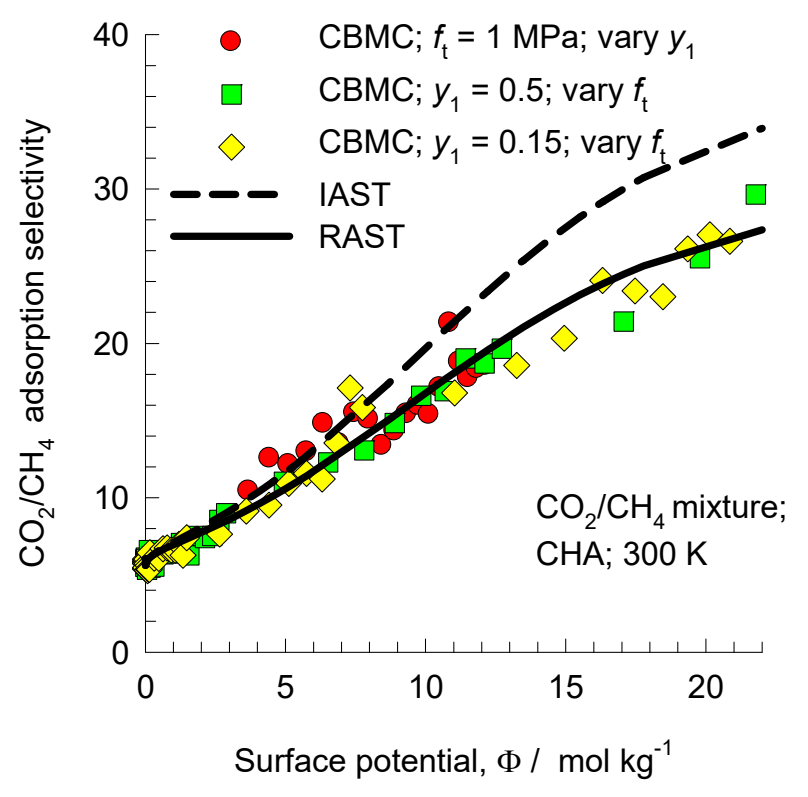

Figure S35. Adsorption selectivity $S_{a d s}$ for $\mathrm{CO}_{2}(1) / \mathrm{CH}_{4}(2)$ mixture adsorption in CHA zeolite at 300 $\mathrm{K}$, for three different campaigns (Campaign A $\left(y_{1}=0.5\right.$, and 0.15) and Campaign B $\left(f_{\mathrm{t}}=1 \mathrm{MPa}\right)$, plotted as function of the surface potential $\Phi$. The CBMC simulated values (indicated by symbols) are compared with RAST (continuous solid lines), and IAST (dashed lines) estimates. The unary isotherm data fits and Margules parameters are provided in Table S8. 
a
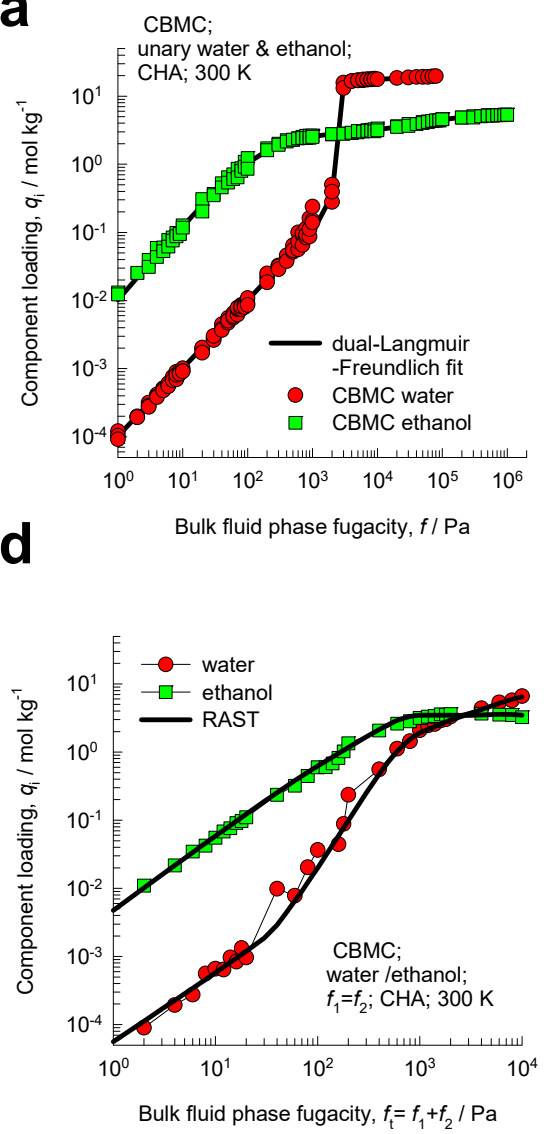

b
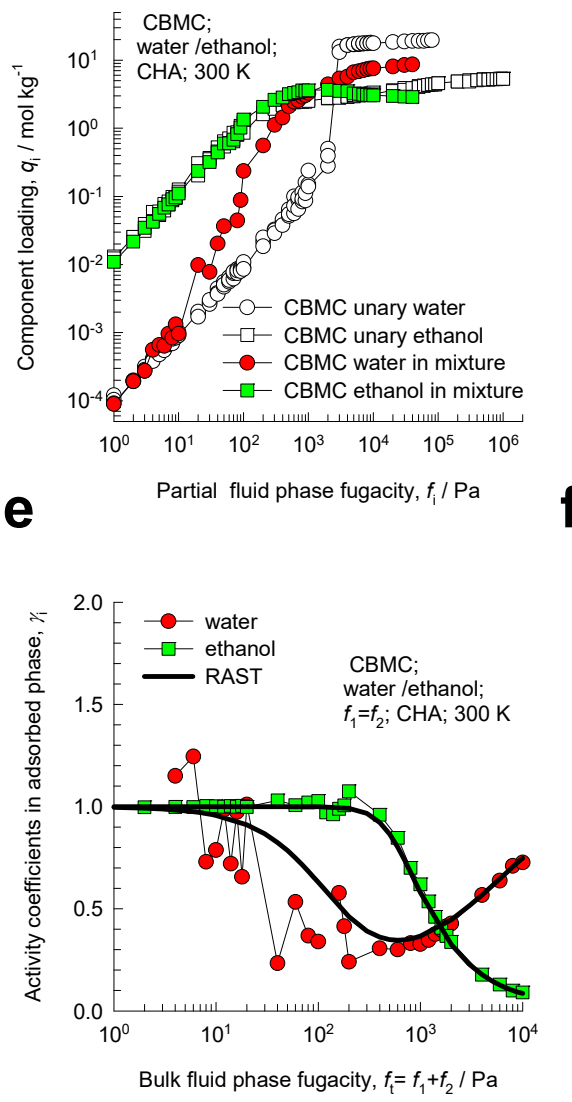

C
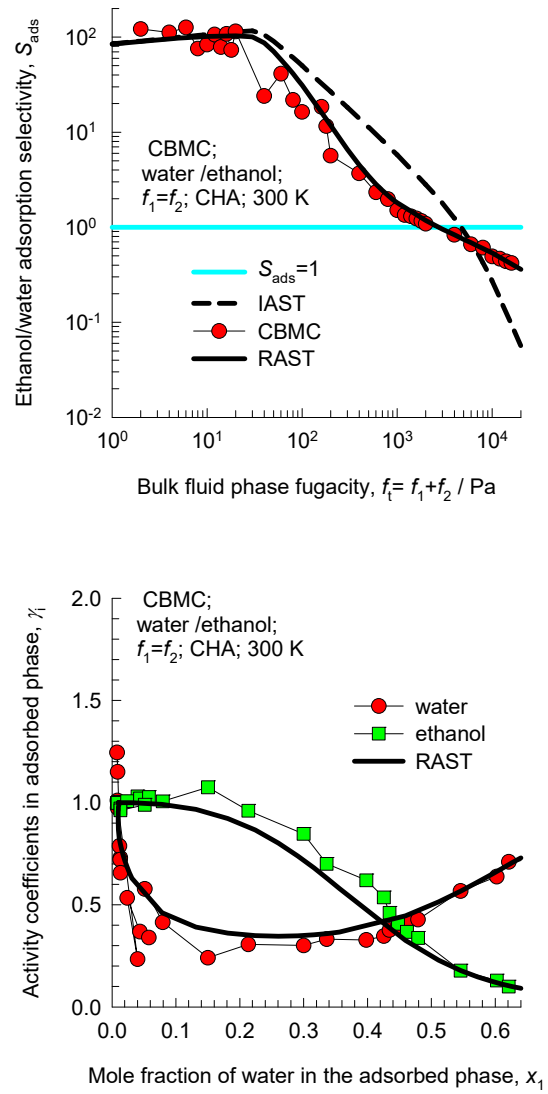

Figure S36. CBMC simulation data and analysis for Campaign A $\left(y_{1}=0.5\right)$ for water/ethanol mixture in CHA at $300 \mathrm{~K}$. (a) Unary isotherms and fits. (b) Component loadings in mixture compared with CBMC simulations of unary isotherms. (c) CBMC data for alcohol/water selectivity compared with IAST and RAST estimates. (d) CBMC data for component loadings in mixture compared with RAST estimates. (e, f) Activity coefficients from CBMC compared with RAST model calculations. The unary isotherm data fits and Margules parameters are provided in Table S8. 

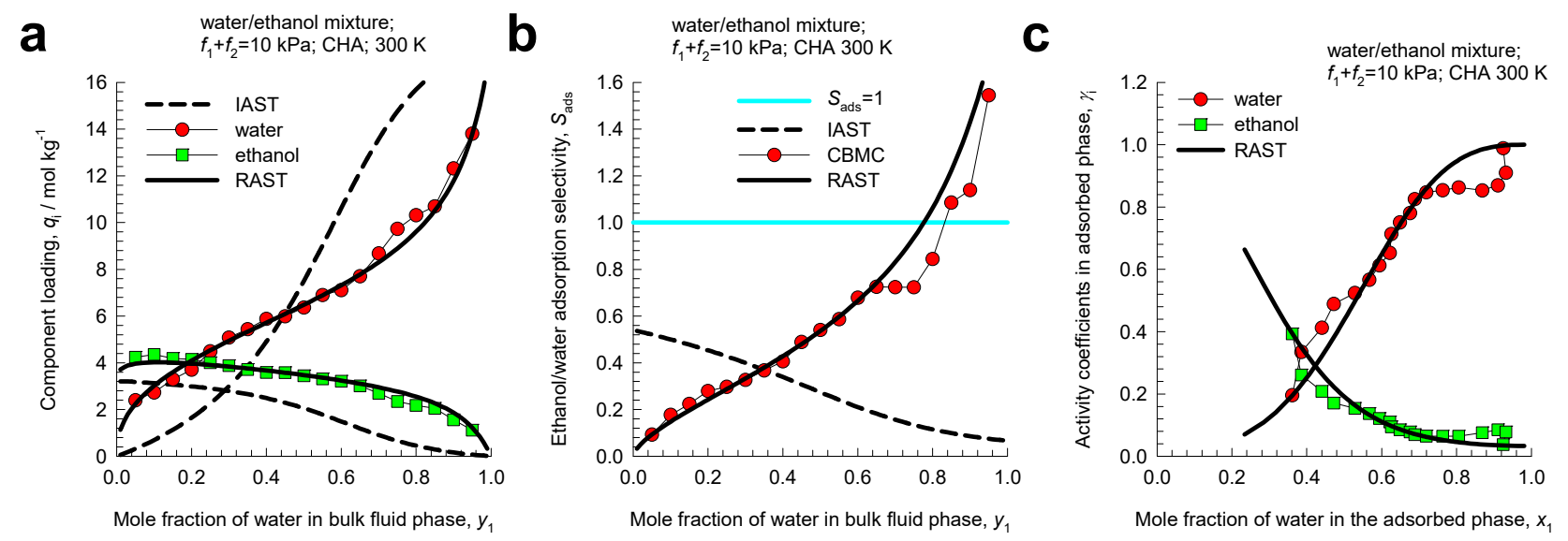

Figure S37. CBMC simulation data and analysis for Campaign $\mathrm{B}\left(f_{\mathrm{t}}=10 \mathrm{kPa}\right)$ for water/ethanol mixture in CHA at $300 \mathrm{~K}$. CBMC data on (a) component loadings, and (b) alcohol/water selectivity compared with IAST and RAST estimates. (c) Activity coefficients from CBMC compared with RAST model calculations. 


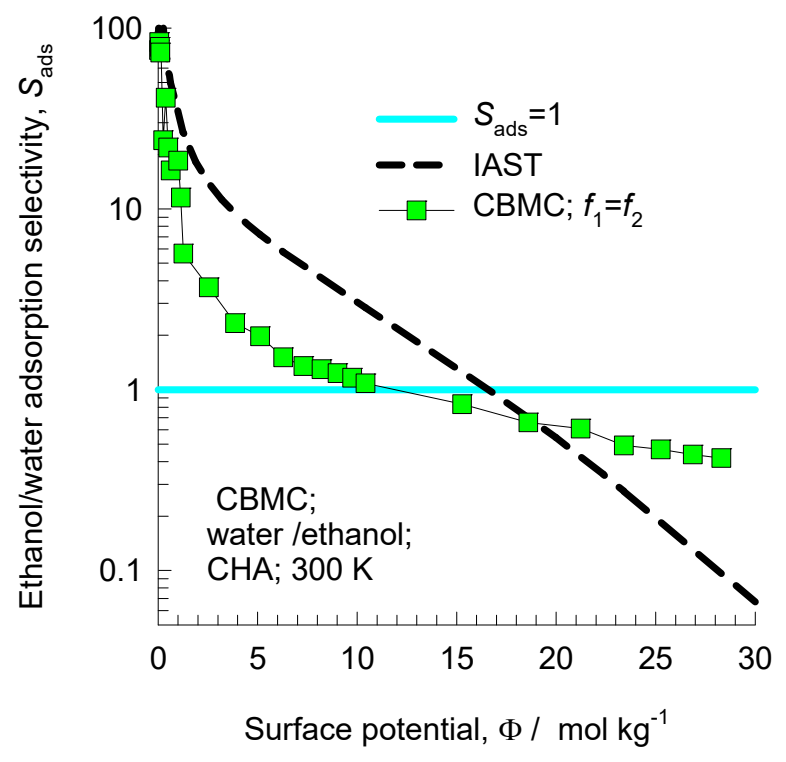

Figure S38. Adsorption selectivity $S_{a d s}$ for water/ethanol mixture in CHA at $300 \mathrm{~K}$, for two different campaigns (Campaign A $\left(y_{1}=0.5\right)$ and Campaign $\mathrm{B}\left(f_{\mathrm{t}}=10 \mathrm{kPa}\right)$, plotted as function of the surface potential $\Phi$. The CBMC simulated values (indicated by symbols) are compared with IAST estimates (indicated by the dashed lines). The unary isotherm data fits and Margules parameters are provided in Table S9. 


\section{Binary mixture adsorption in all-silica DDR zeolite}

DDR consists of cages of $277.8 \AA^{3}$ volume, separated by $3.65 \AA \times 4.37 \AA$ 8-ring windows; the pore landscapes and structural details are provided in Figure S39, and Figure S40.

\section{1 $\mathrm{CO}_{2} / \mathrm{CH}_{4}$ mixture adsorption in all-silica DDR zeolite}

A key assumption of the IAST is that the composition of the adsorbed phase is homogeneously and uniformly distributed within zeolite or metal-organic frameworks. Preferential location of molecules at certain locations within the crystalline, causes segregated adsorption and deviations from the assumption of homogeneous distribution. For separation of $\mathrm{CO}_{2}$ from gaseous mixtures with $\mathrm{CH}_{4}$, cage-type zeolites such as CHA, DDR, LTA, and ERI are of practical interest; these materials consist of cages separated by narrow windows, in the $3.3-4.5 \AA$ range. For adsorption of $\mathrm{CO}_{2} / \mathrm{CH}_{4}$ mixtures, $\mathrm{CBMC}$ simulations ${ }^{59}$ show that the window regions of cage-type zeolites has a significantly higher proportion of $\mathrm{CO}_{2}$ than within the cages; see computational snapshots in Figure S41 for DDR. Due to the segregated nature of mixture adsorption, the IAST is unable to predict the mixture loadings accurately. Due to preferential location of $\mathrm{CO}_{2}$ in the window regions the $\mathrm{CH}_{4}$ molecules experience a less severe competition from $\mathrm{CO}_{2}$.

Figure S42, and Figure S43 present the CBMC data and analysis for two different campaigns. In Campaign A the ratio of partial fugacities $f_{1} / f_{2}=1 ; y_{1}=0.5$ and the bulk mixture fugacity, $f_{t}=f_{1}+f_{2}$ is varied. In Campaign B in which total fugacity is held constant at the value $f_{\mathrm{t}}=1 \mathrm{MPa}$ and the bulk fluid phase mixture composition $y_{1}=f_{1} / f_{t}$ is varied. The IAST calculations overestimate the values of $S_{a d s}$ because the competitive adsorption is less severe due to the segregated nature of adsorption; the competition faced by $\mathrm{CH}_{4}$ is less severe than anticipated because of the preferential location of $\mathrm{CO}_{2}$ in the window regions,. The departures from idealities are quantitatively captured by the RAST with fitted Margules parameters. 


\section{Binary mixture adsorption in all-silica DDR zeolite}

In Figure S44, the CBMC simulated values of the adsorption selectivity $S_{a d s}$ determined from both campaigns A and B are plotted as function of the surface potential $\Phi$. The CBMC simulated selectivity $S_{a d s}$ do not uniquely depend on $\Phi$, as prescribed by IAST. At values of $\Phi>5 \mathrm{~mol} \mathrm{~kg}^{-1}$, the IAST significantly overestimates $S_{a d s}$.

\subsection{Water/ethanol mixture adsorption in all-silica DDR zeolite}

Two types of water/ethanol mixture adsorption campaigns were conducted.

Campaign A. The bulk fluid phase composition held constant at $y_{1}=y_{2}=0.5$, and the bulk fluid phase fugacity $f_{t}=f_{1}+f_{2}$ was varied over a wide range from the Henry regime of adsorption, $f_{t} \rightarrow 0 ; \quad \Phi \rightarrow 0$ , to pore saturation conditions, typically $\Phi>50$.

Campaign B. The bulk fluid phase fugacity was held at a constant value $f_{t}=f_{1}+f_{2}=10 \mathrm{kPa}$, and the bulk fluid phase mixture composition $y_{1}$ was varied $0<y_{1}<1$.

The CBMC data and analysis for Campaign A are presented in Figure S45; the following major characteristics emerge. From Figure $\mathrm{S} 45 \mathrm{~b}$ we note that for a range of partial fugacities, $f_{1}$ in the bulk fluid phase, the component loading for water in the mixture (filled symbols) exceeds that of the pure component. The ethanol/water adsorption selectivity, $S_{a d s}$, determined from CBMC mixture simulations (symbols) has a tendency to undergo selectivity reversal in favor of water at high values of the bulk fluid phase fugacity $f_{t}=f_{1}+f_{2}$, as saturation conditions are approached; see Figure S45c. The selectivity reversal in favor of the smaller guest molecule, water, is the consequence of entropy effects that favor the guest species with the higher packing efficiency, as explained in earlier works. ${ }^{45,52,53,60-62}$ The selectivity reversal phenomena is also anticipated by the IAST model (shown by the dashed line). An important characteristic is that the IAST over-predicts the alcohol/water selectivity at values of $f_{t}=f_{1}+f_{2}$ lower 


\section{Binary mixture adsorption in all-silica DDR zeolite}

than that at which selectivity reversal occurs. For values of $f_{t}=f_{1}+f_{2}$ higher than that at selectivity reversal, the IAST estimates lie below the values determined from CBMC. The conclusion to be drawn is that IAST exaggerates entropy effects. Put another way, hydrogen bonding effects tend to moderate the influence of entropy effects because of molecular clustering attendant with mixture adsorption. As is to be expected the RAST model captures the right trends in the dependence of $S_{a d s}$ on $f_{t}=f_{1}+f_{2}$.

In Figure S45d, we note that the RAST estimates of the component loadings are in reasonably good agreement with CBMC simulated component loadings $q_{1, C B M C} ; q_{2, C B M C}$ (filled symbols). This is to be expected because the model parameters are chosen to fit the CBMC simulated component loadings. The success of the RAST model is therefore to be regarded as testimony to the applicability of the Margules model to describe the activity coefficients for mixture adsorption.

The activity coefficients in the adsorbed phase are plotted in Figure S45e,f. Both activity coefficients tend to unity in the Henry regime, as $\gamma_{i} \rightarrow 1 ; f_{t} \rightarrow 0$. The activity coefficient of water, $\gamma_{1}$, displays a minimum when plotted against the total bulk fluid phase fugacity $f_{t}=f_{1}+f_{2}$. The activity coefficient of alcohol tends to decrease to low values as $f_{t}=f_{1}+f_{2}$ increases. The activity coefficient of water, $\gamma_{1}$, tends to unity as the adsorbed phase mole fraction $x_{1} \rightarrow 1$; it displays a minimum. The activity coefficient of alcohol, $\gamma_{2}$, tends to unity as the adsorbed phase mole fraction $x_{2}=\left(1-x_{1}\right) \rightarrow 1$, decreasing in magnitude as $x_{1} \rightarrow 1$.

The CBMC data and analysis for Campaign B are presented in Figure S46; the following characteristics emerge. In Figure S46a, the RAST calculations using the fitted Margules parameters (continuous solid line) of the component loadings are, in agreement with CBMC simulated component loadings $q_{1, C B M C} ; q_{2, C B M C}$ (filled symbols) for binary mixture plotted as function of the mole fraction of component 1 in the bulk fluid phase, $y_{1}$. In Figure $\mathrm{S} 46 \mathrm{~b}$, the adsorption selectivity, $S_{a d s}$, determined from CBMC mixture simulations (symbols) are compared with calculations using the IAST (dashed line) and RAST 
(continuous solid line). The $x$-axis represents the mole fraction of component 1 in the bulk fluid phase, $y_{1}$. The ethanol/water adsorption selectivity experiences a selectivity reversal. The occurrence of selectivity reversal is caused by hydrogen bonding. This selectivity reversal is not anticipated by the IAST. In Figure S47, the CBMC simulated values of the adsorption selectivity $S_{a d s}$ determined from both campaigns A and B are plotted as function of the surface potential $\Phi$. The CBMC simulated selectivity $S_{a d s}$ do not uniquely depend on $\Phi$, as prescribed by IAST. At values of $\Phi>10 \mathrm{~mol} \mathrm{~kg}^{-1}$, the IAST significantly underestimates the ethanol/water selectivity due to moderation of entropy effects. 


\subsection{List of Tables for Binary mixture adsorption in all-silica DDR zeolite}

Table S10. Dual-site Langmuir-Freundlich parameters for guest molecules in DDR (all-silica) at 300 K.

\begin{tabular}{|l|l|l|l|l|l|l|}
\hline \multirow{2}{*}{} & \multicolumn{2}{|l|}{ Site A } & \multicolumn{2}{l|}{ Site B } \\
\cline { 2 - 7 } & $\begin{array}{l}q_{\mathrm{A}, \text { sat }} \\
\mathrm{mol} \mathrm{kg}\end{array}$ & $\begin{array}{l}b_{\mathrm{A}} \\
\mathrm{Pa}^{-\nu A}\end{array}$ & $\begin{array}{l}v_{\mathrm{A}} \\
\text { dimensionless }\end{array}$ & $\begin{array}{l}q_{\mathrm{B}, \text { at }} \\
\mathrm{mol} \mathrm{kg}^{-1}\end{array}$ & $\begin{array}{l}b_{\mathrm{B}} \\
\mathrm{Pa}^{-v B}\end{array}$ & dimensionless \\
\hline $\mathrm{CO}_{2}$ & 1.5 & $1.010 \mathrm{E}-06$ & 0.79 & 3 & $6.076 \mathrm{E}-06$ & 1 \\
\hline $\mathrm{CH}_{4}$ & 1.4 & $4.035 \mathrm{E}-06$ & 1 & 1.95 & $1.814 \mathrm{E}-06$ & 0.75 \\
\hline
\end{tabular}

Fitted Margules non-ideality parameters for binary $\mathrm{CO}_{2} / \mathrm{CH}_{4}$ mixture adsorption in DDR at $300 \mathrm{~K}$.

\begin{tabular}{|l|l|l|l|}
\hline & $C / \mathrm{kg} \mathrm{mol}^{-1}$ & $A_{12}$ & $A_{21}$ \\
\hline $\mathrm{CO}_{2} / \mathrm{CH}_{4}$ & 0.310 & -1.170 & -1.235 \\
\hline
\end{tabular}


Table S11. Dual-site Langmuir-Freundlich parameters for pure component water, methanol, and ethanol at $300 \mathrm{~K}$ in all-silica DDR zeolite. The fit parameters are based on the CBMC simulations of pure component isotherms presented in earlier work. ${ }^{21,47}$

\begin{tabular}{|c|c|c|c|c|c|c|}
\hline & \multicolumn{3}{|l|}{ Site A } & \multicolumn{3}{|l|}{ Site B } \\
\hline & $\begin{array}{l}q_{\mathrm{A}, \mathrm{sat}} \\
\mathrm{mol} \mathrm{kg}{ }^{-1}\end{array}$ & $\begin{array}{l}b_{\mathrm{A}} \\
\mathrm{Pa}^{-V A}\end{array}$ & $v_{\mathrm{A}}$ & 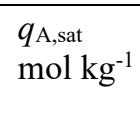 & $\begin{array}{l}b_{\mathrm{A}} \\
\mathrm{Pa}^{-v A}\end{array}$ & $v_{\mathrm{B}}$ \\
\hline water & 6.45 & $2.776 \mathrm{E}-17$ & 4.3 & 2.4 & $1.300 \mathrm{E}-05$ & 1.06 \\
\hline methanol & 1.7 & $1.186 \mathrm{E}-04$ & 1.3 & 1.7 & $6.055 \mathrm{E}-04$ & 0.78 \\
\hline ethanol & 1.6 & $9.962 \mathrm{E}-03$ & 0.88 & 1.2 & $9.160 \mathrm{E}-05$ & 0.66 \\
\hline
\end{tabular}

Fitted Margules non-ideality parameters for binary mixture adsorption in DDR at $300 \mathrm{~K}$. The fits are based on combining CBMC Campaigns A and B

\begin{tabular}{|l|l|l|l|}
\hline & $C / \mathrm{kg} \mathrm{mol}^{-1}$ & $A_{12}$ & $A 21$ \\
\hline water/ethanol & 1.868 & -5.325 & -1.665 \\
\hline
\end{tabular}


Binary mixture adsorption in all-silica DDR zeolite

\subsection{List of Figures for Binary mixture adsorption in all-silica DDR zeolite}

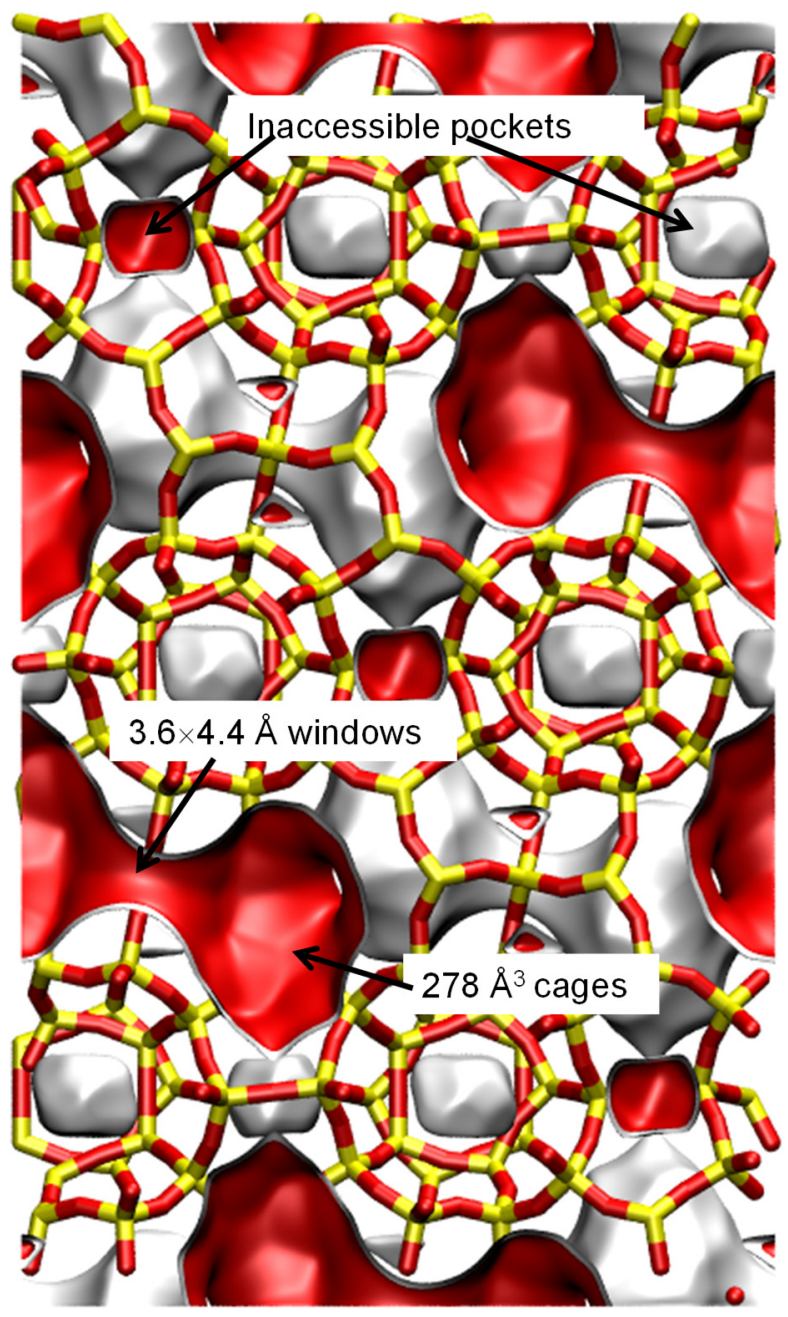

\section{DDR landscape} To convert from molecules per unit cell to $\mathrm{mol} \mathrm{kg}^{-1}$, multiply by 0.06936 .
The pore volume is $0.182 \mathrm{~cm}^{3} / \mathrm{g}$.

There are 12 cages per unit cell. The volume of one DDR cage is $278 A^{3}$, significantly smaller than that of a single cage of FAU (786 $\left.A^{3}\right)$, or ZIF-8 $\left(1168 A^{3}\right)$.

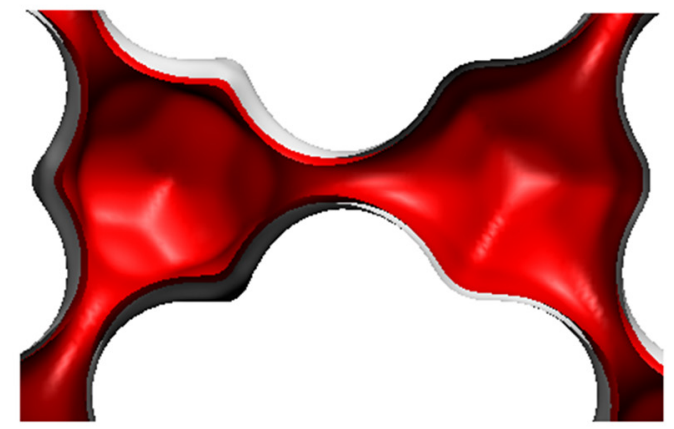

Structural information from: C. Baerlocher, L.B. McCusker, Database of Zeolite Structures, International Zeolite Association, http://www.iza-structure.org/databases/

Figure S39. Pore landscape of all-silica DDR zeolite. 


\section{DDR window and pore dimensions}

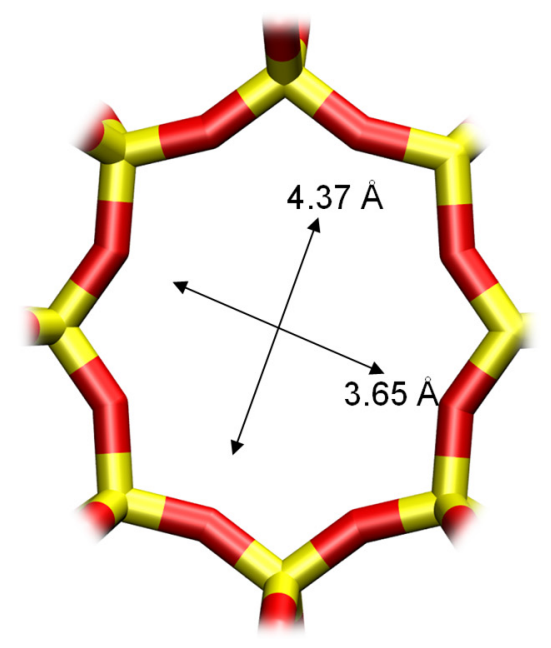

DDR

The window dimensions calculated using the van der Waals diameter of framework atoms $=2.7 \AA$ are indicated above by the arrows.

\begin{tabular}{|c|c|}
\hline & DDR \\
\hline$a / \AA$ & 24.006 \\
\hline$b / \AA$ & 13.86 \\
\hline$c / \AA$ & 40.892 \\
\hline Cell volume / $\AA^{3}$ & 13605.72 \\
\hline conversion factor for [molec/uc] to [mol per kg Framework] & 0.0693 \\
\hline conversion factor for $[\mathrm{molec} / \mathrm{uc}]$ to $\left[\mathrm{kmol} / \mathrm{m}^{3}\right]$ & 0.4981 \\
\hline$\rho[\mathrm{kg} / \mathrm{m} 3]$ & 1759.991 \\
\hline MW unit cell [g/mol(framework)] & 14420.35 \\
\hline$\phi$, fractional pore volume & 0.245 \\
\hline open space / $\AA^{3} /$ uc & 3333.5 \\
\hline Pore volume $/ \mathrm{cm}^{3} / \mathrm{g}$ & 0.139 \\
\hline Surface area $/ \mathrm{m}^{2} / \mathrm{g}$ & 350.0 \\
\hline DeLaunay diameter $/ \AA$ & 3.65 \\
\hline
\end{tabular}

Figure S40. Structural details for DDR zeolite. 


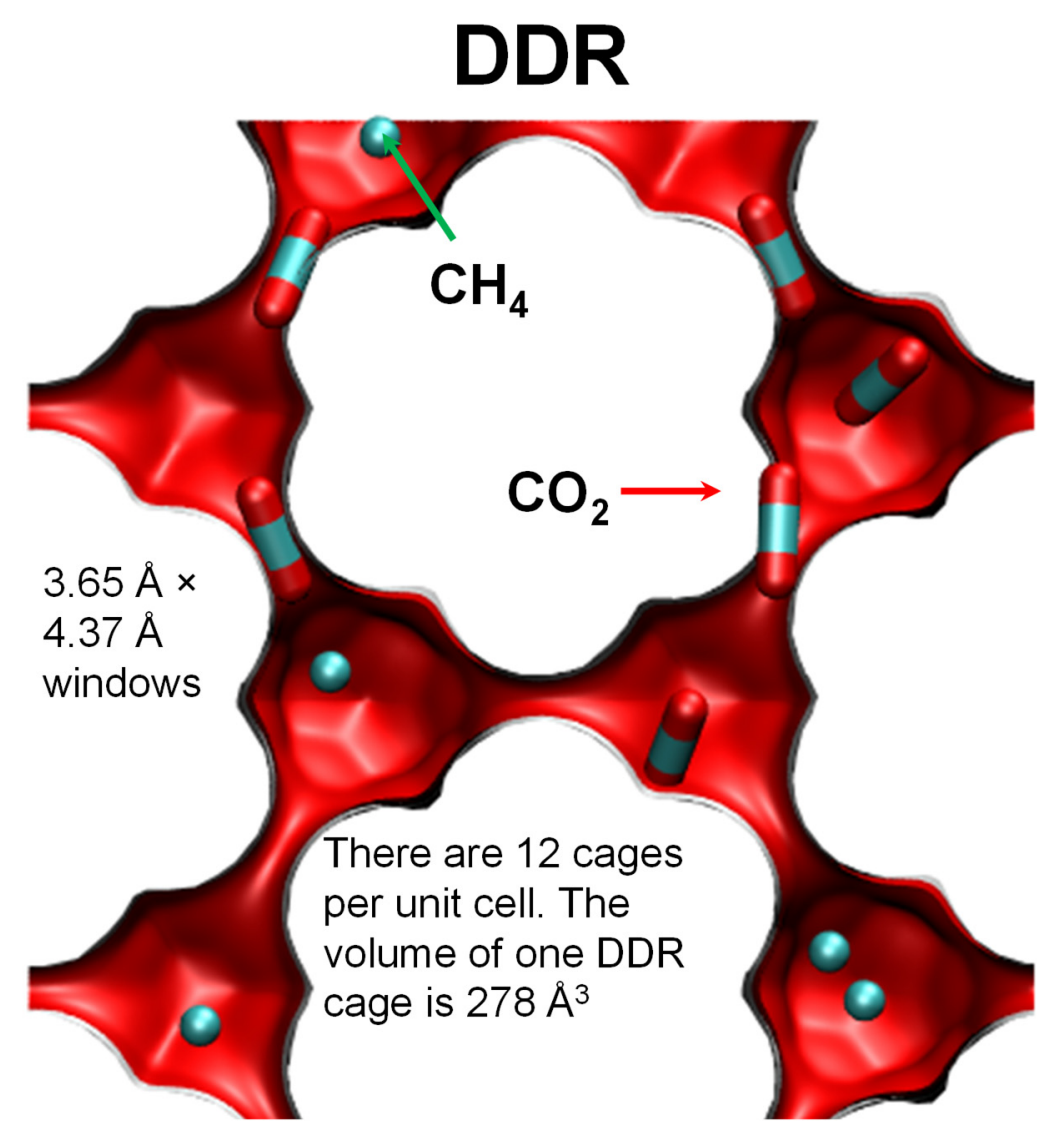

Figure S41. Computational snapshots for $\mathrm{CO}_{2}(1) / \mathrm{CH}_{4}(2)$ mixture adsorption in DDR zeolite at $300 \mathrm{~K}$. 
a

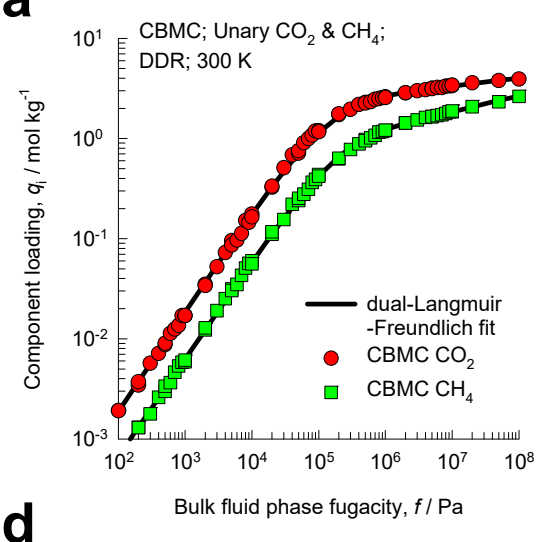

d

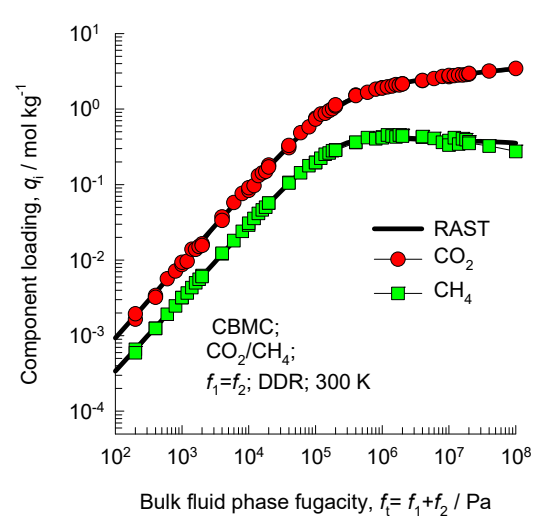

b
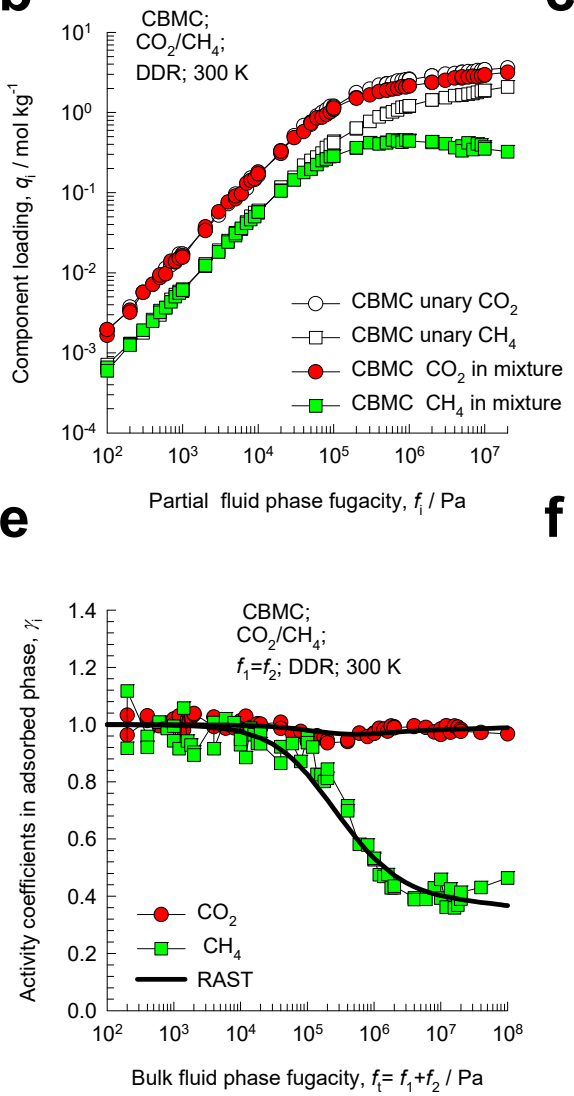

C
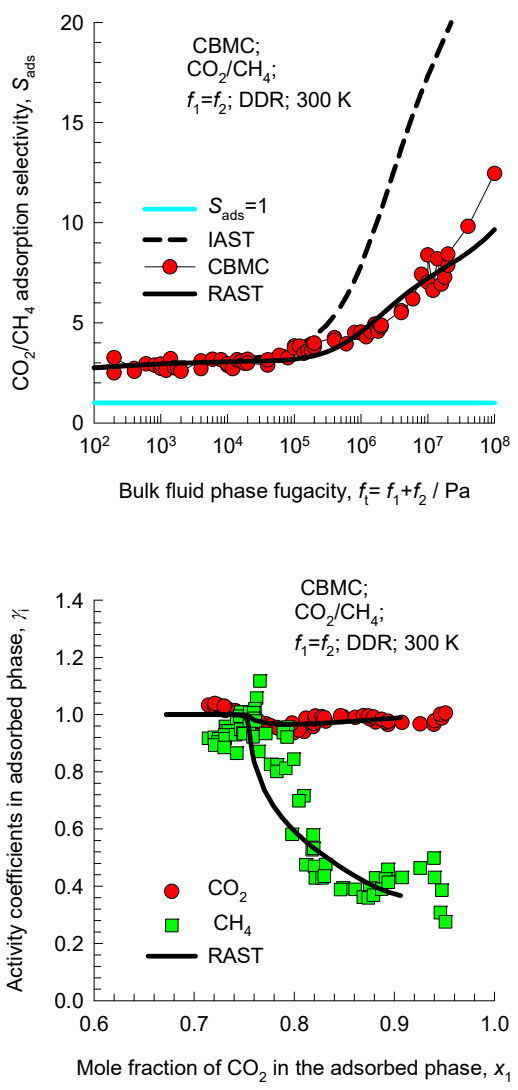

Figure S42. CBMC simulation data and analysis for Campaign A $\left(y_{1}=0.5\right)$ for $\mathrm{CO}_{2}(1) / \mathrm{CH}_{4}(2)$ mixture adsorption in DDR zeolite at $300 \mathrm{~K}$. (a) Unary isotherms and fits. (b) Component loadings in mixture compared with $\mathrm{CBMC}$ simulations of unary isotherms. (c) $\mathrm{CBMC}$ data for $\mathrm{CO}_{2}(1) / \mathrm{CH}_{4}(2)$ adsorption selectivity compared with IAST and RAST estimates. (d) CBMC data for component loadings in mixture compared with RAST estimates. (e, f) Activity coefficients from CBMC compared with RAST model calculations. The unary isotherm data fits and Wilson parameters are provided in Table S10. 
a

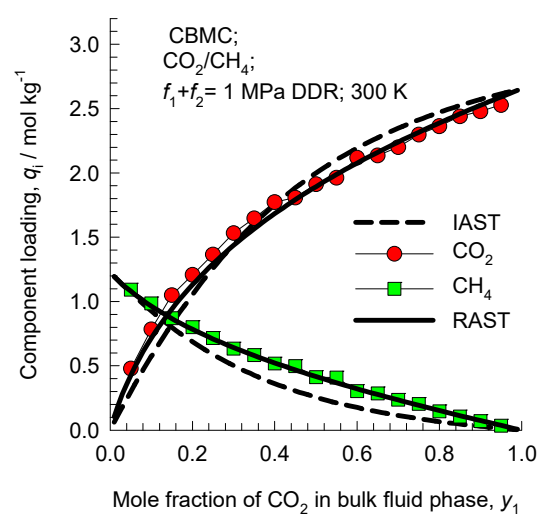

b

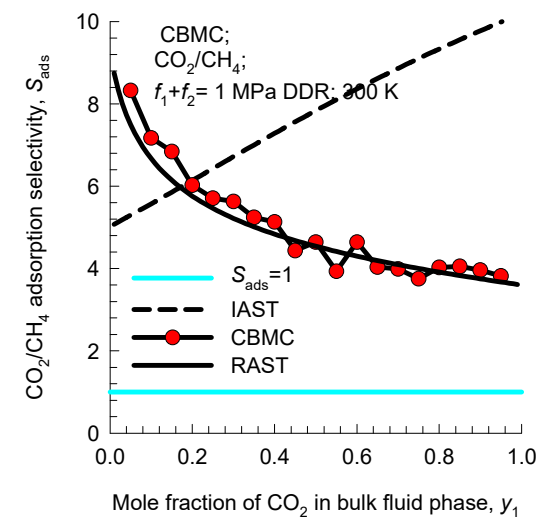

C

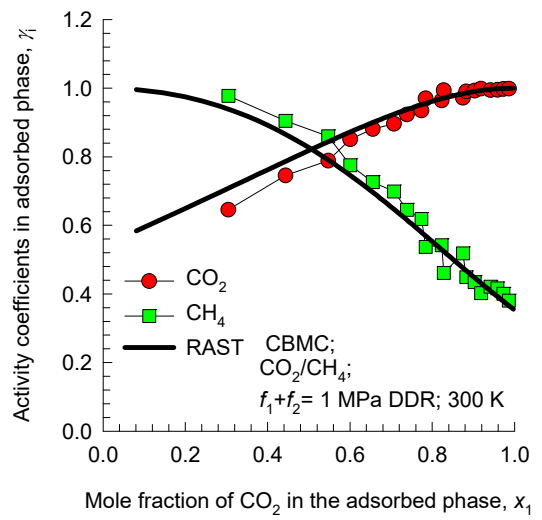

Figure S43. CBMC simulation data and analysis for Campaign B $\left(f_{\mathrm{t}}=1 \mathrm{MPa}\right)$ for $\mathrm{CO}_{2}(1) / \mathrm{CH}_{4}(2)$ mixture adsorption in DDR zeolite at $300 \mathrm{~K}$. CBMC data for (a) component loadings and (b) $\mathrm{CO}_{2}(1) / \mathrm{CH}_{4}(2)$ adsorption selectivity compared with IAST and RAST estimates. (c) Activity coefficients from CBMC compared with RAST model calculations. The unary isotherm data fits and Wilson parameters are provided in Table S10. 


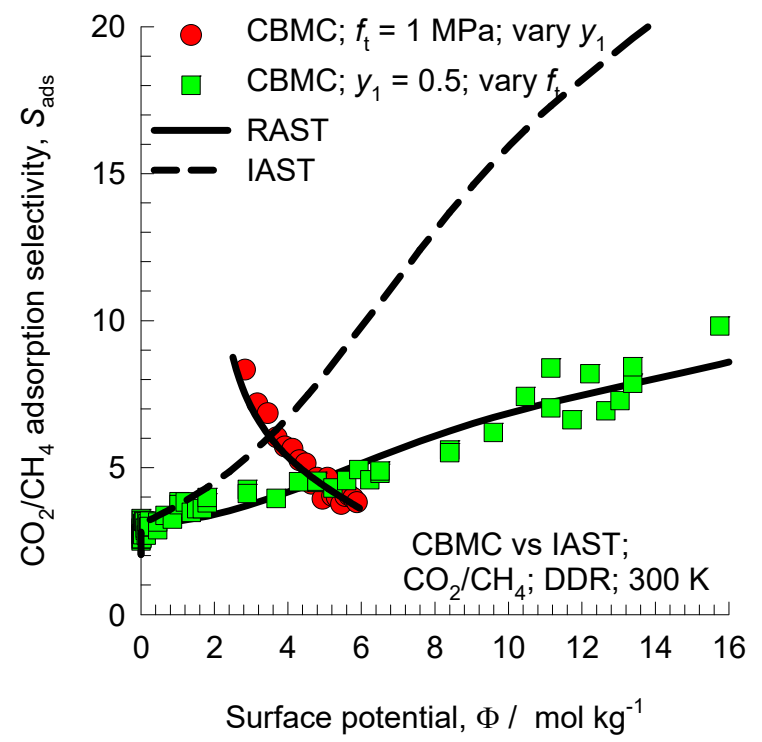

Figure S44. Adsorption selectivity $S_{a d s}$ for $\mathrm{CO}_{2}(1) / \mathrm{CH}_{4}(2)$ mixture adsorption in DDR zeolite at 300 $\mathrm{K}$, for two different campaigns (Campaign A $\left(y_{1}=0.5\right)$ and Campaign $\mathrm{B}\left(f_{\mathrm{t}}=1 \mathrm{MPa}\right)$, plotted as function of the surface potential $\Phi$. The CBMC simulated values (indicated by symbols) are compared with RAST (continuous solid lines), and IAST (dashed lines) estimates. The unary isotherm data fits and Wilson parameters are provided in Table S10. 

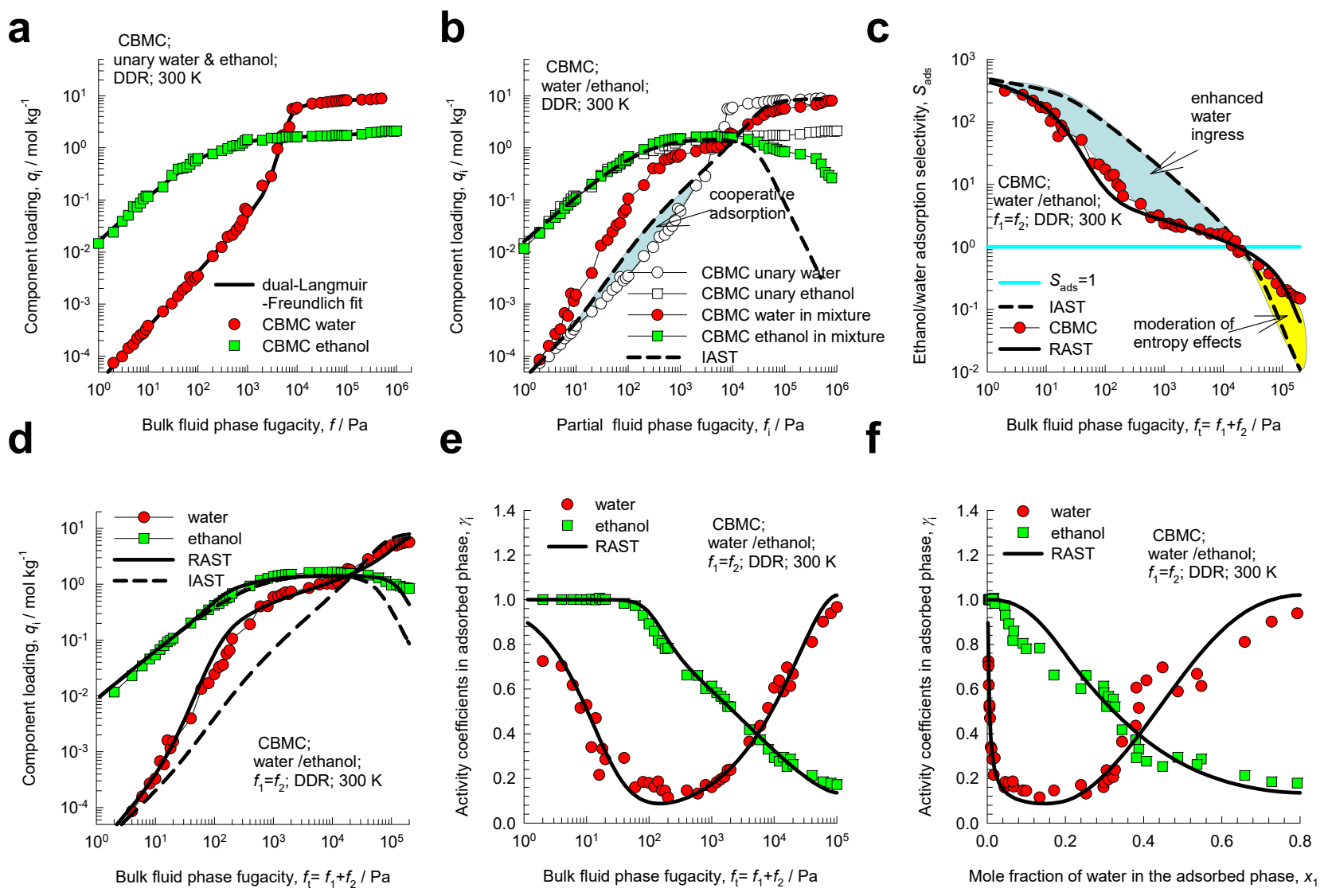

Figure S45. CBMC simulation data and analysis for Campaign A $\left(y_{1}=0.5\right)$ for water/ethanol mixture in DDR at 300 K. (a) Unary isotherms and fits. (b) Component loadings in mixture compared with CBMC simulations of unary isotherms. (c) CBMC data for alcohol/water selectivity compared with IAST and RAST estimates. (d) CBMC data for component loadings in mixture compared with RAST estimates. (e, f) Activity coefficients from CBMC compared with RAST model calculations. The unary isotherm data fits and Margules parameters are provided in Table S11. 

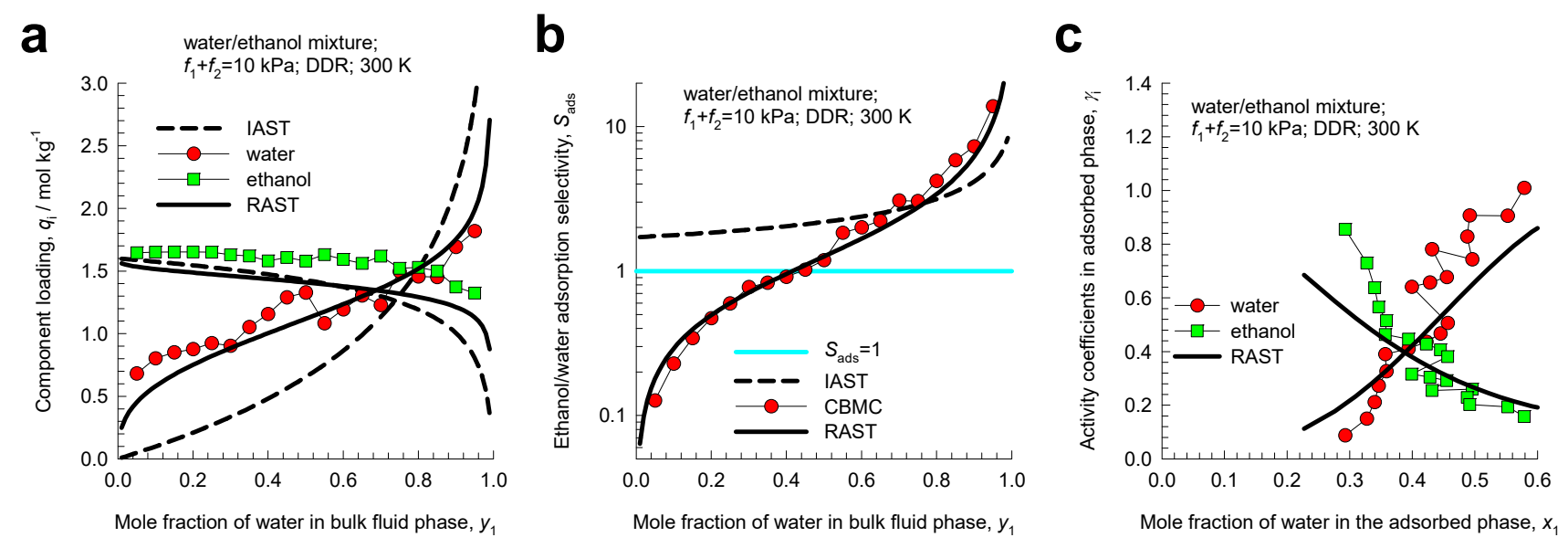

Figure S46. CBMC simulation data and analysis for Campaign $\mathrm{B}\left(f_{\mathrm{t}}=10 \mathrm{kPa}\right)$ for water/ethanol mixture in DDR at $300 \mathrm{~K} . \mathrm{CBMC}$ data on (a) component loadings, and (b) alcohol/water selectivity compared with IAST and RAST estimates. (c) Activity coefficients from CBMC compared with RAST model calculations. The unary isotherm data fits and Margules parameters are provided in Table S11. 


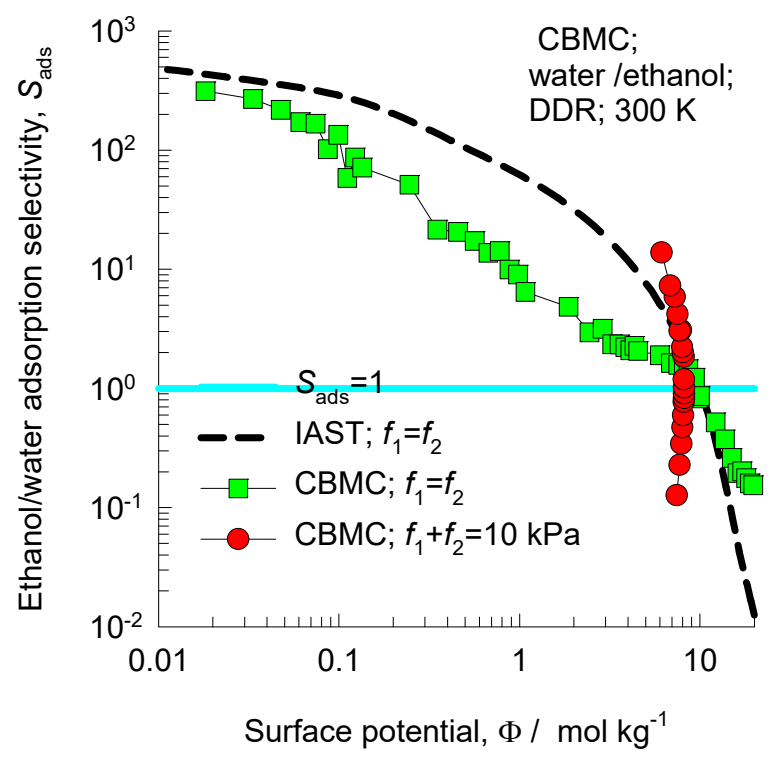

Figure S47. Adsorption selectivity $S_{a d s}$ for water/ethanol mixture in DDR at $300 \mathrm{~K}$ for two different campaigns (Campaign A $\left(y_{1}=0.5\right)$ and Campaign $\mathrm{B}\left(f_{\mathrm{t}}=10 \mathrm{kPa}\right)$, plotted as function of the surface potential $\Phi$. The CBMC simulated values (indicated by symbols) are compared with IAST estimates (indicated by the dashed lines). The unary isotherm data fits and Margules parameters are provided in Table S11. 


\section{Binary mixture adsorption in all-silica MOR zeolite}

MOR zeolite (Mordenite) consists of 12-ring (7.0 $\AA$ × 6.5 $\AA$ ) 1D channels, connected to 8-ring $(5.7 \AA$ $\times 2.6 \AA$ ) pockets; the pore landscapes and structural details are provided in Figure S48, and Figure S49.

\section{1 $\mathrm{CO}_{2} / \mathrm{CH}_{4}$ mixture adsorption in all-silica MOR zeolite}

Computational snapshots of the location of molecules for $\mathrm{CO}_{2} / \mathrm{CH}_{4}$ mixture adsorption show that $\mathrm{CO}_{2}$ get preferentially ensconced in the side-pockets; see Figure S50a. The $\mathrm{CH}_{4}$ molecules can also occupy the side pockets, but their preferred locations are the 12-ring channels. The RDF data in Figure S50b confirms the distances of $\mathrm{CO}_{2}-\mathrm{CH}_{4}$ pairs are significantly higher than for $\mathrm{CH}_{4}-\mathrm{CH}_{4}$ pairs.

Figure S51 presents CBMC simulation data for adsorption of equimolar (partial fugacities $f_{1}=f_{2}$ ) $\mathrm{CO}_{2} / \mathrm{CH}_{4}$ mixtures in MOR zeolite at $300 \mathrm{~K}$. The conventional IAST calculation assumes that $\mathrm{CH}_{4}$ molecules compete with all of the $\mathrm{CO}_{2}$, making no allowance for segregation. We note that the IAST under-predicts the loading of the more weakly adsorbed $\mathrm{CH}_{4}$ in the $\mathrm{CO}_{2} / \mathrm{CH}_{4}$ mixture. The conventional IAST calculation assumes that $\mathrm{CH}_{4}$ molecules compete with all of the $\mathrm{CO}_{2}$, making no allowance for segregation. Due to segregation effects the competition faced by $\mathrm{CH}_{4}$ molecules within the 12-ring channels, where they almost exclusively reside, is smaller than that in the entire pore space. The IAST anticipates a stiffer competition between $\mathrm{CO}_{2}$ and $\mathrm{CH}_{4}$ as it assumes a uniform distribution of composition; consequently the separation selectivity is overestimated. Figure S51c compares $\mathrm{CO}_{2} / \mathrm{CH}_{4}$ adsorption selectivities obtained from CBMC with IAST and RAST estimations.

The estimations of the RAST with fitted Wilson parameters, are shown by the continuous solid lines. Figure S51d presents a comparison of the estimations using the RAST with CBMC simulations of component loadings of equimolar (partial fugacities $f_{1}=f_{2}$ ) $\mathrm{CO}_{2} / \mathrm{CH}_{4}$ mixtures in MOR zeolite at $300 \mathrm{~K}$.

Figure S51e,f shows RAST calculations of the component activity coefficients $\gamma_{1}$, for $\mathrm{CO}_{2}$ and $\mathrm{CH}_{4}$. 


\section{Binary mixture adsorption in all-silica MOR zeolite}

\section{2 $\mathrm{CO}_{2} / \mathrm{C}_{3} \mathrm{H}_{8}$ mixture adsorption in all-silica MOR zeolite}

For $\mathrm{CO}_{2}(1) / \mathrm{C}_{3} \mathrm{H}_{8}(2)$ mixture adsorption in all-silica MOR zeolite at $300 \mathrm{~K}$, the computational snapshots for partial fugacities $f_{1}=f_{2}=20 \mathrm{kPa}$ are shown in Figure $\mathrm{S} 52 . \mathrm{CO}_{2}$ get preferentially ensconced in the side-pockets, but when the side pockets are fully occupied the $\mathrm{CO}_{2}$ can also locate in the 12-ring $1 \mathrm{D}$ channels. The $\mathrm{C}_{3} \mathrm{H}_{8}$ molecules are unable to occupy the side pockets, but their preferred locations are the 12-ring channels.

Figure S53, and Figure S54 present the CBMC data and analysis for two different campaigns. In Campaign A the ratio of partial fugacities $f_{1} / f_{2}=15 / 85$ and the bulk mixture fugacity, $f_{t}=f_{1}+f_{2}$ is varied. In Campaign B in which total fugacity is held constant at the value $f_{\mathrm{t}}=40 \mathrm{kPa}$ and the bulk fluid phase mixture composition $y_{1}=f_{1} / f_{t}$ is varied.

The unary isotherm data are shown in Figure S53a. In the Henry regime, the adsorption strengths are nearly equal. $\mathrm{CO}_{2}$ has a significantly higher saturation capacity, and therefore entropy effects favor the adsorption of $\mathrm{CO}_{2}$ at high pore occupancies. The CBMC data for Campaign $\mathrm{A}$ shows that the $\mathrm{CO}_{2}(1) / \mathrm{C}_{3} \mathrm{H}_{8}(2)$ adsorption selectivity $S_{a d s}$ increases significantly with increasing values of $f_{t}=f_{1}+f_{2}$

. Due to the segregated nature of adsorption, the IAST overestimates the $S_{a d s}$ for $f_{t}>0.5 \mathrm{MPa}$. Interesting, the IAST underestimates the $S_{a d s}$ for $f_{t}<0.5 \mathrm{MPa}$.

The results for Campaign B are even more interesting; see Figure S54. For $y_{1}=f_{1} / f_{t}<0.6, S_{a d s}>1$, and the selectivity is in favor of $\mathrm{CO}_{2}$. The $\mathrm{CBMC}$ simulations show that the adsorption selectivity $S_{a d s}$ is increasingly lowered below unity, i.e. in favor of the alkane, with increasing proportion of $\mathrm{CO}_{2}(1)$ in the bulk gas phase; see Figure S54b. The IAST anticipates $S_{\text {ads }}$ to be virtually independent of $y_{1}$. The conventional IAST calculation assumes that $\mathrm{C}_{3} \mathrm{H}_{8}$ molecules compete with all of the $\mathrm{CO}_{2}$, making no allowance for segregation. Due to segregation effects the competition faced by $\mathrm{C}_{3} \mathrm{H}_{8}$ molecules within the 12-ring channels, where $\mathrm{C}_{3} \mathrm{H}_{8}$ exclusively reside, is smaller than that in the entire pore space. The IAST 


\section{Binary mixture adsorption in all-silica MOR zeolite}

anticipates a stiffer competition between $\mathrm{CO}_{2}$ and $\mathrm{C}_{3} \mathrm{H}_{8}$ as it assumes a uniform distribution of composition; consequently, the separation selectivity is overestimated to a significant extent.

In Figure S55 the adsorption selectivity $S_{a d s}$ is plotted as a function of the surface potential $\Phi$. The dashed lines are the IAST calculations. With increasing values of $\Phi$, as pore saturation conditions are approached, the IAST severely overestimates the $S_{a d s}$. Segregation effects have the influence of moderating the influence of entropy effects that favor $\mathrm{CO}_{2}$ that has the higher saturation capacity. 


\subsection{List of Tables for Binary mixture adsorption in all-silica MOR zeolite}

Table S12. Dual-site Langmuir parameters for $\mathrm{CO}_{2}, \mathrm{CH}_{4}$, and $\mathrm{C}_{3} \mathrm{H}_{8}$ at $300 \mathrm{~K}$ in all-silica MOR zeolite. The fit parameters are based on the CBMC simulations of pure component isotherms presented in earlier works. $^{11,63}$

\begin{tabular}{|l|l|l|l|l|l|l|}
\hline \multirow{2}{*}{} & \multicolumn{2}{|l|}{ Site A } & \multicolumn{2}{l|}{ Site B } \\
\cline { 2 - 7 } & $\begin{array}{l}q_{\mathrm{A}, \mathrm{sat}} \\
\mathrm{mol} \mathrm{kg}{ }^{-1}\end{array}$ & $\begin{array}{l}b_{\mathrm{A}} \\
\mathrm{Pa}^{-v_{A}}\end{array}$ & $\begin{array}{l}v_{\mathrm{A}} \\
\text { dimensionless }\end{array}$ & $\begin{array}{l}q_{\mathrm{B}, \mathrm{sat}} \\
\mathrm{mol} \mathrm{kg}^{-1}\end{array}$ & $\begin{array}{l}b_{\mathrm{B}} \\
\mathrm{Pa}^{-v_{B}}\end{array}$ & $\begin{array}{l}v_{\mathrm{B}} \\
\text { dimensionless }\end{array}$ \\
\hline $\mathrm{CO}_{2}$ & 1.4 & $4.865 \mathrm{E}-04$ & 1 & 4.65 & $1.234 \mathrm{E}-06$ & 1 \\
\hline $\mathrm{CH}_{4}$ & 1.05 & $1.587 \mathrm{E}-08$ & 1 & 2.8 & $2.391 \mathrm{E}-06$ & 1 \\
\hline $\mathrm{C}_{3} \mathrm{H}_{8}$ & 0.18 & $2.112 \mathrm{E}-06$ & 1 & 1 & $3.551 \mathrm{E}-04$ & 1 \\
\hline
\end{tabular}

Fitted Margules non-ideality parameters for binary mixture adsorption in MOR at $300 \mathrm{~K}$.

\begin{tabular}{|l|l|l|l|}
\hline & $C / \mathrm{kg} \mathrm{mol}^{-1}$ & $A_{12}$ & $A_{21}$ \\
\hline $\mathrm{CO}_{2} / \mathrm{CH}_{4}$ in MOR & 0.37 & -1.90 & -1.31 \\
\hline $\mathrm{CO}_{2} / \mathrm{C}_{3} \mathrm{H}_{8}$ in MOR & 0.13 & -15.91 & -14.99 \\
\hline
\end{tabular}




\subsection{List of Figures for Binary mixture adsorption in all-silica MOR zeolite}

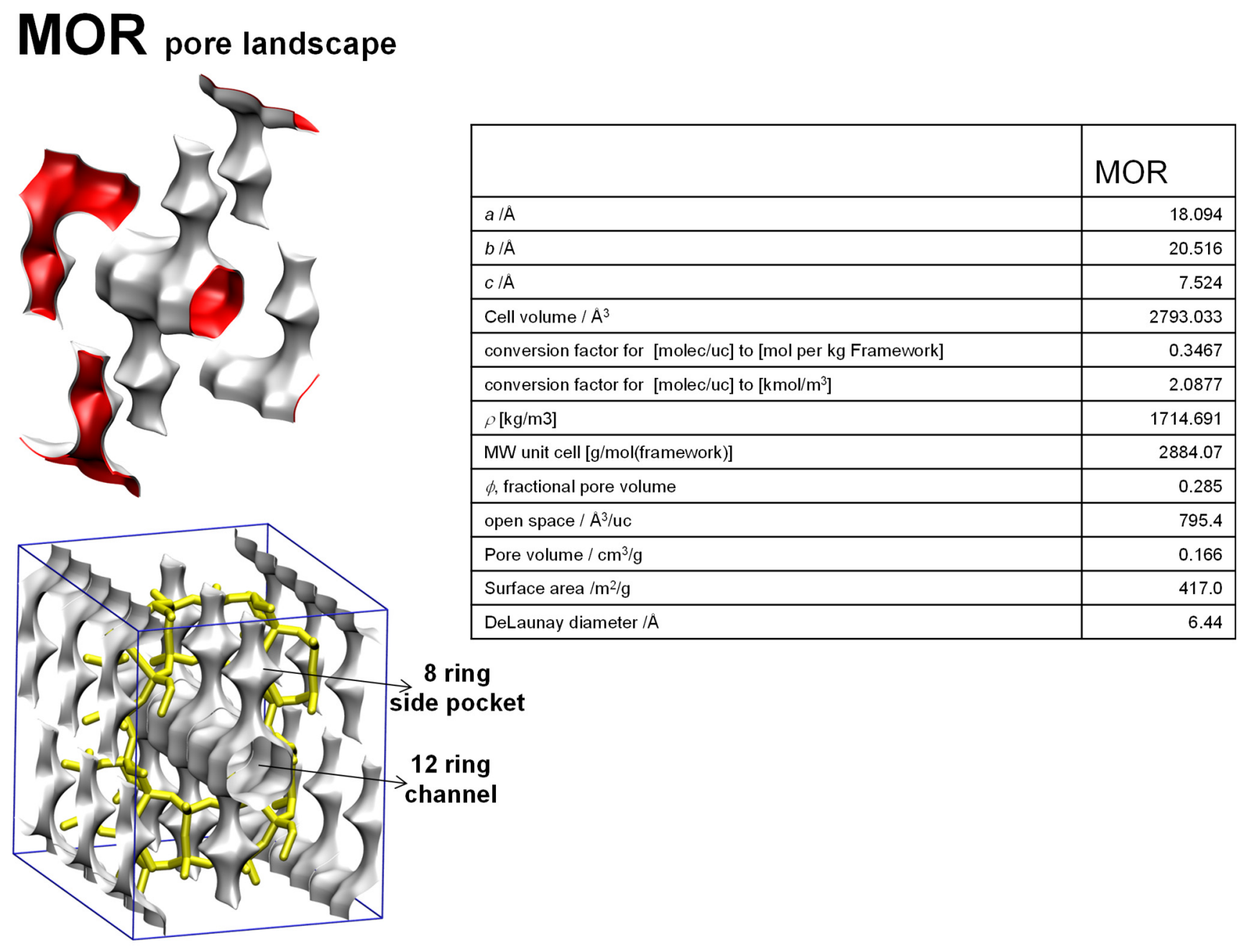

Figure S48. Pore landscape of all-silica MOR zeolite. 
MOR pore dimensions

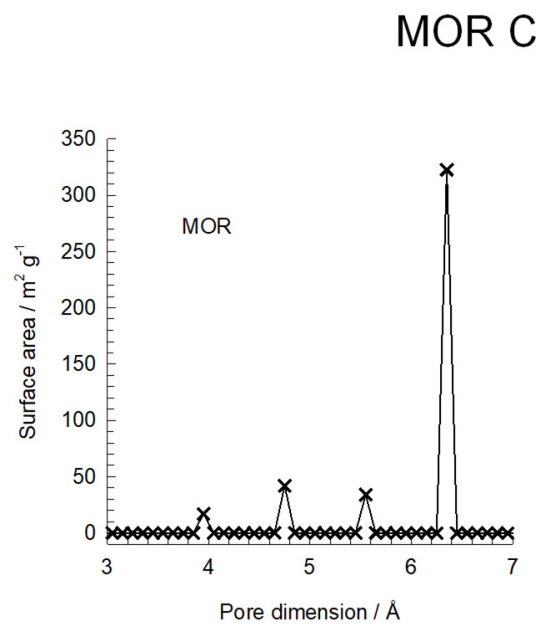

This plot of surface area versus pore dimension is determined using a combination of the DeLaunay triangulation method for pore dimension Düren for determination of the surface area.
8 ring side pocket
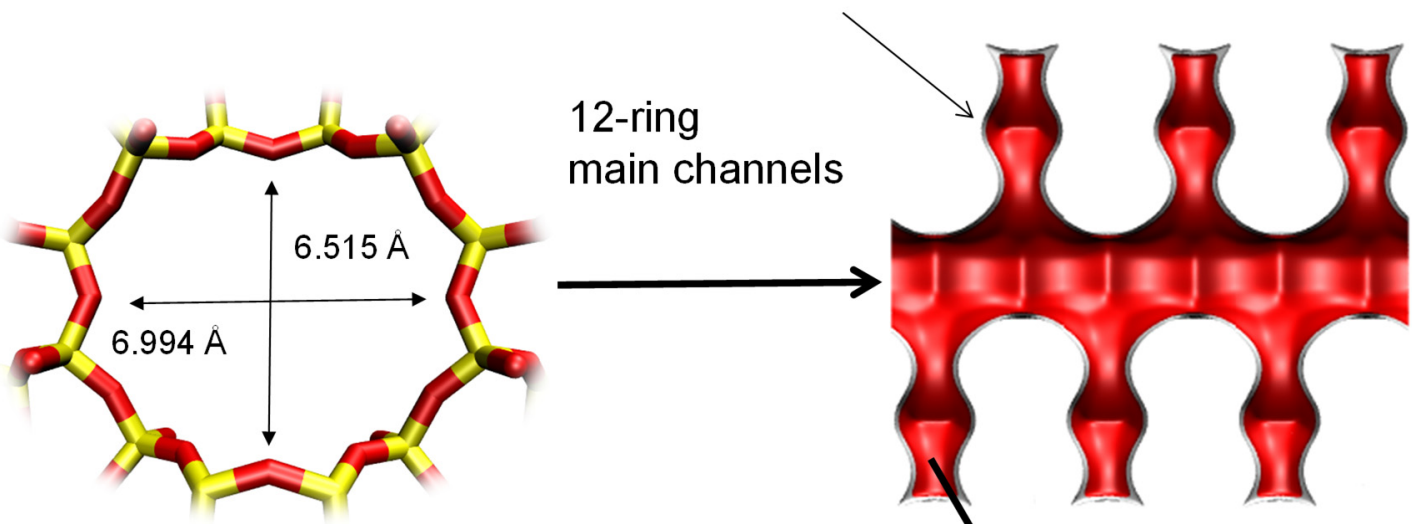

8 ring side pocket

I.

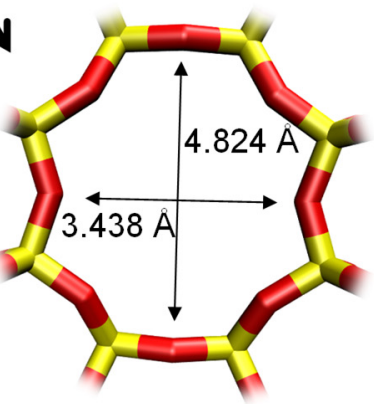

MOR [ $\left[\begin{array}{lll}0 & 1 & 0\end{array}\right]$

Figure S49. Structural details for MOR zeolite. 
(a) Snapshots of $\mathrm{CO}_{2} / \mathrm{CH}_{4}$ mixture adsorption

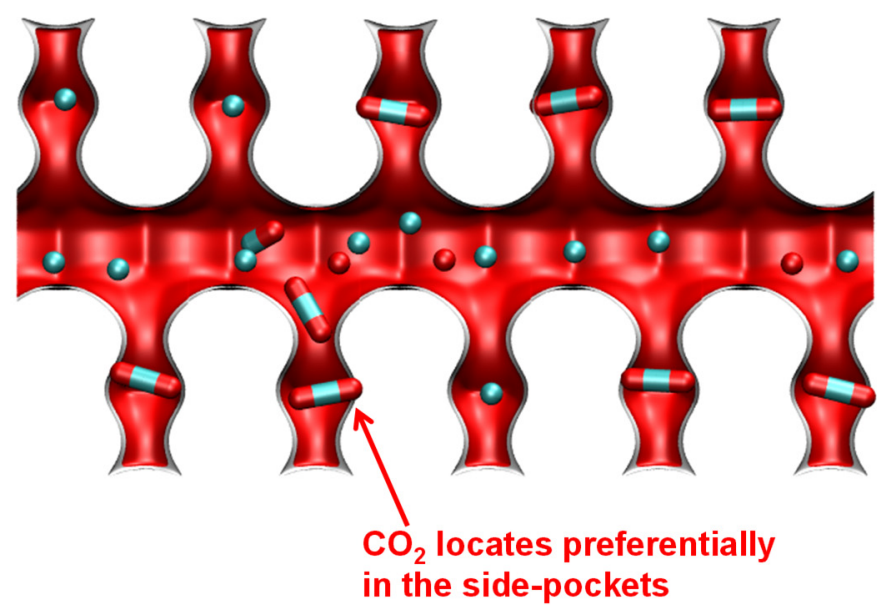

(b) RDF

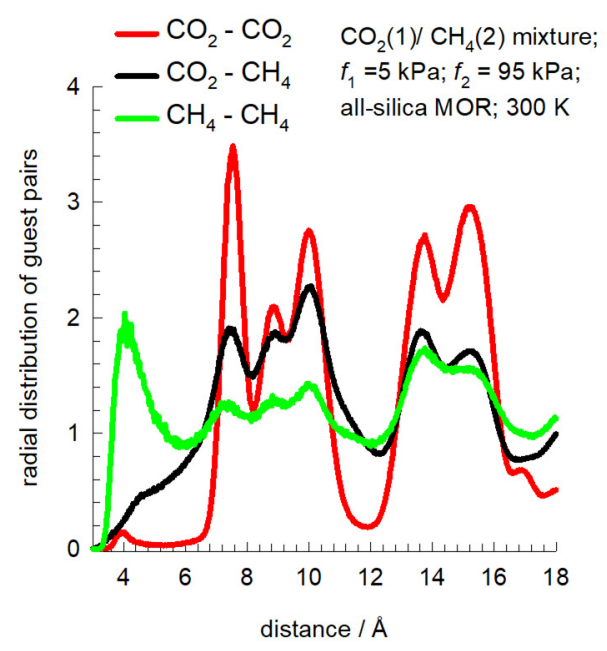

Figure S50. (a) Snapshots showing the location of guest molecules for $\mathrm{CO}_{2}(1) / \mathrm{CH}_{4}(2)$ mixture adsorption in MOR zeolite at $300 \mathrm{~K}$. (b) RDF for $\mathrm{CO}_{2}(1) / \mathrm{CH}_{4}(2)$ mixture adsorption in MOR zeolite at $300 \mathrm{~K}$ 

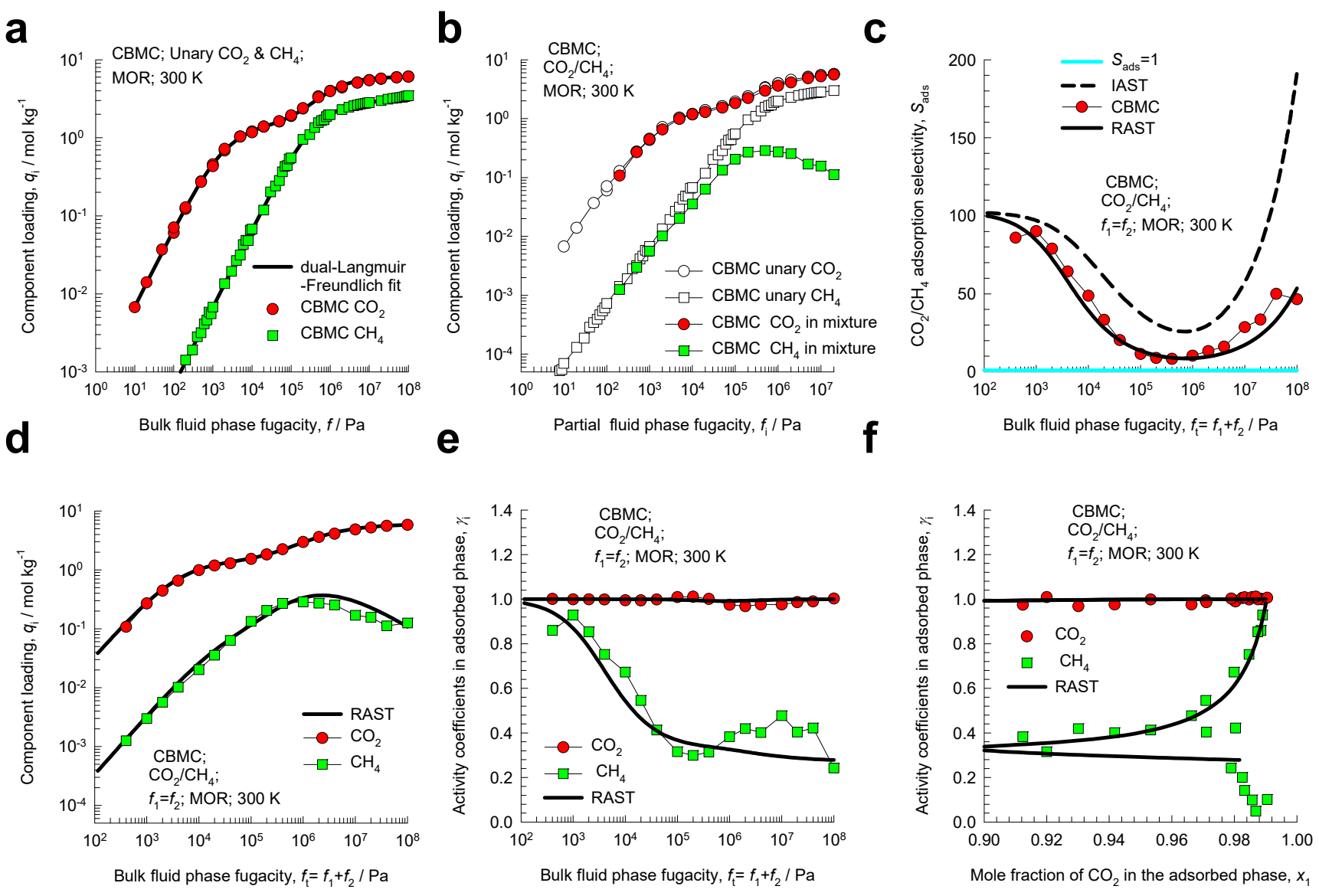

Figure S51. CBMC simulation data and analysis for Campaign A $\left(y_{1}=0.5\right)$ for $\mathrm{CO}_{2}(1) / \mathrm{CH}_{4}(2)$ mixture adsorption in MOR zeolite at $300 \mathrm{~K}$. (a) Unary isotherms and fits. (b) Component loadings in mixture compared with CBMC simulations of unary isotherms. (c) $\mathrm{CBMC}$ data for $\mathrm{CO}_{2}(1) / \mathrm{CH}_{4}(2)$ adsorption selectivity compared with IAST and RAST estimates. (d) CBMC data for component loadings in mixture compared with RAST estimates. (e, f) Activity coefficients from CBMC compared with RAST model calculations. The unary isotherm fit parameters and Margules parameters are provided in Table S12. 


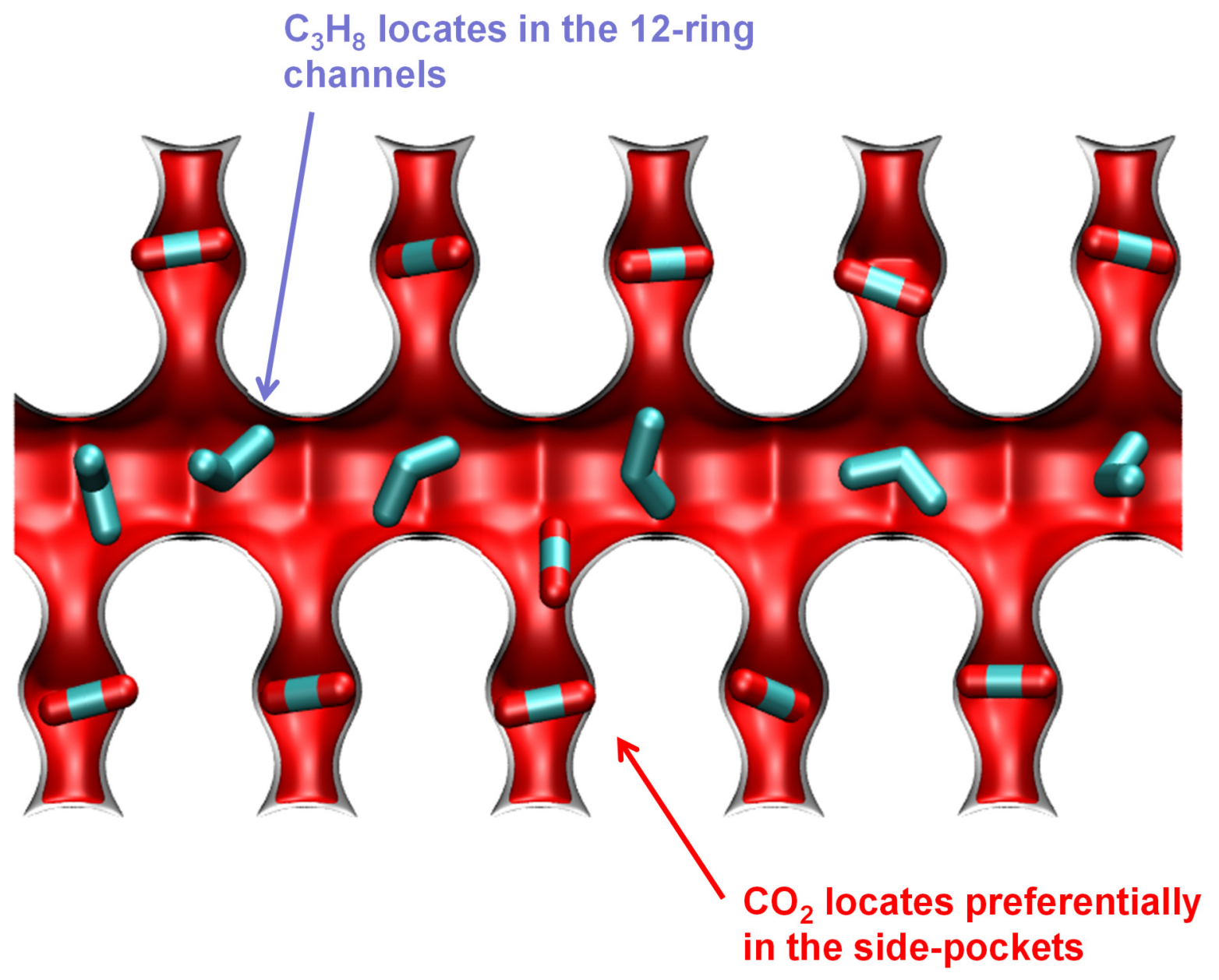

Figure S52. Snapshots showing the location of guest molecules for $\mathrm{CO}_{2}(1) / \mathrm{C}_{3} \mathrm{H}_{8}(2)$ mixture adsorption in MOR zeolite at $300 \mathrm{~K}$. 

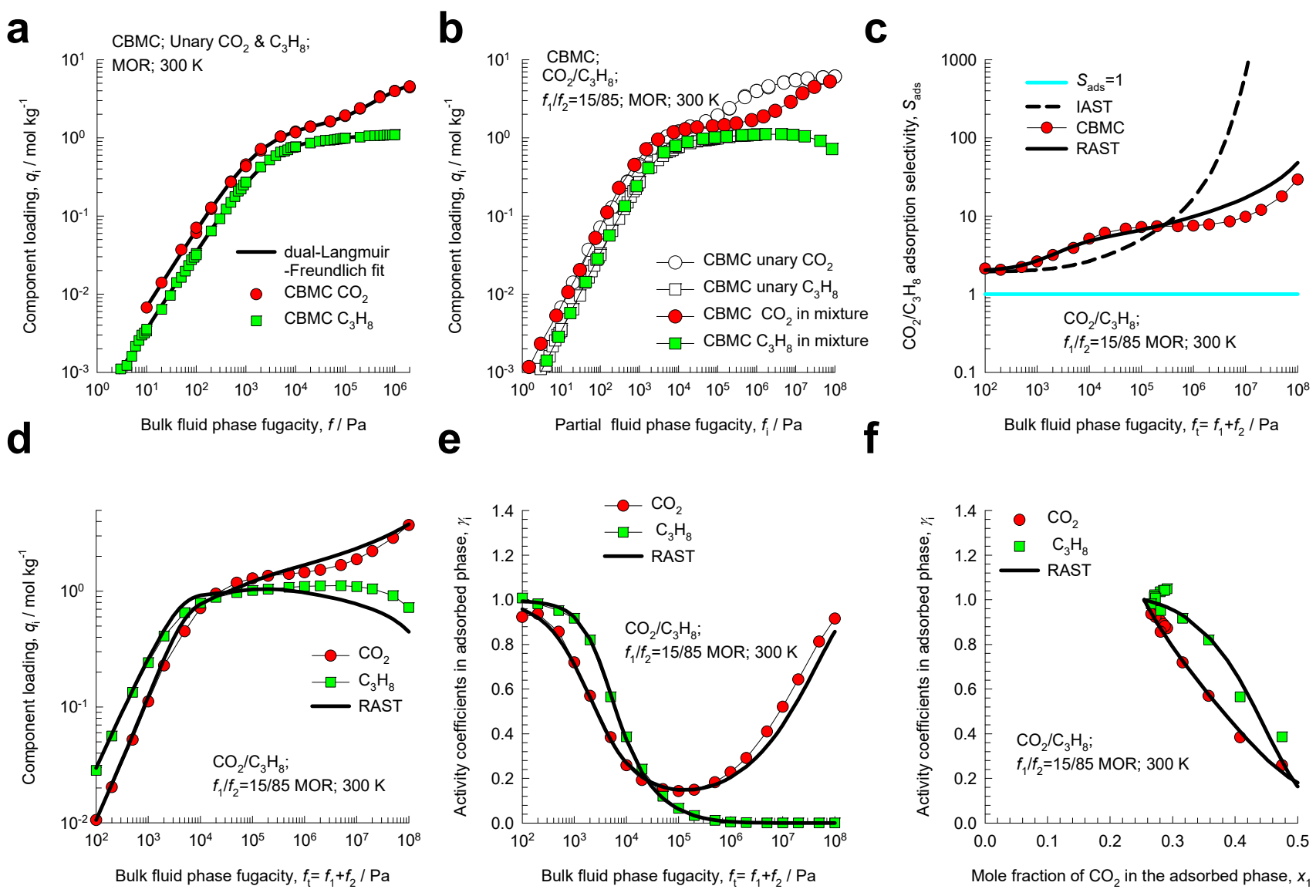

Figure S53. CBMC simulation data and analysis for Campaign $\mathrm{A}\left(y_{1}=0.15\right)$ for $\mathrm{CO}_{2}(1) / \mathrm{C}_{3} \mathrm{H}_{8}(2)$ mixture adsorption in MOR zeolite at $300 \mathrm{~K}$. (a) Unary isotherms and fits. (b) Component loadings in mixture compared with CBMC simulations of unary isotherms. (c) $\mathrm{CBMC}$ data for $\mathrm{CO}_{2}(1) / \mathrm{C}_{3} \mathrm{H}_{8}(2)$ adsorption selectivity compared with IAST and RAST estimates. (d) CBMC data for component loadings in mixture compared with RAST estimates. (e, f) Activity coefficients from CBMC compared with RAST model calculations. The unary isotherm fit parameters and Margules parameters are provided in Table S12. 
a

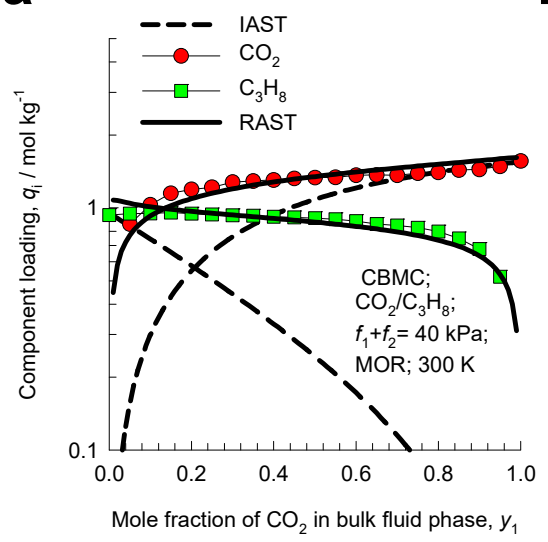

b

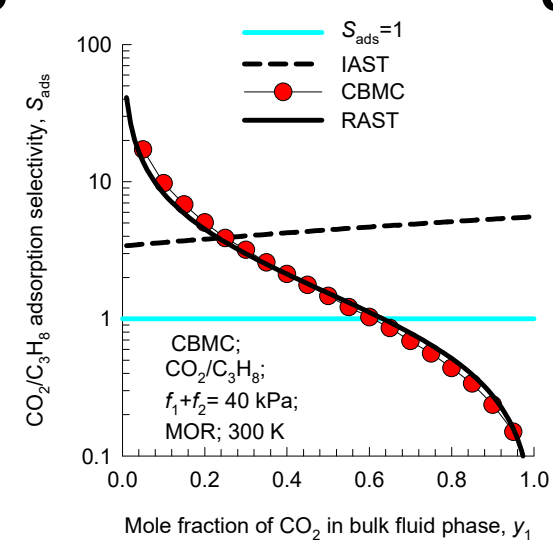

C

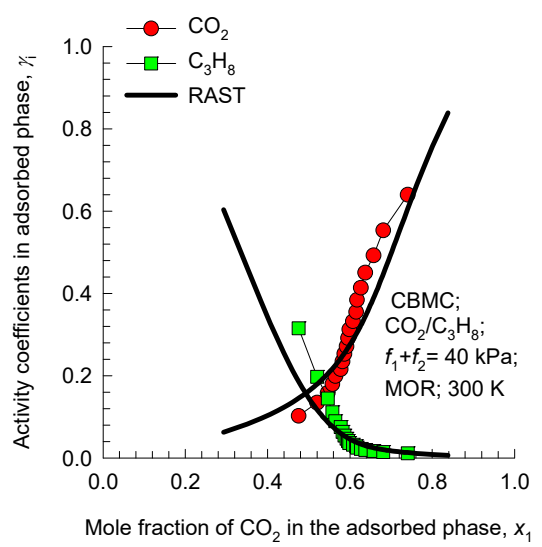

Figure S54. CBMC simulation data and analysis for Campaign B $\left(f_{t}=40 \mathrm{kPa}\right)$ for $\mathrm{CO}_{2}(1) / \mathrm{C}_{3} \mathrm{H}_{8}(2)$ mixture adsorption in MOR zeolite at $300 \mathrm{~K}$. CBMC data for (a) component loadings and (b) $\mathrm{CO}_{2}(1) /$ $\mathrm{C}_{3} \mathrm{H}_{8}(2)$ adsorption selectivity compared with IAST and RAST estimates. (c) Activity coefficients from CBMC compared with RAST model calculations. The unary isotherm fit parameters and Margules parameters are provided in Table S12. 


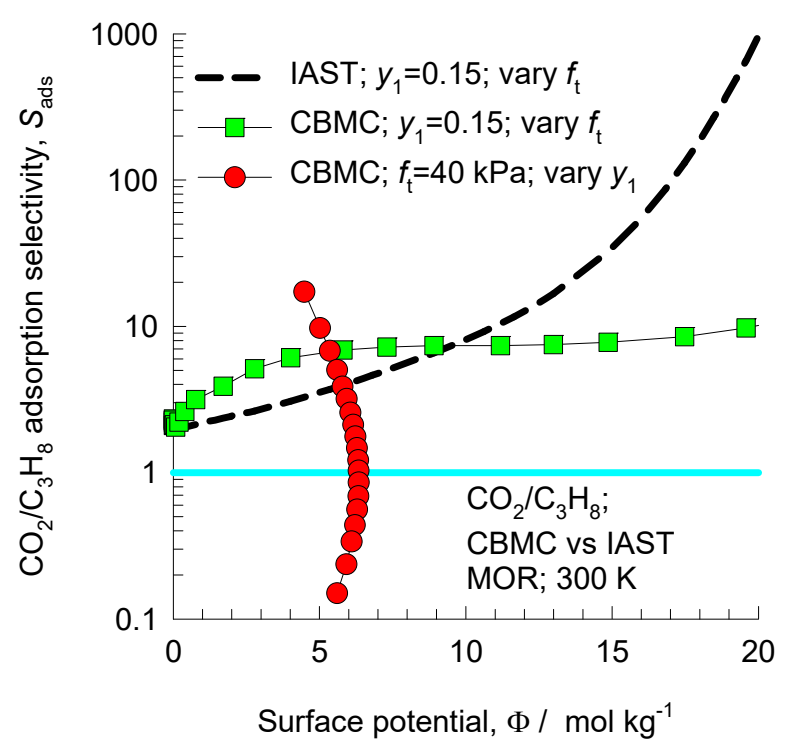

Figure S55. Adsorption selectivity $S_{a d s}$ for $\mathrm{CO}_{2}(1) / \mathrm{C}_{3} \mathrm{H}_{8}(2)$ mixture adsorption in MOR zeolite at 300 $\mathrm{K}$ for two different campaigns (Campaign A $\left(y_{1}=0.5\right)$ and Campaign $\mathrm{B}\left(f_{\mathrm{t}}=40 \mathrm{kPa}\right)$, plotted as function of the surface potential $\Phi$. The CBMC simulated values (indicated by symbols) are compared with IAST estimates (indicated by the dashed lines). The unary isotherm fit parameters and Margules parameters are provided in Table S12. 


\section{$13 \mathrm{CO}_{2} / \mathrm{CH}_{4}$ adsorption in $\mathrm{AFX}$ and $\mathrm{JBW}$ zeolites}

The pore landscapes and structural details of AFX zeolite are presented in Figure S56, and Figure S57. In one unit cell of AFX there are four $490 \AA^{3}$ size cages, connected to four small pockets each of $98 \AA^{3}$. The 8-ring windows separating two cages are $3.44 \AA \times 3.88 \AA$ in size. Guests such as $\mathrm{CH}_{4}, \mathrm{~N}_{2}$, or $\mathrm{H}_{2}$ do not prefer to locate at the window regions, and are preferentially located within the cages. The window regions and the small pockets are preferred locations for $\mathrm{CO}_{2} ;{ }^{11,59,63,64}$ the pockets can be viewed as providing an "egg-carton" structure. Figure S58a shows snapshots for adsorption of binary mixture of $\mathrm{CO}_{2}$ and $\mathrm{CH}_{4}$. Since there are 12 windows per unit cell of AFX, the adsorption selectivity for $\mathrm{CO}_{2}$ is exceptionally high. Due to the slow diffusion of $\mathrm{CO}_{2}$ it is likely that that the $\mathrm{CO}_{2}$ ensconced in the pockets are practically stagnant, and the high selectivities predicted by CBMC simulations may not be realizable in practice. The RDF data in Figure S58b confirms that the distance between $\mathrm{CO}_{2}$ and $\mathrm{CH}_{4}$ pairs is larger than for the $\mathrm{CH}_{4}$ and $\mathrm{CH}_{4}$ pairs.

Figure S59 presents CBMC simulation data for adsorption of equimolar (partial fugacities $f_{1}=f_{2}$ ) $\mathrm{CO}_{2} / \mathrm{CH}_{4}$ mixtures in AFX zeolite at $300 \mathrm{~K}$. The conventional IAST calculation assumes that $\mathrm{CH}_{4}$ molecules compete with all of the $\mathrm{CO}_{2}$, making no allowance for segregation. Due to segregation effects the competition faced by $\mathrm{CH}_{4}$ molecules within the cages, where they almost exclusively reside, is smaller than that in the entire pore space. The IAST anticipates a stiffer competition between $\mathrm{CO}_{2}$ and $\mathrm{CH}_{4}$ as it assumes a uniform distribution of composition; consequently, the adsorption selectivity is overestimated. The estimations of the RAST with fitted Wilson parameters, are shown by the continuous solid lines.

JBW has one-dimensional 8-ring channel structures of about $3.7 \AA$ size; see structural details and pore landscapes in Figure S60, and Figure S61. Interestingly, JBW has the low values of pore volume and surface area. The channel topologies are such that $\mathrm{CO}_{2}$ can nestle nicely in each channel segment; see computational snapshots in Figure S62. The curvature and size of the channels are energetically optimum for location of $\mathrm{CO}_{2}$ molecules. $\mathrm{CH}_{4}$ molecules are too severely constrained in the channel segments and can only occupy the more spacious vertex regions. Due to the segregated nature of the adsorption of $\mathrm{CO}_{2}$ 
and $\mathrm{CH}_{4}$ molecules, the competition endured by $\mathrm{CH}_{4}$ molecules is less severe than anticipated on the basis of the IAST prescription.

Figure S63 presents CBMC simulation data for adsorption of equimolar (partial fugacities $f_{1}=f_{2}$ ) $\mathrm{CO}_{2} / \mathrm{CH}_{4}$ mixtures in JBW zeolite at $300 \mathrm{~K}$. The conventional IAST calculation assumes that $\mathrm{CH}_{4}$ molecules compete with all of the $\mathrm{CO}_{2}$, making no allowance for segregation. Due to segregation effects the competition faced by $\mathrm{CH}_{4}$ molecules that locates preferentially at the vertices is reduced. The IAST anticipates a stiffer competition between $\mathrm{CO}_{2}$ and $\mathrm{CH}_{4}$ as it assumes a uniform distribution of composition; consequently, the adsorption selectivity is overestimated.

Figure S64 compares the $\mathrm{CO}_{2} / \mathrm{CH}_{4}$ mixture adsorption selectivity for MOR, JBW, and AFX zeolites. In all cases, the IAST tends to overestimate the selectivities due to segregated nature of adsorption. 


\subsection{List of Tables for CO2/CH4 adsorption in AFX and JBW zeolites}

Table S13. Dual-site Langmuir-Freundlich parameters for guest molecules in AFX (all-silica) at $300 \mathrm{~K}$.

\begin{tabular}{|c|c|c|c|c|c|c|}
\hline & \multicolumn{3}{|l|}{ Site A } & \multicolumn{3}{|l|}{ Site B } \\
\hline & $\begin{array}{l}q_{\mathrm{A}, \text { sat }} \\
\text { mol kg-1 }\end{array}$ & $\begin{array}{l}b_{\mathrm{A}} \\
\mathrm{Pa}^{-v A}\end{array}$ & $\begin{array}{l}v_{\mathrm{A}} \\
\text { dimensionless }\end{array}$ & $\begin{array}{l}q_{\mathrm{B}, \mathrm{sat}} \\
\mathrm{mol} \mathrm{kg}{ }^{-1}\end{array}$ & $\begin{array}{l}b_{\mathrm{B}} \\
\mathrm{Pa}^{-v B}\end{array}$ & $\begin{array}{l}\nu_{\mathrm{B}} \\
\text { dimensionless }\end{array}$ \\
\hline $\mathrm{CO}_{2}$ & 3 & $1.070 \mathrm{E}-05$ & 0.78 & 6.4 & 7.954E-05 & 0.92 \\
\hline $\mathrm{CH}_{4}$ & 2.9 & $1.761 \mathrm{E}-08$ & 1 & 3.1 & $1.235 \mathrm{E}-06$ & 1 \\
\hline
\end{tabular}

Fitted Wilson non-ideality parameters for binary $\mathrm{CO}_{2} / \mathrm{CH}_{4}$ mixture adsorption in AFX at $300 \mathrm{~K}$.

\begin{tabular}{|l|l|l|l|}
\hline & $C / \mathrm{kg} \mathrm{mol}^{-1}$ & $\Lambda_{12}$ & $\Lambda_{21}$ \\
\hline $\mathrm{CO}_{2} / \mathrm{CH}_{4}$ & 0.18 & 3.05 & 0.33 \\
\hline
\end{tabular}


Table S14. Langmuir parameters for guest molecules in JBW (all-silica) at $300 \mathrm{~K}$.

\begin{tabular}{|c|c|c|c|}
\hline & \multicolumn{3}{|l|}{ Site A } \\
\hline & $\begin{array}{l}q_{\mathrm{A}, \mathrm{sat}} \\
\mathrm{mol} \mathrm{kg}{ }^{-1}\end{array}$ & $\begin{array}{l}b_{\mathrm{A}} \\
\mathrm{Pa}^{-v A}\end{array}$ & $\begin{array}{l}v_{\mathrm{A}} \\
\text { dimensionless }\end{array}$ \\
\hline $\mathrm{CO}_{2}$ & 2.8 & 6.937E-05 & 1 \\
\hline $\mathrm{CH}_{4}$ & 2.6 & $1.2 \mathrm{E}-07$ & 1 \\
\hline
\end{tabular}




\subsection{List of Figures for $\mathrm{CO} 2 / \mathrm{CH} 4$ adsorption in $\mathrm{AFX}$ and JBW zeolites}

\section{AFX pore landscape}

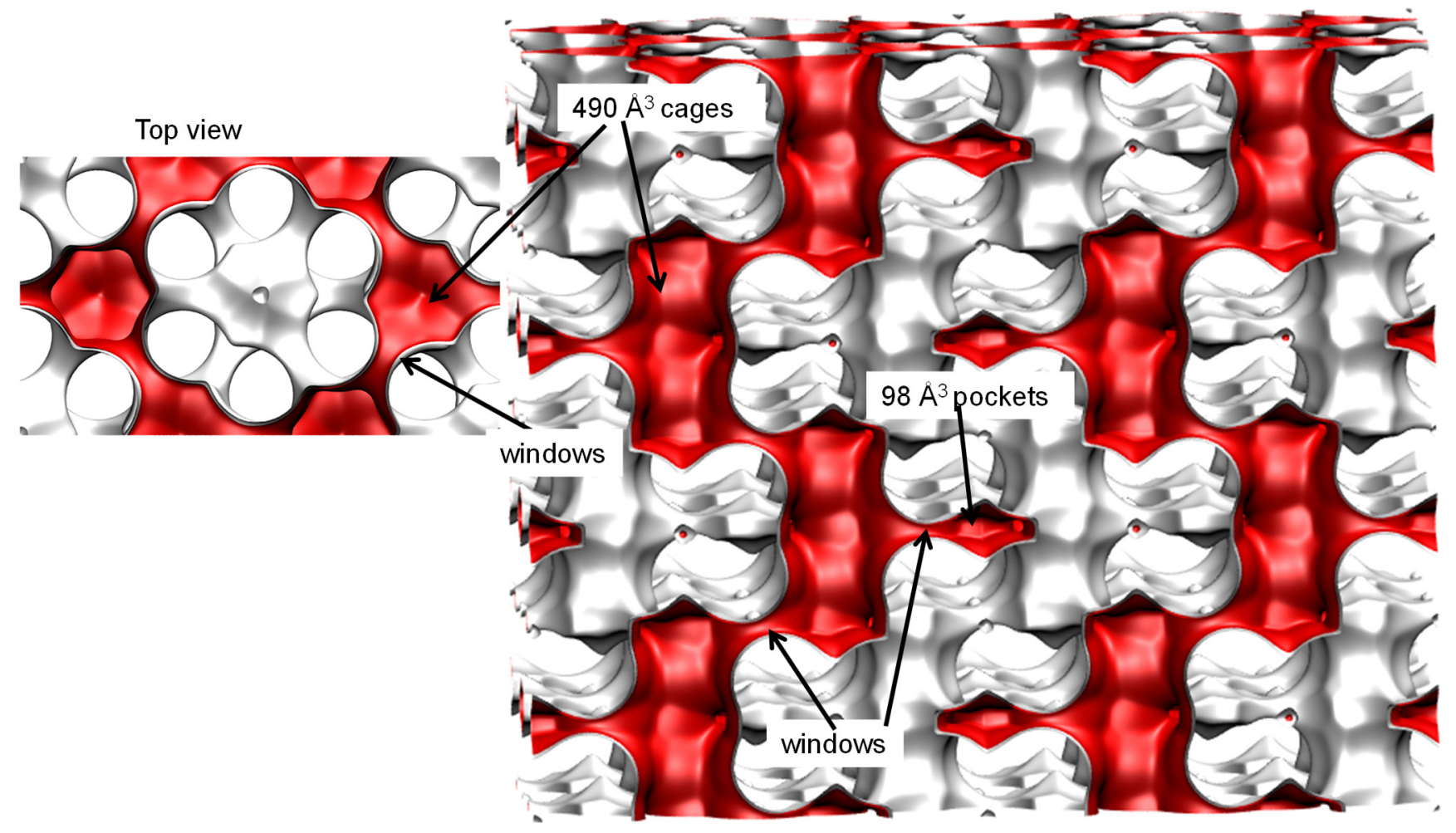

Structural information from: C. Baerlocher, L.B. McCusker, Database of Zeolite Structures, International Zeolite Association, http://www.iza-structure.org/databases/

Figure S56. Pore landscape of all-silica AFX zeolite. 


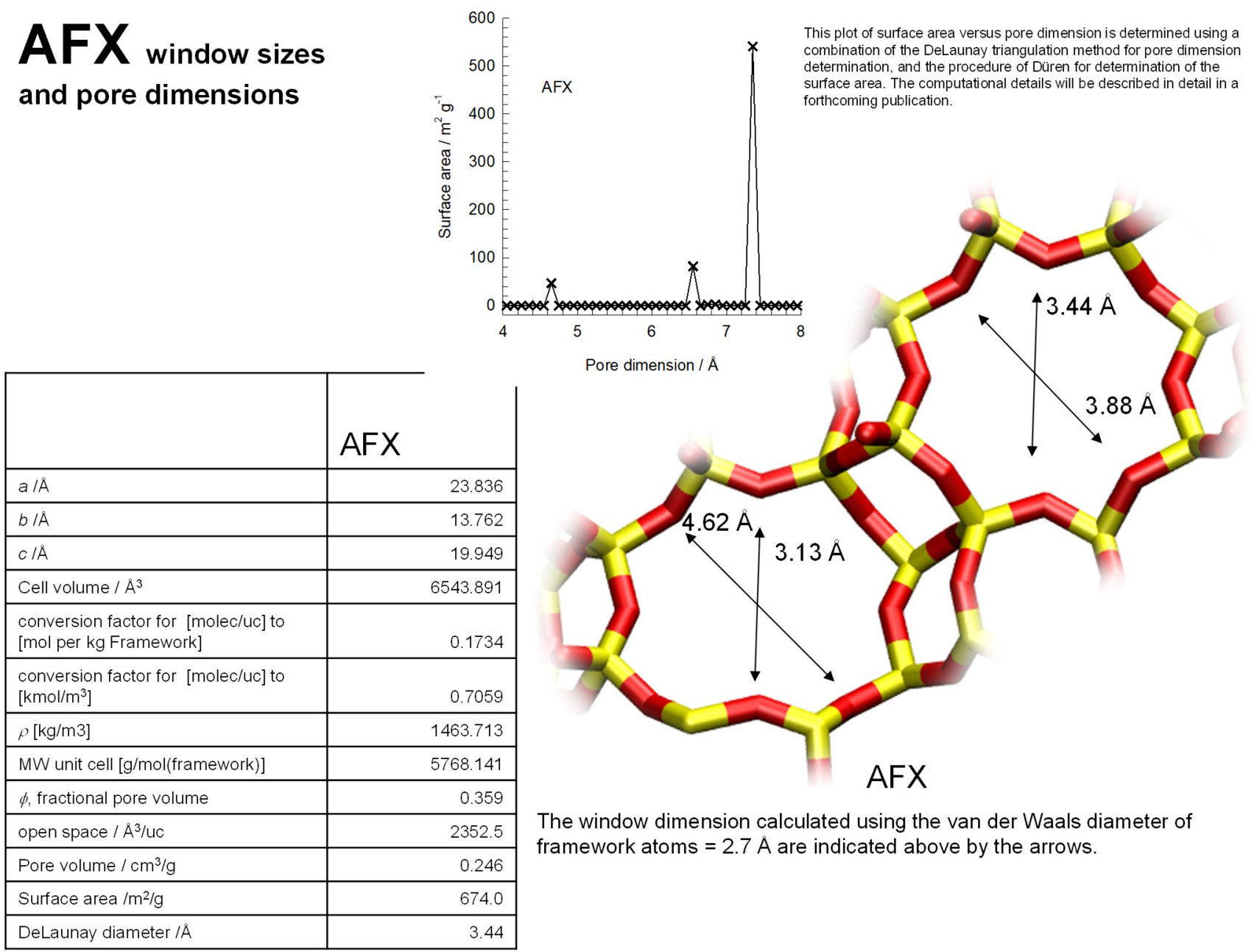

Figure S57. Structural details for AFX zeolite. 


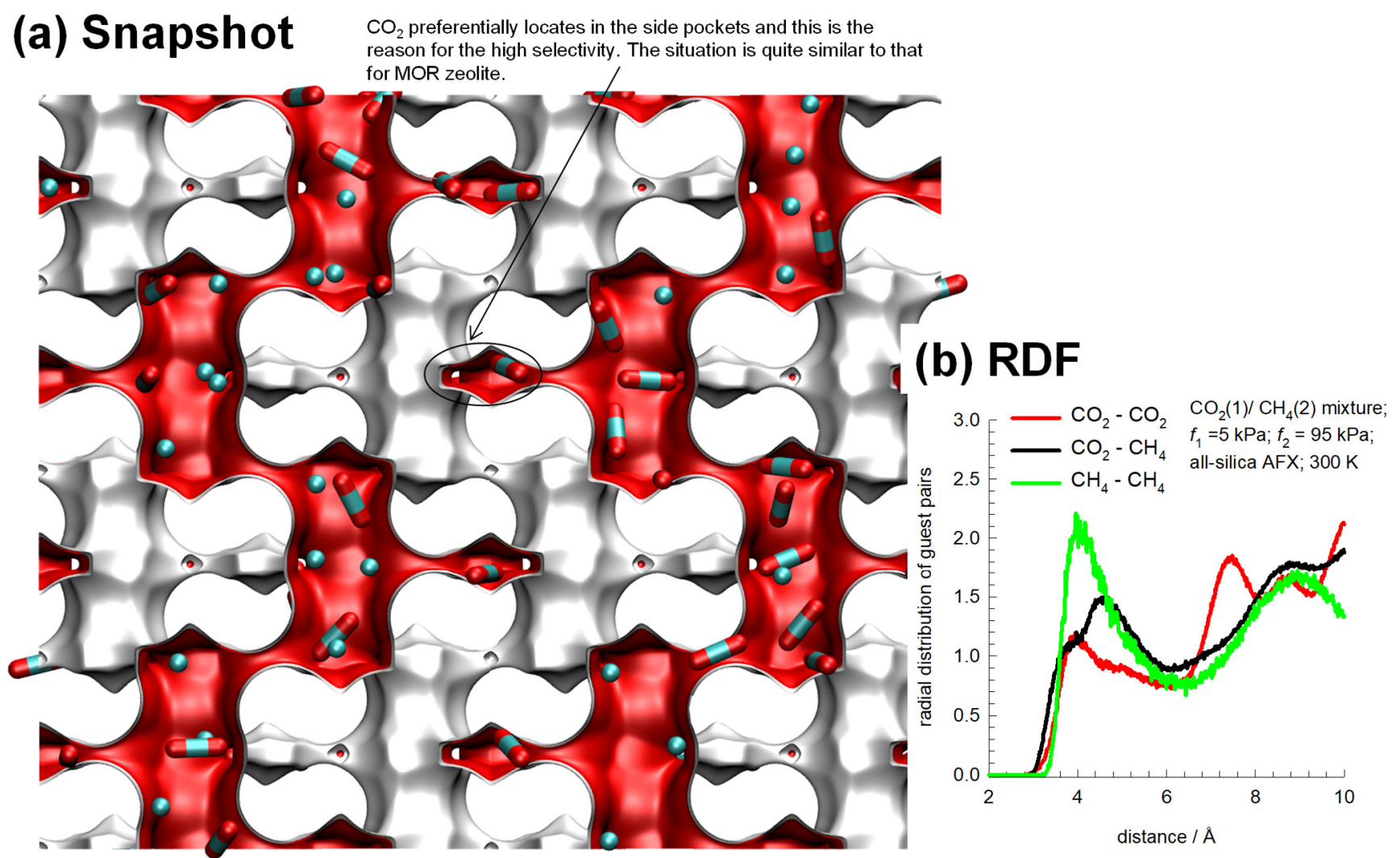

Figure S58. (a) Snapshots showing the location of guest molecules for $\mathrm{CO}_{2}(1) / \mathrm{CH}_{4}(2)$ mixture adsorption in AFX zeolite at $300 \mathrm{~K}$. (b) RDFs for $\mathrm{CO}_{2}(1) / \mathrm{CH}_{4}(2)$ mixture adsorption in AFX zeolite at $300 \mathrm{~K}$ 

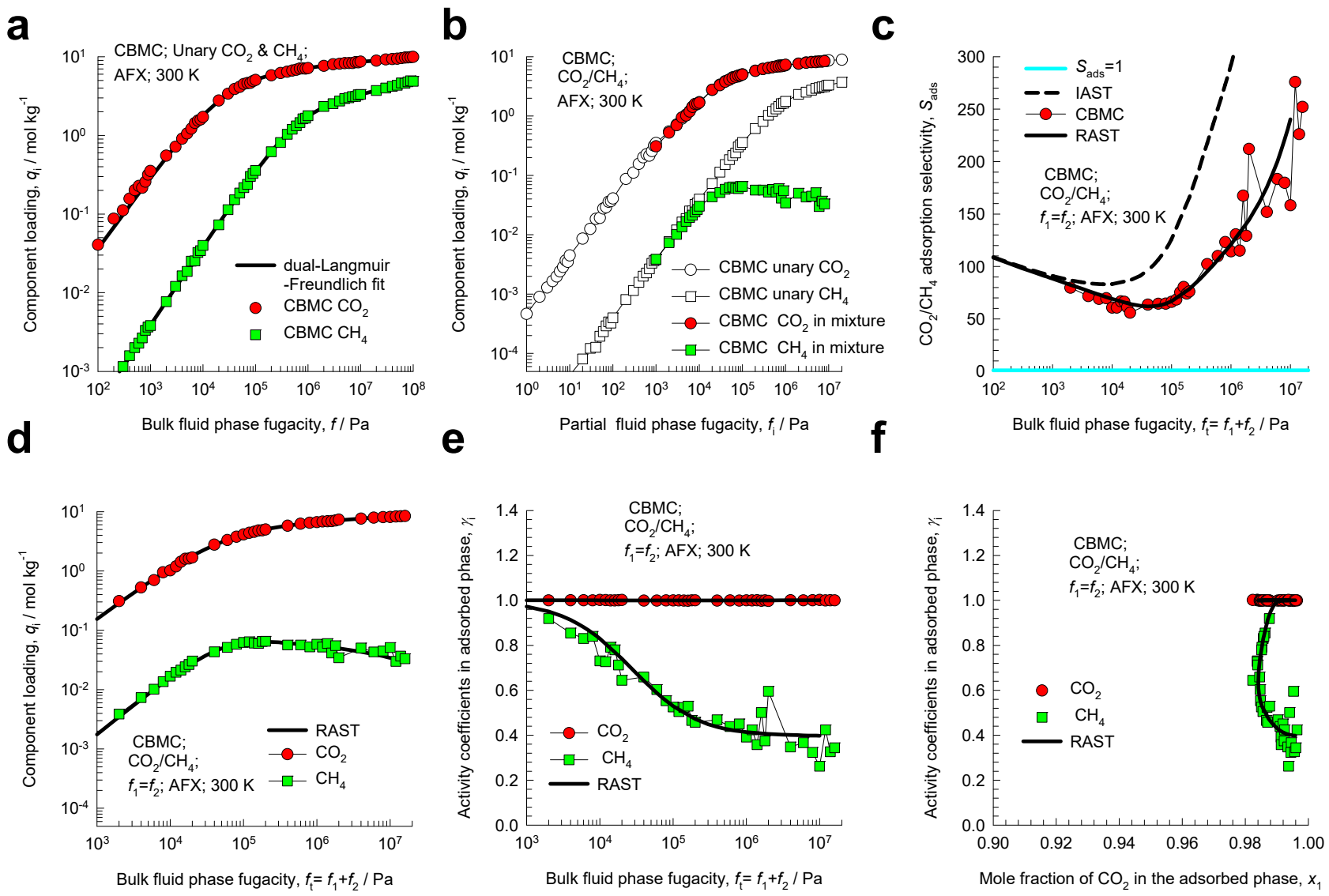

Figure S59. CBMC simulation data and analysis for Campaign A $\left(y_{1}=0.5\right)$ for $\mathrm{CO}_{2}(1) / \mathrm{CH}_{4}(2)$ mixture adsorption in AFX zeolite at $300 \mathrm{~K}$. (a) Unary isotherms and fits. (b) Component loadings in mixture compared with CBMC simulations of unary isotherms. (c) $\mathrm{CBMC}$ data for $\mathrm{CO}_{2}(1) / \mathrm{CH}_{4}(2)$ adsorption selectivity compared with IAST and RAST estimates. (d) CBMC data for component loadings in mixture compared with RAST estimates. (e, f) Activity coefficients from CBMC compared with RAST model calculations. The unary isotherm fit parameters and Wilson parameters are provided in Table S13. 
JBW landscapes
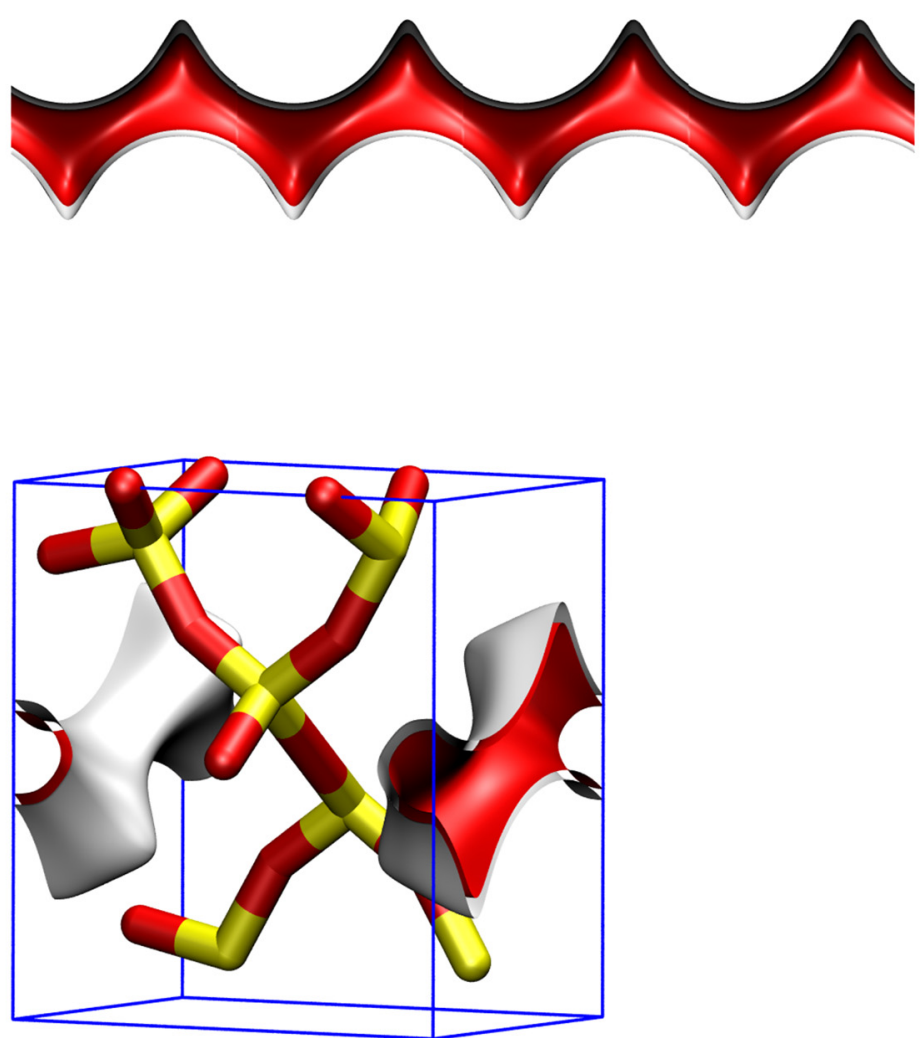
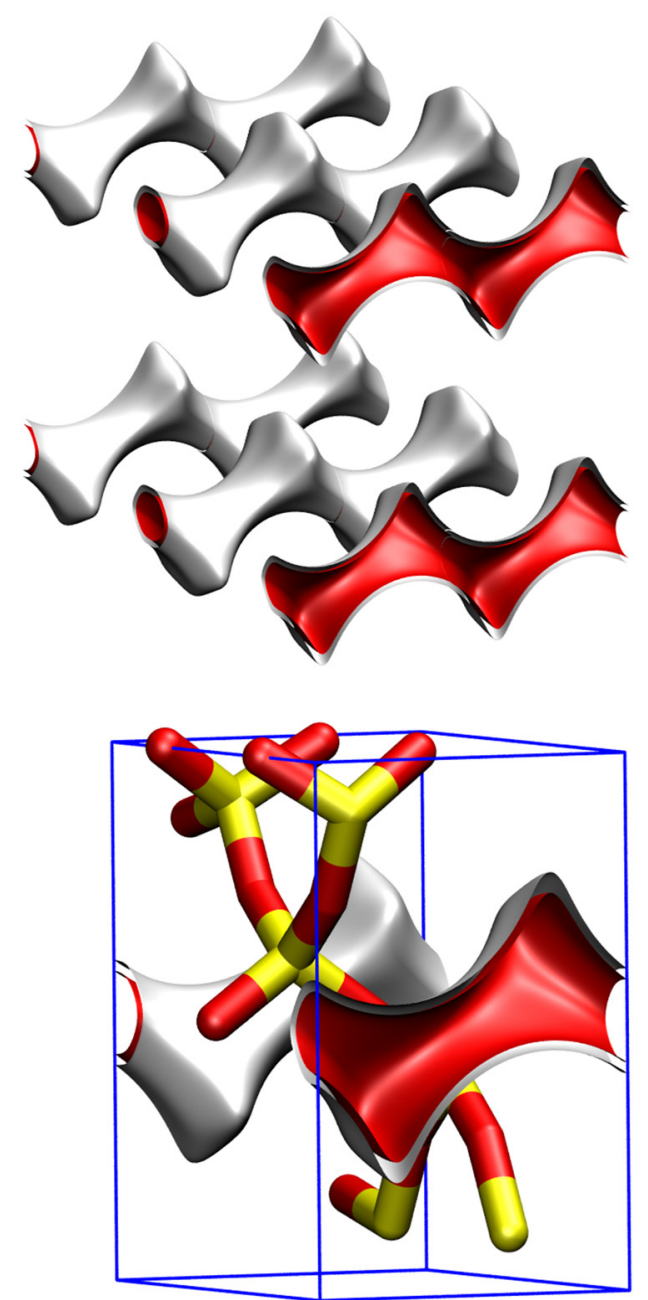

Figure S60. Pore landscape of all-silica JBW zeolite. 


\section{JBW pore dimensions}

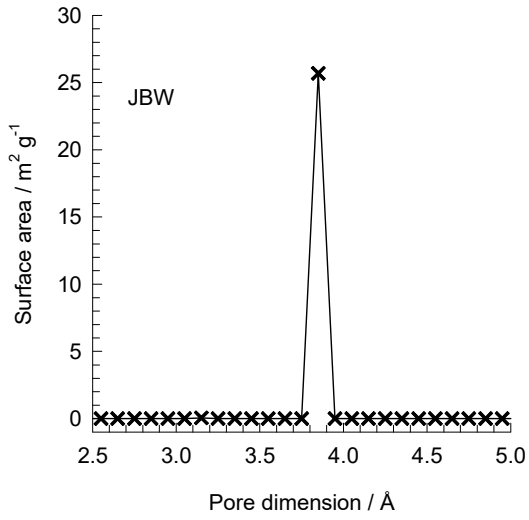

This plot of surface area versus pore dimension is determined using a combination of the DeLaunay triangulation method for pore dimension determination, and the procedure of Düren for determination of the surface area. The computational details will be described in detail in a forthcoming publication.

\begin{tabular}{|l|r|}
\hline & JBW \\
\hline$a / \AA$ & 5.256 \\
\hline$b / \AA$ & 7.45 \\
\hline$c / \AA$ & 8.159 \\
\hline Cell volume / ${ }^{3}$ & 319.4836 \\
\hline conversion factor for [molec/uc] to $[\mathrm{mol}$ per $\mathrm{kg}$ & 2.7739 \\
\hline Framework] & 32.2019 \\
\hline conversion factor for [molec/uc] to $\left[\mathrm{kmol} / \mathrm{m}^{3}\right]$ & 1873.8 \\
\hline$\rho[\mathrm{kg} / \mathrm{m} 3]$ & 360.5088 \\
\hline MW unit cell $[\mathrm{g} / \mathrm{mol}$ (framework)] & 0.161 \\
\hline$\phi$, fractional pore volume & 51.6 \\
\hline open space $/ \AA^{3} / \mathrm{uc}$ & 0.086 \\
\hline Pore volume $/ \mathrm{cm}^{3} / \mathrm{g}$ & 25.1 \\
\hline Surface area $/ \mathrm{m}^{2} / \mathrm{g}$ & 3.66 \\
\hline DeLaunay diameter $/ \AA$ &
\end{tabular}

Figure S61. Structural details for JBW zeolite. 


\section{JBW snapshots}

JBW has one-dimensional 8-ring channel structures of about 3.7

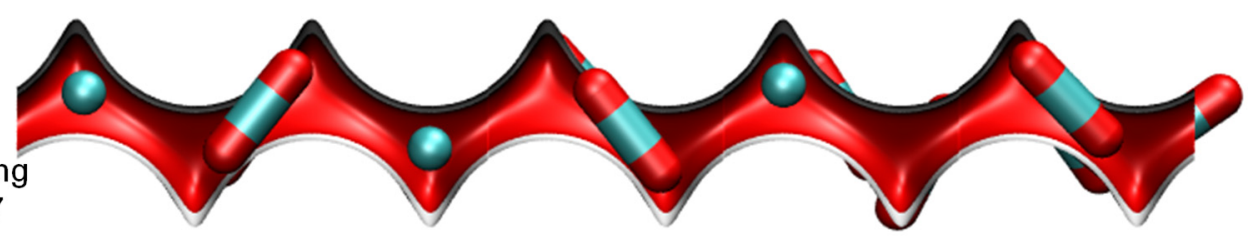
A size. The channel topologies are such that $\mathrm{CO}_{2}$ - $\tan$ nestle nicely in each channel segment. The curvature and size of the channels are energetically optimum for location of $\mathrm{CO}_{2}$ molecules. $\mathrm{CH}_{4}$ molecules are too severely constrainedin the channel segments and can onty occupy the more spacious vertex regions.

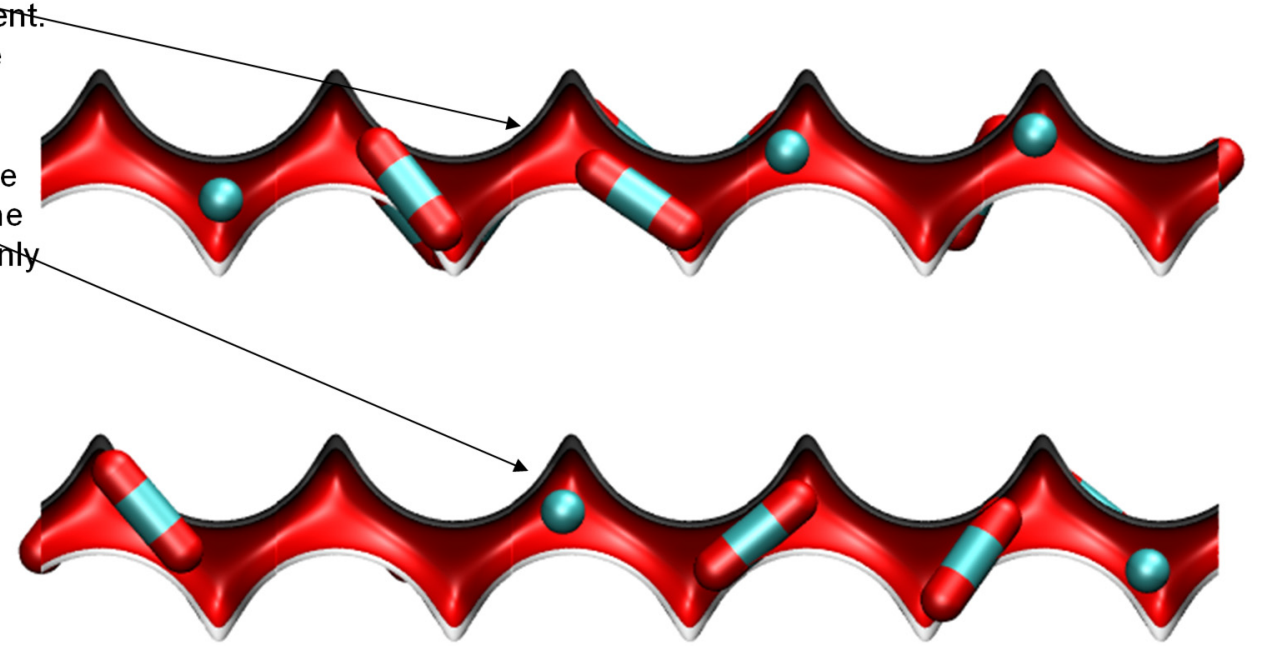

Figure S62. Snapshots showing the location of guest molecules for $\mathrm{CO}_{2}(1) / \mathrm{CH}_{4}(2)$ mixture adsorption in JBW zeolite at $300 \mathrm{~K}$. 
a

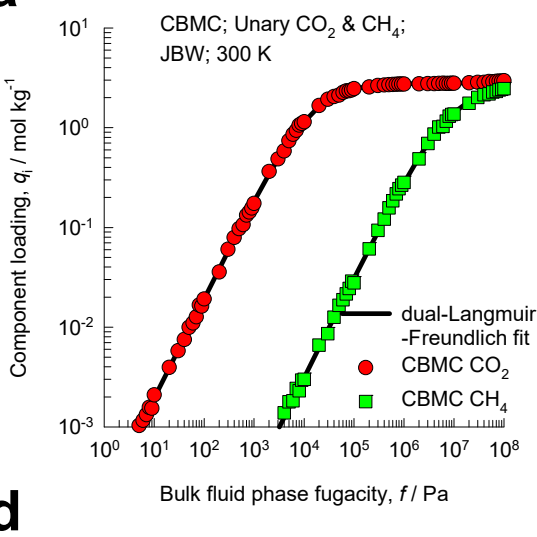
$\mathrm{CO}_{2} / \mathrm{CH}_{4}$

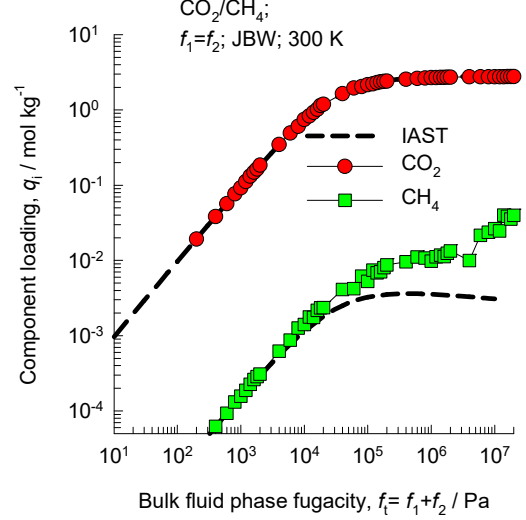

b
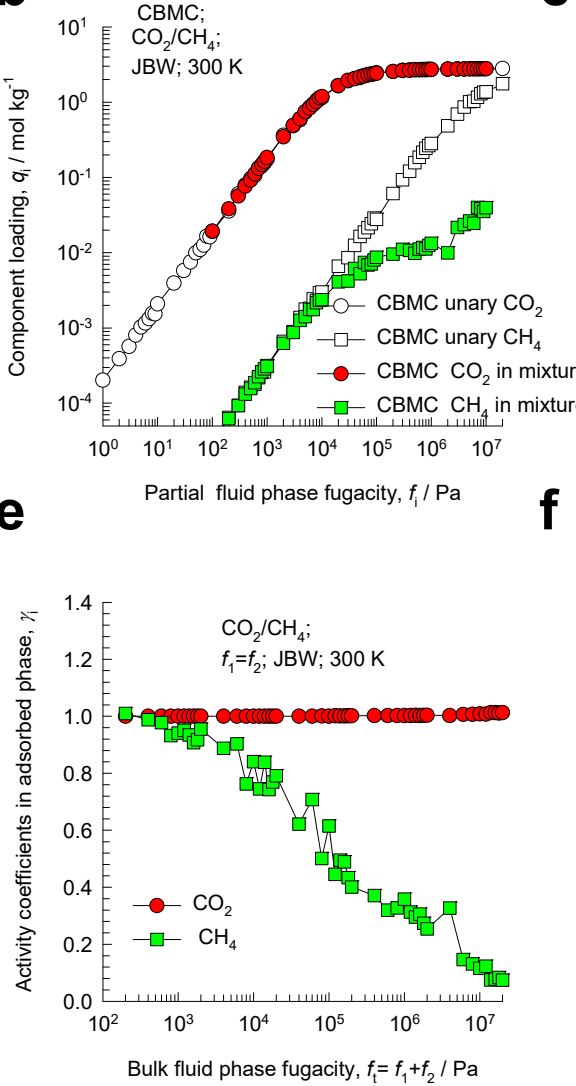

C
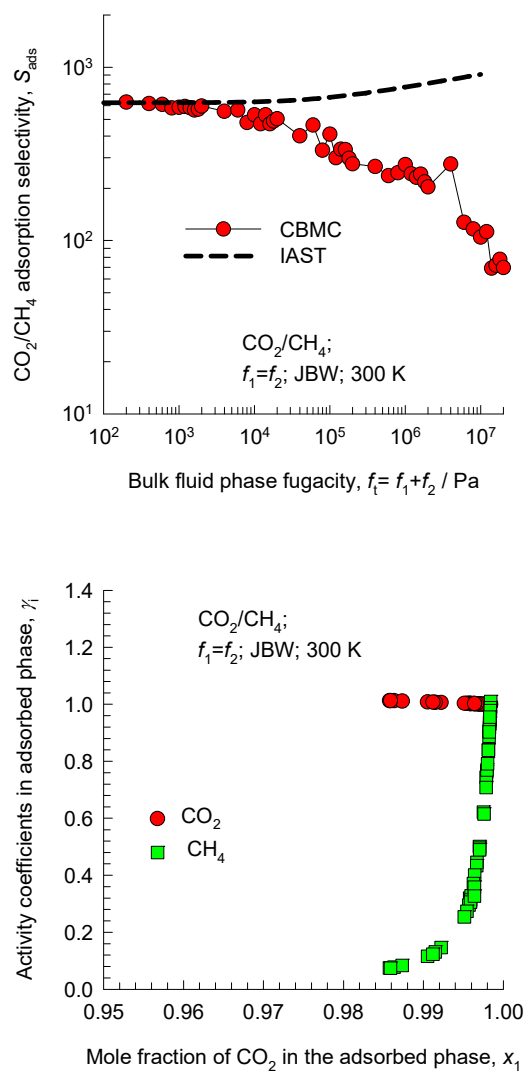

Figure S63. CBMC simulation data and analysis for Campaign A $\left(y_{1}=0.5\right)$ for $\mathrm{CO}_{2}(1) / \mathrm{CH}_{4}(2)$ mixture adsorption in JBW zeolite at $300 \mathrm{~K}$. (a) Unary isotherms and fits. (b) Component loadings in mixture compared with CBMC simulations of unary isotherms. (c) $\mathrm{CBMC}$ data for $\mathrm{CO}_{2}(1) / \mathrm{CH}_{4}(2)$ adsorption selectivity compared with IAST estimates. (d) CBMC data for component loadings in mixture compared with IAST estimates. (e, f) Activity coefficients from CBMC simulation data. The unary isotherm fit parameters in Table S14. 


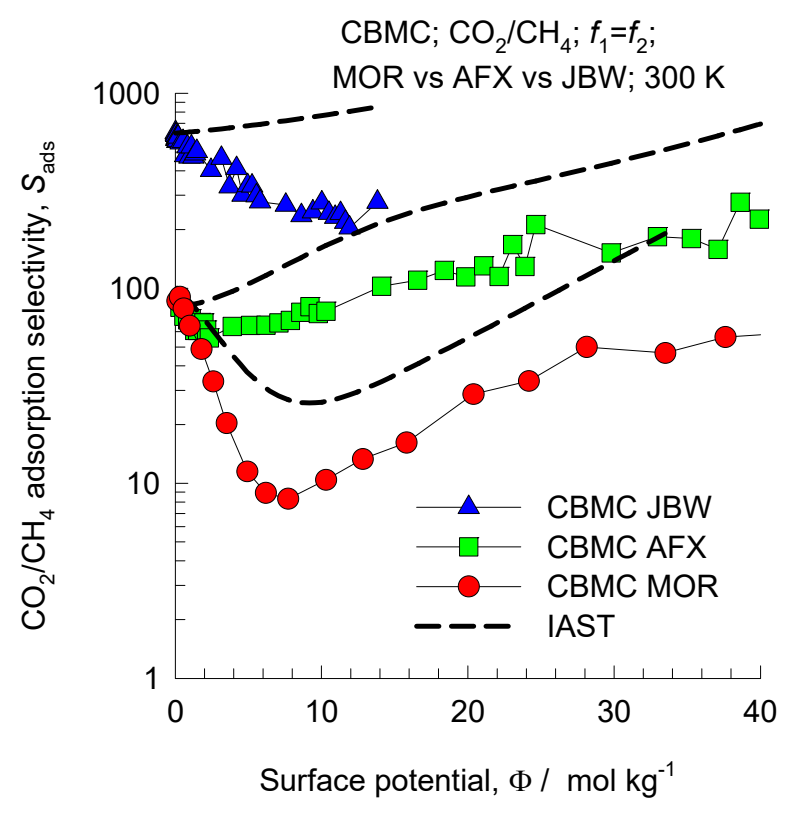

Figure S64. Adsorption selectivity $S_{a d s}$ for $\mathrm{CO}_{2}(1) / \mathrm{CH}_{4}(2)$ mixture adsorption in AFX, MOR, and JBW zeolites at $300 \mathrm{~K}$ for Campaign A $\left(y_{1}=0.5\right)$, plotted as function of the surface potential $\Phi$. The CBMC simulated values (indicated by symbols) are compared with IAST estimates (indicated by the dashed lines). 


\section{Mixture adsorption in LTA zeolite}

LTA (Linde Type A) all-silica zeolite consist of cages of $743 \AA^{3}$ volume, separated by $4.11 \AA \times 4.47 \AA$ 8-ring windows; the pore landscapes and structural details are provided in Figure S65, and Figure S66. Figure S67 presents the structural details of cation-exchanged LTA-4A; per unit cell LTA-4A has $96 \mathrm{Si}$, $96 \mathrm{Al}, 96 \mathrm{Na}^{+}, \mathrm{Si} / \mathrm{Al}=1$.

\section{1 $\mathrm{CO}_{2} / \mathrm{C}_{3} \mathrm{H}_{8}$ mixture adsorption in LTA-4A zeolite}

Two different campaigns were carried out for $\mathrm{CBMC}$ simulations of $\mathrm{CO}_{2}(1) / \mathrm{C}_{3} \mathrm{H}_{8}(2)$ mixture adsorption in LTA-4A zeolite at $300 \mathrm{~K}$. In Campaign A, the mole fraction of $\mathrm{CO}_{2}(1)$ in the bulk gas phase is held constant, $y_{1}=0.1$, and the bulk gas phase fugacity $f_{\mathrm{t}}=f_{1}+f_{2}$ was varied, and in Campaign $\mathrm{B}$, the mole fraction of $\mathrm{CO}_{2}(1)$ in the bulk gas phase, $y_{1}$ was varied from 0 to 1 , keeping the bulk gas phase mixture fugacity $f_{\mathrm{t}}=f_{1}+f_{2}$ constant at a value of $1 \mathrm{MPa}$. The results of these two separate campaigns are presented, respectively, in Figure S68, and Figure S69.

The CBMC data in Figure S68 for Campaign A show that for $f_{t}=f_{1}+f_{2}<10^{6} \mathrm{~Pa}$, the selectivity $S_{\text {ads }}$ is in favor of $\mathrm{C}_{3} \mathrm{H}_{8}$; with increasing values of the bulk gas phase fugacity $f_{t}=f_{1}+f_{2}>10^{6}$, the adsorption selectivity $S_{a d s}$ becomes increasingly in favor of $\mathrm{CO}_{2}$, due to strong Coulombic interactions with the extra-framework cations $\mathrm{Na}^{+}$; see Figure S68c. The IAST does not anticipate this selectivity reversal in favor of $\mathrm{CO}_{2}$.

The CBMC simulations can be matched by quantification of thermodynamic non-idealities using the Margules parameters as specified in Table S15. Figure S68e,f show the RAST calculations of the activity coefficients.

The CBMC simulations for $\mathrm{CO}_{2}(1) / \mathrm{C}_{3} \mathrm{H}_{8}(2)$ mixture adsorption at $f_{\mathrm{t}}=1 \mathrm{MPa}$, and varying mole fractions of $\mathrm{CO}_{2}(1)$ in the bulk gas phase, $y_{1}$, are shown in Figure S69. For $y_{1}<0.1, S_{a d s}>1$, and the 
selectivity is in favor of $\mathrm{CO}_{2}$. The CBMC simulations show that the adsorption selectivity $S_{a d s}$ is increasingly lowered below unity, i.e. in favor of the alkane, with increasing proportion of $\mathrm{CO}_{2}(1)$ in the bulk gas phase; see Figure S69b. The IAST anticipates $S_{\text {ads }}$ to be virtually independent of composition in the bulk fluid phase. Figure S69c shows the RAST calculations of the activity coefficients as function of the mole fraction of $\mathrm{CO}_{2}(1)$ in the adsorbed phase, $x_{1}$.

In Figure S70, the two sets of CBMC data on the adsorption selectivity $S_{a d s}$ are plotted against the surface potential $\Phi$. Due to thermodynamic non-idealities, the adsorption selectivity is not uniquely determined by $\Phi$. CBMC simulations show that two types of selectivity reversals can be realized: (i) maintaining the bulk gas composition constant at $y_{1}=0.1$, and increasing the total mixture fugacity to values $f_{t}=f_{1}+f_{2}>10^{6} \mathrm{~Pa}$, ensuring that $\Phi>27 \mathrm{~mol} \mathrm{~kg}^{-1}$, and (ii) maintain the total mixture fugacity $f_{t}=f_{1}+f_{2}=10^{6} \mathrm{~Pa}$, and increasing the mole fraction of $\mathrm{CO}_{2}$ in the bulk gas mixture to values in excess of 0.1 , again ensuring that $\Phi>27 \mathrm{~mol} \mathrm{~kg}^{-1}$.

The rationale for the quantitative failures IAST estimates can be traced to congregation of $\mathrm{CO}_{2}$ near the $\mathrm{Na}^{+}$cations, as witnessed in the RDFs for various guest pairs $\mathrm{CO}_{2}-\mathrm{CO}_{2}, \mathrm{CO}_{2}-\mathrm{Na}^{+}, \mathrm{CO}_{2}-\mathrm{C}_{3} \mathrm{H}_{8}$, and $\mathrm{C}_{3} \mathrm{H}_{8}-$ $\mathrm{C}_{3} \mathrm{H}_{8}$ shown in Figure S71. It is noteworthy that the first peaks of $\mathrm{CO}_{2}-\mathrm{CO}_{2}$ and $\mathrm{Na}^{+}-\mathrm{Na}^{+}$are close together. Also noteworthy is that the first peaks of $\mathrm{CO}_{2}-\mathrm{CO}_{2}$ and $\mathrm{CO}_{2}-\mathrm{C}_{3} \mathrm{H}_{8}$ are farther apart, indicating segregation effects. Also noteworthy, is that a number of peaks occur for $\mathrm{CO}_{2}-\mathrm{CO}_{2}$ pairs; two of these peaks correspond to the window-to-window distances of 8.68, and $12.27 \AA$.

Figure S72 shows snapshots of the location of $\mathrm{CO}_{2}(1)$, and $\mathrm{C}_{3} \mathrm{H}_{8}(2)$ molecules within the pore topology of LTA-4A zeolite. We note that the $\mathrm{CO}_{2}$ is almost exclusively located at the windows, or near the window entrance regions. Due to configurational restraints $\mathrm{C}_{3} \mathrm{H}_{8}$ can only located at the cage interiors. 
Mixture adsorption in LTA zeolite

Consequently, the competition between the adsorption of $\mathrm{CO}_{2}$ and $\mathrm{C}_{3} \mathrm{H}_{8}$ is less severe than assumed in the homogenous distribution that is inherent in the IAST prescription.

\section{2 $\mathrm{CO}_{2} / \mathrm{nC}_{4} \mathrm{H}_{10}$ mixture adsorption in LTA-4A zeolite}

Thermodynamic non-ideality effects were also investigated for $\mathrm{CO}_{2}(1) / \mathrm{nC}_{4} \mathrm{H}_{10}(2)$ mixture adsorption in LTA-4A zeolite at $300 \mathrm{~K}$. Four different CBMC simulation campaigns were conducted.

(i) Campaign $\mathrm{A}\left(y_{1}=0.5\right)$ for $\mathrm{CO}_{2}(1) / \mathrm{nC}_{4} \mathrm{H}_{10}(2)$ mixture adsorption

(ii) Campaign $\mathrm{A}\left(y_{1}=0.9\right)$ for $\mathrm{CO}_{2}(1) / \mathrm{nC}_{4} \mathrm{H}_{10}(2)$ mixture adsorption

(iii) Campaign $\mathrm{B}\left(f_{\mathrm{t}}=100 \mathrm{kPa}\right)$ for $\mathrm{CO}_{2}(1) / \mathrm{nC}_{4} \mathrm{H}_{10}(2)$ mixture adsorption

(iv) Campaign $\mathrm{B}\left(f_{\mathrm{t}}=500 \mathrm{kPa}\right)$ for $\mathrm{CO}_{2}(1) / \mathrm{nC}_{4} \mathrm{H}_{10}(2)$ mixture adsorption

The CBMC data and analysis are presented in Figure S73, Figure S74, Figure S75, and Figure S76.

The IAST fails to anticipate the selectivity reversals in the two campaigns B; see Figure S75, and Figure S76.

\section{3 $\mathrm{CO}_{2} / \mathrm{CH}_{4} / \mathrm{N}_{2}$ mixture adsorption in all-silica LTA zeolite}

CBMC simulations were carried out for five different mixtures in LTA (all-silica) zeolite at $300 \mathrm{~K}$ : (i) $50 / 50 \mathrm{CO}_{2} / \mathrm{CH}_{4}$, (ii) $50 / 50 \mathrm{CO}_{2} / \mathrm{N}_{2}$, (iii) $15 / 85 \mathrm{CO}_{2} / \mathrm{N}_{2}$, (iv) $50 / 50 \mathrm{CH}_{4} / \mathrm{N}_{2}$, and (v) equimolar $\left(f_{1}=f_{2}=f_{3}\right)$ $1 / 1 / 1 \mathrm{CO}_{2} / \mathrm{CH}_{4} / \mathrm{N}_{2}$. The adsorption selectivities, $S_{\text {ads }}$ of the three different pairs $\mathrm{CO}_{2} / \mathrm{CH}_{4}, \mathrm{CO}_{2} / \mathrm{N}_{2}$, and $\mathrm{CH}_{4} / \mathrm{N}_{2}$ were determined both from binary and ternary mixtures. The CBMC data on the pair selectivities are plotted in Figure S77a,b,c as function of the surface potential, $\Phi$, determined from IAST calculations using the isotherm fits reported in Table S16. When compared at the same value of $\Phi$, the selectivities are the same in the binary mixture as in the ternary mixture, in agreement with the IAST prescription. Put another way, the presence of component 3 in the ternary mixture has no influence of the adsorption selectivity for the 1-2 pair. 


\subsection{List of Tables for Mixture adsorption in LTA zeolite}

Table S15. Dual-site Langmuir-Freundlich parameters for pure components $\mathrm{CO}_{2}, \mathrm{C}_{3} \mathrm{H}_{8}$, and $\mathrm{nC}_{4} \mathrm{H}_{10}$, at $300 \mathrm{~K}$ in LTA-4A zeolite (96 Si, $96 \mathrm{Al}, 96 \mathrm{Na}^{+}, \mathrm{Si} / \mathrm{Al}=1$ ). The fit parameters are based on the CBMC simulations of pure component isotherms.

\begin{tabular}{|l|l|l|l|l|l|l|}
\hline \multirow{2}{*}{} & \multicolumn{2}{|l|}{ Site A } & \multicolumn{2}{l|}{ Site B } \\
\cline { 2 - 7 } & $\begin{array}{l}q_{\mathrm{A}, \mathrm{sat}} \\
\mathrm{mol} \mathrm{kg}{ }^{-1}\end{array}$ & $\begin{array}{l}b_{\mathrm{A}} \\
\mathrm{Pa}^{-v_{A}}\end{array}$ & $\begin{array}{l}v_{\mathrm{A}} \\
\text { dimensionless }\end{array}$ & $\begin{array}{l}q_{\mathrm{B}, \mathrm{sat}} \\
\mathrm{mol} \mathrm{kg}^{-1}\end{array}$ & $\begin{array}{l}b_{\mathrm{B}} \\
\mathrm{Pa}^{-v_{B}}\end{array}$ & $\begin{array}{l}v_{\mathrm{B}} \\
\text { dimensionless }\end{array}$ \\
\hline $\mathrm{CO}_{2}$ & 3.1 & $4.13 \times 10^{-4}$ & 1 & 1.7 & $2.095 \times 10^{-7}$ & 1 \\
\hline $\mathrm{C}_{3} \mathrm{H}_{8}$ & 2.5 & $2.21 \times 10^{-2}$ & 1 & 0.9 & $6.18 \times 10^{-6}$ & 1 \\
\hline $\mathrm{nC}_{4} \mathrm{H}_{10}$ & 1.8 & 1.14 & 1 & 0.55 & $5.06 \times 10^{-3}$ & 1 \\
\hline
\end{tabular}

Fitted Margules non-ideality parameters for binary mixture adsorption in LTA-4A at $300 \mathrm{~K}$.

\begin{tabular}{|l|l|l|l|}
\hline & $C / \mathrm{kg} \mathrm{mol}^{-1}$ & $A_{12}$ & $A_{21}$ \\
\hline $\mathrm{CO}_{2} / \mathrm{C}_{3} \mathrm{H}_{8}$ in LTA-4A & 0.142 & -3.736 & -0.511 \\
\hline
\end{tabular}


Table S16. Dual-site Langmuir-Freundlich parameters for guest molecules in LTA (all-silica) at $300 \mathrm{~K}$. To convert from molecules $\mathrm{uc}^{-1}$ to $\mathrm{mol} \mathrm{kg} \mathrm{kg}^{-1}$, multiply by 0.086683044 .

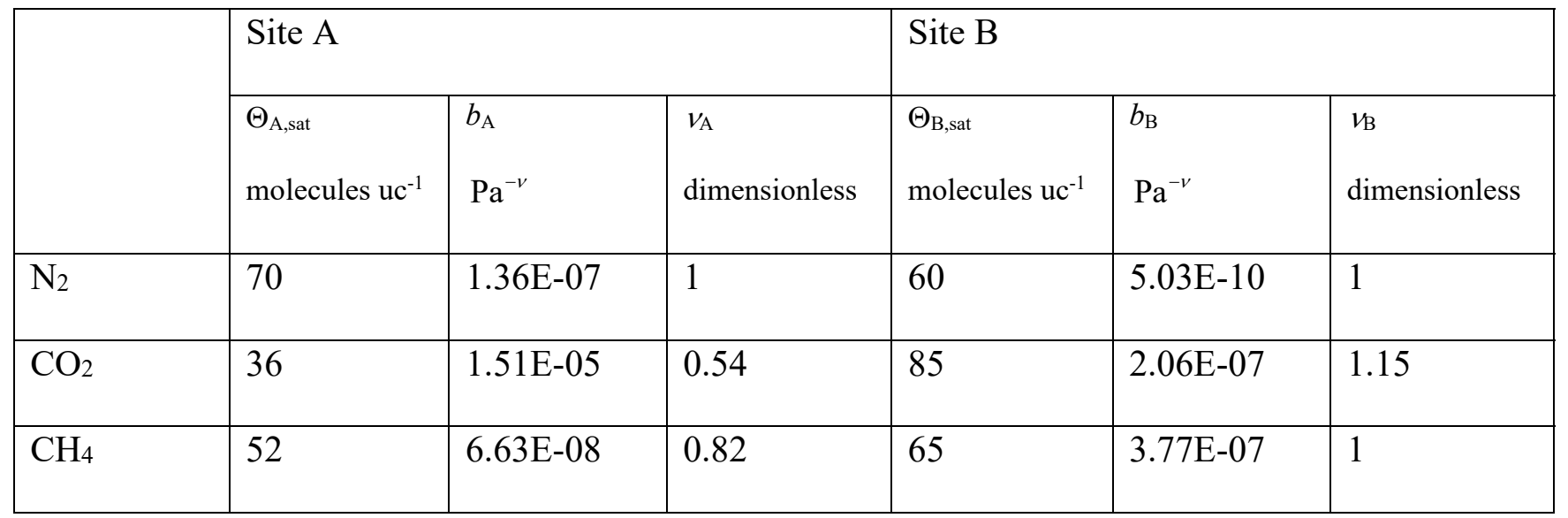




\subsection{List of Figures for Mixture adsorption in LTA zeolite}

\section{LTA (all silica) landscapes}
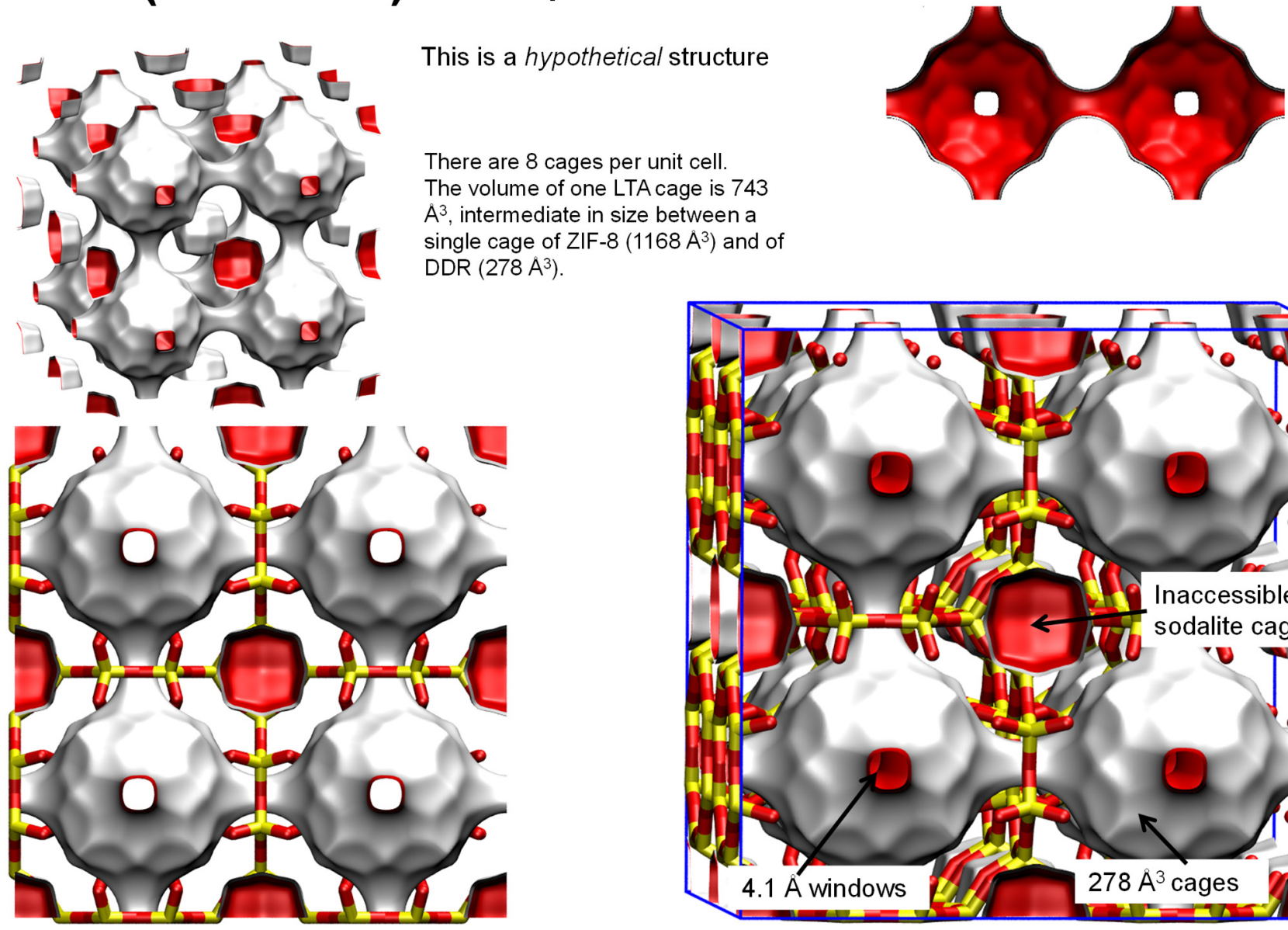

ile cage of ZIF-8 $\left(1168 A^{3}\right)$ and of

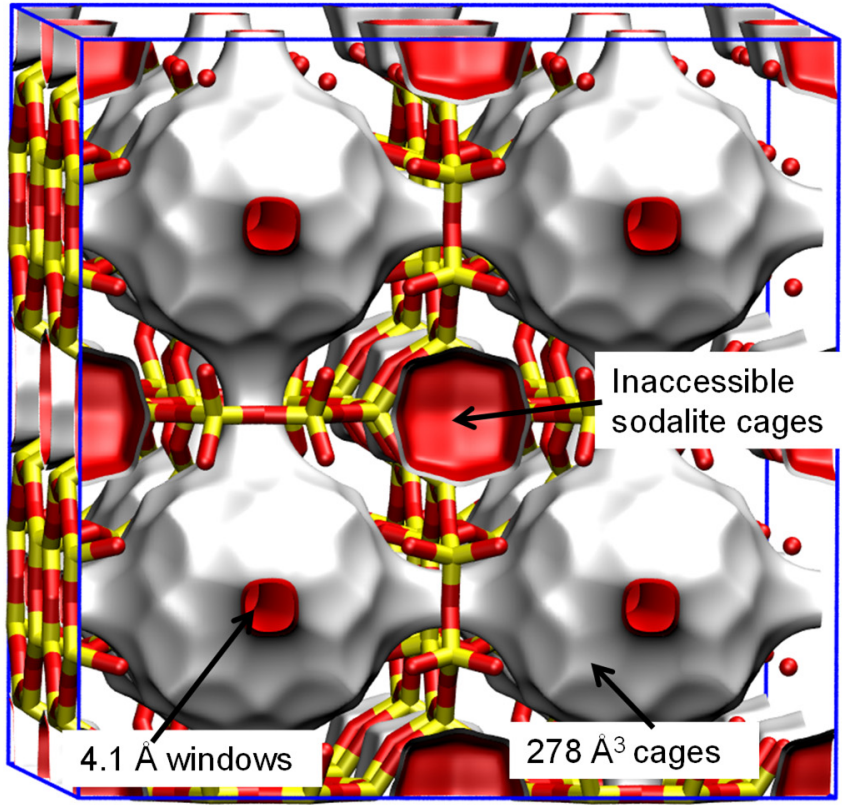

Figure S65. Pore landscape of all-silica LTA zeolite. 


\section{LTA (all-silica) window and pore dimensions}

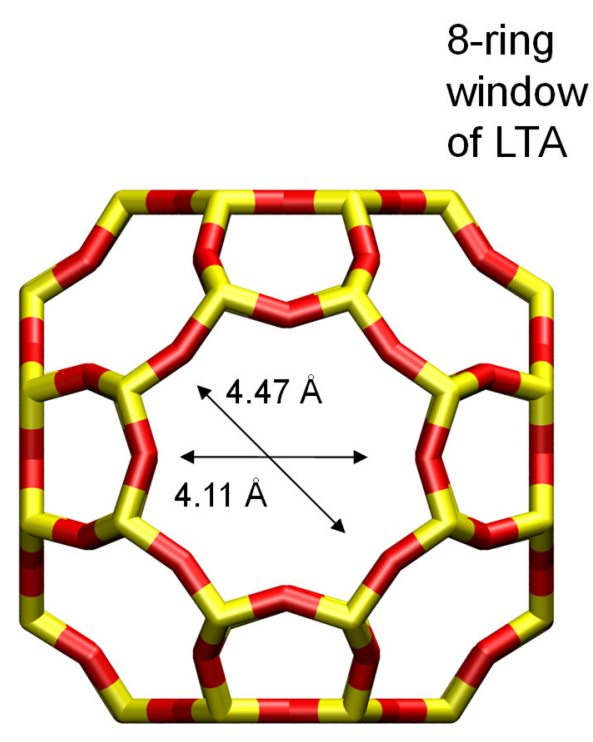

The window dimension calculated using the van der Waals diameter of framework atoms $=2.7 \mathrm{~A}$ is indicated above by the arrows.

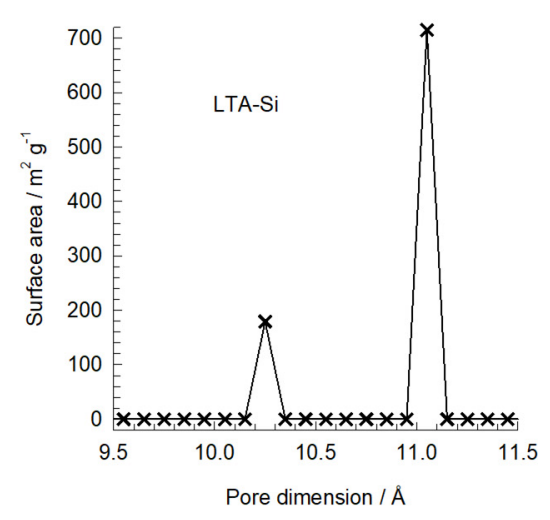

\begin{tabular}{|c|c|}
\hline & LTA-Si \\
\hline$a / \AA$ & 24.61 \\
\hline$b / A$ & 24.61 \\
\hline$c / \AA$ & 24.61 \\
\hline Cell volume / $\AA^{3}$ & 14905.1 \\
\hline conversion factor for [molec/uc] to [mol per kg Framework] & 0.0867 \\
\hline conversion factor for $[\mathrm{molec} / \mathrm{uc}]$ to $\left[\mathrm{kmol} / \mathrm{m}^{3}\right]$ & 0.2794 \\
\hline$\rho[\mathrm{kg} / \mathrm{m} 3]$ & 1285.248 \\
\hline MW unit cell [g/mol(framework)] & 11536.28 \\
\hline$\phi$, fractional pore volume & 0.399 \\
\hline open space / $\AA^{3} / u c$ & 5944.4 \\
\hline Pore volume $/ \mathrm{cm}^{3} / \mathrm{g}$ & 0.310 \\
\hline Surface area $/ \mathrm{m}^{2} / \mathrm{g}$ & 896.0 \\
\hline DeLaunay diameter $/ \AA$ & 4.10 \\
\hline
\end{tabular}

Figure S66. Structural details for all-silica LTA zeolite. 

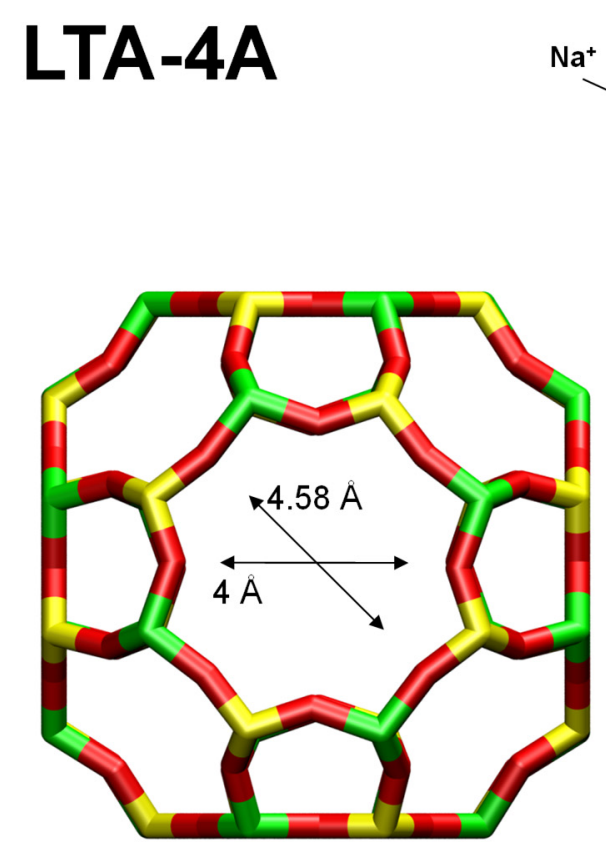

\section{LTA-4A}

The window dimension calculated using the van der Waals diameter of framework atoms $=2.7 \mathrm{~A}$ is indicated above by the arrow.

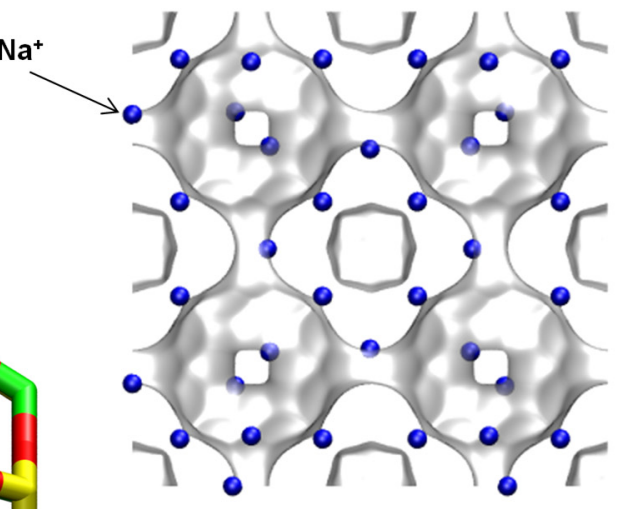

LTA-4A (96 Na+)

\begin{tabular}{|c|c|}
\hline & LTA-4A \\
\hline$a / \AA$ & 24.555 \\
\hline$b / \AA$ & 24.555 \\
\hline$c / A$ & 24.555 \\
\hline Cell volume / $\AA^{3}$ & 14805.39 \\
\hline conversion factor for [molec/uc] to [mol per kg Framework] & 0.0733 \\
\hline conversion factor for $[\mathrm{molec} / \mathrm{uc}]$ to $\left[\mathrm{kmol} / \mathrm{m}^{3}\right]$ & 0.2991 \\
\hline$\rho[\mathrm{kg} / \mathrm{m} 3]$ (with cations) & 1529.55 \\
\hline MW unit cell [g/mol(framework+cations)] & 13637.27 \\
\hline$\phi$, fractional pore volume & 0.375 \\
\hline open space / $\AA^{3} / \mathrm{uc}$ & 5552.0 \\
\hline Pore volume $/ \mathrm{cm}^{3} / \mathrm{g}$ & 0.245 \\
\hline \multicolumn{2}{|l|}{ Surface area $/ \mathrm{m}^{2} / \mathrm{g}$} \\
\hline DeLaunay diameter $/ \AA$ & 4.00 \\
\hline
\end{tabular}

Figure S67. Structural details for LTA-4A zeolite. 
a
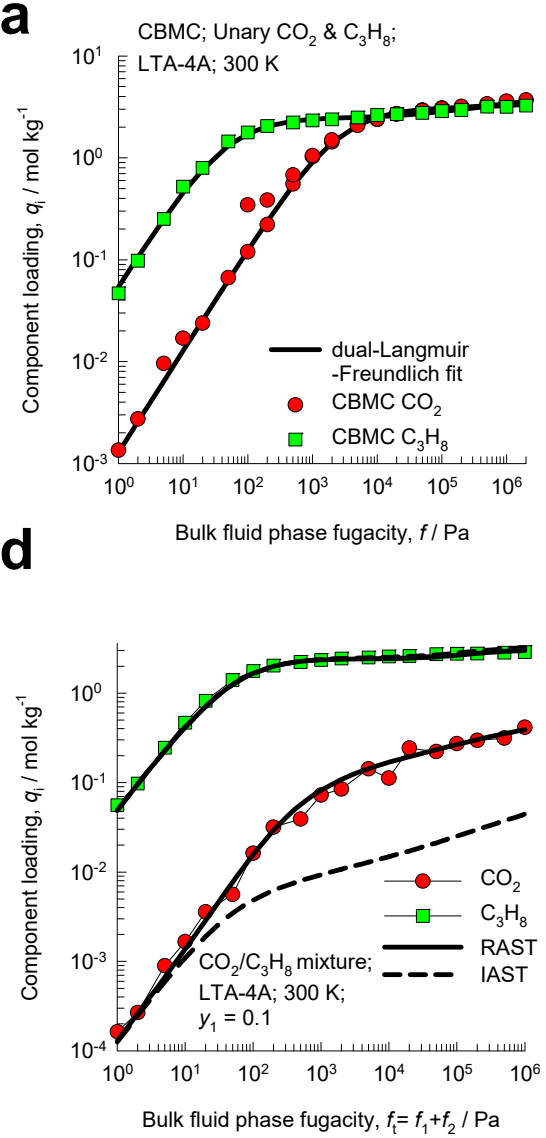
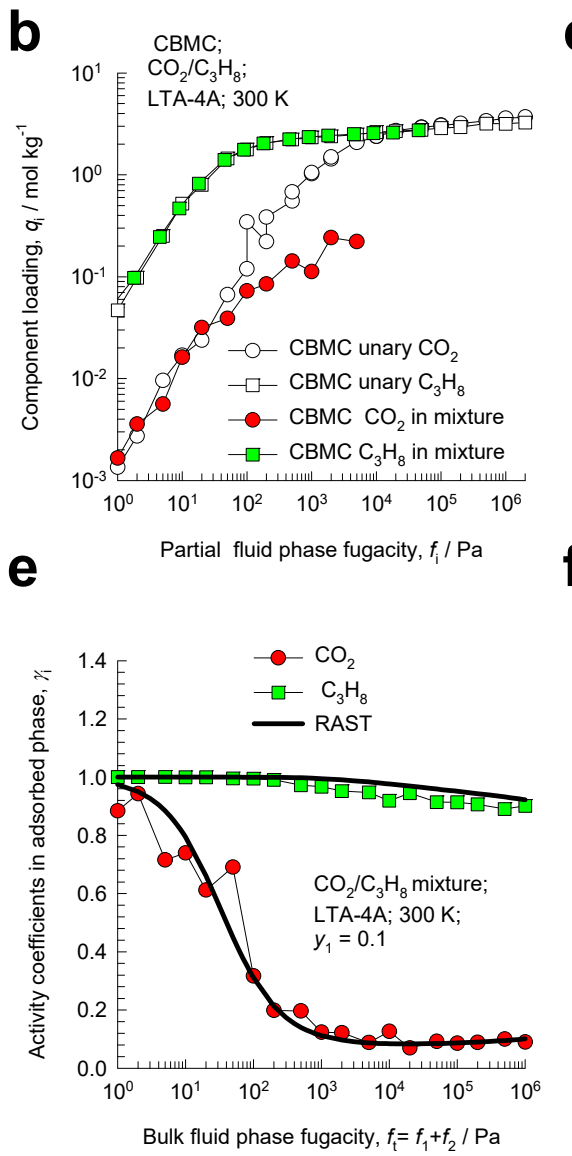

C
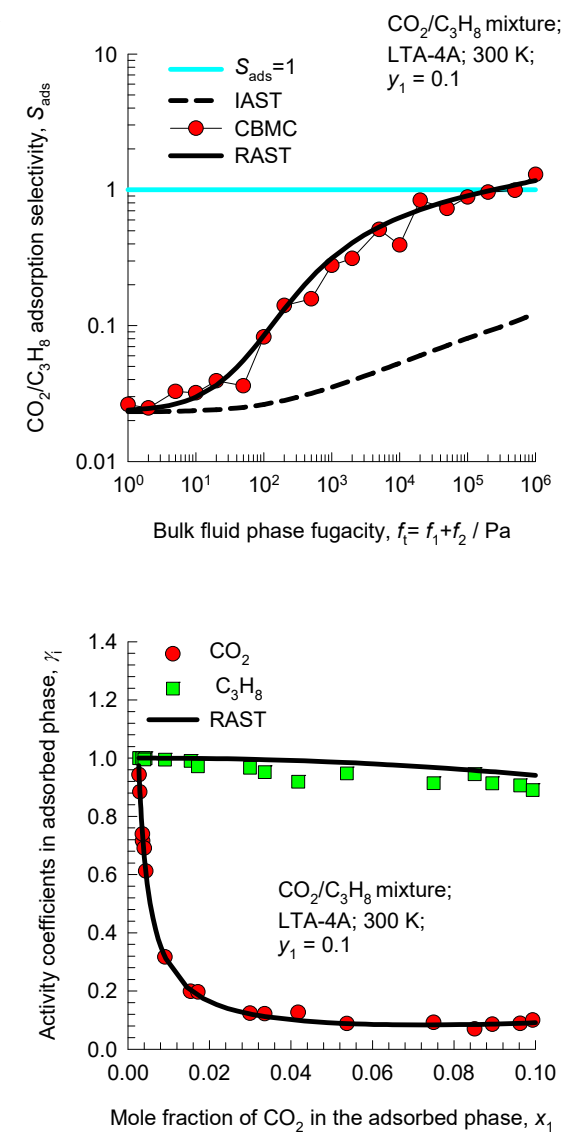

Figure S68. CBMC simulation data and analysis for Campaign A $\left(y_{1}=0.1\right)$ for $\mathrm{CO}_{2}(1) / \mathrm{C}_{3} \mathrm{H}_{8}(2)$ mixture adsorption in LTA-4A zeolite at $300 \mathrm{~K}$. (a) Unary isotherms and fits. (b) Component loadings in mixture compared with CBMC simulations of unary isotherms. (c) $\mathrm{CBMC}$ data for $\mathrm{CO}_{2}(1) / \mathrm{C}_{3} \mathrm{H}_{8}(2)$ adsorption selectivity compared with IAST and RAST estimates. (d) CBMC data for component loadings in mixture compared with RAST estimates. (e, f) Activity coefficients from CBMC compared with RAST model calculations. The unary isotherm fit parameters and Margules parameters are provided in Table S15. 

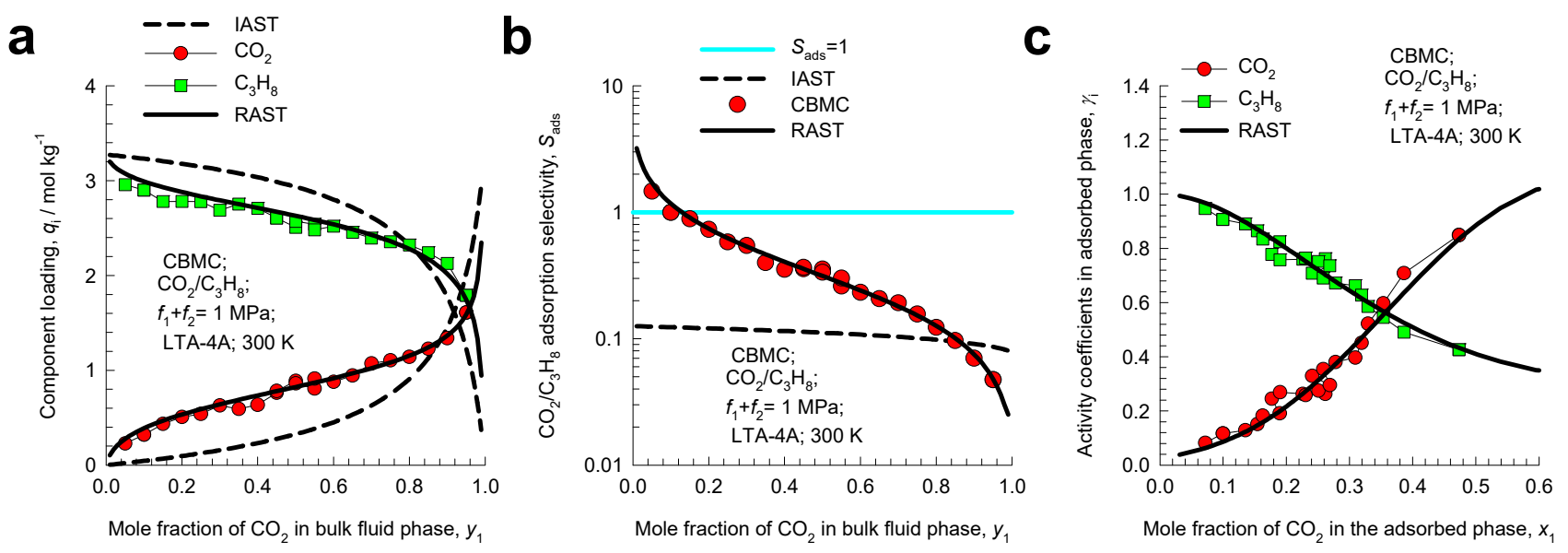

Figure S69. CBMC simulation data and analysis for Campaign $\mathrm{B}\left(f_{\mathrm{t}}=1 \mathrm{MPa}\right)$ for $\mathrm{CO}_{2}(1) / \mathrm{C}_{3} \mathrm{H}_{8}(2)$ mixture adsorption in LTA-4A zeolite at $300 \mathrm{~K}$. CBMC data for (a) component loadings and (b) $\mathrm{CO}_{2}(1) /$ $\mathrm{C}_{3} \mathrm{H}_{8}(2)$ adsorption selectivity compared with IAST and RAST estimates. (c) Activity coefficients from CBMC compared with RAST model calculations. The unary isotherm fit parameters and Margules parameters are provided in Table S15. 


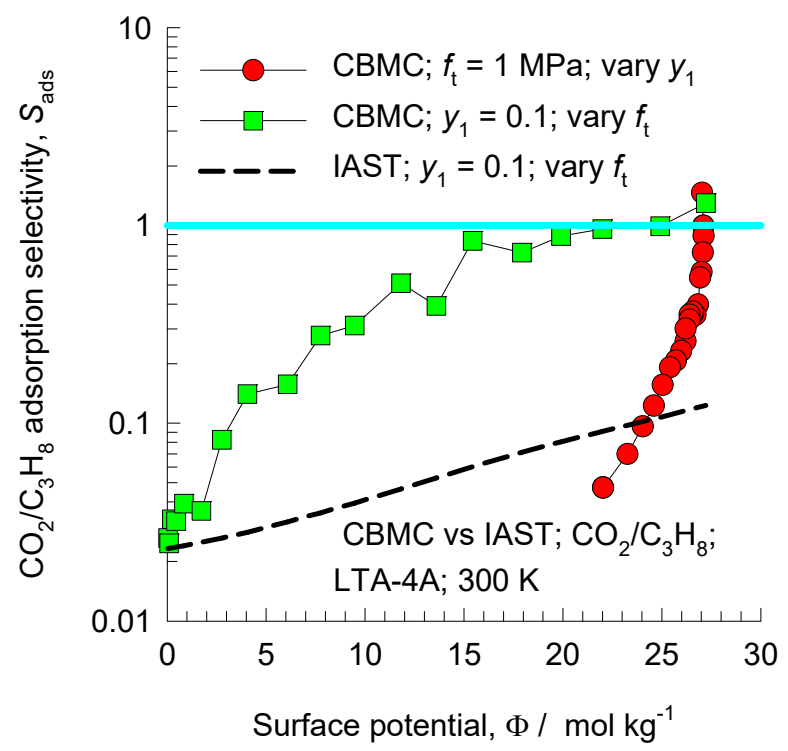

Figure S70. Adsorption selectivity $S_{a d s}$ for $\mathrm{CO}_{2}(1) / \mathrm{C}_{3} \mathrm{H}_{8}(2)$ mixture adsorption in LTA-4A zeolite at $300 \mathrm{~K}$ for two different campaigns (Campaign A $\left(y_{1}=0.1\right)$ and Campaign $\mathrm{B}\left(f_{\mathrm{t}}=1 \mathrm{MPa}\right)$, plotted as function of the surface potential $\Phi$. The CBMC simulated values (indicated by symbols) are compared with IAST estimates (indicated by the dashed lines). The unary isotherm fit parameters and Margules parameters are provided in Table S15. 

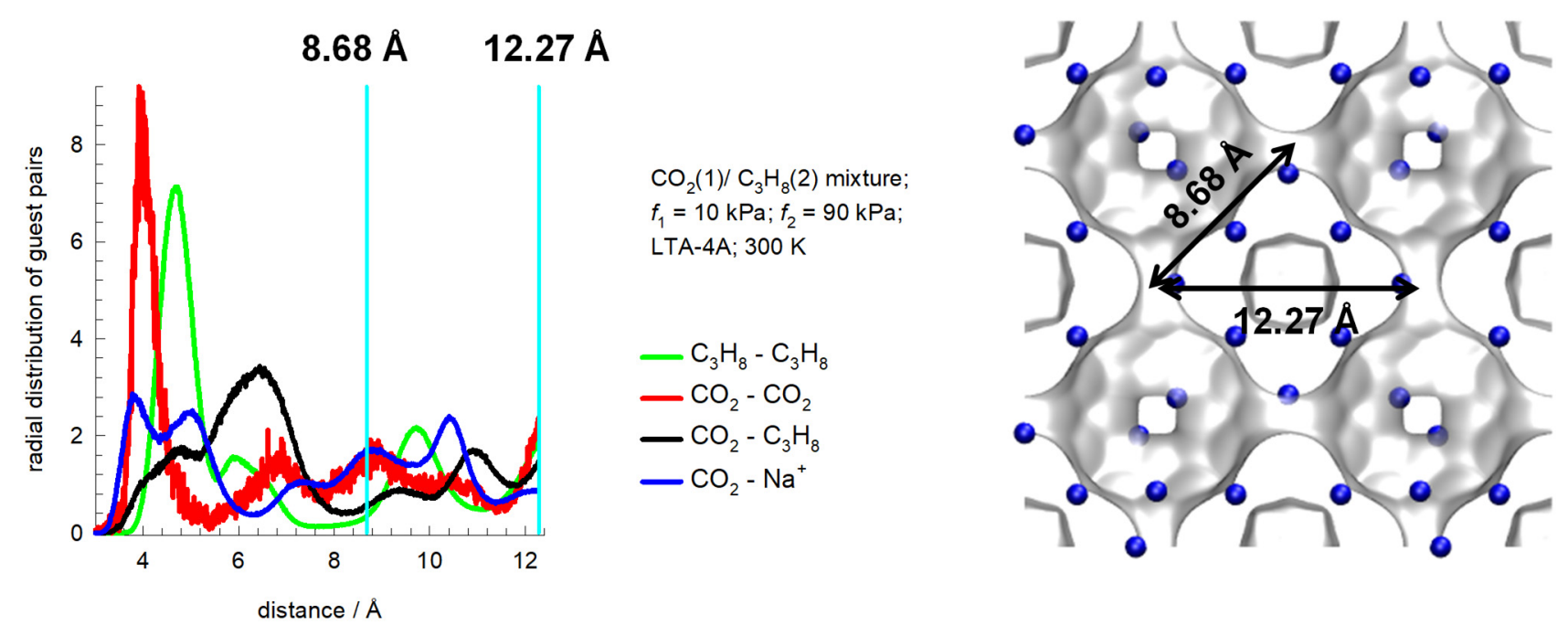

Figure S71. Radial distribution of guest pairs determined from CBMC simulations for adsorption of $\mathrm{CO}_{2} / \mathrm{C}_{3} \mathrm{H}_{8}$ mixtures in LTA-4A zeolite at $300 \mathrm{~K}$ and total fugacity $f_{\mathrm{t}}=100 \mathrm{kPa}$, and $y_{1}=0.1$. 
$\mathrm{CO}_{2} / \mathrm{C}_{3} \mathrm{H}_{8}$ mixture adsorption in LTA-4A zeolite;

Snapshot for $f_{\mathrm{CO} 2}=800 \mathrm{kPa} ; f_{\mathrm{C} 3 \mathrm{H} 8}=200 \mathrm{kPa}$

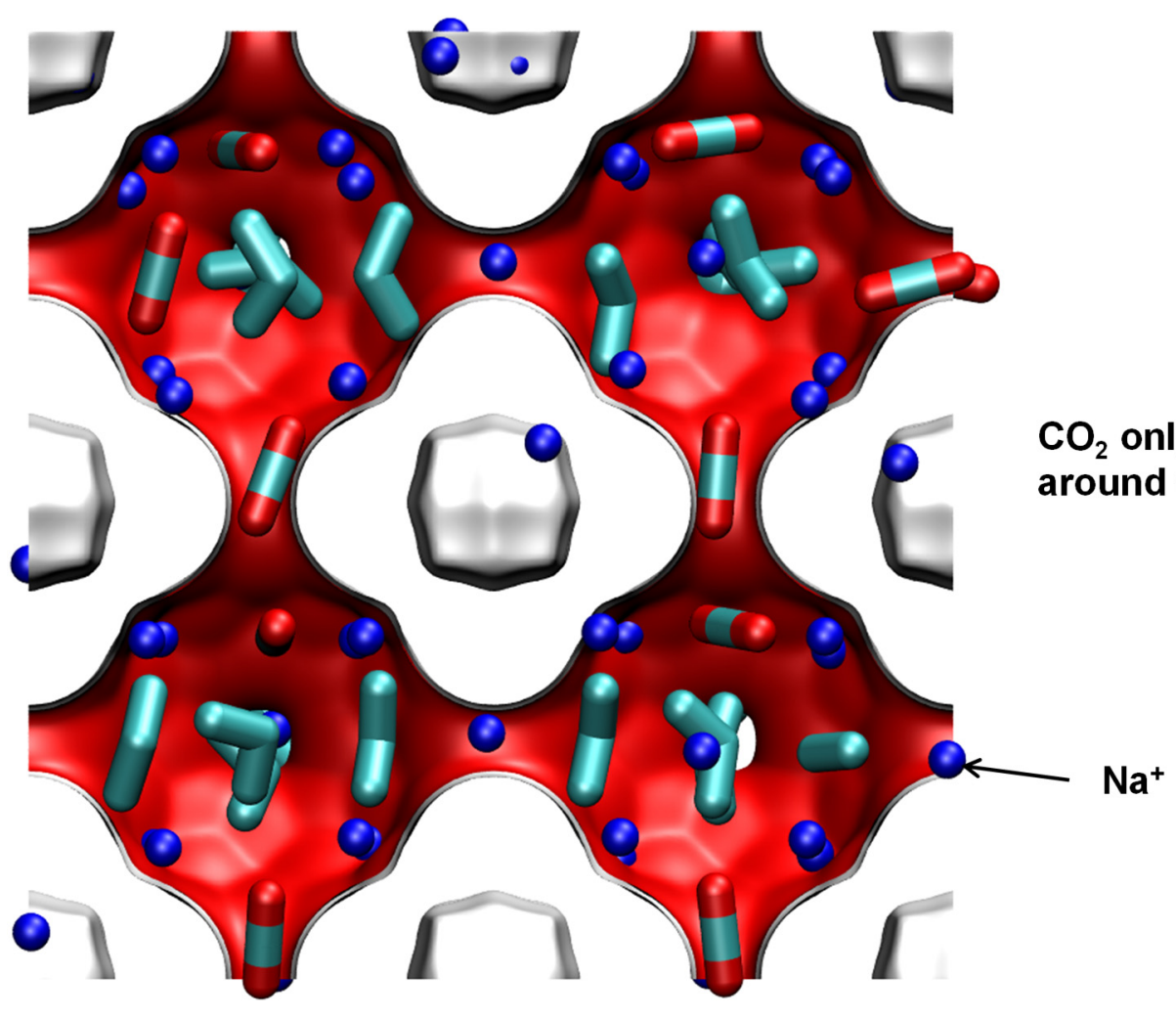

Figure $\mathrm{S} 72$. Computational snapshot showing the location of $\mathrm{CO}_{2}$, and $\mathrm{C}_{3} \mathrm{H}_{8}$ within the cages of LTA$4 \mathrm{~A}$ zeolite at $300 \mathrm{~K}$ and total fugacity $f_{\mathrm{t}}=1 \mathrm{MPa}$. The component partial fugacities are $f_{1}=0.8 \mathrm{MPa}$, and $f_{2}=0.2 \mathrm{MPa}$. 

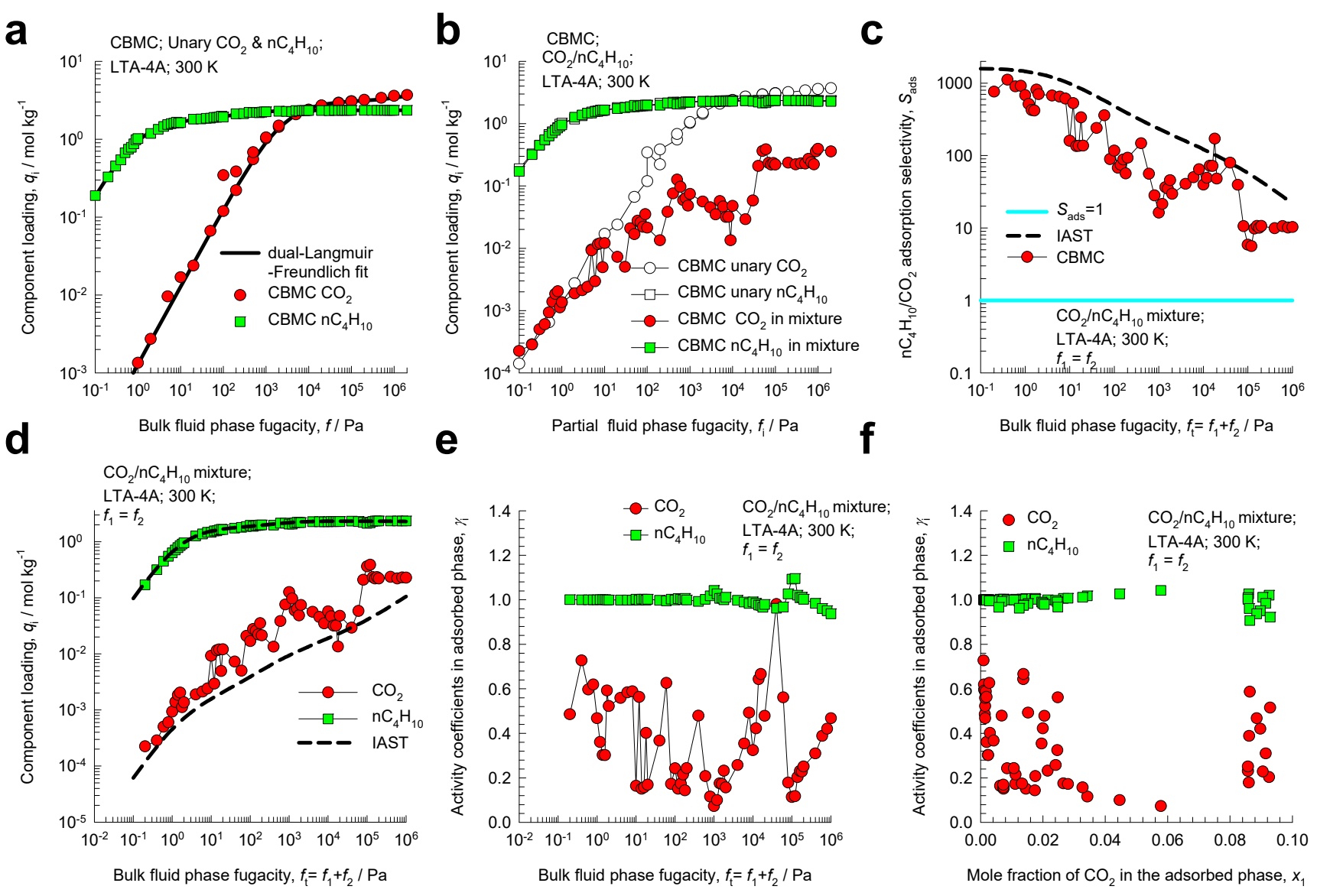

Figure S73. CBMC simulation data and analysis for Campaign A $\left(y_{1}=0.5\right)$ for $\mathrm{CO}_{2}(1) / \mathrm{nC}_{4} \mathrm{H}_{10}(2)$ mixture adsorption in LTA-4A zeolite at $300 \mathrm{~K}$. (a) Unary isotherms and fits. (b) Component loadings in mixture compared with $\mathrm{CBMC}$ simulations of unary isotherms. (c) $\mathrm{CBMC}$ data for $\mathrm{nC}_{4} \mathrm{H}_{10}(2) / \mathrm{CO}_{2}(1)$ adsorption selectivity compared with IAST estimates. (d) CBMC data for component loadings in mixture compared with IAST estimates. (e, f) Activity coefficients from CBMC. The unary isotherm fit parameters are provided in Table S15. 

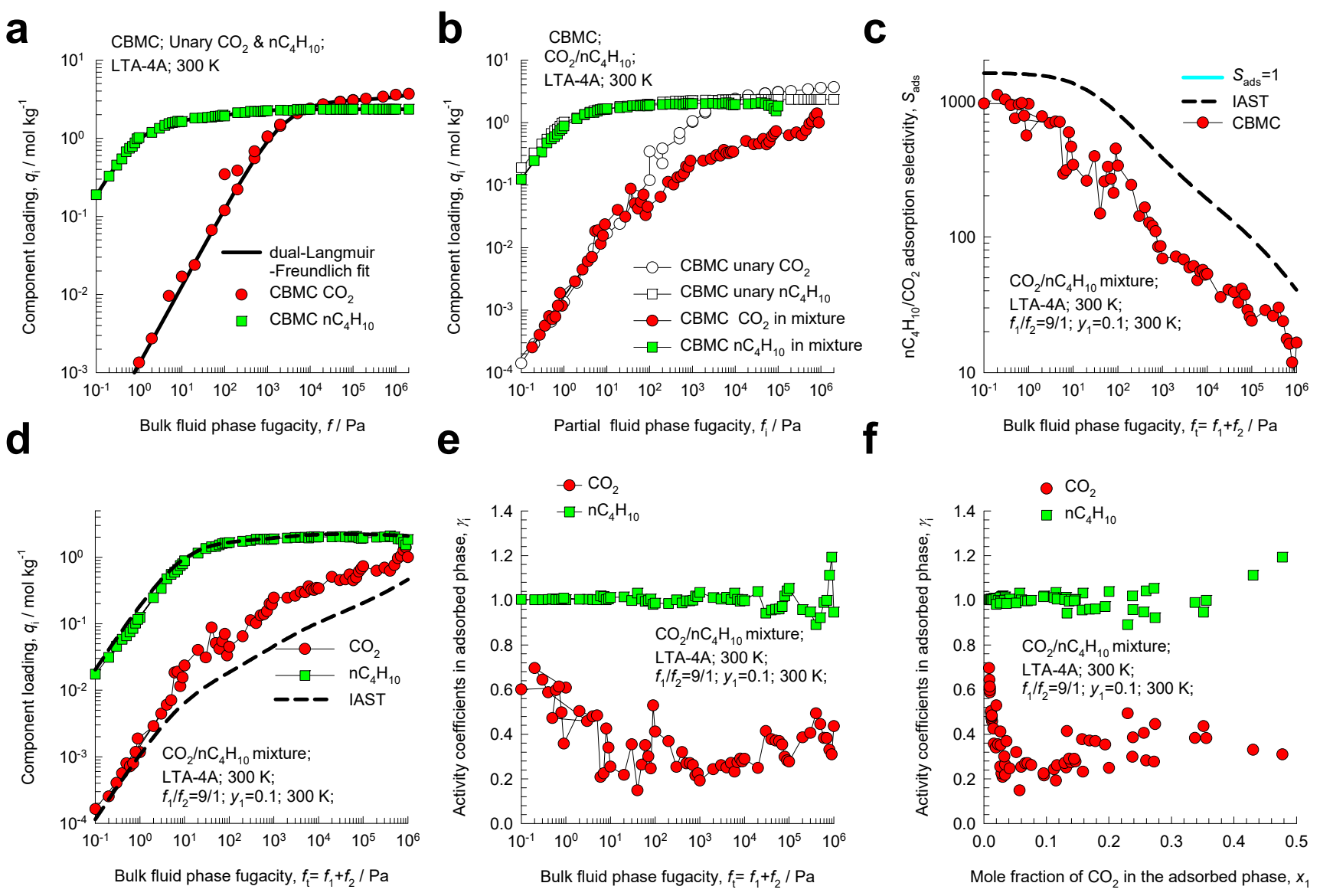

Figure S74. CBMC simulation data and analysis for Campaign A $\left(y_{1}=0.9\right)$ for $\mathrm{CO}_{2}(1) / \mathrm{nC}_{4} \mathrm{H}_{10}(2)$ mixture adsorption in LTA-4A zeolite at $300 \mathrm{~K}$. (a) Unary isotherms and fits. (b) Component loadings in mixture compared with CBMC simulations of unary isotherms. (c) $\mathrm{CBMC}$ data for $\mathrm{nC}_{4} \mathrm{H}_{10}(2) / \mathrm{CO}_{2}(1)$ adsorption selectivity compared with IAST estimates. (d) CBMC data for component loadings in mixture compared with IAST estimates. (e, f) Activity coefficients from CBMC. The unary isotherm fit parameters are provided in Table S15. 

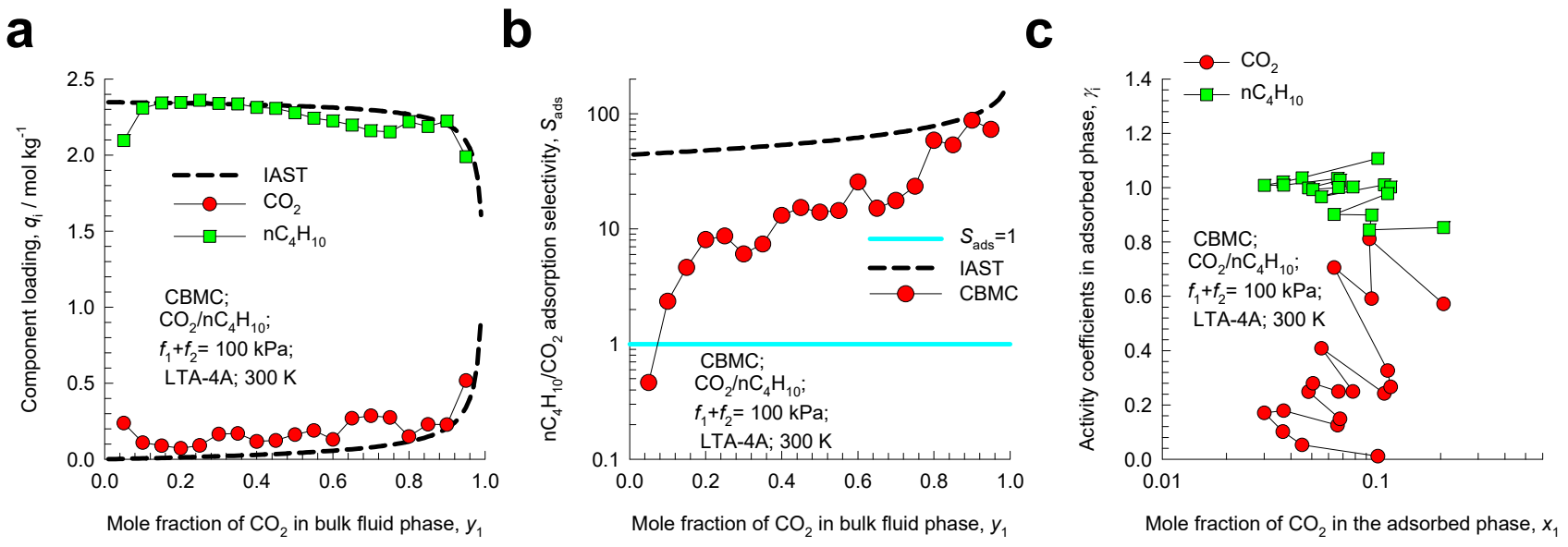

Figure S75. CBMC simulation data and analysis for Campaign $\mathrm{B}\left(f_{\mathrm{t}}=100 \mathrm{kPa}\right)$ for $\mathrm{CO}_{2}(1) / \mathrm{nC}_{4} \mathrm{H}_{10}(2)$ mixture adsorption in LTA-4A zeolite at $300 \mathrm{~K}$. CBMC data for (a) component loadings and (b) $\mathrm{nC}_{4} \mathrm{H}_{10}(2) / \mathrm{CO}_{2}(1)$ adsorption selectivity compared with IAST estimates. (c) Activity coefficients from CBMC. The unary isotherm fit parameters are provided in Table S15. 

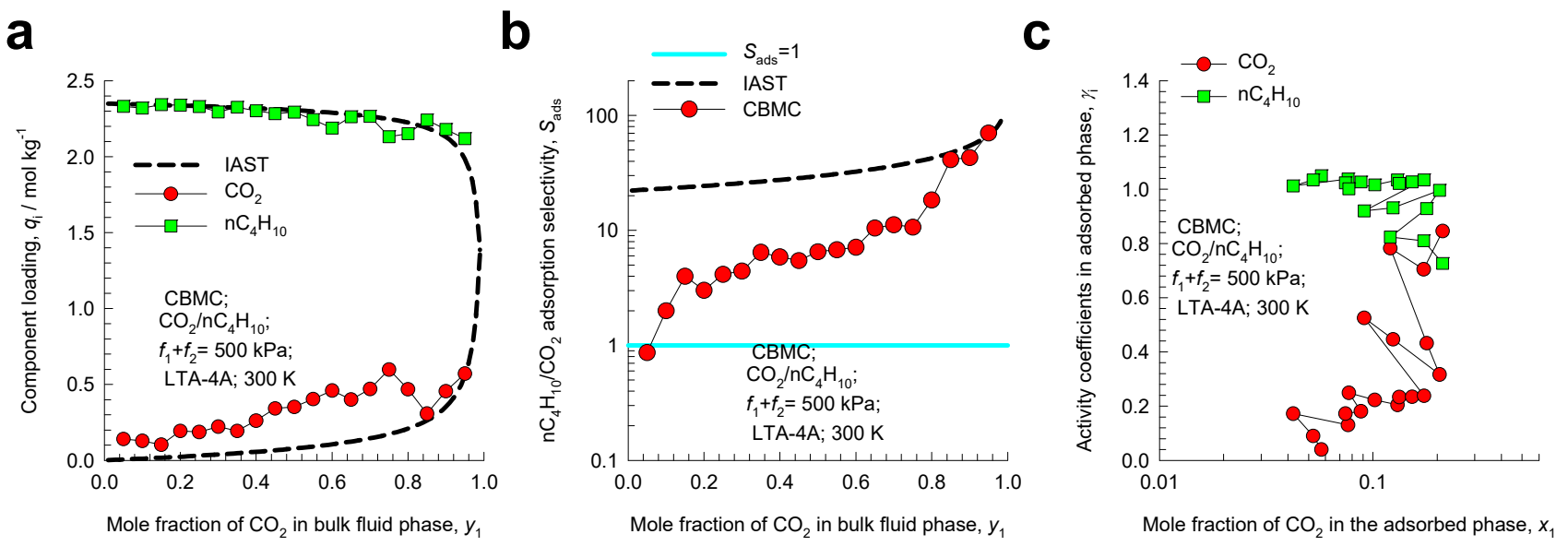

Figure S76. CBMC simulation data and analysis for Campaign $\mathrm{B}\left(f_{\mathrm{t}}=500 \mathrm{kPa}\right)$ for $\mathrm{CO}_{2}(1) / \mathrm{nC}_{4} \mathrm{H}_{10}(2)$ mixture adsorption in LTA-4A zeolite at $300 \mathrm{~K}$. CBMC data for (a) component loadings and (b) $\mathrm{nC}_{4} \mathrm{H}_{10}(2) / \mathrm{CO}_{2}(1)$ adsorption selectivity compared with IAST estimates. (c) Activity coefficients from CBMC. The unary isotherm fit parameters are provided in Table S15. 

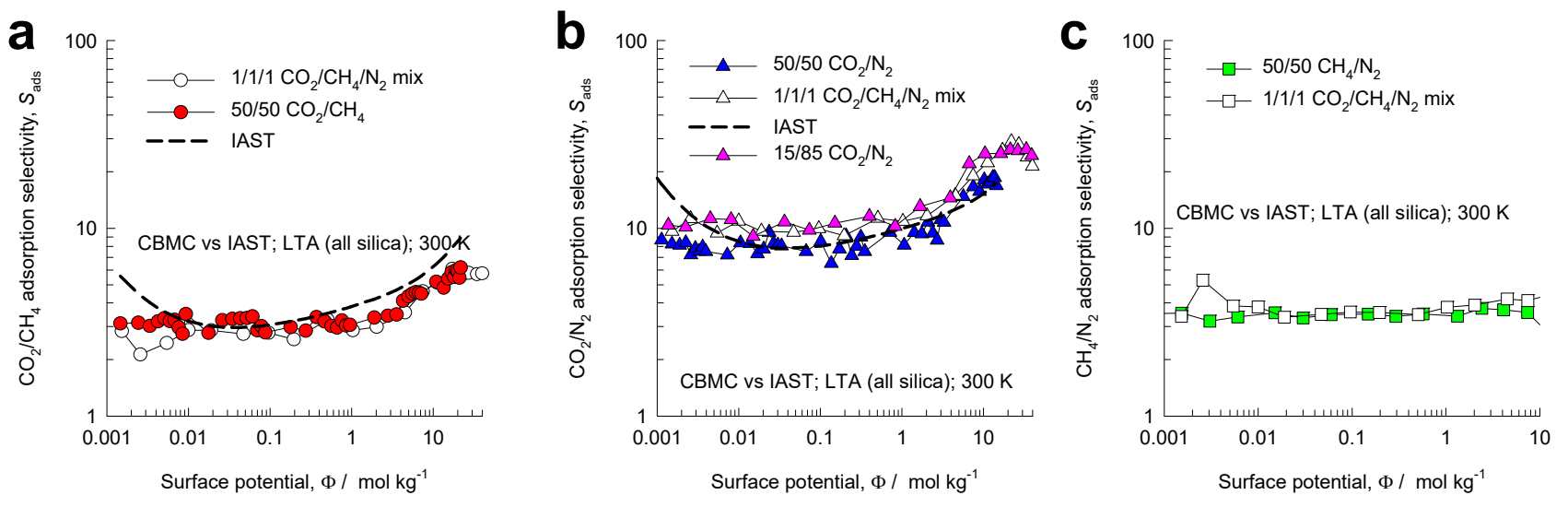

Figure S77. CBMC simulations (indicated by symbols) of the (a) $\mathrm{CO}_{2} / \mathrm{CH}_{4}$, (b) $\mathrm{CO}_{2} / \mathrm{N}_{2}$, and (c) $\mathrm{CH}_{4} / \mathrm{N}_{2}$, adsorption selectivities, $S_{a d s}$, determined from different CBMC campaigns: (i) $50 / 50 \mathrm{CO}_{2} / \mathrm{CH}_{4}$, (ii) $50 / 50$ $\mathrm{CO}_{2} / \mathrm{N}_{2}$, (iii) $15 / 85 \mathrm{CO}_{2} / \mathrm{N}_{2}$, (iv) $50 / 50 \mathrm{CH}_{4} / \mathrm{N}_{2}$, and (v) equimolar $\left(f_{1}=f_{2}=f_{3}\right) 1 / 1 / 1 \mathrm{CO}_{2} / \mathrm{CH}_{4} / \mathrm{N}_{2}$, mixtures in LTA (all-silica) zeolite at $300 \mathrm{~K}$. The dashed lines are the IAST calculations (indicated by dashed lines). The $x$-axes represent the surface potential, $\Phi$, determined from IAST model calculations. 


\section{Mixture adsorption in FAU (all-silica) and NaX zeolites}

Figure S78 presents the structural details of FAU (all-silica) zeolite. It has cages of $786 \AA^{3}$ volume, separated by $7.4 \AA 12$-ring windows. Figure S79 show the structural details of $\mathrm{NaX}\left(=86 \mathrm{Na}^{+} / \mathrm{uc}=13 \mathrm{X}\right)$ zeolite. Per unit cell of $\mathrm{NaX}$ zeolite we have $106 \mathrm{Si}, 86 \mathrm{Al}, 86 \mathrm{Na}^{+}$with $\mathrm{Si} / \mathrm{Al}=1.23$. This material is also commonly referred to by its trade name: $13 \mathrm{X}$ zeolite.

\section{1 $\mathrm{CO}_{2} / \mathrm{CH}_{4}$ mixture adsorption in $\mathrm{NaX}$ zeolite}

Figure S80 presents the CBMC data for simulation of Campaign A $\left(y_{1}=0.5\right.$, varying $\left.f_{\mathrm{t}}\right) \mathrm{CO}_{2} / \mathrm{CH}_{4}$ mixtures in $\mathrm{NaX}$ zeolite at $300 \mathrm{~K}$. Figure S81 presents the CBMC data for simulation of Campaign B $\left(f_{\mathrm{t}}=\right.$ $1 \mathrm{MPa}$, varying $\left.y_{1}\right) \mathrm{CO}_{2} / \mathrm{CH}_{4}$ mixtures in $\mathrm{NaX}$ zeolite at $300 \mathrm{~K}$. The IAST severely overestimated the adsorption selectivity $S_{a d s}$ because it assumes a homogeneous distribution of both guest adsorbates over the entire pore space. Due to congregation of $\mathrm{CO}_{2}$ around the cations $\mathrm{Na}+$, there is segregation of adsorbates. The competition faced by $\mathrm{CH}_{4}$ is less severe than anticipated by the IAST. To match the CBMC mixture simulation data on the component loadings, we need to introduce activity coefficients. Use of the RAST with fitted Margules parameters results in a good match with the CBMC mixture data; see Figure S80d, and Figure S81a. Figure S80e,f and Figure S81c show RAST calculations of the activity coefficients in the adsorbed phase. It is noteworthy that the activity coefficient of $\mathrm{CO}_{2}$ is virtually unity over the entire composition range. On the other hand, the activity coefficient of $\mathrm{CH}_{4}$ shows increasing departure from unity with increasing bulk fluid phase fugacity $f_{\mathrm{t}}$. The activity coefficient of $\mathrm{CH}_{4}$ shows increasing departure from unity with increasing mole fraction of $\mathrm{CO}_{2}$ in the adsorbed phase, $x_{1}$.

The failure of the IAST is traceable to the non-uniform distribution of the guest molecules $\mathrm{CO}_{2}$, and $\mathrm{CH}_{4}$ within the cages of $\mathrm{NaX}$ zeolite. To demonstrate this, the CBMC simulation data on the spatial 


\section{Mixture adsorption in FAU (all-silica) and $\mathrm{NaX}$ zeolites}

locations of the guest molecules were sampled to determine the inter-molecular distances. By sampling a total of $10^{5}$ simulation steps, the radial distribution of the separation distances between the molecular pairs $\mathrm{CO}_{2}-\mathrm{CO}_{2}, \mathrm{CO}_{2}-\mathrm{Na}^{+}, \mathrm{CO}_{2}-\mathrm{CH}_{4}$, and $\mathrm{CH}_{4}-\mathrm{CH}_{4}$ were determined. The samples were taken up to a radial distance of $12 \AA$, but the $x$-axis has been truncated at $8 \AA$ because only the first peaks are of interest in the discussions to follow. The plotted RDF data has been normalized such that the area under each of the curves is identical to one another (and equals 1000). Figure S82a presents the RDF data for a total fugacity $f_{\mathrm{t}}=1 \mathrm{MPa}$ and $y_{1}=0.01$. If we compare the first peaks, it is noteworthy that the $\mathrm{CO}_{2}-\mathrm{CO}_{2}$, and $\mathrm{CO}_{2}-\mathrm{Na}^{+}$ pairs are close together, indicating that the major proportion of $\mathrm{CO}_{2}$ congregates around the cations. A further point to note is that the $\mathrm{CO}_{2}-\mathrm{CH}_{4}$ separation distance is significantly higher than the $\mathrm{CO}_{2}-\mathrm{CO}_{2}$ and $\mathrm{CH}_{4}-\mathrm{CH}_{4}$ separation distances. This implies that the $\mathrm{CH}_{4}$ molecules face a less severe competitive adsorption with $\mathrm{CO}_{2}$ than is anticipated by the IAST.

A visual appreciation of the congregation effects can be gained from the snapshot presented in Figure S83.

The primary reason for the congregation of $\mathrm{CO}_{2}$ molecules is the presence of cations. In order to demonstrate this, we also carried out $\mathrm{CBMC}$ simulations for adsorption of $\mathrm{CO}_{2} / \mathrm{CH}_{4}$ mixtures in all-silica zeolite at a total fugacity $f_{\mathrm{t}}=500 \mathrm{kPa}$ and $y_{1}=0.2$ at $300 \mathrm{~K}$. The RDF data on the distances between the molecular pairs $\mathrm{CO}_{2}-\mathrm{CO}_{2}, \mathrm{CO}_{2}-\mathrm{CH}_{4}$, and $\mathrm{CH}_{4}-\mathrm{CH}_{4}$ are shown in Figure $\mathrm{S} 82 \mathrm{~b}$. We note that the peaks occur at practically the same intermolecular distances. This indicates that there are no congregation effects and that the guest molecules are homogeneously distributed within the pore landscape. Such a homogeneous distribution of guest molecules fulfils the requirement of the IAST theory. Consequently, we should expect the IAST to provide a good quantitative description of $\mathrm{CO}_{2} / \mathrm{CH}_{4}$ mixture adsorption in all-silica zeolite.

To confirm this expectation, Figure S84a compares the CBMC simulated values of the adsorption selectivity for $50 / 50 \mathrm{CO}_{2} / \mathrm{CH}_{4}, 20 / 80 \mathrm{CO}_{2} / \mathrm{CH}_{4}, 15 / 85 \mathrm{CO}_{2} / \mathrm{N}_{2}, 20 / 80 \mathrm{CO}_{2} / \mathrm{N}_{2}$, and $20 / 40 / 40 \mathrm{CO}_{2} / \mathrm{CH}_{4} / \mathrm{N}_{2}$ mixtures in all-silica FAU with the corresponding IAST calculations. The $\mathrm{CO}_{2} / \mathrm{CH}_{4}$, and $\mathrm{CO}_{2} / \mathrm{N}_{2}$ selectivities are uniquely determined by the surface potential $\Phi$, irrespective of the composition of the 


\section{Mixture adsorption in FAU (all-silica) and $\mathrm{NaX}$ zeolites}

bulk fluid phase mixture and the presence of the third component. The IAST estimations are in good agreement with the CBMC simulated values of $S_{a d s}$.

In sharp contrast, the IAST calculations severely over-predict the adsorption selectivity for equimolar $\mathrm{CO}_{2} / \mathrm{CH}_{4}$ mixtures in $\mathrm{NaX}$ zeolite because the actual competition faced by $\mathrm{CH}_{4}$ is less severe due to congregation effects; Figure S84b. Also shown in Figure $\mathrm{S} 84 \mathrm{~b}$ are the $\mathrm{CBMC}$ data for $\mathrm{CO}_{2} / \mathrm{CH}_{4}$ mixture adsorption in $\mathrm{NaY}$ zeolite $\left(138 \mathrm{Si}, 54 \mathrm{Al}, 54 \mathrm{Na}^{+}, \mathrm{Si} / \mathrm{Al}=2.56\right)$; the IAST estimates are also in excess of the CBMC data, but the departures are less than that experienced with $\mathrm{NaX}$.

\section{2 $\mathrm{CO}_{2} / \mathrm{C}_{3} \mathrm{H}_{8}$ mixture adsorption in $\mathrm{NaX}$ zeolite}

Three different $\mathrm{CBMC}$ simulation campaigns were conducted for $\mathrm{CO}_{2} / \mathrm{C}_{3} \mathrm{H}_{8}$ mixture adsorption in $\mathrm{NaX}$ zeolite at $300 \mathrm{~K}$. In Campaign A the composition of the bulk fluid mixture was maintained at $y_{1}=0.5$, and the total fluid phase mixture fugacity $f_{\mathrm{t}}$ was varied; the data analysis is shown in Figure S85. Figure S86, and Figure S87 show the results of two CBMC campaigns in which in which the total bulk fluid phase fugacity was maintained, respectively, at $f_{\mathrm{t}}=50 \mathrm{kPa}$, and $f_{\mathrm{t}}=1 \mathrm{MPa}$. The CBMC data for all three data sets were combined to determine the Margules parameters for use in the RAST.

With increasing $f_{\mathrm{t}}$ the IAST estimates become progressively worse; see Figure S85c. The RAST estimates of the component loadings are in good agreement with the CBMC data, as is to be expected. The RAST calculations of the activity coefficients of $\mathrm{CO}_{2}$, and $\mathrm{C}_{3} \mathrm{H}_{8}$ are shown in Figure S85e,f. Figure S86c, and Figure S87c. It is noteworthy that the activity coefficient of $\mathrm{CO}_{2}$ is virtually unity over the entire composition range. On the other hand, the activity coefficient of $\mathrm{C}_{3} \mathrm{H}_{8}$ shows increasing departure from unity with increasing bulk fluid phase fugacity $f_{\mathrm{t}}$. The activity coefficient of $\mathrm{C}_{3} \mathrm{H}_{8}$ shows increasing departure from unity with increasing mole fraction of $\mathrm{CO}_{2}$ in the adsorbed phase, $x_{1}$.

Figure S88 plots the adsorption selectivity $S_{a d s}$ for $\mathrm{CO}_{2}(1) / \mathrm{C}_{3} \mathrm{H}_{8}(2)$ mixture adsorption in NaX zeolite at $300 \mathrm{~K}$ for three different campaigns (Campaign A $\left(y_{1}=0.5\right)$ and Campaign $\mathrm{B}\left(f_{\mathrm{t}}=1 \mathrm{MPa}\right.$, and $f_{\mathrm{t}}=50$ $\mathrm{kPa}$ ), plotted as function of the surface potential $\Phi$. The IAST anticipates an unique dependence of $S_{a d s}$ 
on $\Phi$. The CBMC data however show that $S_{a d s}$ is not uniquely determined by surface potential $\Phi$ due to non-idealities that vary with composition of the adsorbed mixture.

Particularly remarkable are the results of Campaign B in which the total bulk fluid phase fugacity is maintained at $f_{\mathrm{t}}=50 \mathrm{kPa}$; see Figure $\mathrm{S} 86$. We note that as the mole fraction of $\mathrm{CO}_{2}$ in the bulk gas phase, $y_{1}$, is increased, the CBMC data shows selectivity reversal at $y_{1}>0.8$, in agreement with the experimental findings of Costa et al. ${ }^{65}$ This selectivity reversal in disfavor of $\mathrm{CO}_{2}$ is not anticipated by the IAST.

The failure of the IAST to provide quantitatively accurate estimates of component loadings, and adsorption selectivities is attributable to the inhomogeneous distribution of adsorbates in the pore space of $\mathrm{NaX}$ zeolite, caused by strong binding of $\mathrm{CO}_{2}$ with the extra-framework cations. The inhomogeneous distribution is clearly visualized by the computational snapshot in Figure S 89 for $f_{1}=0.5 \mathrm{MPa}$, and $f_{2}=$ $0.5 \mathrm{MPa}$. We note that the bottom cage contains only $\mathrm{CO}_{2}$, and there is no $\mathrm{C}_{3} \mathrm{H}_{8}$ present in that cage. One of the key assumptions of the IAST is that the distribution of adsorbates within the pore space is homogenous.

To quantify the inhomogeneous distribution of adsorbates, the CBMC simulation data on the spatial locations of the guest molecules were sampled to determine the inter-molecular distances. By sampling a total of $10^{7}$ simulation steps, the radial distribution of the separation distances between the molecular pairs $\mathrm{CO}_{2}-\mathrm{CO}_{2}, \mathrm{CO}_{2}-\mathrm{Na}^{+}, \mathrm{CO}_{2}-\mathrm{C}_{3} \mathrm{H}_{8}$, and $\mathrm{C}_{3} \mathrm{H}_{8}-\mathrm{C}_{3} \mathrm{H}_{8}$ were determined. Figure $\mathrm{S} 90$ presents the RDF data for a total fugacity $f_{\mathrm{t}}=1 \mathrm{MPa}$ and $y_{1}=0.5$. The samples were taken up to a radial distance of $12 \AA$, but the $x$ axis has been truncated at $8 \AA$ because only the first peaks are of interest in the discussions to follow. The plotted RDF data has been normalized such that the area under each of the curves is identical to one another (and equals 1000). If we compare the first peaks, it is noteworthy that the $\mathrm{CO}_{2}-\mathrm{CO}_{2}$, and $\mathrm{CO}_{2}$ $\mathrm{Na}^{+}$pairs are close together, indicating that the major proportion of $\mathrm{CO}_{2}$ congregates around the cations. A further point to note is that the $\mathrm{CO}_{2}-\mathrm{C}_{3} \mathrm{H}_{8}$ separation distance is significantly higher than the $\mathrm{CO}_{2}-\mathrm{CO}_{2}$ and $\mathrm{CO}_{2}-\mathrm{Na}^{+}$separation distances. This implies that the $\mathrm{C}_{3} \mathrm{H}_{8}$ molecules face a less severe competitive adsorption with $\mathrm{CO}_{2}$ than is anticipated by the IAST. 
Mixture adsorption in FAU (all-silica) and NaX zeolites

A different way to establish the reasons for the failure of the IAST is to compare the adsorption selectivities of $\mathrm{CO}_{2}(1) / \mathrm{C}_{3} \mathrm{H}_{8}(2)$ and $\mathrm{CH}_{4}(1) / \mathrm{C}_{3} \mathrm{H}_{8}(2)$ mixtures. For the mixture of alkanes, there are no segregation effects to be expected, and the IAST estimates are in good agreement with CBMC simulation data; see Figure S91. The IAST estimates become poor when we replace $\mathrm{CH}_{4}$ by $\mathrm{CO}_{2}$. 


\subsection{List of Tables for Mixture adsorption in FAU (all-silica) and NaX zeolites}

Table S17. Dual-site Langmuir parameters for pure components $\mathrm{CO}_{2}, \mathrm{CH}_{4}$, and $\mathrm{C}_{3} \mathrm{H}_{8}$ at $300 \mathrm{~K}$ in $\mathrm{NaX}$ zeolite containing $86 \mathrm{Na}^{+} / \mathrm{uc}$ with $\mathrm{Si} / \mathrm{Al}=1.23$. The fit parameters are based on the $\mathrm{CBMC}$ simulations of pure component isotherms.

\begin{tabular}{|c|c|c|c|c|}
\hline & \multicolumn{2}{|l|}{ Site A } & \multicolumn{2}{|l|}{ Site B } \\
\hline & $\begin{array}{l}q_{\mathrm{A}, \mathrm{sat}} \\
\mathrm{mol} \mathrm{kg}{ }^{-1}\end{array}$ & $\begin{array}{l}b_{\mathrm{A}} \\
\mathrm{Pa}^{-1}\end{array}$ & $\begin{array}{l}q_{\mathrm{B}, \mathrm{sat}} \\
\mathrm{mol} \mathrm{kg}{ }^{-1}\end{array}$ & $\begin{array}{l}b_{\mathrm{B}} \\
\mathrm{Pa}^{-1}\end{array}$ \\
\hline $\mathrm{CO}_{2}$ & 1.7 & $1.39 \times 10^{-5}$ & 4.2 & $4.78 \times 10^{-4}$ \\
\hline $\mathrm{CH}_{4}$ & 5.8 & $2.07 \times 10^{-6}$ & & \\
\hline $\mathrm{C}_{3} \mathrm{H}_{8}$ & 3.1 & $8.91 \times 10^{-4}$ & 0.65 & $4.09 \times 10^{-6}$ \\
\hline
\end{tabular}

Fitted Margules non-ideality parameters for binary mixture adsorption in $\mathrm{NaX}$ at $300 \mathrm{~K}$.

\begin{tabular}{|l|l|l|l|}
\hline & $C / \mathrm{kg} \mathrm{mol}^{-1}$ & $A 12$ & $A 21$ \\
\hline $\mathrm{CO}_{2} / \mathrm{CH}_{4}$ in $\mathrm{NaX}$ & 1.021 & -0.632 & -0.693 \\
\hline $\mathrm{CO}_{2} / \mathrm{C}_{3} \mathrm{H}_{8}$ in $\mathrm{NaX}$ & 0.038 & -3.082 & -2.170 \\
\hline
\end{tabular}


Table S18. Dual-site Langmuir-Freundlich parameters for pure components $\mathrm{CO}_{2}, \mathrm{CH}_{4}, \mathrm{H}_{2}$, and $\mathrm{N}_{2}$ at $300 \mathrm{~K}$ in all-silica FAU. The fit parameters are based on the CBMC simulations of pure component isotherms presented in earlier works. ${ }^{11,64,66}$

\begin{tabular}{|c|c|c|c|c|c|c|}
\hline & \multicolumn{3}{|l|}{ Site A } & \multicolumn{3}{|l|}{ Site B } \\
\hline & $\begin{array}{l}q_{\mathrm{A}, \mathrm{sat}} \\
\mathrm{mol} \mathrm{kg}^{-1}\end{array}$ & $\begin{array}{l}b_{\mathrm{A}} \\
\mathrm{Pa}^{-v_{A}}\end{array}$ & $\begin{array}{l}v_{\mathrm{A}} \\
\text { dimensionless }\end{array}$ & $\begin{array}{l}q_{\mathrm{B}, \mathrm{sat}} \\
\mathrm{mol} \mathrm{kg}^{-1}\end{array}$ & $\begin{array}{l}b_{\mathrm{B}} \\
\mathrm{Pa}^{-v_{B}}\end{array}$ & $\begin{array}{l}\nu_{\mathrm{B}} \\
\text { dimensionless }\end{array}$ \\
\hline $\mathrm{CO}_{2}$ & 2.4 & $2.52 \times 10^{-14}$ & 2.4 & 6.7 & $6.74 \times 10^{-7}$ & 1 \\
\hline $\mathrm{CH}_{4}$ & 4 & $7 \times 10^{-9}$ & 0.86 & 6.5 & $2.75 \times 10^{-7}$ & 1 \\
\hline $\mathrm{H}_{2}$ & 6.9 & $3.506 \mathrm{E}-08$ & 1 & 16.7 & $3.848 \mathrm{E}-09$ & 1 \\
\hline $\mathrm{N}_{2}$ & 5.2 & $1.55 \times 10^{-9}$ & 1 & 5.8 & $1.32 \times 10^{-7}$ & 1 \\
\hline
\end{tabular}


15.4 List of Figures for Mixture adsorption in FAU (all-silica) and NaX zeolites

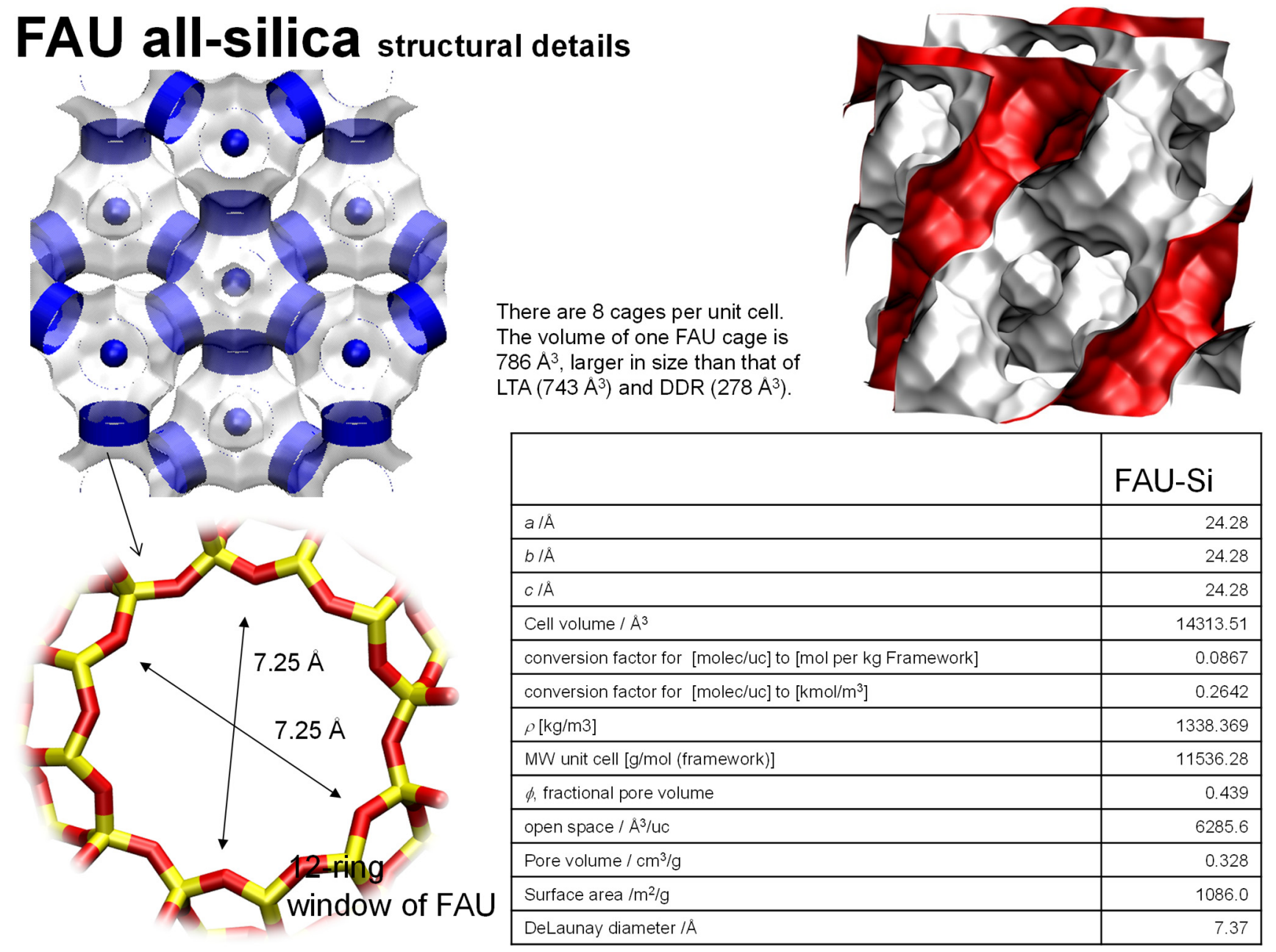

Figure S78. Pore landscape for all-silica FAU zeolite. 


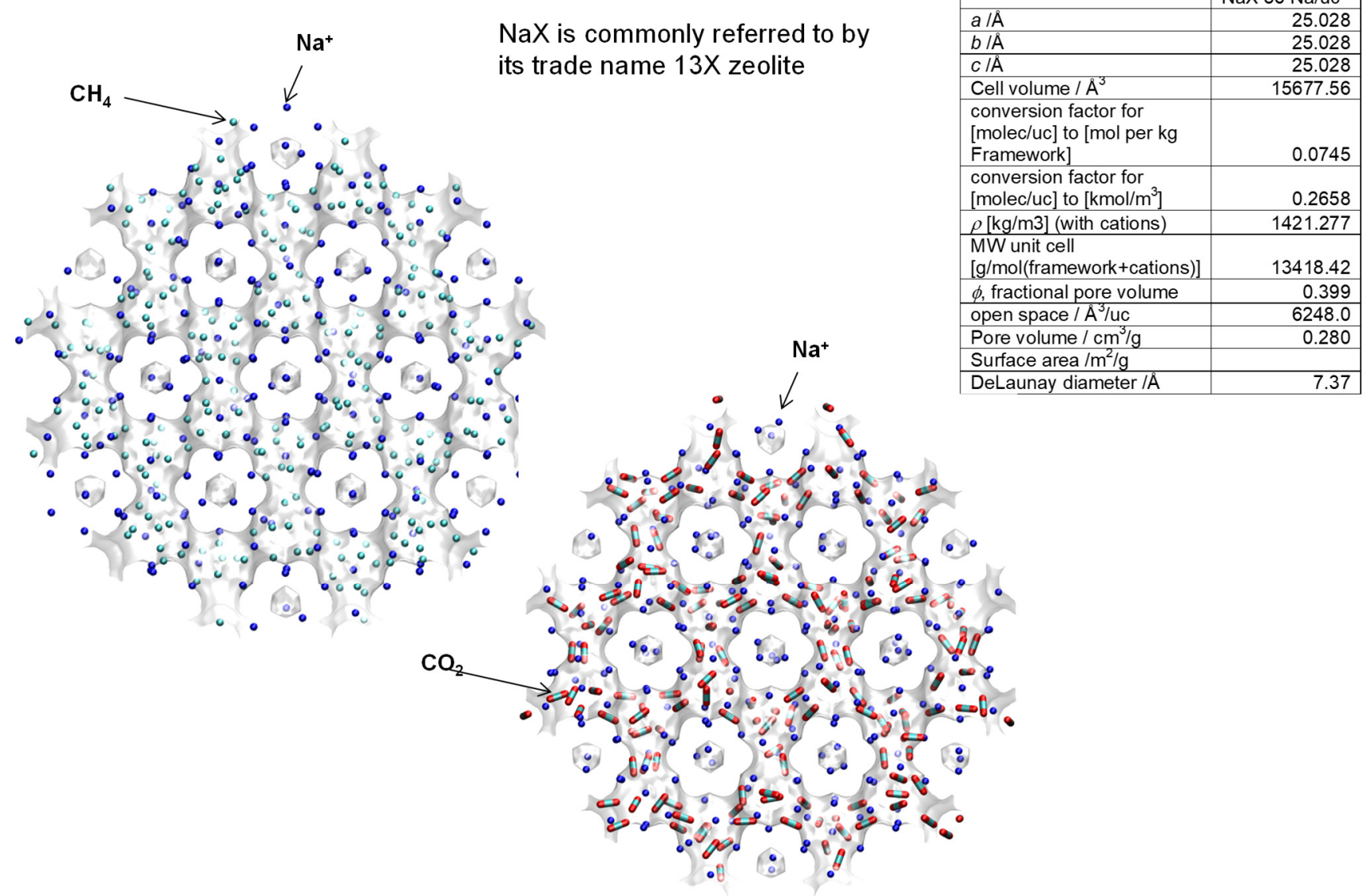

Figure S79. Structural details for $\mathrm{NaX}$ zeolite (106 Si, $86 \mathrm{Al}, 86 \mathrm{Na}^{+}, \mathrm{Si} / \mathrm{Al}=1.23$ ) 
a
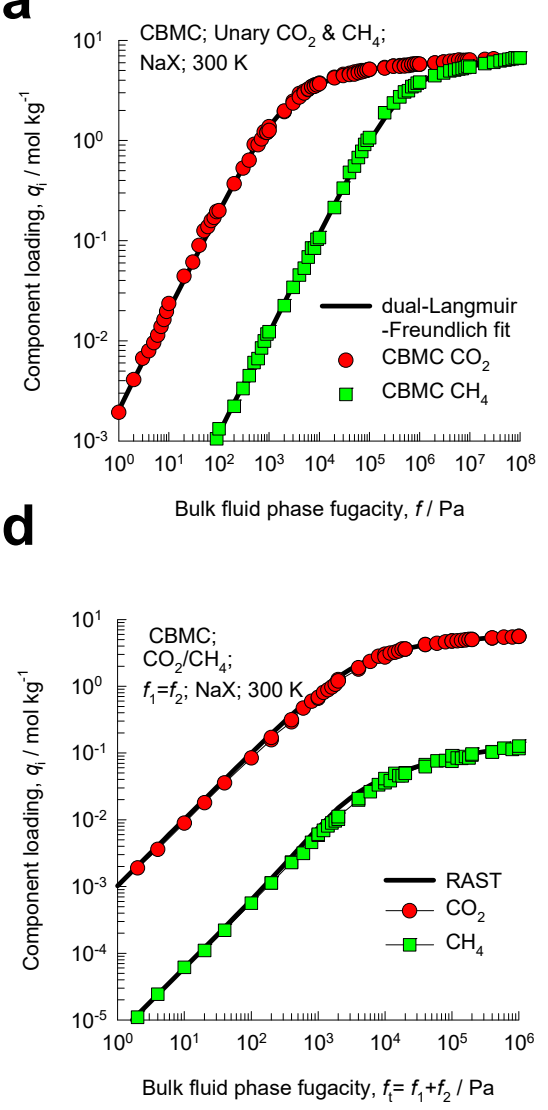

b
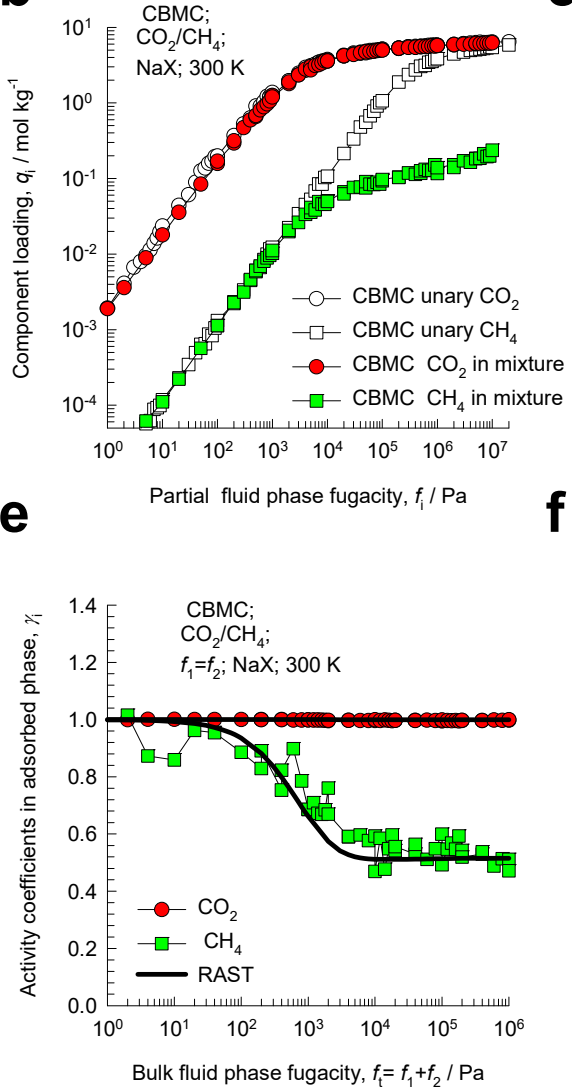

C

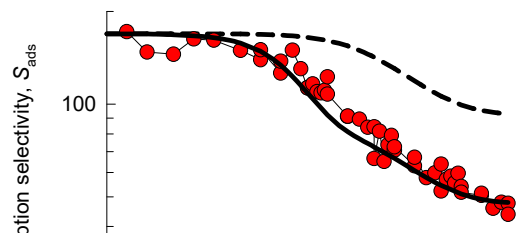

f

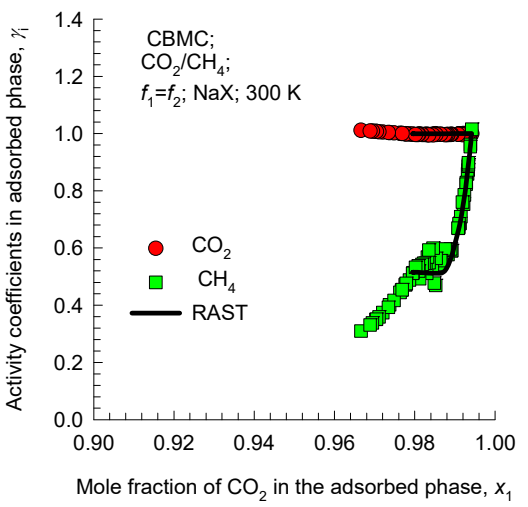

Figure S80. CBMC simulation data and analysis for Campaign $\mathrm{A}\left(y_{1}=0.5\right)$ for $\mathrm{CO}_{2}(1) / \mathrm{CH}_{4}(2)$ mixture adsorption in $\mathrm{NaX}$ zeolite at $300 \mathrm{~K}$. (a) Unary isotherms and fits. (b) Component loadings in mixture compared with CBMC simulations of unary isotherms. (c) $\mathrm{CBMC}$ data for $\mathrm{CO}_{2}(1) / \mathrm{CH}_{4}(2)$ adsorption selectivity compared with IAST and RAST estimates. (d) CBMC data for component loadings in mixture compared with RAST estimates. (e, f) Activity coefficients from CBMC compared with RAST model calculations. The unary isotherm fit parameters and Margules parameters are provided in Table S17. 
a

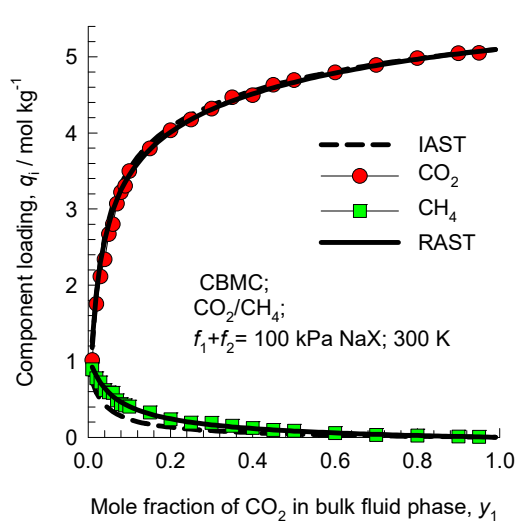

b

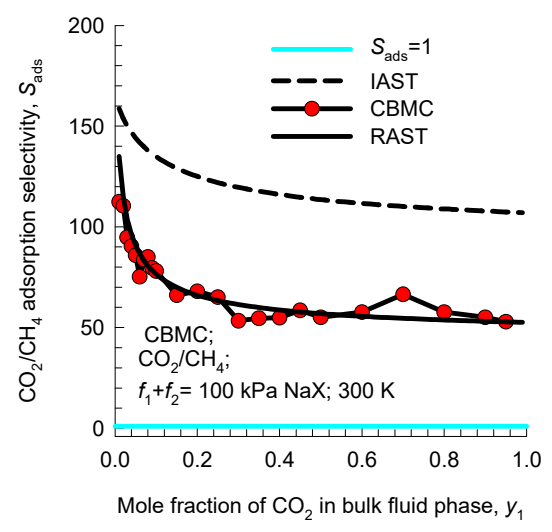

C

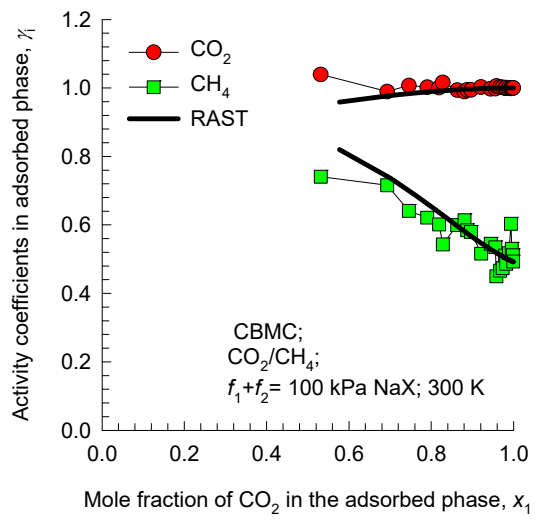

Figure S81. CBMC simulation data and analysis for Campaign B $\left(f_{\mathrm{t}}=100 \mathrm{kPa}\right)$ for $\mathrm{CO}_{2}(1) / \mathrm{CH}_{4}(2)$ mixture adsorption in $\mathrm{NaX}$ zeolite at $300 \mathrm{~K}$. CBMC data for (a) component loadings and (b) $\mathrm{CO}_{2}(1) /$ $\mathrm{CH}_{4}(2)$ adsorption selectivity compared with IAST and RAST estimates. (c) Activity coefficients from CBMC compared with RAST model calculations. The unary isotherm fit parameters and Margules parameters are provided in Table S17. 

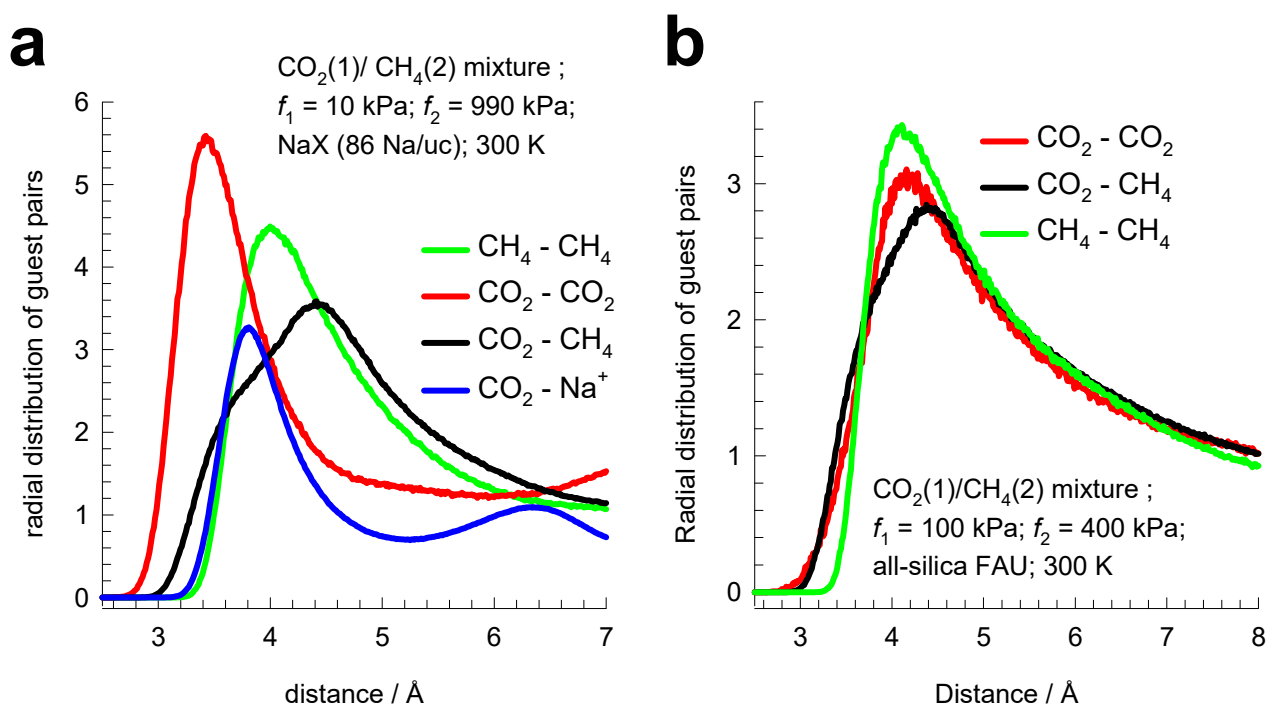

Figure S82. (a) Radial distribution of guest pairs determined from CBMC simulations for adsorption of $\mathrm{CO}_{2} / \mathrm{CH}_{4}$ mixtures in $\mathrm{NaX}$ zeolite at $300 \mathrm{~K}$ and total fugacity $f_{\mathrm{t}}=1 \mathrm{MPa}$, and $y_{1}=0.01$. (b) Radial distribution of guest pairs determined from CBMC simulations for adsorption of $\mathrm{CO}_{2} / \mathrm{CH}_{4}$ mixtures in all-silica FAU zeolite at $300 \mathrm{~K}$ and total fugacity $f_{\mathrm{t}}=500 \mathrm{kPa}$, and $y_{1}=0.2$. 


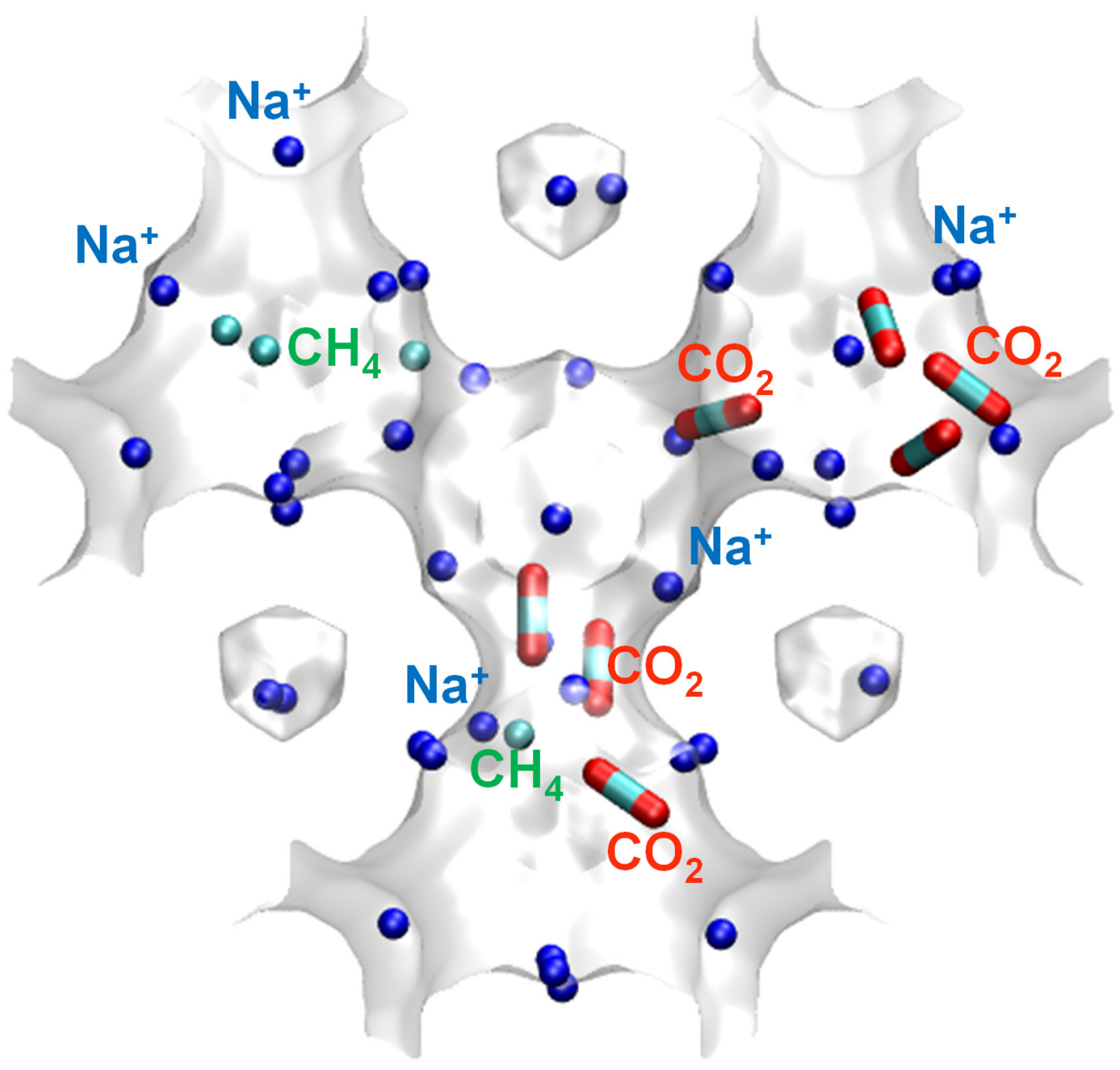

Figure S83. Snapshot showing the location of $\mathrm{CO}_{2}, \mathrm{CH}_{4}$, and $\mathrm{Na}+$ cations within the pore landscape of $\mathrm{NaX}\left(106 \mathrm{Si}, 86 \mathrm{Al}, 86 \mathrm{Na}^{+}, \mathrm{Si} / \mathrm{Al}=1.23\right)$ zeolite at $300 \mathrm{~K}$ and total fugacity $f_{\mathrm{t}}=100 \mathrm{kPa}$, and $y_{1}=0.02$. 
a

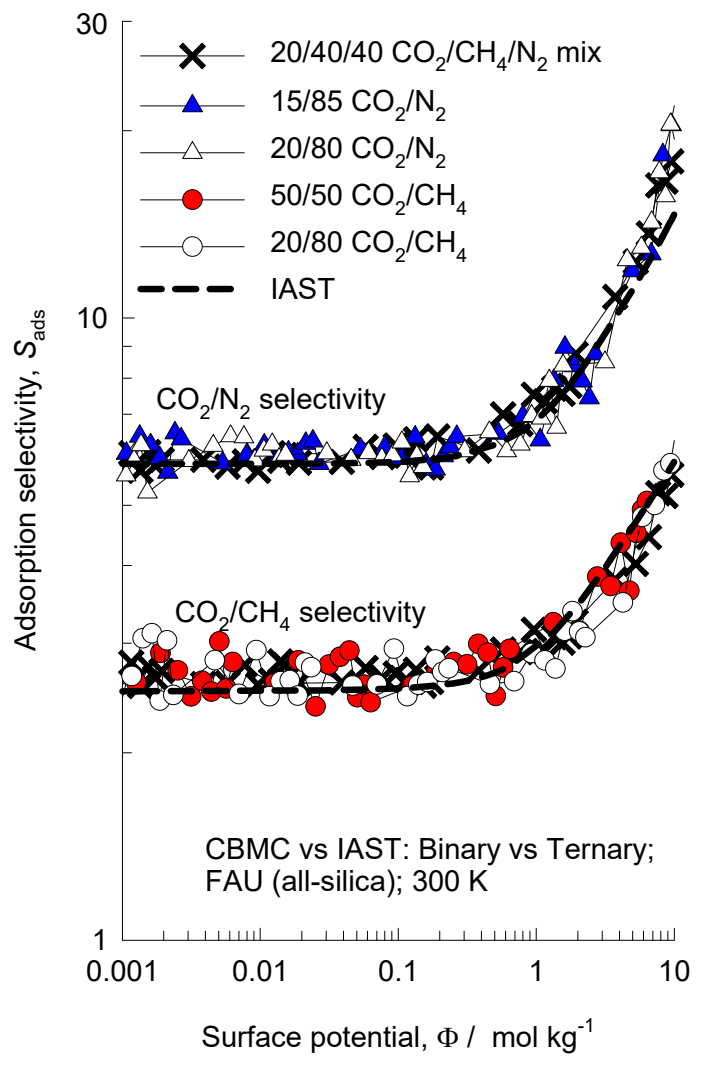

b

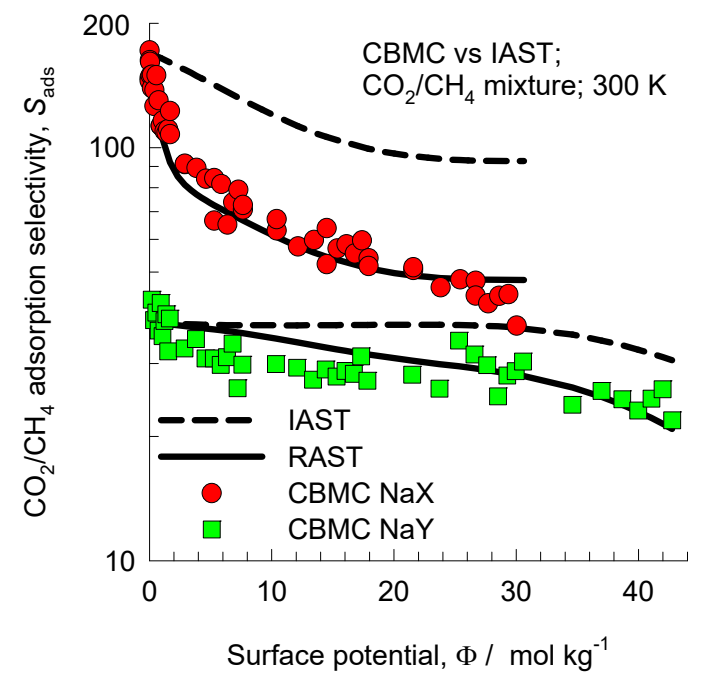

Figure S84. (a) CBMC data for adsorption selectivity of 50/50 $\mathrm{CO}_{2} / \mathrm{CH}_{4}, 20 / 80 \mathrm{CO}_{2} / \mathrm{CH}_{4}, 15 / 85$ $\mathrm{CO}_{2} / \mathrm{N}_{2}, 20 / 80 \mathrm{CO}_{2} / \mathrm{N}_{2}$, and $20 / 40 / 40 \mathrm{CO}_{2} / \mathrm{CH}_{4} / \mathrm{N}_{2}$ mixtures in all-silica FAU. (b) Comparison $\mathrm{CO}_{2} / \mathrm{CH}_{4}$ adsorption selectivities determined from CBMC simulations for $\mathrm{NaY}$ (138 Si, $54 \mathrm{Al}, 54 \mathrm{Na}^{+}, \mathrm{Si} / \mathrm{Al}=2.56$ ), and $\mathrm{NaX}\left(106 \mathrm{Si}, 86 \mathrm{Al}, 86 \mathrm{Na}^{+}, \mathrm{Si} / \mathrm{Al}=1.23\right)$ zeolites for at $300 \mathrm{~K}$. The $x$-axes represent the surface potential $\Phi$. The continuous solid and dashed lines are the RAST, and IAST estimations, respectively. 

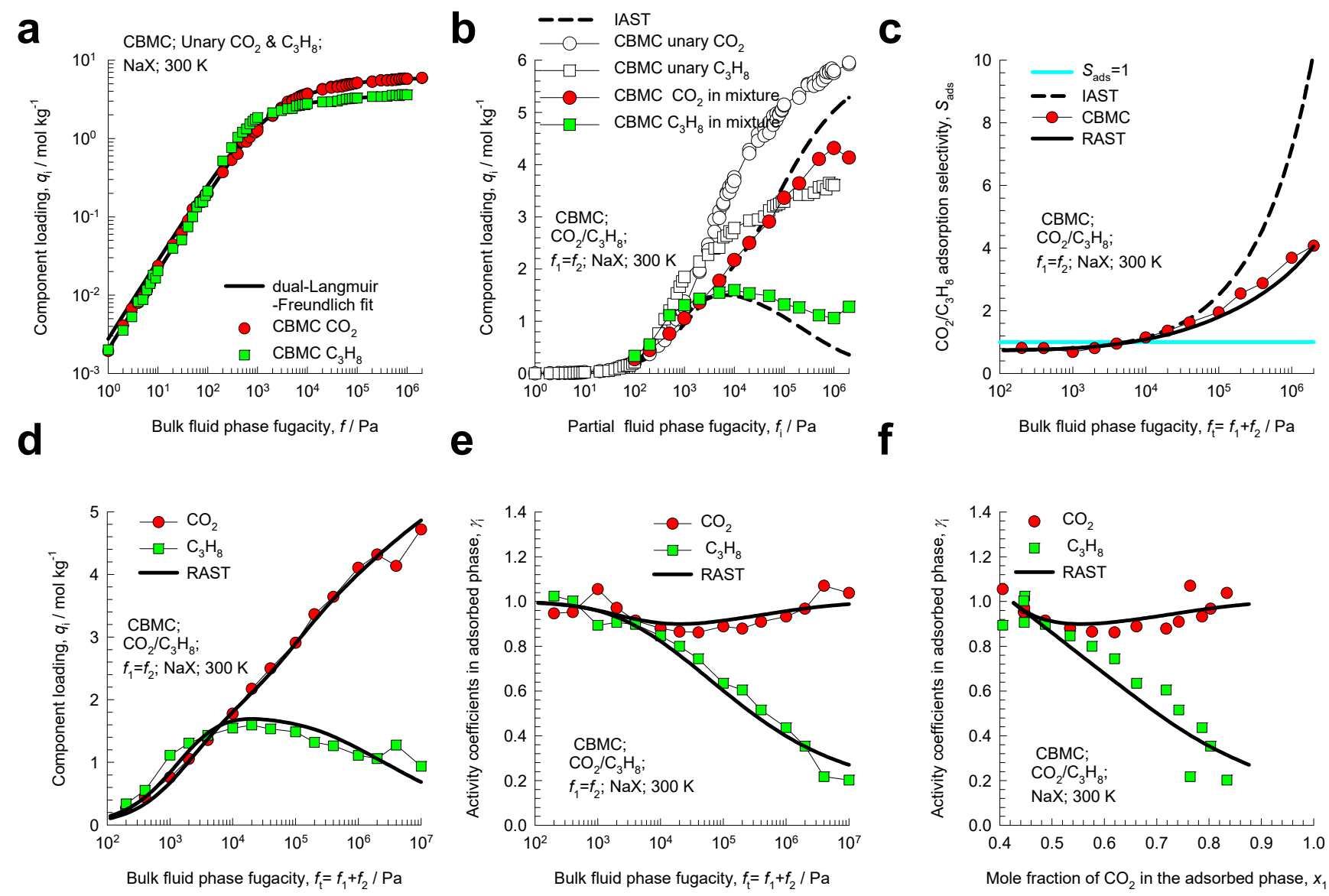

Figure S85. CBMC simulation data and analysis for Campaign $\mathrm{A}\left(y_{1}=0.5\right)$ for $\mathrm{CO}_{2}(1) / \mathrm{C}_{3} \mathrm{H}_{8}(2)$ mixture adsorption in $\mathrm{NaX}$ zeolite at $300 \mathrm{~K}$. (a) Unary isotherms and fits. (b) Component loadings in mixture compared with CBMC simulations of unary isotherms. (c) $\mathrm{CBMC}$ data for $\mathrm{CO}_{2}(1) / \mathrm{C}_{3} \mathrm{H}_{8}(2)$ adsorption selectivity compared with IAST and RAST estimates. (d) CBMC data for component loadings in mixture compared with RAST estimates. (e, f) Activity coefficients from CBMC compared with RAST model calculations. The unary isotherm fit parameters and Margules parameters are provided in Table S17. 

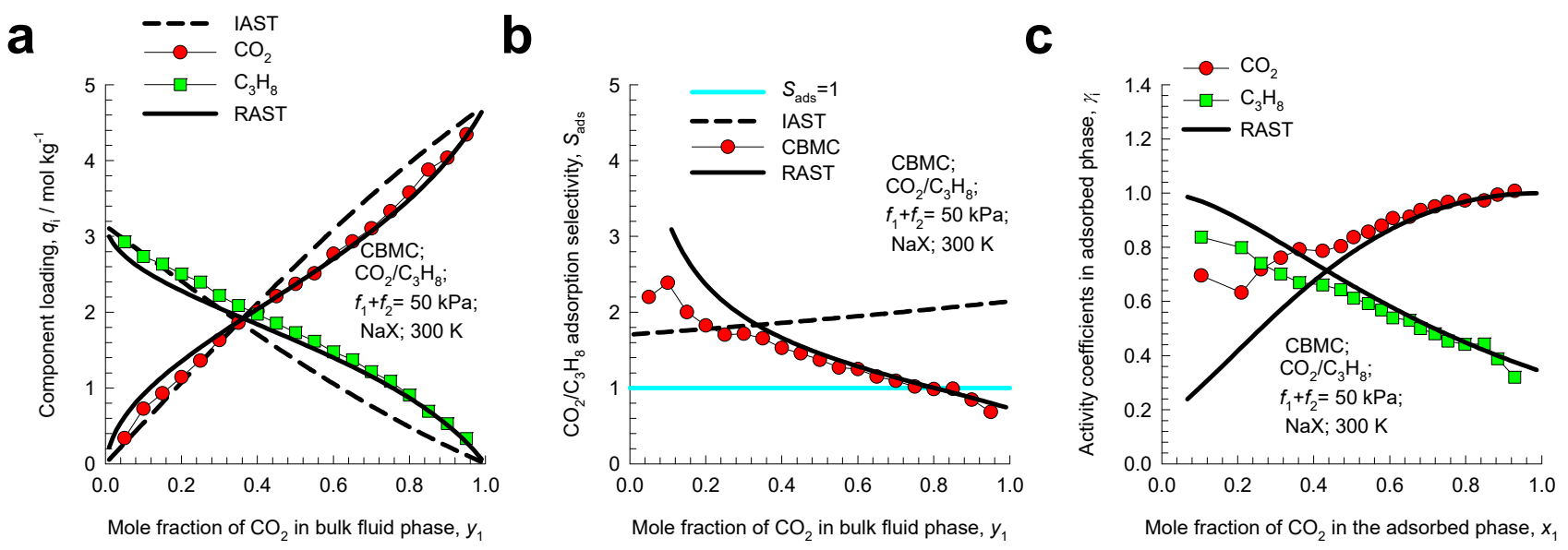

Figure S86. CBMC simulation data and analysis for Campaign $\mathrm{B}\left(f_{\mathrm{t}}=50 \mathrm{kPa}\right)$ for $\mathrm{CO}_{2}(1) / \mathrm{C}_{3} \mathrm{H}_{8}(2)$ mixture adsorption in $\mathrm{NaX}$ zeolite at $300 \mathrm{~K}$. CBMC data for (a) component loadings and (b) $\mathrm{CO}_{2}(1) /$ $\mathrm{C}_{3} \mathrm{H}_{8}(2)$ adsorption selectivity compared with IAST and RAST estimates. (c) Activity coefficients from CBMC compared with RAST model calculations. The unary isotherm fit parameters and Margules parameters are provided in Table S17. 

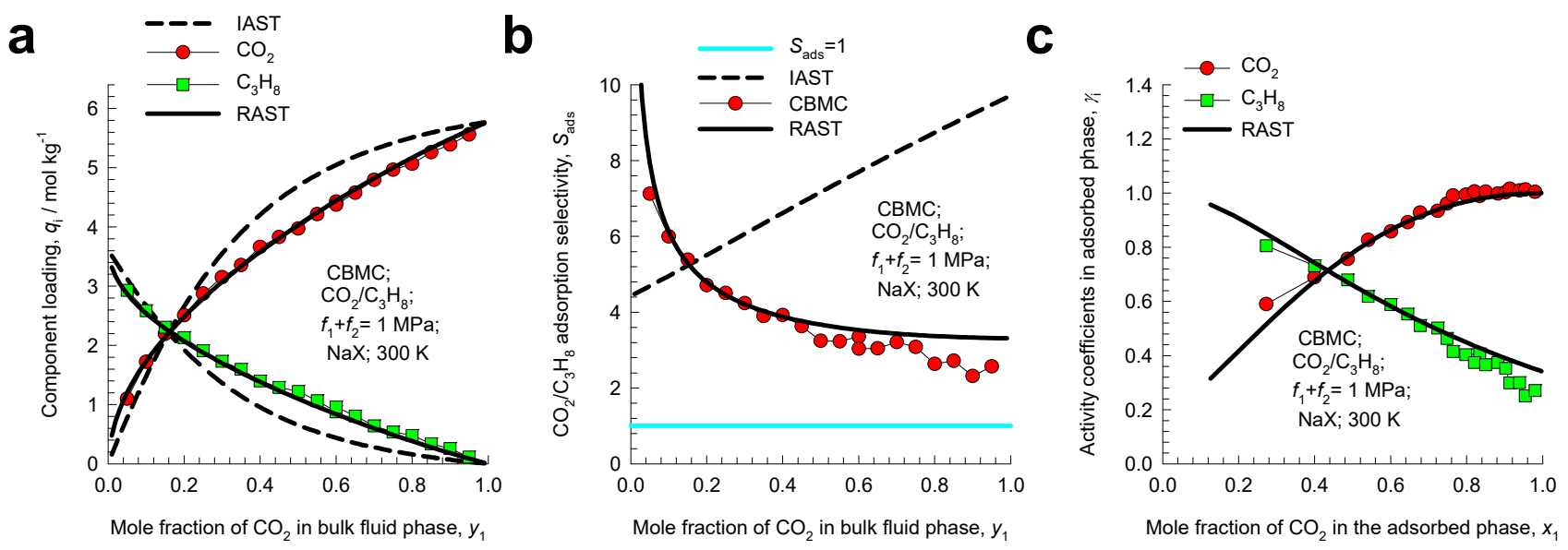

Figure S87. CBMC simulation data and analysis for Campaign $\mathrm{B}\left(f_{\mathrm{t}}=1 \mathrm{MPa}\right)$ for $\mathrm{CO}_{2}(1) / \mathrm{C}_{3} \mathrm{H}_{8}(2)$ mixture adsorption in $\mathrm{NaX}$ zeolite at $300 \mathrm{~K}$. CBMC data for (a) component loadings and (b) $\mathrm{CO}_{2}(1) /$ $\mathrm{C}_{3} \mathrm{H}_{8}(2)$ adsorption selectivity compared with IAST and RAST estimates. (c) Activity coefficients from CBMC compared with RAST model calculations. The unary isotherm fit parameters and Margules parameters are provided in Table S17. 


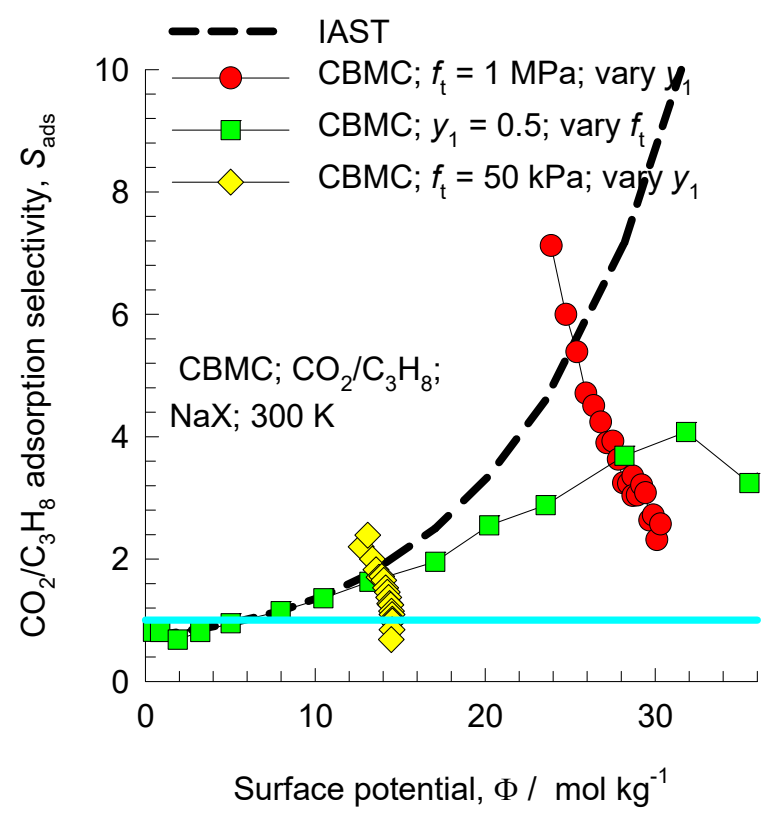

Figure S88. Adsorption selectivity $S_{a d s}$ for $\mathrm{CO}_{2}(1) / \mathrm{C}_{3} \mathrm{H}_{8}(2)$ mixture adsorption in NaX zeolite at 300 $\mathrm{K}$ for three different campaigns (Campaign A $\left(y_{1}=0.5\right)$ and Campaign $\mathrm{B}\left(f_{\mathrm{t}}=1 \mathrm{MPa}\right.$, and $\left.f_{\mathrm{t}}=50 \mathrm{kPa}\right)$, plotted as function of the surface potential $\Phi$. The CBMC simulated values (indicated by symbols) are compared with IAST estimates (indicated by the dashed lines). The unary isotherm fit parameters and Margules parameters are provided in Table S17. 
$\mathrm{CO}_{2} / \mathrm{C}_{3} \mathrm{H}_{8}$ mixture adsorption in $\mathrm{NaX}(=13 \mathrm{X})$ zeolite;

Snapshot for $f_{\mathrm{CO} 2}=500 \mathrm{kPa} ; f_{\mathrm{C} 3 \mathrm{H} 8}=500 \mathrm{kPa}$

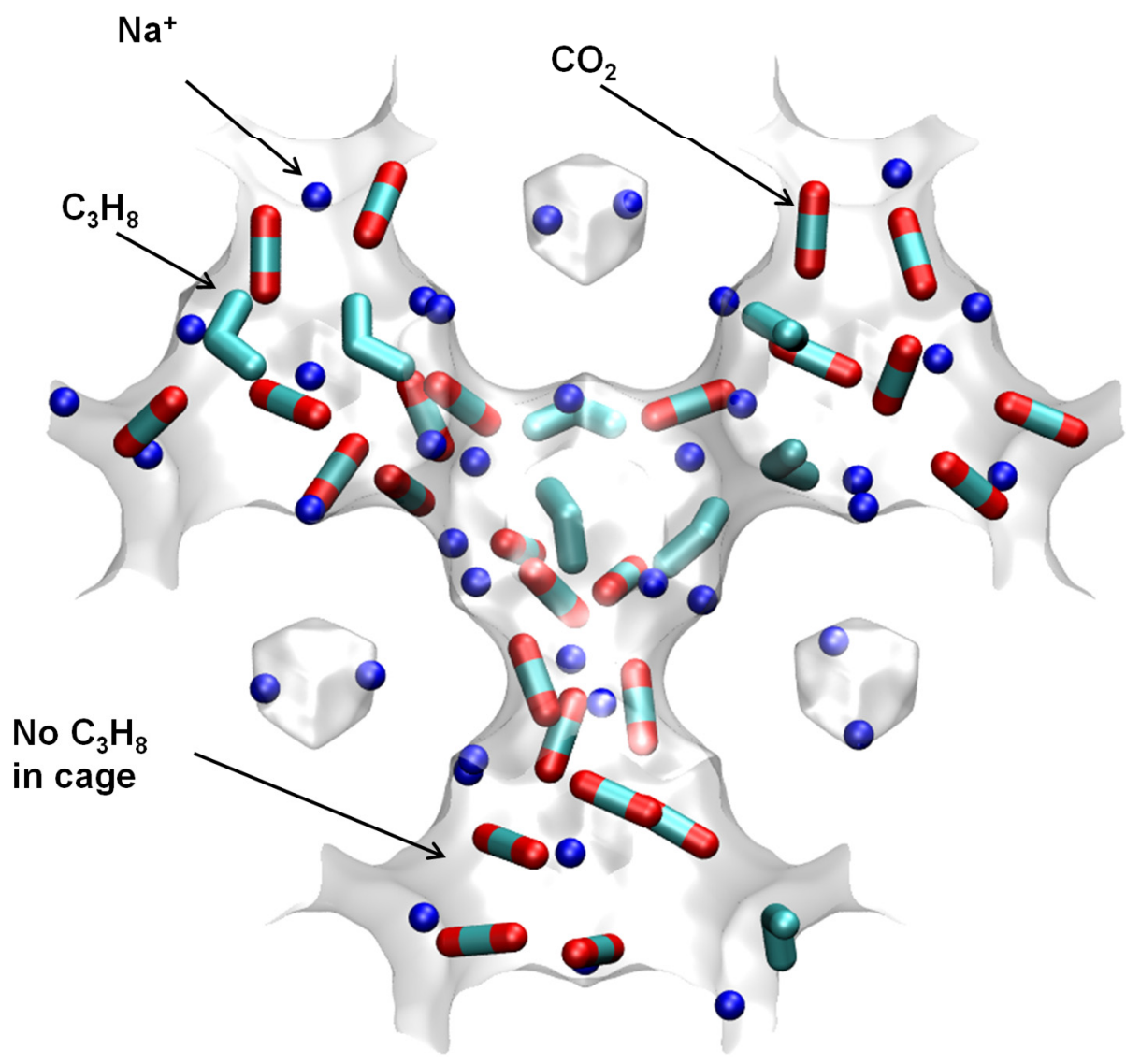

Figure S89. Computational snapshots showing the location of $\mathrm{CO}_{2}$, and $\mathrm{C}_{3} \mathrm{H}_{8}$ within the cages of $\mathrm{NaX}$ zeolite at $300 \mathrm{~K}$ and total fugacity $f_{\mathrm{t}}=1 \mathrm{MPa}$. The component partial fugacities are $f_{1}=0.5 \mathrm{MPa}$, and $f_{2}$ $=0.5 \mathrm{MPa}$. 


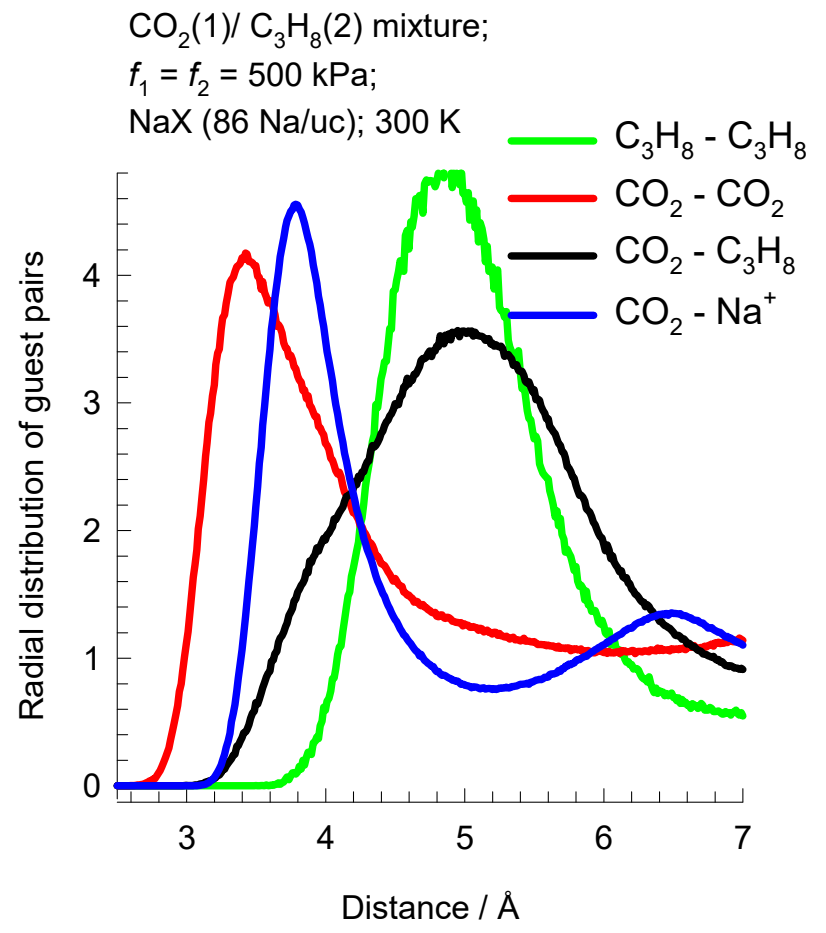

Figure S90. Radial distribution of guest pairs determined from CBMC simulations for adsorption of $\mathrm{CO}_{2} / \mathrm{C}_{3} \mathrm{H}_{8}$ mixtures in $\mathrm{NaX}$ zeolite at $300 \mathrm{~K}$ and total fugacity $f_{\mathrm{t}}=1 \mathrm{MPa}$, and $y_{1}=0.5$. 


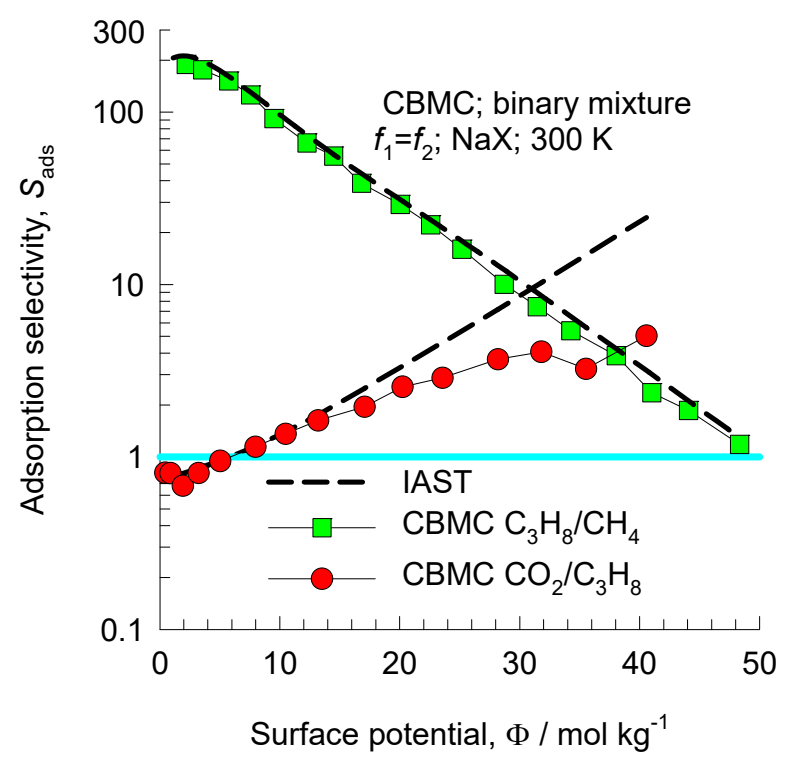

Figure S91. Adsorption selectivity $S_{a d s}$ for equimolar $\left(f_{1}=f_{2} ; y_{1}=0.5\right) \quad \mathrm{CO}_{2}(1) / \mathrm{C}_{3} \mathrm{H}_{8}(2)$ and $\mathrm{C}_{3} \mathrm{H}_{8}(1) / \mathrm{CH}_{4}(2)$ mixture adsorption in $\mathrm{NaX}$ zeolite at $300 \mathrm{~K}$, plotted as function of the surface potential $\Phi$. The CBMC simulated values (indicated by symbols) are compared with IAST estimates (indicated by the dashed lines). 


\section{$16 \mathrm{CO}_{2} / \mathrm{CH}_{4}$ mixture adsorption in $\mathrm{Mg}_{2}$ (dobdc)}

The pore landscapes and structural details of $\mathrm{Mg}_{2}$ (dobdc) are presented in Figure S92, and Figure S93. This MOF consists of 1D hexagonal-shaped channels of $11 \AA$.

Computational snapshots in Figure $\mathrm{S} 94$ demonstrate that $\mathrm{CO}_{2}$ molecules are in close proximity to the open metal $\mathrm{Mg}^{2+}$ sites, whereas non-polar guests such as $\mathrm{CH}_{4}$ are farther removed and are predominantly located at the channel interiors. Put another way, the guest molecules for $\mathrm{CO}_{2} / \mathrm{CH}_{4}$ mixture adsorption are distributed non-homogeneously within the channels.

Figure S95 presents CBMC simulation data for adsorption of equimolar (partial fugacities $f_{1}=f_{2}$ ) $\mathrm{CO}_{2} / \mathrm{CH}_{4}$ mixtures in $\mathrm{Mg}_{2}\left(\right.$ dobdc) at $300 \mathrm{~K}$. The conventional IAST calculation assumes that $\mathrm{CH}_{4}$ molecules compete with all of the $\mathrm{CO}_{2}$, making no allowance for segregation. Due to segregation effects the competition faced by $\mathrm{CH}_{4}$ molecules within the channel interiors, where they almost exclusively reside, is smaller than that in the entire pore space. The IAST anticipates a stiffer competition between $\mathrm{CO}_{2}$ and $\mathrm{CH}_{4}$ as it assumes a uniform distribution of composition; consequently, the adsorption selectivity is overestimated. The estimations of the RAST with fitted Wilson parameters, are shown by the continuous solid lines.

Figure S96 plots the adsorption selectivity $S_{a d s}$ for equimolar $\left(f_{1}=f_{2} ; \quad y_{1}=0.5\right) \mathrm{CO}_{2}(1) / \mathrm{CH}_{4}(2)$ and $\mathrm{CO}_{2}(1) / \mathrm{N}_{2}(2)$ mixture adsorption in $\mathrm{Mg}_{2}($ dobdc) at $300 \mathrm{~K}$, as function of the surface potential $\Phi$. The CBMC simulated values (indicated by symbols) are compared with IAST estimates (indicated by the dashed lines). For both mixtures, the IAST tends to overestimate the selectivities due to segregated nature of adsorption. 


\subsection{List of Tables for $\mathrm{CO} 2 / \mathrm{CH} 4$ mixture adsorption in Mg2(dobdc)}

Table S19. Dual-site Langmuir-Freundlich parameters for guest molecules in $\mathrm{Mg}_{2}(\mathrm{dobdc})$ at $300 \mathrm{~K}$.

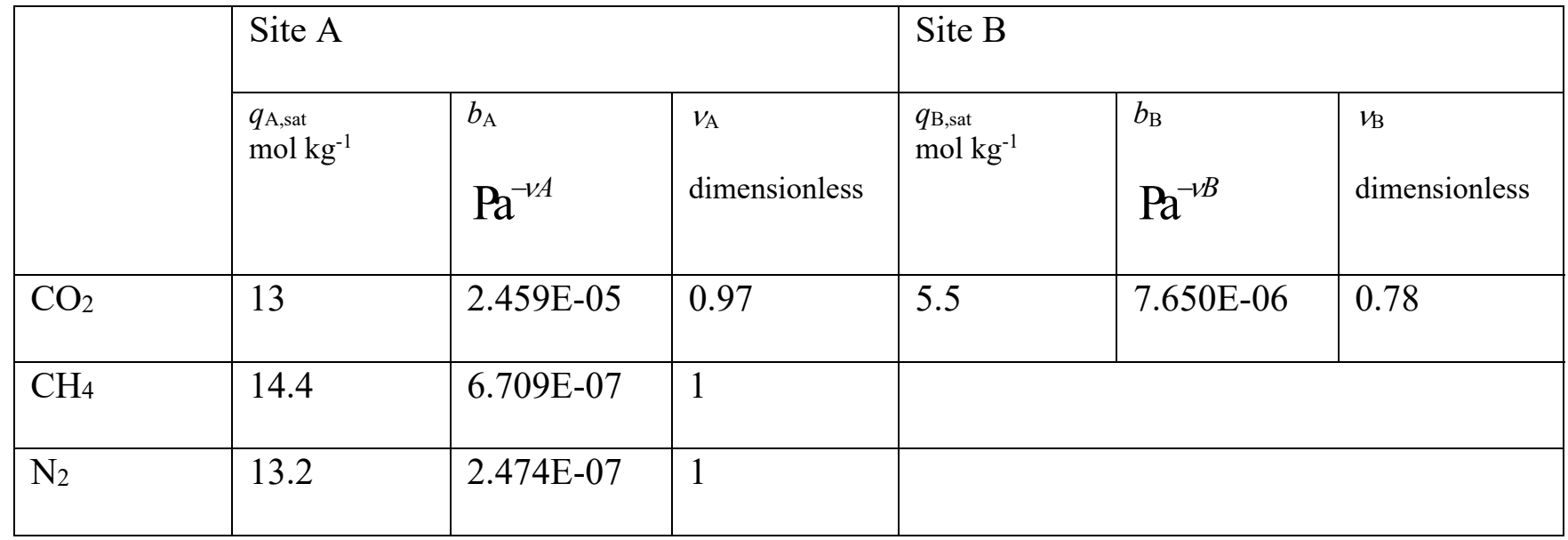

Fitted Wilson non-ideality parameters for binary $\mathrm{CO}_{2} / \mathrm{CH}_{4}$ mixture adsorption in $\mathrm{Mg}_{2}$ (dobdc) at $300 \mathrm{~K}$.

\begin{tabular}{|l|l|l|l|}
\hline & $C / \mathrm{kg} \mathrm{mol}^{-1}$ & $\Lambda_{12}$ & $\Lambda_{21}$ \\
\hline $\mathrm{CO}_{2} / \mathrm{CH}_{4}$ & 0.056 & 3.622 & 0.167 \\
\hline
\end{tabular}




\subsection{List of Figures for $\mathrm{CO} 2 / \mathrm{CH} 4$ mixture adsorption in $\mathrm{Mg2}$ (dobdc)}

\section{$\mathbf{M g}_{2}($ dobdc $)$ pore landscapes}
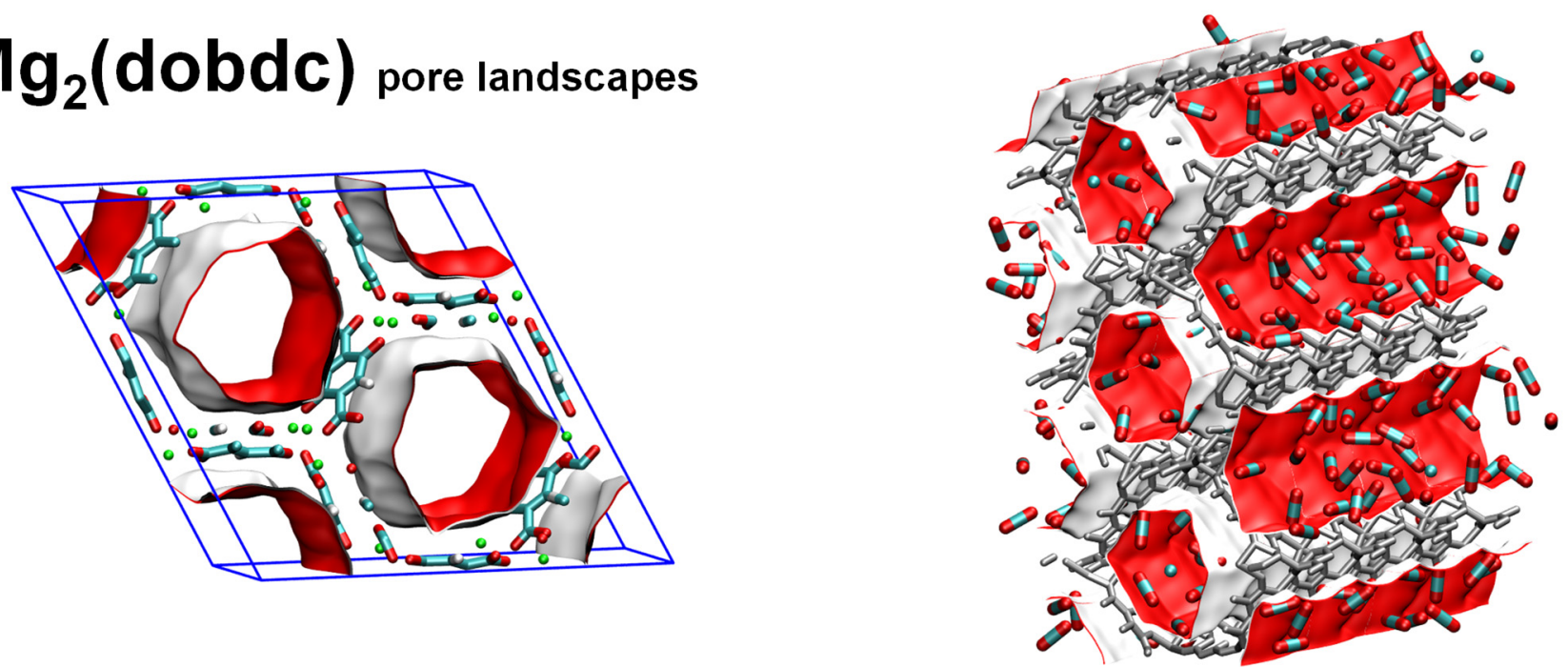

2,5- dioxido-1,4benzenedicarboxylate $=$ dobdc $^{4}$ -<smiles>O=C([O-])c1cc([O-])c(C(=O)[O-])cc1[O-]</smiles>

$\mathrm{Mg}_{2}$ (dobdc) $\mathrm{Mg}$
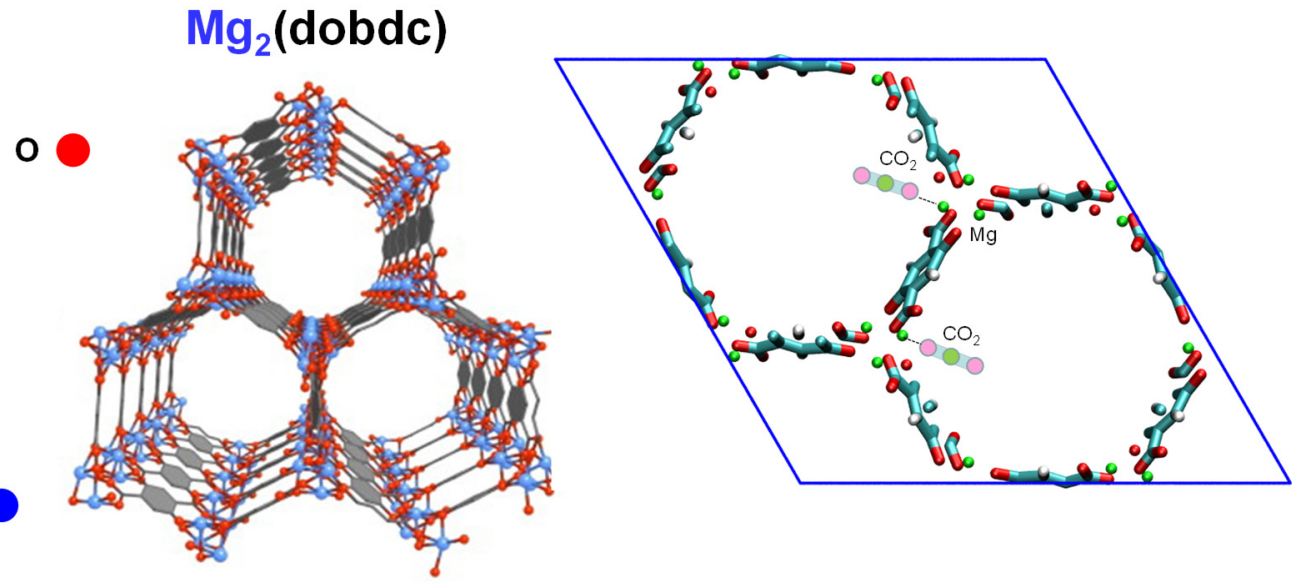

Figure S92. Pore landscape of $\mathrm{Mg}_{2}$ (dobdc). 


\section{$\mathbf{M g}_{2}($ dobdc) pore dimensions}

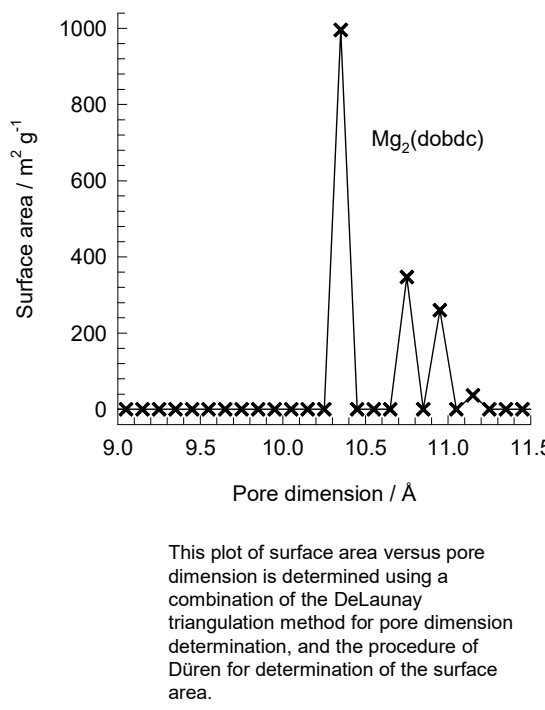

\begin{tabular}{|l|r|}
\hline & MgMOF-74 \\
\hline$a / \AA$ & 25.8621 \\
\hline$b / \AA$ & 25.8621 \\
\hline$c / \AA$ & 6.91427 \\
\hline Cell volume / ${ }^{3}$ & 4005.019 \\
\hline conversion factor for [molec/uc] to $[\mathrm{mol}$ per $\mathrm{kg}$ Framework] & 0.4580 \\
\hline conversion factor for $[\mathrm{molec} / \mathrm{uc}]$ to $\left[\mathrm{kmol} / \mathrm{m}^{3}\right]$ & 0.5856 \\
\hline$\rho[\mathrm{kg} / \mathrm{m} 3]$ & 905.367 \\
\hline MW unit cell $[\mathrm{g} / \mathrm{mol}($ framework$)]$ & 2183.601 \\
\hline$\phi$, fractional pore volume & 0.708 \\
\hline open space $/ \AA^{3} / \mathrm{uc}$ & 2835.6 \\
\hline Pore volume $/ \mathrm{cm}^{3} / \mathrm{g}$ & 0.782 \\
\hline Surface area $/ \mathrm{m}^{2} / \mathrm{g}$ & 1640.0 \\
\hline DeLaunay diameter $/ \AA$ & 10.66 \\
\hline
\end{tabular}

Figure S93. Structural details for $\mathrm{Mg}_{2}$ (dobdc). 

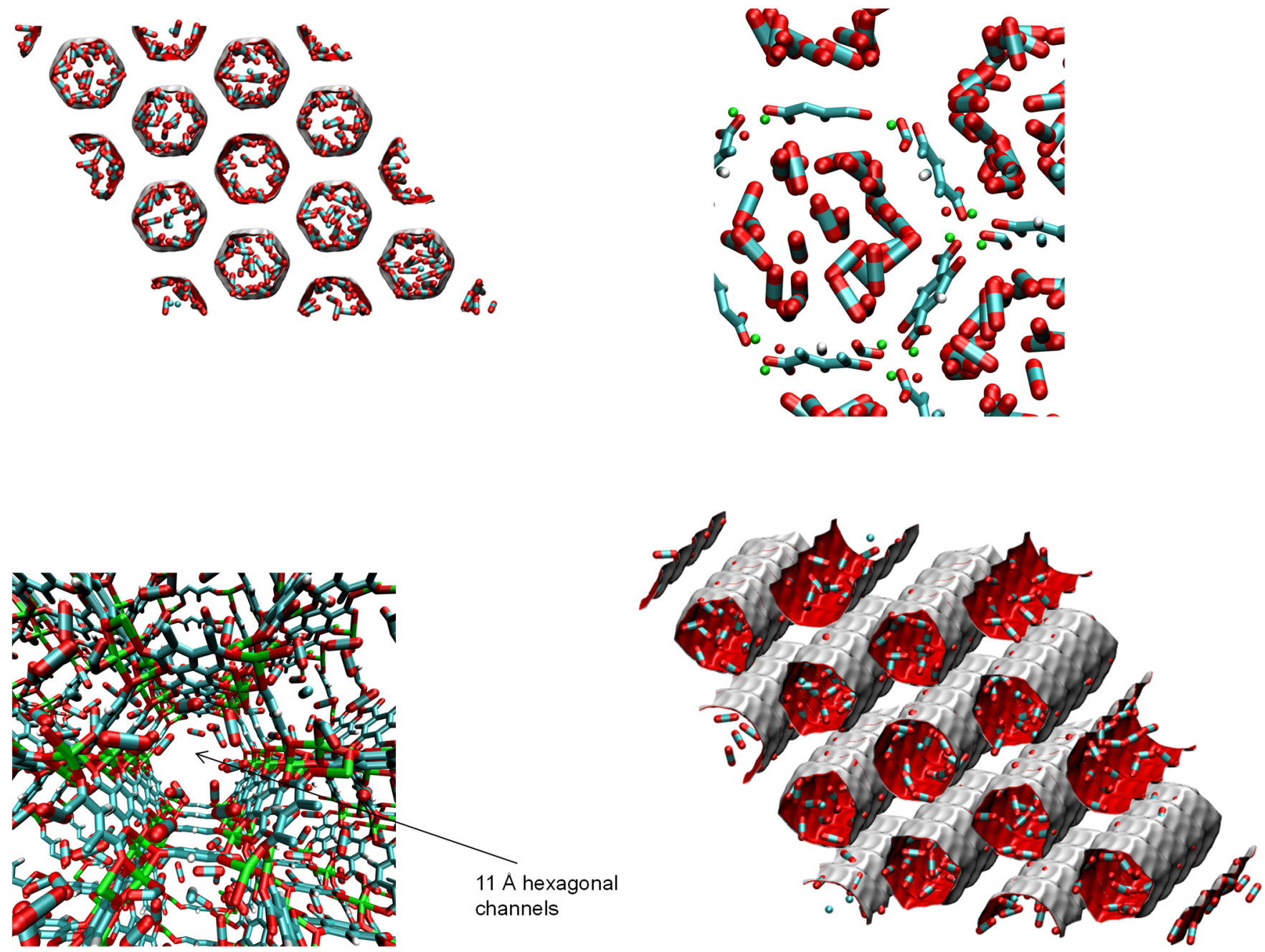

Figure S94. Snapshots showing the location of guest molecules $\mathrm{CO}_{2}(1)$, and $\mathrm{CH}_{4}(2)$ in $\mathrm{Mg}_{2}$ (dobdc) at $300 \mathrm{~K}$. 
a
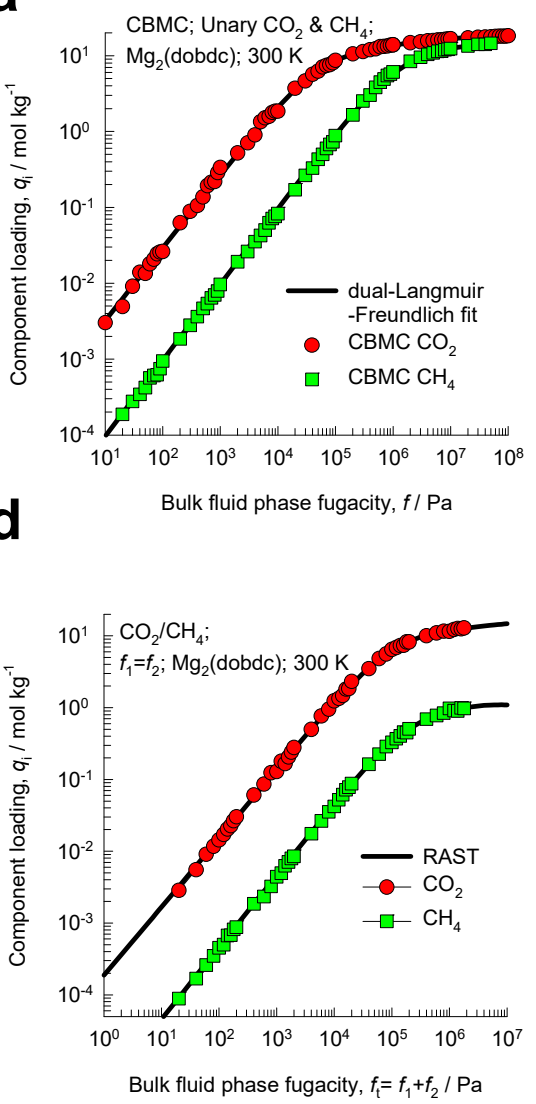

b
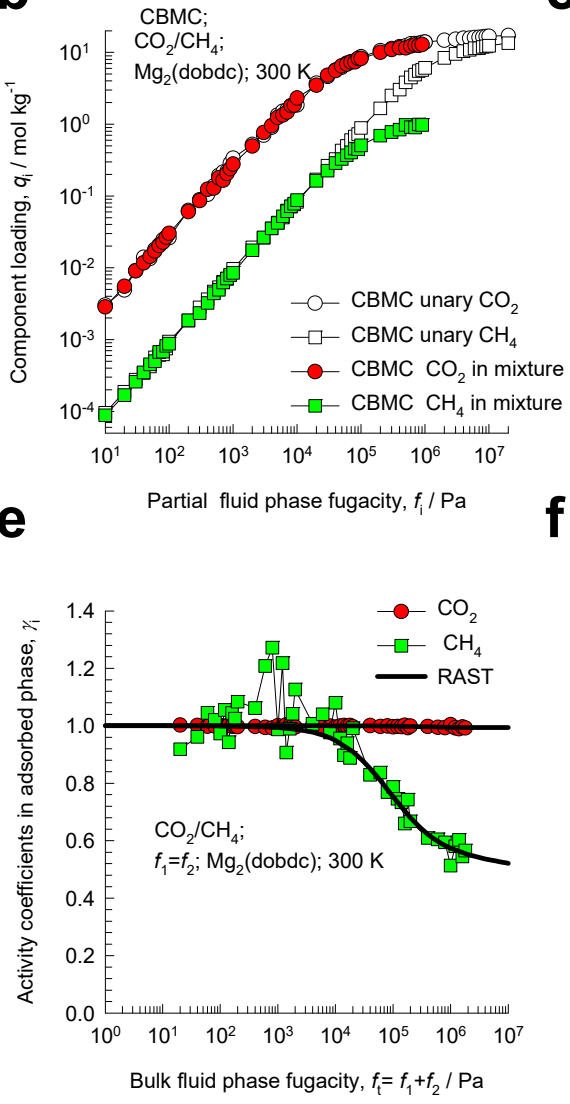

C
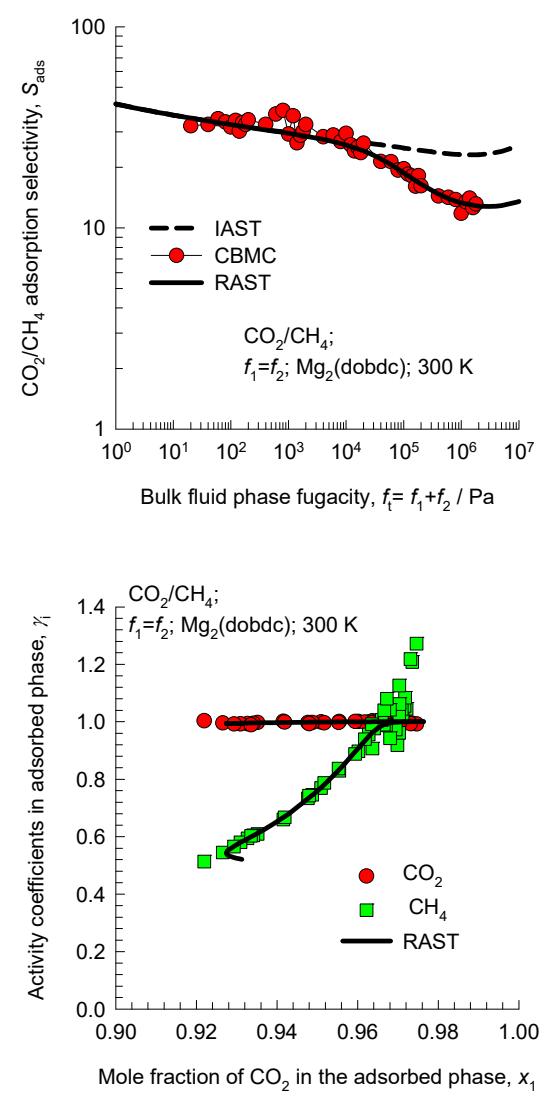

Figure S95. CBMC simulation data and analysis for equimolar $\left(f_{1}=f_{2} ; \quad y_{1}=0.5\right) \mathrm{CO}_{2}(1) / \mathrm{CH}_{4}(2)$ mixture adsorption in $\mathrm{Mg}_{2}(\mathrm{dobdc})$ at $300 \mathrm{~K}$. (a) Unary isotherms and fits. (b) Component loadings in mixture compared with CBMC simulations of unary isotherms. (c) $\mathrm{CBMC}$ data for $\mathrm{CO}_{2}(1) / \mathrm{CH}_{4}(2)$ adsorption selectivity compared with IAST and RAST estimates. (d) CBMC data for component loadings in mixture compared with RAST estimates. $(e, f)$ Activity coefficients from CBMC compared with RAST model calculations. The unary isotherm fit parameters and Wilson parameters are provided in Table S19. 


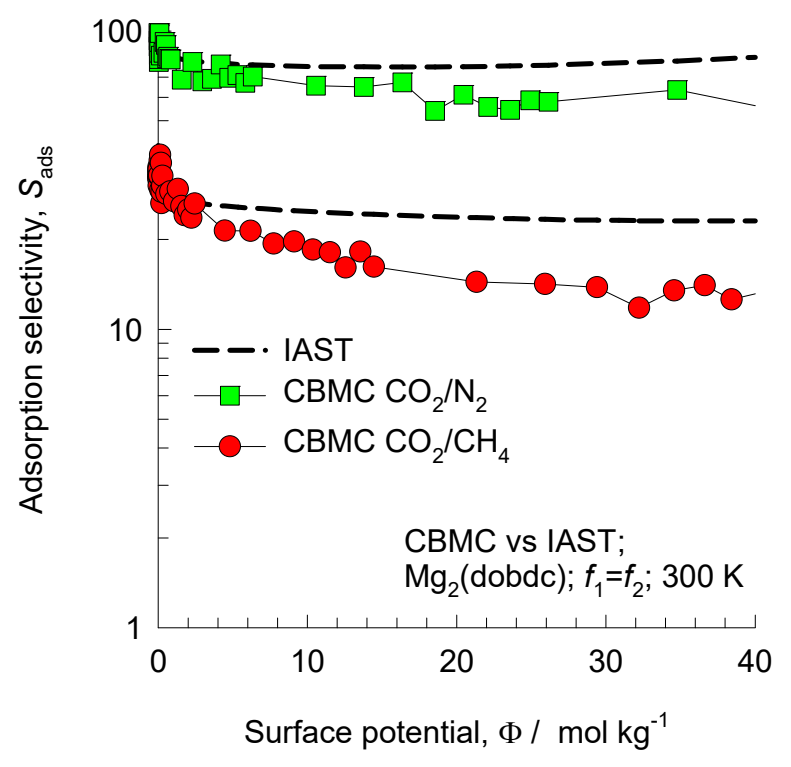

Figure S96. Adsorption selectivity $S_{a d s}$ for equimolar $\left(f_{1}=f_{2} ; y_{1}=0.5\right) \quad \mathrm{CO}_{2}(1) / \mathrm{CH}_{4}(2)$ and $\mathrm{CO}_{2}(1) / \mathrm{N}_{2}(2)$ mixture adsorption in $\mathrm{Mg}_{2}($ dobdc) at $300 \mathrm{~K}$, plotted as function of the surface potential $\Phi$ . The CBMC simulated values (indicated by symbols) are compared with IAST estimates (indicated by the dashed lines). 


\section{Adsorption of hexane isomers in $\mathrm{Mg}_{2}($ dobdc) and $\mathrm{Co}(\mathrm{BDP})$}

The separation of hexane isomers, n-hexane (nC6), 2-methylpentane (2MP), 3-methylpentane (3MP), 2,2 dimethylbutane (22DMB), and 2,3 dimethylbutane (23DMB) is required for production of high-octane gasoline. The values of the Research Octane Number (RON) increases with the degree of branching. ${ }^{67}$ The di-branched isomers (22DMB, 23DMB) have significantly higher RON values than that of the linear isomer (nC6), and mono-branched isomers (2MP, 3MP). The RON values are: $\mathrm{nC6}=30,2 \mathrm{MP}=74.5$, $3 \mathrm{MP}=75.5,22 \mathrm{DMB}=94,23 \mathrm{DMB}=105$. Therefore, di-branched isomers are preferred products for incorporation into the high-octane gasoline pool. ${ }^{4,68,69}$

Our earlier works, ${ }^{4,11,67,70,71}$ had presented CBMC data for the adsorption of unary, ternary and 5component mixtures of hexane isomers in a wide variety of zeolites, and MOFs. Here we analyze the adsorption of equimolar ternary $\left(f_{1}=f_{2}=f_{3}\right)$ nC6/3MP/22DMB and equimolar 5-component $\left(f_{1}=f_{2}=f_{3}=f_{4}=f_{5}\right)$ nC6/2MP.3MP/22DMB/23DMB mixtures at $433 \mathrm{~K}$ in two $1 \mathrm{D} \mathrm{MOFS}: \mathrm{Mg}_{2}(\mathrm{dobdc})$ (with hexagonal $11 \AA$ channels) and Co(BDP) (with square channels of $10 \AA$ ). The The pore landscapes and structural details of Co(BDP) are presented in Figure S97, and Figure S98.

Computational snapshots of the conformation of hexane isomers within the channels of $\mathrm{Mg}_{2}(\mathrm{dobdc})$ Co(BDP) are shown in Figure S99, and Figure S100, respectively.

Figure S101a,b,c,d present CBMC simulation data on the component loadings for adsorption of $(a, c)$ equimolar ternary $\left(f_{1}=f_{2}=f_{3}\right) \quad \mathrm{nC6} / 3 \mathrm{MP} / 22 \mathrm{DMB}$ and $(\mathrm{b}, \mathrm{d})$ equimolar 5-component $\left(f_{1}=f_{2}=f_{3}=f_{4}=f_{5}\right)$ C6/2MP.3MP/22DMB/23DMB mixtures at $433 \mathrm{~K}$ in two (a, b) $\operatorname{Mg}_{2}($ dobdc) and (c, d) $\mathrm{Co}(\mathrm{BDP})$. These data were used to determine the $\mathrm{nC6} / 3 \mathrm{MP}$ and $3 \mathrm{MP} / 22 \mathrm{DMB}$ adsorption selectivities in $\mathrm{Mg}_{2}($ dobdc $)$ and $\mathrm{Co}(\mathrm{BDP})$, both from $\mathrm{nC} / 3 \mathrm{MP} / 22 \mathrm{DMB}$ and nC6/2MP.3MP/22DMB/23DMB mixture simulations. The two data sets of the adsorption selectivities 
follow a unique dependence on the surface potential, $\Phi$, determined using the IAST for either 3component or 5-component mixtures as appropriate; see Figure S102. This equivalence follows the IAST prescription of eq (S13).

Put another way, the adsorption selectivity for the 1-2 pair is independent of the presence of component 3 in the ternary mixture and of the presence of the 3,4, and 5 in the quinary mixture. 
Adsorption of hexane isomers in Mg2(dobdc) and Co(BDP)

\subsection{List of Tables for Adsorption of hexane isomers in Mg2(dobdc) and Co(BDP)}

Table S20. Dual-site Langmuir-Freundlich parameters for pure component hexane isomers at $433 \mathrm{~K}$ in $\mathrm{Mg}_{2}$ (dobdc). The fits are based on CBMC simulation data of Krishna and van Baten. ${ }^{11}$

\begin{tabular}{|c|c|c|c|c|c|c|}
\hline & \multicolumn{3}{|l|}{ Site A } & \multicolumn{3}{|l|}{ Site B } \\
\hline & $\begin{array}{l}q_{\mathrm{i}, \mathrm{A}, \mathrm{sat}} \\
\mathrm{mol} \mathrm{kg}^{-1}\end{array}$ & $\begin{array}{l}b_{\mathrm{i}, \mathrm{A}} \\
\mathrm{Pa}^{-v_{i}}\end{array}$ & $\begin{array}{l}v_{\mathrm{i}, \mathrm{A}} \\
\text { dimensionless }\end{array}$ & $\begin{array}{l}q_{\mathrm{i}, \mathrm{B}, \mathrm{sat}} \\
\mathrm{mol} \mathrm{kg}^{-1}\end{array}$ & $\begin{array}{l}b_{\mathrm{i}, \mathrm{B}} \\
\mathrm{Pa}^{-v_{i}}\end{array}$ & $\begin{array}{l}v_{\mathrm{i}, \mathrm{B}} \\
\text { dimensionless }\end{array}$ \\
\hline $\mathrm{nC6}$ & 3.3 & 4.396E-07 & 2.2 & 1.25 & $1.081 \mathrm{E}-03$ & 0.7 \\
\hline $2 \mathrm{MP}$ & 3.25 & $2.350 \mathrm{E}-07$ & 2.27 & 1.35 & $6.855 \mathrm{E}-04$ & 0.76 \\
\hline $3 \mathrm{MP}$ & 2.25 & $5.478 \mathrm{E}-11$ & 3.55 & 2.1 & $4.813 \mathrm{E}-04$ & 1 \\
\hline 22DMB & 2.9 & $6.410 \mathrm{E}-06$ & 1.5 & 1.45 & $2.514 \mathrm{E}-04$ & 0.76 \\
\hline $23 \mathrm{DMB}$ & 2.8 & $1.401 \mathrm{E}-08$ & 2.65 & 1.55 & 5.595E-04 & 0.9 \\
\hline
\end{tabular}


Table S21. Dual-site Langmuir-Freundlich parameters for pure component hexane isomers at $433 \mathrm{~K}$ in Co(BDP). The fits are based on CBMC simulation data of Krishna and van Baten. ${ }^{11}$

\begin{tabular}{|c|c|c|c|c|c|c|}
\hline & \multicolumn{3}{|l|}{ Site A } & \multicolumn{3}{|l|}{ Site B } \\
\hline & 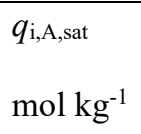 & $\begin{array}{l}b_{\mathrm{i}, \mathrm{A}} \\
\mathrm{Pa}^{-v_{i}}\end{array}$ & $\begin{array}{l}v_{\mathrm{i}, \mathrm{A}} \\
\text { dimensionless }\end{array}$ & $\begin{array}{l}q_{\mathrm{i}, \mathrm{B}, \mathrm{sat}} \\
\mathrm{mol} \mathrm{kg}^{-1}\end{array}$ & $\begin{array}{l}b_{\mathrm{i}, \mathrm{B}} \\
\mathrm{Pa}^{-v_{i}}\end{array}$ & $\begin{array}{l}v_{1, \mathrm{~B}} \\
\text { dimensionless }\end{array}$ \\
\hline $\mathrm{nC6}$ & 1.47 & $2.813 \mathrm{E}-04$ & 0.77 & 4 & $2.286 \mathrm{E}-07$ & 2 \\
\hline $2 \mathrm{MP}$ & 1.66 & $2.508 \mathrm{E}-04$ & 0.75 & 3.95 & $6.834 \mathrm{E}-07$ & 1.8 \\
\hline $3 \mathrm{MP}$ & 1.8 & $2.002 \mathrm{E}-04$ & 0.76 & 3.9 & $1.151 \mathrm{E}-06$ & 1.7 \\
\hline $22 \mathrm{DMB}$ & 2.06 & $5.431 \mathrm{E}-05$ & 0.8 & 3.45 & $1.800 \mathrm{E}-05$ & 1.2 \\
\hline 23DMB & 4.08 & $1.016 \mathrm{E}-04$ & 1 & 1.1 & $1.055 \mathrm{E}-09$ & 2.65 \\
\hline
\end{tabular}


Adsorption of hexane isomers in Mg2(dobdc) and Co(BDP)

17.2 List of Figures for Adsorption of hexane isomers in Mg2(dobdc) and Co(BDP)

\section{Co(BDP) pore landscapes}
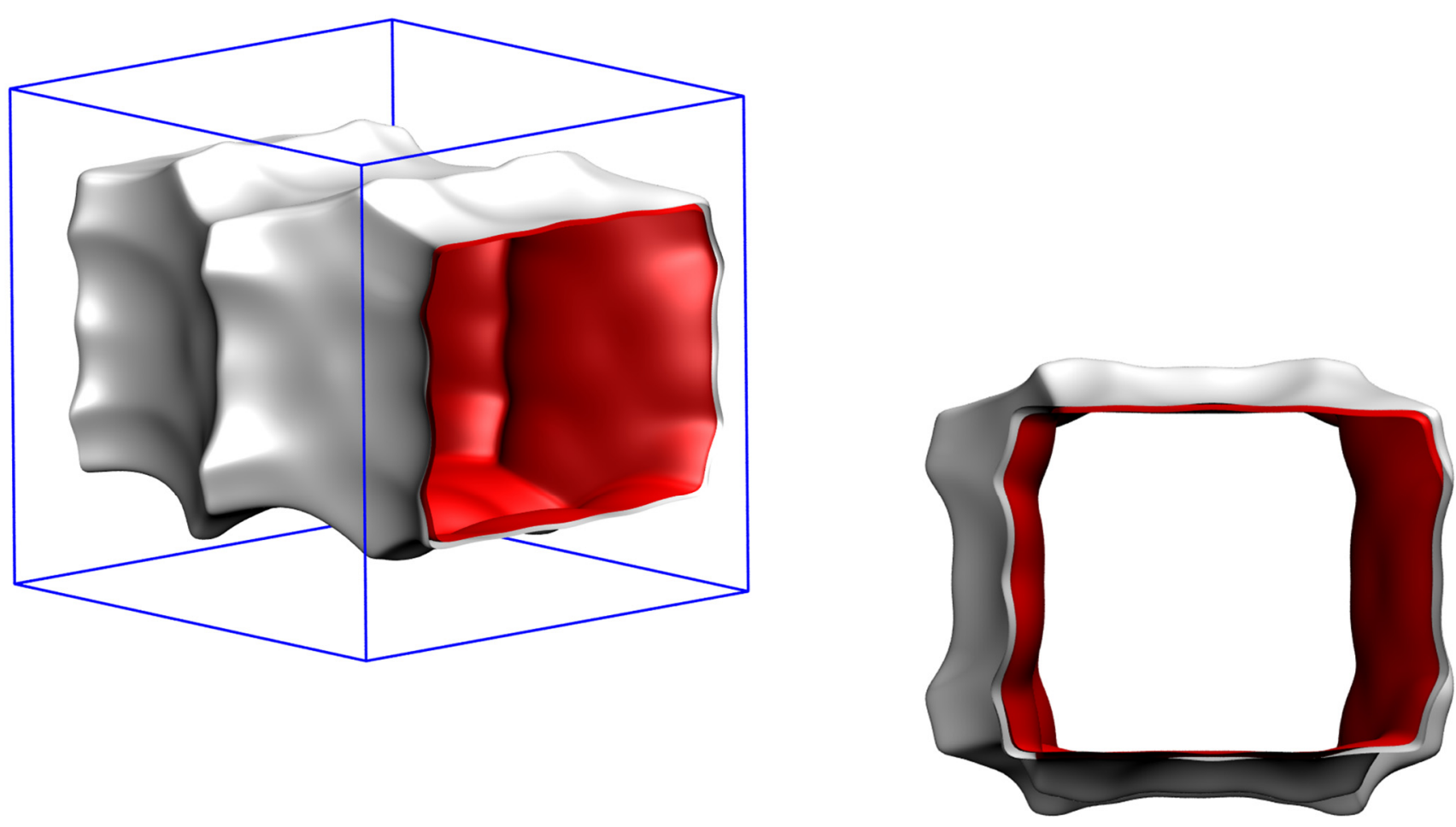

Figure S97. Pore landscape of Co(BDP) 


\section{Co(BDP) pore landscapes}

\begin{tabular}{|l|r|}
\hline & CoBDP \\
\hline$a / \AA$ & 13.2529 \\
\hline$b / \AA$ & 13.253 \\
\hline$c / \AA$ & 13.995 \\
\hline $\begin{array}{l}\text { Cell volume / } \AA^{3} \\
\text { conversion factor for } \\
\text { [molec/uc] to [mol per kg } \\
\text { Framework] }\end{array}$ & 2458.091 \\
\hline $\begin{array}{l}\text { conversion factor for } \\
\text { [molec/uc] to [kmol/m }{ }^{3} \text { ] }\end{array}$ & 0.9362 \\
\hline$\rho$ [kg/m3] (with cations) & 1.0102 \\
\hline $\begin{array}{l}\text { MW unit cell } \\
\text { [g/mol(framework+cations)] }\end{array}$ & 1068.094 \\
\hline$\phi$, fractional pore volume & 0.669 \\
\hline open space $/ \AA^{3} / \mathrm{uc}$ & 1643.9 \\
\hline Pore volume $/ \mathrm{cm}^{3} / \mathrm{g}$ & 0.927 \\
\hline Surface area $/ \mathrm{m}^{2} / \mathrm{g}$ & 2148.8 \\
\hline DeLaunay diameter $/ \AA$ & 9.97 \\
\hline
\end{tabular}

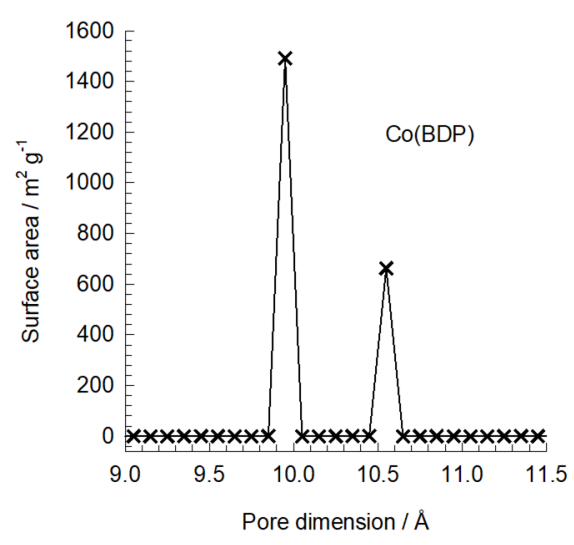

To convert from molecules per unit cell to $\mathrm{mol} \mathrm{kg}^{-1}$, multiply by 0.9362 . The pore volume is $0.927 \mathrm{~cm}^{3} / \mathrm{g}$

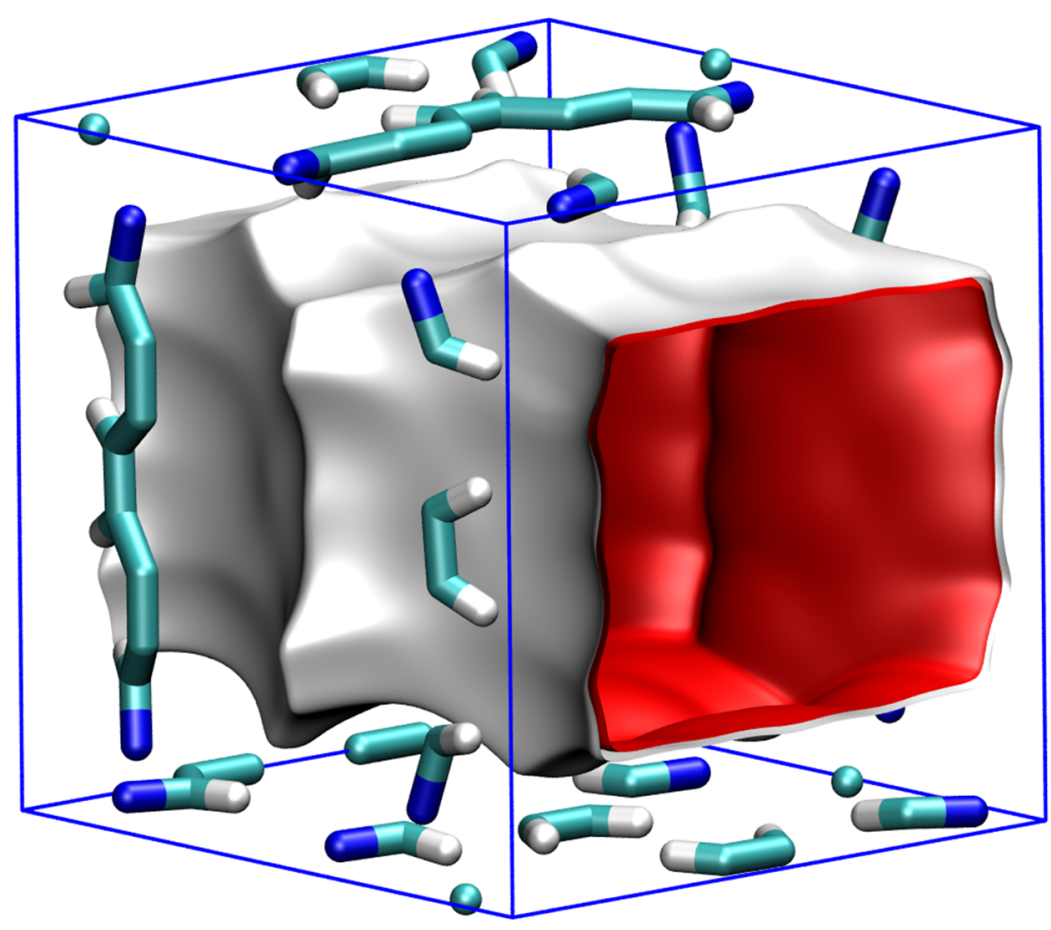

Figure S98. Structural details for $\mathrm{Co}(\mathrm{BDP})$. 


\section{MgMOF-74 snapshot of pure hexanes}
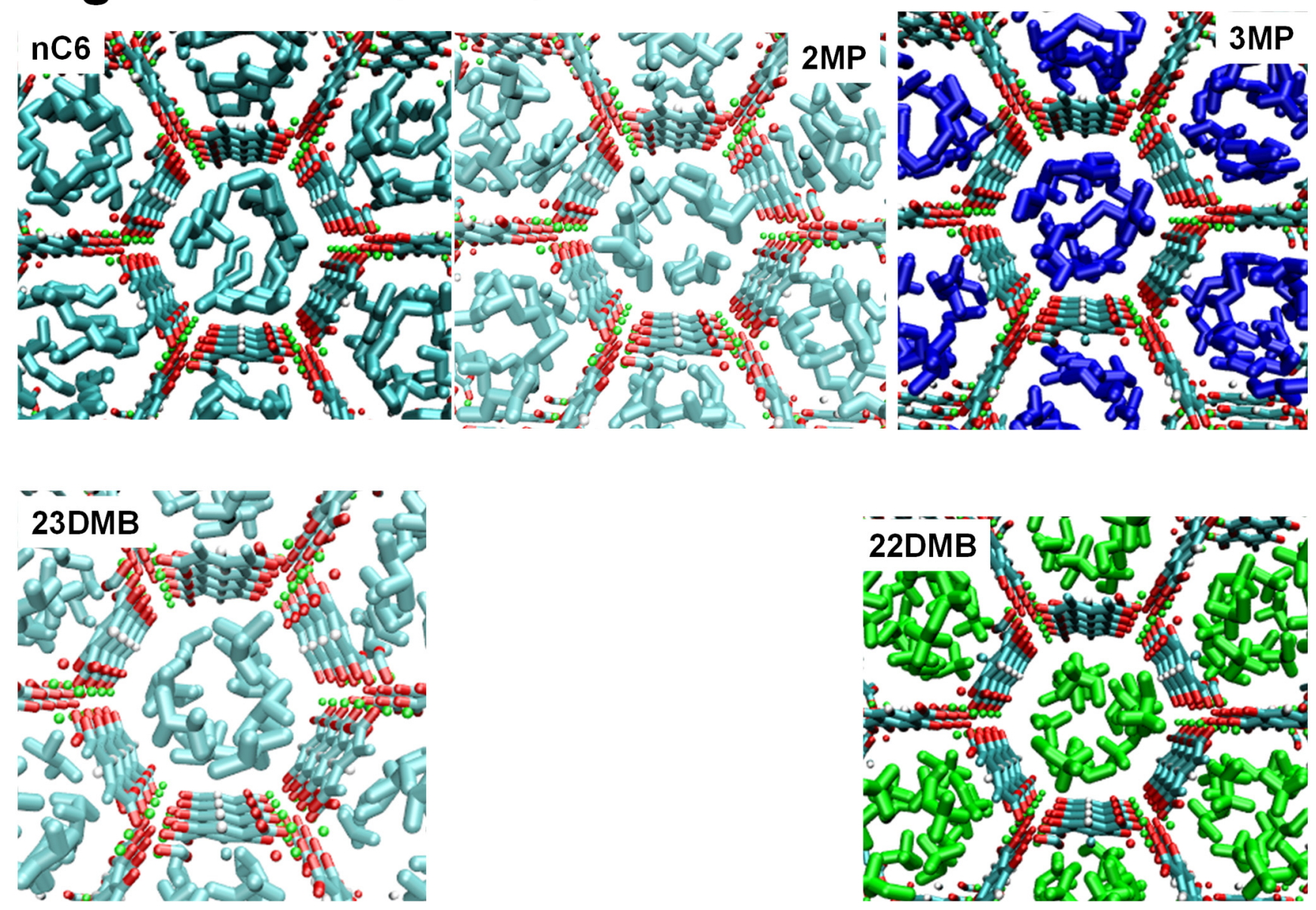

Figure S99. Computational snapshots of the conformation of hexane isomers within the 1D channels of

$\mathrm{Mg}_{2}$ (dobdc). 


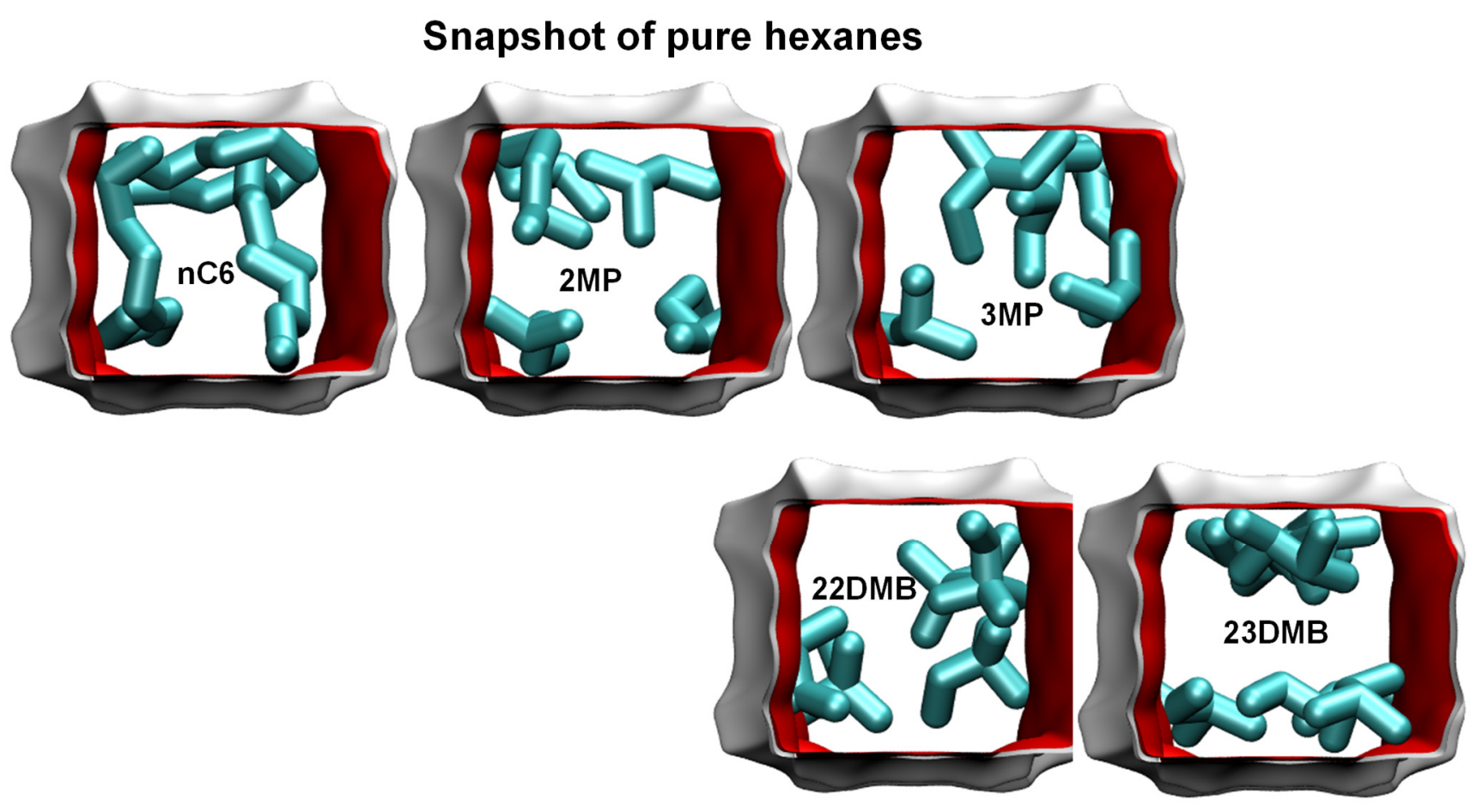

Figure S100. Computational snapshots of the conformation of hexane isomers within the 1D channels of $\mathrm{Co}(\mathrm{BDP})$. 
a

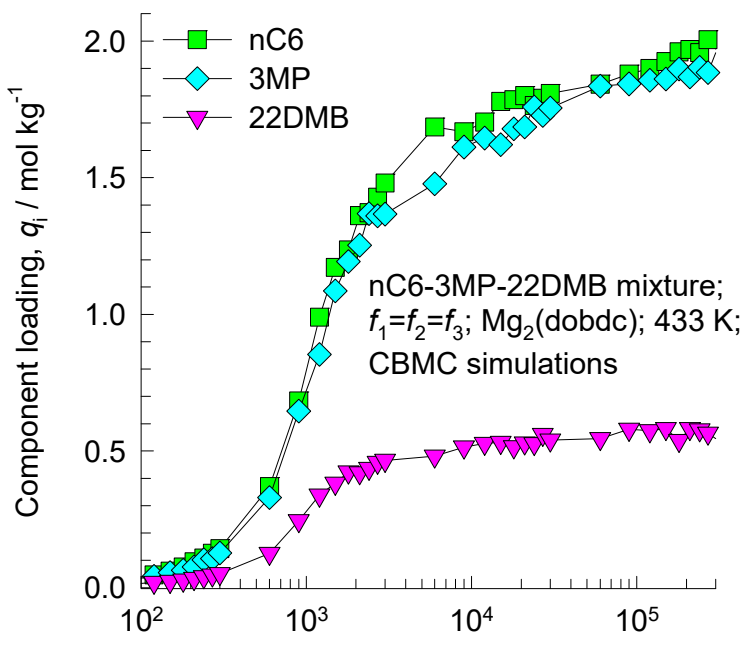

Total fluid phase fugacity, $f_{\mathrm{t}} / \mathrm{Pa}$

C

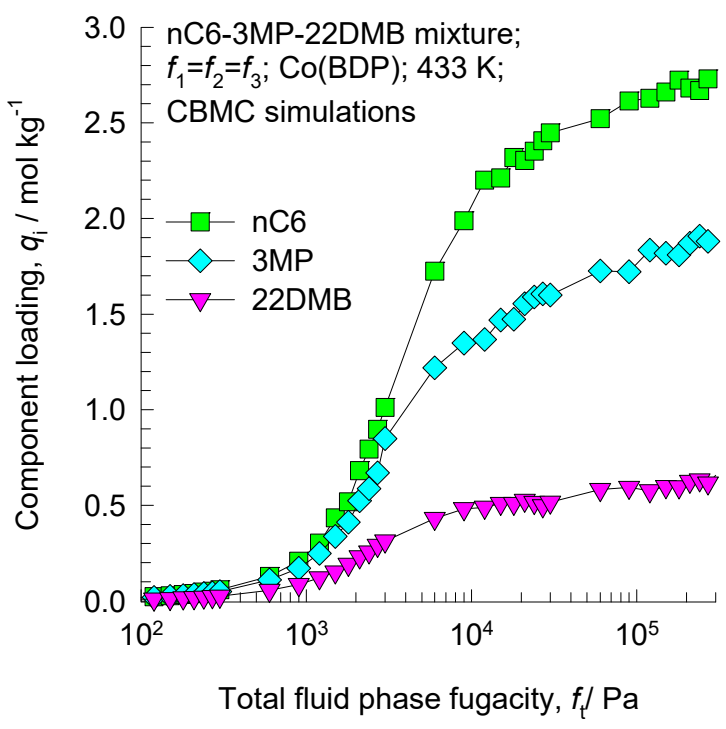

b

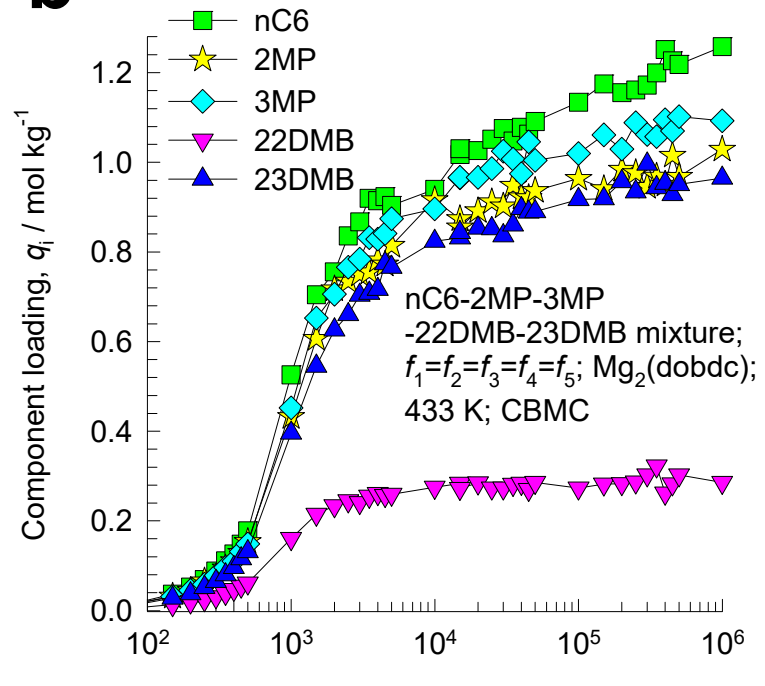

Total fluid phase fugacity, $f_{t} / \mathrm{Pa}$

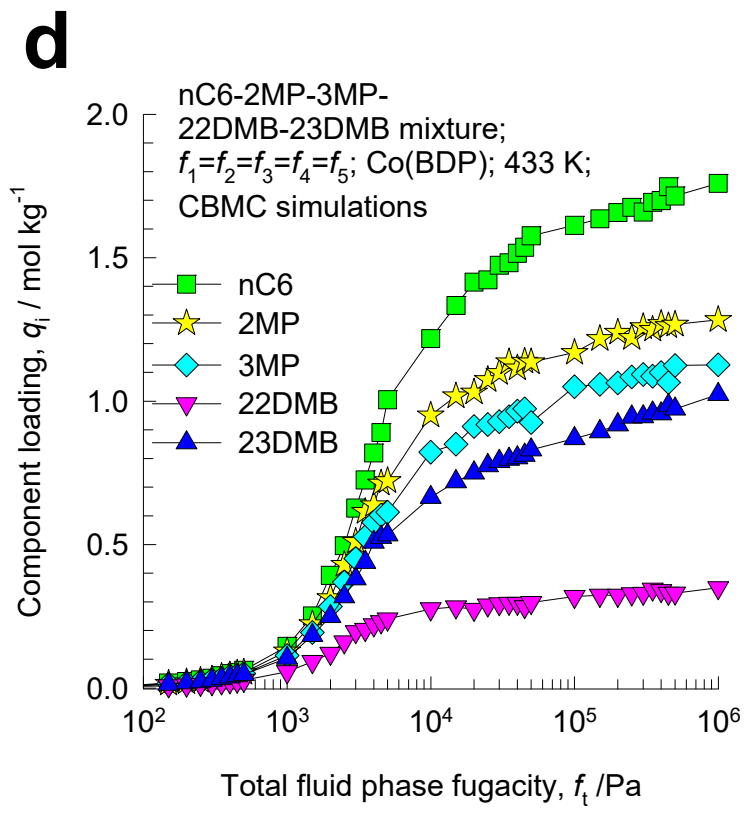

Figure S101. CBMC simulations for adsorption of (a, c) equimolar ternary $\left(f_{1}=f_{2}=f_{3}\right)$ $\mathrm{nC} 6 / 3 \mathrm{MP} / 22 \mathrm{DMB}$ and (b, d) equimolar 5-component $\left(f_{1}=f_{2}=f_{3}=f_{4}=f_{5}\right)$ nC6/2MP.3MP/22DMB/23DMB mixtures at $433 \mathrm{~K}$ in two $1 \mathrm{D}$ MOFs $(\mathrm{a}, \mathrm{b}) \mathrm{Mg}_{2}$ (dobdc) (with hexagonal $11 \AA ̊$ channels) and (c, d) $\mathrm{Co}(\mathrm{BDP})$ (with square channels of $10 \AA$ ). 
a

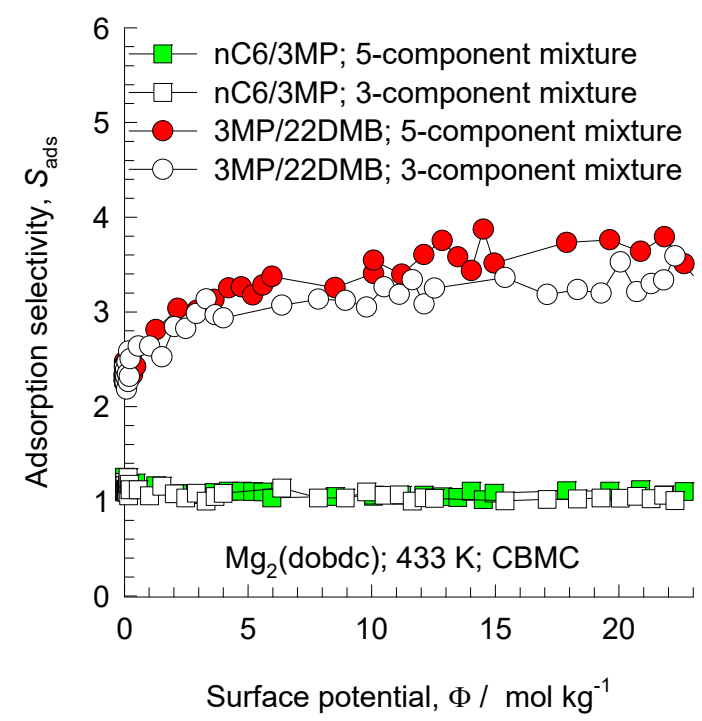

b

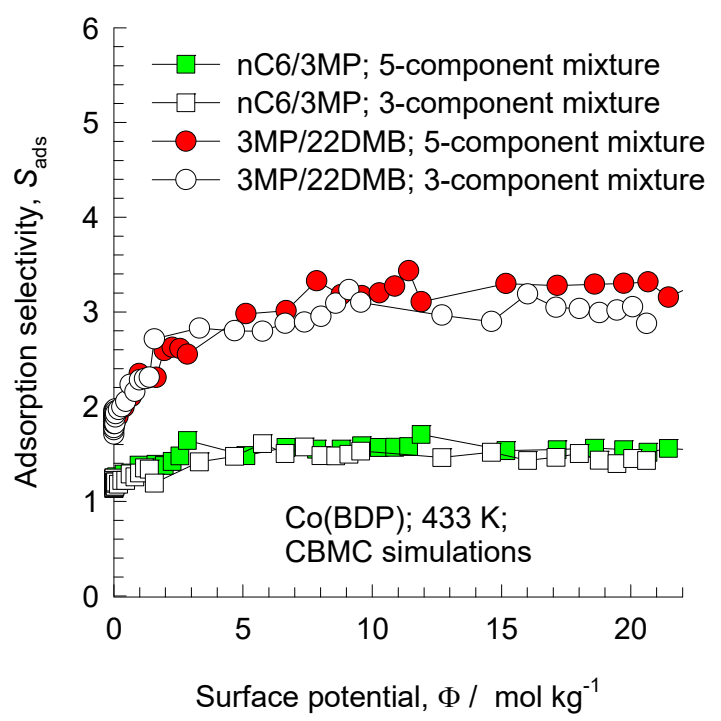

Figure S102. Comparing the $\mathrm{nC} 6 / 3 \mathrm{MP}$ and 3MP/22DMB adsorption selectivities in (a) $\mathrm{Mg}_{2}$ (dobdc) and (b) $\mathrm{Co}(\mathrm{BDP})$. In the plots the adsorption selecitivities were determined from both CBMC simulations for adsorption of equimolar $\left(f_{1}=f_{2}=f_{3}\right)$ nC6/3MP/22DMB and equimolar $\left(f_{1}=f_{2}=f_{3}=f_{4}=f_{5}\right)$ nC6/2MP.3MP/22DMB/23DMB mixtures at $433 \mathrm{~K}$. The $x$-axis represents the surface potential, $\Phi$, determined using the IAST for either 3-component or 5-component mixtures as appropriate. 


\section{$18 \mathrm{C}_{2} \mathrm{H}_{2} / \mathrm{C}_{2} \mathrm{H}_{4}$ mixture adsorption in ZUL-100 and ZUL-200}

Configurational-Bias Monte Carlo (CBMC) simulations, using the methodologies as detailed in earlier publications, ${ }^{3,5,9,11-14}$ were carried out to determine the adsorption isotherms for unary $\mathrm{C}_{2} \mathrm{H}_{2}$, unary $\mathrm{C}_{2} \mathrm{H}_{4}$, and 1/99 $\mathrm{C}_{2} \mathrm{H}_{2} / \mathrm{C}_{2} \mathrm{H}_{4}$ mixtures in ZUL-100 and ZUL-200 at $298 \mathrm{~K}$. The structural details are provided in earlier work. ${ }^{72}$ These MOFs have no open metal sites. The ZUL-100 and ZUL-200 structures were considered to be rigid in the simulations. simulation box for conducting CBMC simulations consisted of $3 \times 2 \times 3=18$ unit cells. The CBMC simulation data are the same as reported in our recent work. ${ }^{72}$

The interactions between adsorbed molecules are described with Lennard-Jones terms. For the atoms in the host metal organic framework, the generic $\mathrm{UFF}^{29}$ and $\mathrm{DREIDING}^{30}$ force fields were used; the Lennard-Jones parameters $\sigma_{\text {host }}, \frac{\varepsilon_{\text {host }}}{k_{B}}$ values are specified in Table S22. The united atom model was used to describe $-\mathrm{CH}$ groups in $\mathrm{C}_{2} \mathrm{H}_{2}$, and $-\mathrm{CH}_{2}$ groups in $\mathrm{C}_{2} \mathrm{H}_{4}$. The Lennard-Jones parameters for the $-\mathrm{CH}_{2}$ groups in $\mathrm{C}_{2} \mathrm{H}_{4}$ were taken from Ban et al. ${ }^{73}$ The Lennard-Jones parameters for the $-\mathrm{CH}$ groups in $\mathrm{C}_{2} \mathrm{H}_{2}$ were taken from Jorgenson et al.. ${ }^{74}$ The Lennard-Jones parameters $\sigma_{\text {guest }}, \frac{\varepsilon_{\text {guest }}}{k_{B}}$ are tabulated in Table S23.

The Lorentz-Berthelot mixing rules were applied for calculating the Lennard-Jones parameters describing guest-host interactions

$$
\begin{aligned}
& \sigma_{\text {guest-host }}=\frac{\left(\sigma_{\text {guest }}+\sigma_{\text {host }}\right)}{2} \\
& \frac{\varepsilon_{\text {guest-host }}}{k_{B}}=\sqrt{\frac{\varepsilon_{\text {guest }}}{k_{B}} \times \frac{\varepsilon_{\text {host }}}{k_{B}}}
\end{aligned}
$$


The interactions of the guest pseudo-atoms with the F atoms of the framework are dominant. Table S24 summarizes the values of the Lennard-Jones parameters for guest $-\mathrm{F}$ interactions that are used in the simulations.

The Lennard-Jones potentials are shifted and cut at 12 A. Since both ZUL-100 and ZUL-200 do not contain open metal sites, the electrostatic charge interactions are not considered.

Figure S103 presents CBMC simulation data (indicated by the red and green symbols) for the component loadings for adsorption of $1 / 99 \mathrm{C}_{2} \mathrm{H}_{2} / \mathrm{C}_{2} \mathrm{H}_{4}$ mixtures in ZUL-100 at $298 \mathrm{~K}$. The dashed lines are IAST calculations of mixture adsorption equilibrium using the dual-Langmuir fits of unary isotherms determined from CBMC. There is good agreement between CBMC mixture simulations and IAST calculations.

Figure S104a presents CBMC simulation data (indicated by the red and green symbols) for the component loadings for adsorption of $1 / 99 \mathrm{C}_{2} \mathrm{H}_{2} / \mathrm{C}_{2} \mathrm{H}_{4}$ mixtures in ZUL-200 at $298 \mathrm{~K}$. The dashed lines are IAST calculations of adsorption equilibrium using the dual-Langmuir fits of unary isotherms determined from CBMC. There is good agreement between CBMC mixture simulations and IAST calculations.

Figure $\mathrm{S} 105$ plots the $\mathrm{C}_{2} \mathrm{H}_{2} / \mathrm{C}_{2} \mathrm{H}_{4}$ adsorption selectivity $S_{a d s}$ for $1 / 99 \mathrm{C}_{2} \mathrm{H}_{2} / \mathrm{C}_{2} \mathrm{H}_{4}$ mixture adsorption in ZUL-100 and ZUL-200 zeolites at $298 \mathrm{~K}$, as function of the surface potential $\Phi$. The IAST estimates, shown by the dashed lines are in good agreement with the CBMC data for both hosts. 
18.1 List of Tables for $\mathrm{C} 2 \mathrm{H} 2 / \mathrm{C} 2 \mathrm{H} 4$ mixture adsorption in ZUL-100 and ZUL-200

Table S22. Lennard-Jones parameters for host atoms in ZUL-100, and ZUL-200.

\begin{tabular}{|l|l|l|l|}
\hline atom & $\sigma_{\text {host }}$ & $\frac{\varepsilon_{\text {host }}}{k_{B}}$ & Literature source \\
& $\AA$ & $\mathrm{K}$ & \\
\hline $\mathrm{Cu}$ & 3.1137 & 2.5164 & $\mathrm{UFF}^{29}$ \\
\hline $\mathrm{F}$ & 3.0932 & 36.4872 & DREIDING \\
\hline $\mathrm{N}$ & 3.2626 & 38.9532 & DREIDING \\
\hline $\mathrm{S}$ & 3.5903 & 173.1253 & DREIDING \\
\hline $\mathrm{Nb}$ & 2.8197 & 29.6930 & UFF $^{29}$ \\
\hline $\mathrm{Ti}$ & 2.8286 & 8.5556 & UFF $^{29}$ \\
\hline $\mathrm{C}$ & 3.4730 & 47.8611 & DREIDING \\
\hline $\mathrm{O}$ & 3.0332 & 48.1631 & DREIDING \\
\hline $\mathrm{H}$ & 2.8464 & 7.6497 & DREIDING \\
\hline
\end{tabular}


Table S23. Lennard-Jones parameters for guest pseudo-atoms.

\begin{tabular}{|l|l|l|l|}
\hline (pseudo-) atom & $\sigma_{\text {guest }}$ & $\frac{\varepsilon_{\text {guest }}}{k_{B}}$ & Literature source \\
& $\AA$ & $\mathrm{K}$ & \\
\hline$-\mathrm{CH}$ & 3.8 & 57.8782776 & Gautam et al. $^{75}$ \\
\hline$-\mathrm{CH}_{2}$ & 3.68 & 92.5 & Ban et al. $^{73}$ \\
\hline
\end{tabular}


Table S24. Lennard-Jones parameters for the guest - host (F atoms) interactions.

\begin{tabular}{|l|l|l|l|}
\hline (pseudo-) & host & $\sigma_{\text {guest-host }}$ & $\frac{\varepsilon_{\text {guest }- \text { host }}}{k_{B}}$ \\
& atom & $\AA$ & $\mathrm{K}$ \\
\hline$-\mathrm{CH}$ & $\mathrm{F}$ & $\frac{(3.8+3.0932)}{2}=3.446$ & 275.727 \\
\hline$-\mathrm{CH}_{2}$ & $\mathrm{~F}$ & $\frac{(3.68+3.0932)}{2}=3.38$ & 58.09529 \\
& & & \\
& & & \\
\end{tabular}


Table S25. Dual-site Langmuir-Freundlich parameters for guest molecules in ZUL-100 at $298 \mathrm{~K}$.

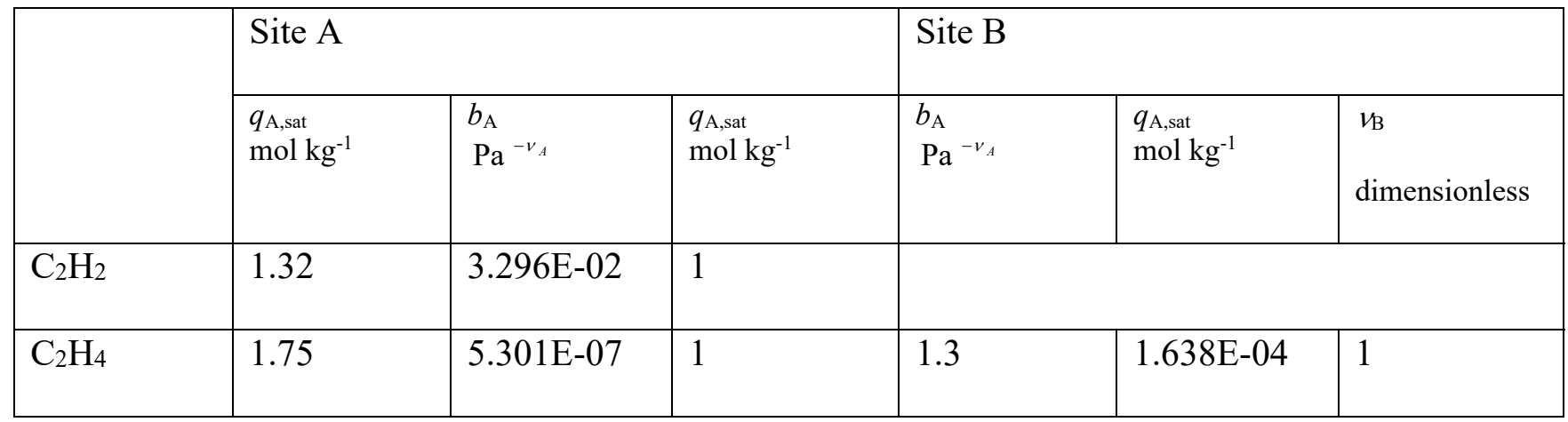

Table S26. Dual-site Langmuir-Freundlich parameters for guest molecules in ZUL-200 at $298 \mathrm{~K}$.

\begin{tabular}{|l|l|l|l|l|l|l|}
\hline \multirow{2}{*}{} & \multicolumn{2}{|l|}{ Site A } & \multicolumn{2}{l|}{ Site B } \\
\cline { 2 - 7 } & $\begin{array}{l}q_{\mathrm{A}, \text { sat }} \\
\mathrm{mol} \mathrm{kg}^{-1}\end{array}$ & $\begin{array}{l}b_{\mathrm{A}} \\
\mathrm{Pa}^{-v_{A}}\end{array}$ & $\begin{array}{l}q_{\mathrm{A}, \text { sat }} \\
\mathrm{mol} \mathrm{kg}^{-1}\end{array}$ & $\begin{array}{l}b_{\mathrm{A}} \\
\mathrm{Pa}^{-v_{A}}\end{array}$ & $\begin{array}{l}q_{\mathrm{A}, \text { sat }} \\
\mathrm{mol} \mathrm{kg}^{-1}\end{array}$ & dimensionless \\
\hline $\mathrm{C}_{2} \mathrm{H}_{2}$ & 1.24 & $1.146 \mathrm{E}-02$ & 1 & & $1.687 \mathrm{E}-04$ & 1 \\
\hline $\mathrm{C}_{2} \mathrm{H}_{4}$ & 3 & $6.923 \mathrm{E}-08$ & 1 & 1.25 & 1 & \\
\hline
\end{tabular}




\subsection{List of Figures for $\mathrm{C} 2 \mathrm{H} 2 / \mathrm{C} 2 \mathrm{H} 4$ mixture adsorption in $\mathrm{ZUL}-100$ and ZUL-200}
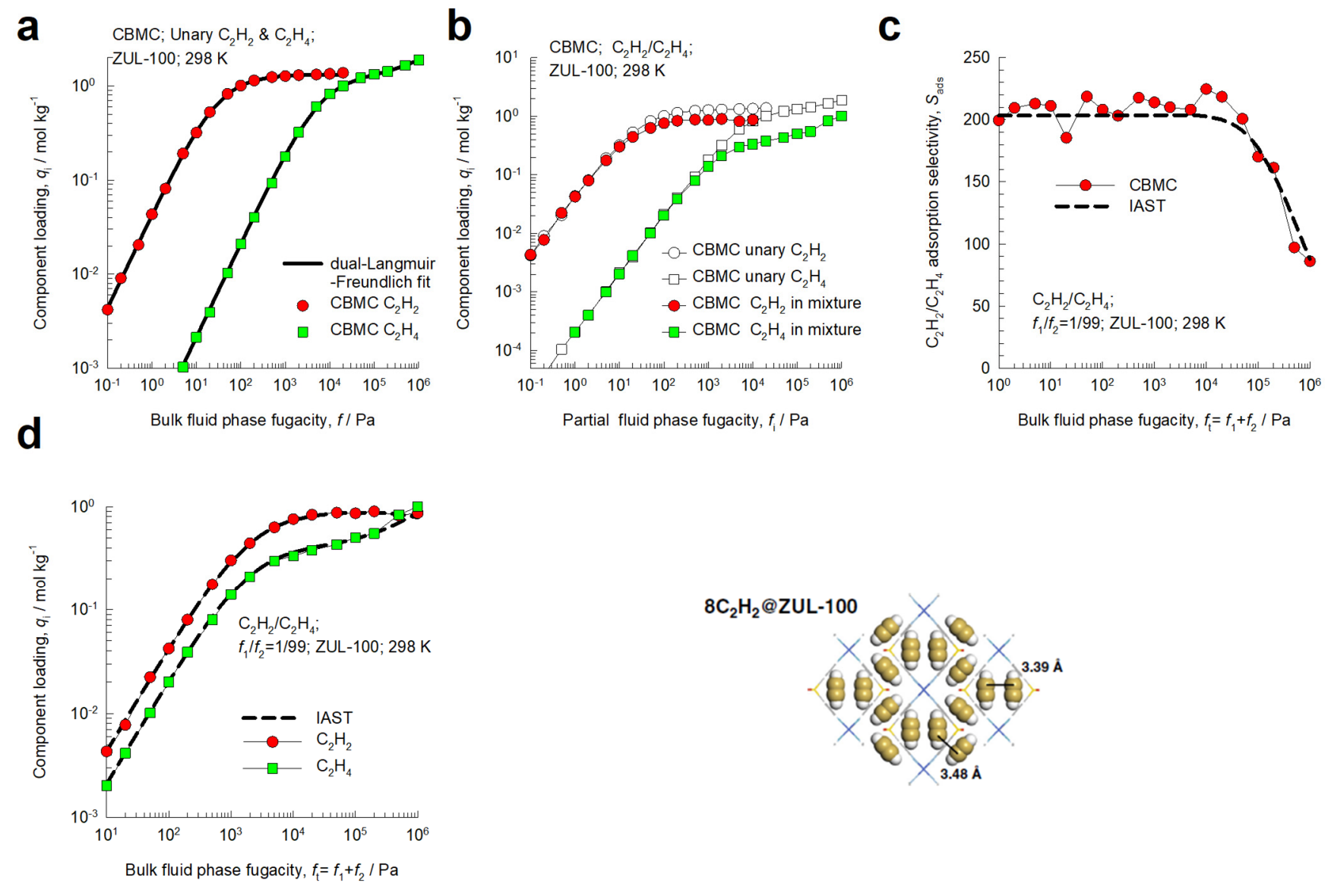

Figure S103. CBMC simulation data and analysis for $1 / 99 \mathrm{C}_{2} \mathrm{H}_{2} / \mathrm{C}_{2} \mathrm{H}_{4}$ mixtures in ZUL-100 at $298 \mathrm{~K}$.

(a) Unary isotherms and fits. (b) Component loadings in mixture compared with CBMC simulations of unary isotherms. (c) CBMC data for $\mathrm{C}_{2} \mathrm{H}_{2} / \mathrm{C}_{2} \mathrm{H}_{4}$ adsorption selectivity compared with IAST estimates. (d) CBMC data for component loadings in mixture compared with IAST estimates. The unary isotherm fit parameters are provided in Table S25. 

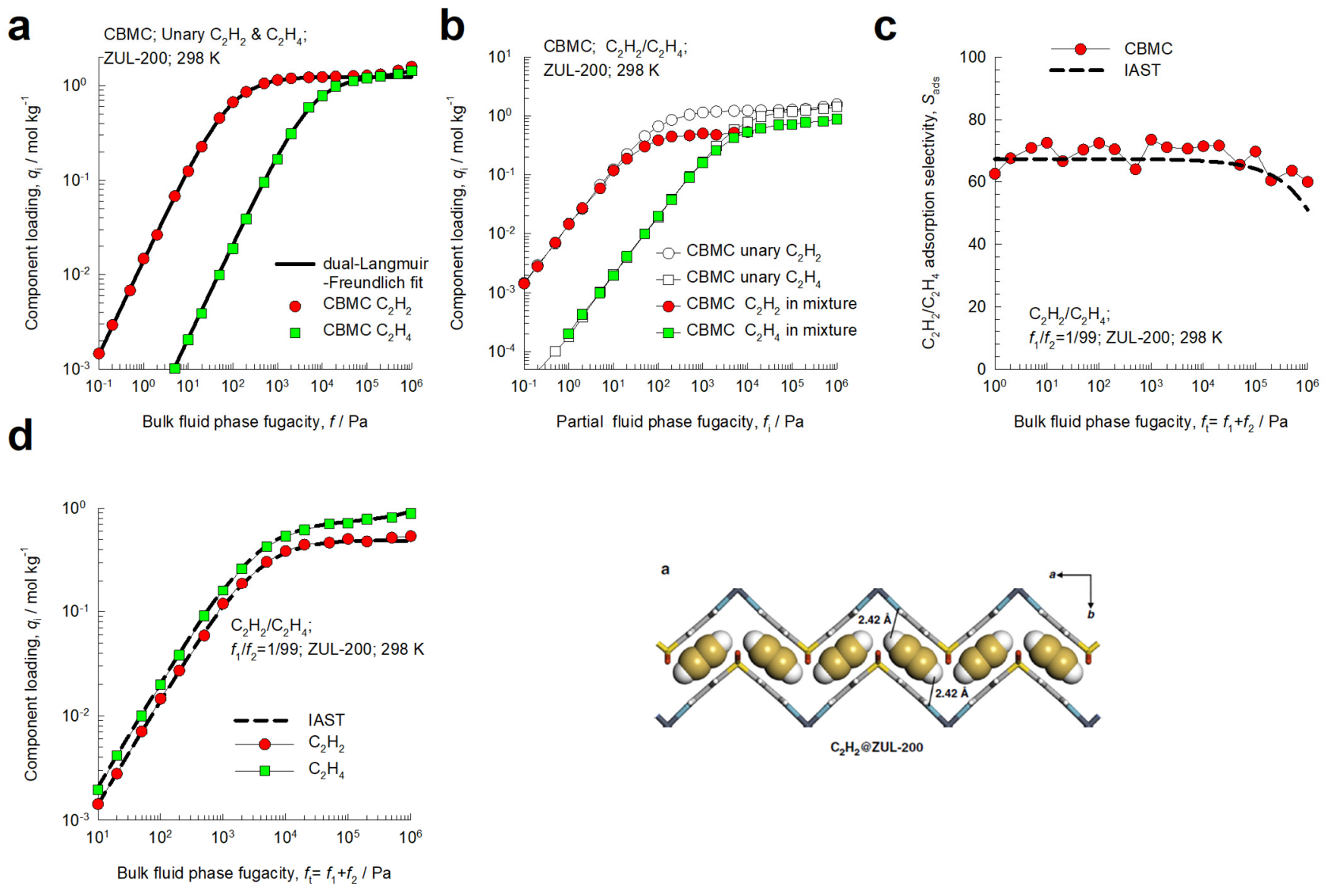

Figure S104. CBMC simulation data and analysis for $1 / 99 \mathrm{C}_{2} \mathrm{H}_{2} / \mathrm{C}_{2} \mathrm{H}_{4}$ mixtures in ZUL-200 at $298 \mathrm{~K}$.

(a) Unary isotherms and fits. (b) Component loadings in mixture compared with CBMC simulations of unary isotherms. (c) CBMC data for $\mathrm{C}_{2} \mathrm{H}_{2} / \mathrm{C}_{2} \mathrm{H}_{4}$ adsorption selectivity compared with IAST estimates. (d) CBMC data for component loadings in mixture compared with IAST estimates. The unary isotherm fit parameters are provided in Table S26. 


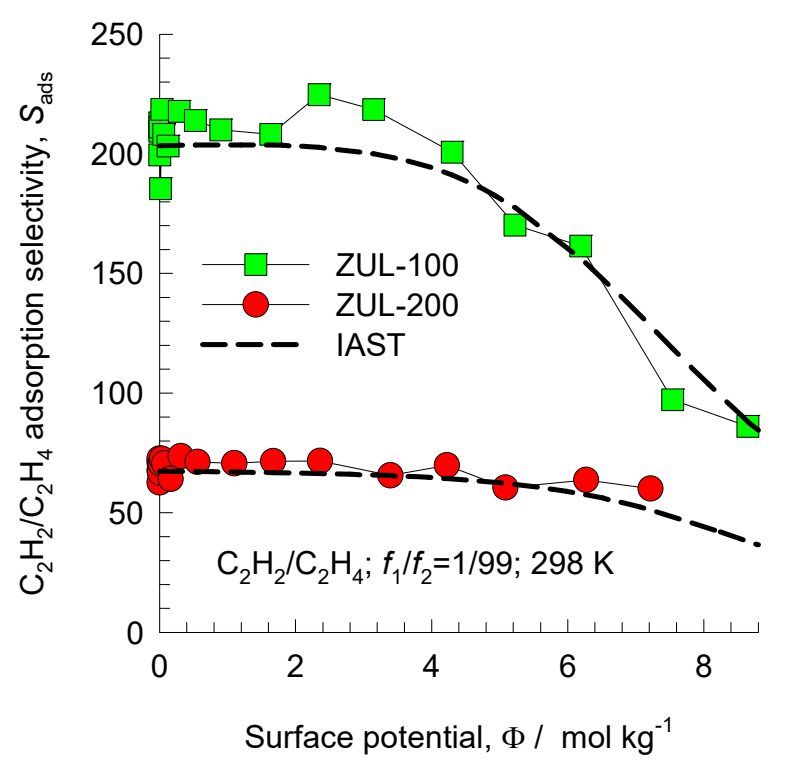

Figure S105. Adsorption selectivity $S_{a d s}$ for $1 / 99 \mathrm{C}_{2} \mathrm{H}_{2} / \mathrm{C}_{2} \mathrm{H}_{4}$ mixture adsorption in ZUL-100 and ZUL200 zeolites at $298 \mathrm{~K}$, plotted as function of the surface potential $\Phi$. The CBMC simulated values (indicated by symbols) are compared with IAST estimates (indicated by the dashed lines). 


\section{Nomenclature}

\section{Latin alphabet}

$A \quad$ surface area per $\mathrm{kg}$ of framework, $\mathrm{m}^{2} \mathrm{~kg}^{-1}$

$A_{12}, A_{21} \quad$ Margules parameters, dimensionless

$b_{\mathrm{i}} \quad$ Langmuir parameter, $\mathrm{Pa}^{-1}$

C

constant used in eq (S37), $\mathrm{kg} \mathrm{mol}^{-1}$

$f_{\mathrm{i}} \quad$ partial fugacity of species $i, \mathrm{~Pa}$

$f_{\mathrm{t}} \quad$ total fugacity of bulk fluid mixture, $\mathrm{Pa}$

$G^{\text {excess }} \quad$ excess Gibbs free energy, $\mathrm{J} \mathrm{mol}^{-1}$

$n \quad$ number of species in the mixture, dimensionless

$p_{\mathrm{i}} \quad$ partial pressure of species $i, \mathrm{~Pa}$

$p_{\mathrm{t}} \quad$ total system pressure, $\mathrm{Pa}$

$P_{i}^{0} \quad$ sorption pressure, $\mathrm{Pa}$

$q_{\mathrm{i}} \quad$ molar loading of species $i, \mathrm{~mol} \mathrm{~kg}^{-1}$

$q_{\mathrm{t}} \quad$ total molar loading of mixture, $\mathrm{mol} \mathrm{kg}^{-1}$

$q_{\mathrm{i}, \mathrm{sat}} \quad$ molar loading of species $i$ at saturation, mol kg-1

$R \quad$ gas constant, $8.314 \mathrm{~J} \mathrm{~mol}^{-1} \mathrm{~K}^{-1}$

$S_{\text {ads }} \quad$ adsorption selectivity, dimensionless

T absolute temperature, $\mathrm{K}$

$V_{\mathrm{p}} \quad$ pore volume, $\mathrm{m}^{3} \mathrm{~kg}^{-1}$

$x_{\mathrm{i}} \quad$ mole fraction of species $i$ in adsorbed phase, dimensionless

$y_{\mathrm{i}} \quad$ mole fraction of species $i$ in bulk fluid mixture, dimensionless 


\section{Greek letters}

activity coefficient of component $i$ in adsorbed phase, dimensionless

$\theta$

fractional occupancy, dimensionless

$\Theta_{\mathrm{i}} \quad$ loading of species $i$, molecules per unit cell

$\Lambda_{\mathrm{ij}} \quad$ Wilson parameters, dimensionless

$\mu_{\mathrm{i}}$

molar chemical potential, $\mathrm{J}_{\mathrm{mol}}^{-1}$

$v$

Freundlich exponent, dimensionless

$\pi$

spreading pressure, $\mathrm{N} \mathrm{m}^{-1}$

$\rho \quad$ framework density, $\mathrm{kg} \mathrm{m}^{-3}$

$\Phi$

surface potential, mol kg-1

\section{Subscripts}

$\mathrm{i}, \mathrm{j} \quad$ components in mixture

$\mathrm{t}$

referring to total mixture

sat

referring to saturation conditions

\section{Superscripts}

0

referring to pure component loading

excess

referring to excess parameter 


\section{References}

(1) Baerlocher, C.; Meier, W. M.; Olson, D. H. Atlas of Zeolite Framework Types. 5th Edition, Elsevier: Amsterdam, 2002; pp

(2) Baerlocher, C.; McCusker, L. B. Database of Zeolite Structures. http://www.izastructure.org/databases/, International Zeolite Association, 10 January 2002.

(3) Krishna, R. Diffusion in Porous Crystalline Materials. Chem. Soc. Rev. 2012, 41, 3099-3118. https://doi.org/10.1039/C2CS15284C.

(4) Krishna, R. The Maxwell-Stefan Description of Mixture Diffusion in Nanoporous Crystalline Materials. Microporous Mesoporous Mater. 2014, 185, 30-50.

(5) Krishna, R. Describing the Diffusion of Guest Molecules inside Porous Structures. J. Phys. Chem. C 2009, 113, 19756-19781.

(6) Krishna, R.; van Baten, J. M. Investigating the Relative Influences of Molecular Dimensions and Binding Energies on Diffusivities of Guest Species Inside Nanoporous Crystalline Materials $J$. Phys. Chem. C 2012, 116, 23556-23568.

(7) Krishna, R.; van Baten, J. M. Investigating the Influence of Diffusional Coupling on Mixture Permeation across Porous Membranes J. Membr. Sci. 2013, 430, 113-128.

(8) Krishna, R.; van Baten, J. M. Influence of Adsorption Thermodynamics on Guest Diffusivities in Nanoporous Crystalline Materials. Phys. Chem. Chem. Phys. 2013, 15, 7994-8016.

(9) Krishna, R.; van Baten, J. M. Insights into diffusion of gases in zeolites gained from molecular dynamics simulations. Microporous Mesoporous Mater. 2008, 109, 91-108.

(10) Krishna, R.; van Baten, J. M. Diffusion of alkane mixtures in MFI zeolite. Microporous Mesoporous Mater. 2008, 107, 296-298.

(11) Krishna, R.; van Baten, J. M. In silico screening of metal-organic frameworks in separation applications. Phys. Chem. Chem. Phys. 2011, 13, 10593-10616.

(12) Krishna, R.; van Baten, J. M. In Silico Screening of Zeolite Membranes for $\mathrm{CO}_{2}$ Capture. $J$. Membr. Sci. 2010, 360, 323-333.

(13) Krishna, R.; van Baten, J. M. Describing Mixture Diffusion in Microporous Materials under Conditions of Pore Saturation. J. Phys. Chem. C 2010, 114, 11557-11563.

(14) Krishna, R.; van Baten, J. M. Diffusion of alkane mixtures in zeolites. Validating the Maxwell-Stefan formulation using MD simulations. J. Phys. Chem. B 2005, 109, 6386-6396.

(15) Ryckaert, J. P.; Bellemans, A. Molecular dynamics of liquid alkanes. Faraday Discuss. Chem. Soc. 1978, 66, 95-106.

(16) Dubbeldam, D.; Calero, S.; Vlugt, T. J. H.; Krishna, R.; Maesen, T. L. M.; Smit, B. United Atom Forcefield for Alkanes in Nanoporous Materials. J. Phys. Chem. B 2004, 108, 12301-12313.

(17) Kumar, A. V. A.; Jobic, H.; Bhatia, S. K. Quantum effects on adsorption and diffusion of hydrogen and deuterium in microporous materials $J$. Phys. Chem. B 2006, 110, 16666-16671.

(18) Makrodimitris, K.; Papadopoulos, G. K.; Theodorou, D. N. Prediction of permeation properties of $\mathrm{CO}_{2}$ and $\mathrm{N}_{2}$ through silicalite via molecular simulations. J. Phys. Chem. B 2001, 105, 777788. 
(19) García-Pérez, E.; Parra, J. B.; Ania, C. O.; García-Sánchez, A.; Van Baten, J. M.; Krishna, R.; Dubbeldam, D.; Calero, S. A computational study of $\mathrm{CO}_{2}, \mathrm{~N}_{2}$ and $\mathrm{CH}_{4}$ adsorption in zeolites. Adsorption 2007, 13, 469-476.

(20) García-Sánchez, A.; Ania, C. O.; Parra, J. B.; Dubbeldam, D.; Vlugt, T. J. H.; Krishna, R.; Calero, S. Development of a Transferable Force Field for Carbon Dioxide Adsorption in Zeolites. $J$. Phys. Chem. C 2009, 113, 8814-8820.

(21) Krishna, R.; van Baten, J. M. Hydrogen Bonding Effects in Adsorption of Water-alcohol Mixtures in Zeolites and the Consequences for the Characteristics of the Maxwell-Stefan Diffusivities. Langmuir 2010, 26, 10854-10867.

(22) Krishna, R.; van Baten, J. M. Mutual slowing-down effects in mixture diffusion in zeolites. J. Phys. Chem. C 2010, 114, 13154-13156.

(23) Krishna, R.; van Baten, J. M. Highlighting Pitfalls in the Maxwell-Stefan Modeling of Water-Alcohol Mixture Permeation across Pervaporation Membranes. J. Membr. Sci. 2010, 360, 476482 .

(24) Kuhn, J.; Castillo-Sanchez, J. M.; Gascon, J.; Calero, S.; Dubbeldam, D.; Vlugt, T. J. H.; Kapteijn, F.; Gross, J. Adsorption and Diffusion of Water, Methanol, and Ethanol in All-Silica DD3R: Experiments and Simulation. J. Phys. Chem. C 2009, 113, 14290-14301.

(25) Rick, S. W. A Reoptimization of the Five-site Water Potential (TIP5P) for use with Ewald Sums. J. Chem. Phys. 2004, 120, 6085-6093.

(26) Chen, B.; Potoff, J. J.; Siepmann, J. I. Monte Carlo Calculations for Alcohols and Their Mixtures with Alkanes. Transferable Potentials for Phase Equilibria. 5. United-Atom Description of Primary, Secondary, and Tertiary Alcohols. J. Phys. Chem. B 2001, 105, 3093-3104.

(27) Kiselev, A. V.; Lopatkin, A. A.; Shul'ga, A. A. Molecular statistical calculation of gas adsorption by silicalite. Zeolites 1985, 5, 261-267.

(28) Frenkel, D.; Smit, B. Understanding Molecular Simulations: From Algorithms to Applications. 2nd Edition, Academic Press: San Diego, 2002; pp

(29) Rappé, A. K.; Casewit, C. J.; Colwel, K. S.; Goddard, W. A.; Skiff, W. M. UFF, A Full Periodic Table Force Field for Molecular Mechanics and Molecular Dynamics Simulations. J. Am. Chem. Soc. 1992, 114, 10024-10035.

(30) Mayo, S. L.; Olafson, B. D.; Goddard, W. A. DREIDING: A Generic Force Field for Molecular Simulations. J. Phys. Chem. 1990, 94, 8897-8909.

(31) Britt, D.; Furukawa, H.; Wang, B.; Glover, T. G.; Yaghi, O. M. Highly efficient separation of carbon dioxide by a metal-organic framework replete with open metal sites. Proc. Natl. Acad. Sci. U.S.A. 2009, 106, 20637-20640.

(32) Rosi, N. L.; Kim, J.; Eddaoudi, M.; Chen, B.; O’Keeffe, M.; Yaghi, O. M. Rod Packings and Metal-Organic Frameworks Constructed from Rod-Shaped Secondary Building Units. J. Am. Chem. Soc. 2005, 127, 1504-1518.

(33) Dietzel, P. D. C.; Panella, B.; Hirscher, M.; Blom, R.; Fjellvåg, H. Hydrogen adsorption in a nickel based coordination polymer with open metal sites in the cylindrical cavities of the desolvated framework. Chem. Commun. 2006, 959-961.

(34) Dietzel, P. D. C.; Besikiotis, V.; Blom, R. Application of metal-organic frameworks with coordinatively unsaturated metal sites in storage and separation of methane and carbon dioxide. $J$. Mater. Chem. 2009, 19, 7362-7370.

(35) Caskey, S. R.; Wong-Foy, A. G.; Matzger, A. J. Dramatic Tuning of Carbon Dioxide Uptake via Metal Substitution in a Coordination Polymer with Cylindrical Pores. J. Am. Chem. Soc. 2008, 130, 10870-10871.

(36) Yazaydın, A. Ö.; Snurr, R. Q.; Park, T. H.; Koh, K.; Liu, J.; LeVan, M. D.; Benin, A. I.; Jakubczak, P.; Lanuza, M.; Galloway, D. B.; Low, J. J.; Willis, R. R. Screening of Metal-Organic Frameworks for Carbon Dioxide Capture from Flue Gas using a Combined Experimental and Modeling Approach. J. Am. Chem. Soc. 2009, 131, 18198-18199. 
(37) Choi, H. J.; Dincă, M.; Long, J. R. Broadly Hysteretic $\mathrm{H}_{2}$ Adsorption in the Microporous Metal-Organic Framework Co(1,4-benzenedipyrazolate). J. Am. Chem. Soc. 2008, 130, 7848-7850.

(38) Salles, F.; Maurin, G.; Serre, C.; Llewellyn, P. L.; Knöfel, C.; Choi, H. J.; Filinchuk, Y.; Oliviero, L.; Vimont, A.; Long, J. R.; Férey, G. Multistep N 2 Breathing in the Metal-Organic Framework Co(1,4-benzenedipyrazolate). J. Am. Chem. Soc. 2010, 132, 13782-13788.

(39) Zhang, C.; Yang, X. Molecular dynamics simulation of ethanol/water mixtures for structure and diffusion properties. Fluid Phase Equilib. 2005, 231, 1-10.

(40) Ruthven, D. M. Principles of Adsorption and Adsorption Processes. John Wiley: New York, 1984; pp 1-433.

(41) Myers, A. L.; Prausnitz, J. M. Thermodynamics of Mixed Gas Adsorption. A.I.Ch.E.J. 1965, 11, 121-130.

(42) Siperstein, F. R.; Myers, A. L. Mixed-Gas Adsorption. A.I.Ch.E.J. 2001, 47, 1141-1159.

(43) Streb, A.; Mazzotti, M. Adsorption for efficient low carbon hydrogen production: part 1adsorption equilibrium and breakthrough studies for $\mathrm{H}_{2} / \mathrm{CO}_{2} / \mathrm{CH}_{4}$ on zeolite $13 \mathrm{X}$. Adsorption 2021, $x$, xx. https://doi.org/10.1007/s10450-021-00306-y.

(44) Krishna, R.; Van Baten, J. M. Using Molecular Simulations to Unravel the Benefits of Characterizing Mixture Permeation in Microporous Membranes in Terms of the Spreading Pressure. ACS Omega 2020, 5, 32769-32780. https://dx.doi.org/10.1021/acsomega.0c05269.

(45) Krishna, R.; Van Baten, J. M. Elucidation of Selectivity Reversals for Binary Mixture Adsorption in Microporous Adsorbents. ACS Omega 2020, 5, 9031-9040. https://doi.org/10.1021/acsomega.0c01051.

(46) Krishna, R.; Van Baten, J. M. Using Molecular Simulations for Elucidation of Thermodynamic Non-Idealities in Adsorption of $\mathrm{CO}_{2}$-containing Mixtures in NaX Zeolite. ACS Omega 2020, 5, 20535-20542. https://doi.org/10.1021/acsomega.0c02730.

(47) Krishna, R.; Van Baten, J. M. Water/Alcohol Mixture Adsorption in Hydrophobic Materials: Enhanced Water Ingress caused by Hydrogen Bonding. ACS Omega 2020, 5, 28393-28402. https://doi.org/10.1021/acsomega.0c04491.

(48) Krishna, R.; Van Baten, J. M. Investigating the Non-idealities in Adsorption of $\mathrm{CO}_{2}$-bearing Mixtures in Cation-exchanged Zeolites. Sep. Purif. Technol. 2018, 206, 208-217. https://doi.org/10.1016/j.seppur.2018.06.009.

(49) Krishna, R. Occupancy Dependency of Maxwell-Stefan Diffusivities in Ordered Crystalline Microporous Materials. ACS Omega 2018, 3, 15743-15753. https://doi.org/10.1021/acsomega.8b02465.

(50) Talu, O.; Myers, A. L. Rigorous Thermodynamic Treatment of Gas-Adsorption. A.I.Ch.E.J. 1988, 34, 1887-1893.

(51) Talu, O.; Zwiebel, I. Multicomponent Adsorption Equilibria of Nonideal Mixtures. A.I.Ch.E.J. 1986, 32, 1263-1276.

(52) Krishna, R. Separating Mixtures by Exploiting Molecular Packing Effects in Microporous Materials. Phys. Chem. Chem. Phys. 2015, 17, 39-59.

(53) Krishna, R. Elucidation and Characterization of Entropy Effects in Mixture Separations with Micro-porous Crystalline Adsorbents. Sep. Purif. Technol. 2019, 215, 227-241. https://doi.org/10.1016/j.seppur.2019.01.014.

(54) Vlugt, T. J. H.; Zhu, W.; Kapteijn, F.; Moulijn, J. A.; Smit, B.; Krishna, R. Adsorption of linear and branched alkanes in the silicalite-1. J. Am. Chem. Soc. 1998, 120, 5599-5600.

(55) Vlugt, T. J. H.; Krishna, R.; Smit, B. Molecular Simulations of Adsorption Isotherms for Linear and Branched Alkanes and Their Mixtures in Silicalite. J. Phys. Chem. B 1999, 103, 1102-1118.

(56) Krishna, R.; Smit, B.; Calero, S. Entropy effects during sorption of alkanes in zeolites. Chem. Soc. Rev. 2002, 31, 185-194.

(57) Schenk, M.; Vidal, S. L.; Vlugt, T. J. H.; Smit, B.; Krishna, R. Separation of alkane isomers by exploiting entropy effects during adsorption on silicalite-1: A configurational-bias Monte Carlo simulation study. Langmuir 2001, 17, 1558-1570. 
(58) Titze, T.; Chmelik, C.; Kärger, J.; van Baten, J. M.; Krishna, R. Uncommon Synergy Between Adsorption and Diffusion of Hexane Isomer Mixtures in MFI Zeolite Induced by Configurational Entropy Effects J. Phys. Chem. C 2014, 118, 2660-2665.

(59) Krishna, R.; van Baten, J. M. Segregation effects in adsorption of $\mathrm{CO}_{2}$ containing mixtures and their consequences for separation selectivities in cage-type zeolites. Sep. Purif. Technol. 2008, 61, 414-423.

(60) Krishna, R.; van Baten, J. M. Separating n-alkane mixtures by exploiting differences in the adsorption capacity within cages of CHA, AFX and ERI zeolites. Sep. Purif. Technol. 2008, 60, 315320.

(61) Krishna, R.; van Baten, J. M. Entropy-based Separation of Linear Chain Molecules by Exploiting Differences in the Saturation Capacities in Cage-type Zeolites. Sep. Purif. Technol. 2011, 76, 325-330.

(62) Krishna, R.; van Baten, J. M. Commensurate-Incommensurate Adsorption and Diffusion in Ordered Crystalline Microporous Materials. Phys. Chem. Chem. Phys. 2017, 19, 20320-20337.

(63) Krishna, R.; van Baten, J. M. A comparison of the $\mathrm{CO}_{2}$ capture characteristics of zeolites and metal-organic frameworks. Sep. Purif. Technol. 2012, 87, 120-126.

(64) Krishna, R.; van Baten, J. M. Investigating cluster formation in adsorption of $\mathrm{CO}_{2}, \mathrm{CH}_{4}$, and Ar in zeolites and metal organic frameworks at sub-critical temperatures. Langmuir 2010, 26, 39813992.

(65) Costa, E.; Calleja, G.; Jimenez, A.; Pau, J. Adsorption Equilibrium of Ethylene, Propane, Propylene, Carbon Dioxide, and Their Mixtures in 13X Zeolite. J. Chem. Eng. Data 1991, 36, 218-224.

(66) Krishna, R.; van Baten, J. M. Highlighting a variety of unusual characteristics of adsorption and diffusion in microporous materials induced by clustering of guest molecules. Langmuir 2010, 26, 8450-8463.

(67) Herm, Z. R.; Wiers, B. M.; Van Baten, J. M.; Hudson, M. R.; Zajdel, P.; Brown, C. M.; Maschiocchi, N.; Krishna, R.; Long, J. R. Separation of Hexane Isomers in a Metal-Organic Framework with Triangular Channels Science 2013, 340, 960-964.

(68) Krishna, R.; van Baten, J. M. Screening of zeolite adsorbents for separation of hexane isomers: A molecular simulation study. Sep. Purif. Technol. 2007, 55, 246-255.

(69) Dubbeldam, D.; Krishna, R.; Calero, S.; Yazaydın, A. Ö. Computer-Assisted Screening of Ordered Crystalline Nanoporous Adsorbents for Separation of Alkane Isomers. Angew. Chem. Int. Ed. 2012, 51, 11867-11871.

(70) Krishna, R. Methodologies for Evaluation of Metal-Organic Frameworks in Separation Applications. RSC Adv. 2015, 5, 52269-52295.

(71) Krishna, R. Metrics for Evaluation and Screening of Metal-Organic Frameworks for Applications in Mixture Separations. ACS Omega 2020, 5, 16987-17004. https://doi.org/10.1021/acsomega.0c02218.

(72) Shen, J.; He, X.; Ke, T.; Krishna, R.; van Baten, J. M.; Chen, R.; Bao, Z.; Xing, H.; Dincă, M.; Zhang, Z.; Yang, Q.; Ren, Q. Simultaneous interlayer and intralayer space control in twodimensional metal-organic frameworks for acetylene/ethylene separation. Nat. Commun. 2020, 11, 6259. https://doi.org/10.1038/s41467-020-20101-7.

(73) Ban, S.; van Laak, A.; de Jongh, P. E.; van der Eerden, J. P. J. M.; Vlugt, T. J. H. Adsorption Selectivity of Benzene and Propene Mixtures for Various Zeolites. J. Phys. Chem. C 2007, $111,17241-17248$.

(74) Jorgensen, W. L.; Madura, J. D.; Swenson, C. J. Optimized Intermolecular Potential Functions for Liquid Hydrocarbons. J. Am. Chem. Soc. 1984, 106, 6638-6646.

(75) Gautam, S.; Mitra, S.; Mukhopadhyay, R.; Chaplot, S. L. Diffusion of acetylene inside NaY zeolite: Molecular dynamics simulation studies. Phys. Rev. E 2006, 74, 041202. 


\section{References}

